



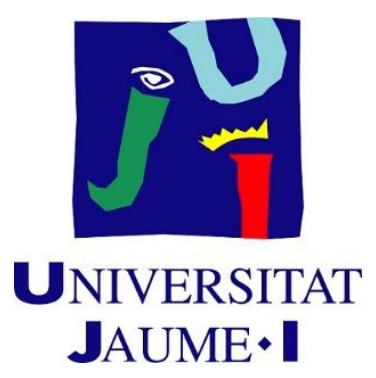

Programa de Doctorat en Tecnologies Industrials i Materials

Escola de Doctorat de la Universitat Jaume I

\section{Environmental Evaluation for the Development of Photovoltaic Devices Based on Halide Perovskite through Life Cycle Assessment}

\section{Memòria presentada per Jaume Adrià Alberola Borràs per a optar al grau de doctor amb menció Internacional per la Universitat Jaume I}

\section{Author:}

Jaume Adrià Alberola Borràs

Signed by ALBEROLA BORRAS, JAUME ADRIA (FIRMA) - ID : $\star \star \star 7926 * \star$ on the day $18 / 11 / 2021$ with a certificate emitted by AC DNIE 005

\section{Directed by:}

\section{Professor María Rosario Vidal Nadal}

Signed by MARIA ROSARIO VIDAL NADAL - NIF:21652812Z el día $19 / 11 / 2021$ con un certificado emitido por ACCVCA-120

\section{Professor Iván Mora Seró}

Firmado por IVAN MORA SERO -

NIF:33453681C el día 19/11/2021 con un

certificado emitido por ACCVCA-120 



\section{Finançament rebut}

The development of this thesis was possible thanks to the following funding:

1. Fundación Balaguer-Gonel Hermanos (Ajudes per a la realització d'estades d'investigació en centres d'I+D+i estrangers de doctorands i doctorandes que realitzen tesis que opten a la menció de doctor o doctora internacional)

2. ERC Consolidator Grant (724424 - No-LIMIT)

3. SPECIFIC Innovation and Knowledge Centre (EP/N02083/1)

4. Self assembly of Perovskite Absorber layers - Cells Engineered into Modules Project (EP/M01524/1)

5. MINECO of Spain under project MAT2013-47192-C3-1-R

6. MINECO of Spain under Project MAT2016-76892-C3-1-R

7. Generalitat Valenciana under project ACOMP/2015/105

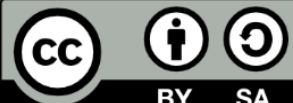

This work is licensed under the Creative Commons Attribution-ShareAlike 4.0 International License. To view a copy of this license, visit

http://creativecommons.org/licenses/by-sa/4.0/. 

Thesis by compendium of publications:

J.-A. Alberola-Borràs, R. Vidal, E.J. Juárez-Pérez, E. Mas-Marzá, A. Guerrero, I. MoraSeró, Relative impacts of methylammonium lead triiodide perovskite solar cells based on life cycle assessment, Solar Energy Materials \& Solar Cells/Elsevier. 179 (2018) 169-177.

doi: 10.1016/j.solmat.2017.11.008

Impact factor (2018): 6.019

J.-A. Alberola-Borràs, R. Vidal, I. Mora-Seró, Evaluation of multiple cation/anion perovskite solar cells through life cycle assessment, Sustainable Energy \& Fuels/The Royal Society of Chemistry. 2 (2018) 1600-1609.

doi: $10.1039 /$ C8SE00053K

Impact factor (2018): 4.912

J.-A. Alberola-Borràs, J.A. Baker, F. De Rossi, R. Vidal, D. Beynon, K.E.A. Hooper, T.M. Watson, I. Mora-Seró, Perovskite Photovoltaic Modules: Life Cycle Assessment of Pre-industrial Production Process, iScience/Cell Press. 9 (2018) 542-551.

doi: $10.1016 /$ j.isci.2018.10.020

Impact factor (2019): 4.447

This thesis has been accepted by the co-authors of the publications listed above that have waved the right to present them as a part of another PhD thesis. 



\section{Acknowledgments}

From the beginning of the adventure of undergoing a doctoral thesis, my tutor Rosario Vidal supported me. I consider the determined confidence she deposited on me as fundamental. I also appreciate she cared about me as one of her doctoral children. I would also like to thank her for assuming that chief tutoring role. Some months later Iván Mora joined us as a co-director of the thesis. His contribution have undoubtfully improved the quality of the thesis. Besides, his continuous recommendations of making everything simpler have become everlasting knowledge for me to hold. The task of both of them have eventually been essential for my personal development purposes as a doctoral student.

My desire for completing a doctoral degree comes from my experience in a research group called PIMA as a postgraduate. Along with the members of this group I truly discovered what science and a scientist are. This was thanks to people such as Estefanía Sánchez Safont, Luis Cabedo, José Gámez and Jennifer González, among others. I would like to include in this category other scientist with which I collaborated at that time, with my first published article as a result. They are Rosa Mondragón Cazorla, Leonor Hernández and Enrique Juliá. My contact with them has endured along my doctoral period. An especial mention is for Rosa Mondragón Cazorla, whom I acknowledge the interesting conversations in the many days commuting to the University in the train.

More people joined the PIMA group, such as Jorge García Cañadas, Braulio Beltran, Fran Romero, Nuno Araújo and Aziz Aldureid, among others. An especial mention is for Adrián Mota Babiloni, whom I want to thank for his encouragement in pursuing the doctoral training and useful recommendations. I appreciate the interesting conversations we had along the lunchtime and for considering me as one member more of their group.

Apart from that, I would like to mention the colleagues of the GID research group, where I mostly developed the thesis. Nuria Sánchez-Pantoja developed her doctoral thesis concurrently to me. Others had either undergraduate or postgraduate stays in the group, such as Higinio Martínez, Eva Esteve Recatalà, Javier Sánchez, Ana García, Gemma Tidó and many more. Two Mexican professors visited the group, Claudia Saldaña and Sarah Messina. I acknowledge the good moments spent with them.

During my doctoral period I also worked at Instituto de Tecnología Cerámica. I thank them for the good time spent in the spare time in there. In particular, Irina Celades, Raul Moliner, Fernando Romero, Alicia Andreu, Vicenta Sanfélix, Eliseo Monfort, Salva Gomar, Alberto Escrig and Teresa Ros. I also thank Teresa Ros for everything I could learn from her. 
I found the Predoctoral Research stay at Swansea University very enriching. It was challenging for me because of being in a new place for me and in a different culture. Fortunately, the people in there made me feel like in home, especially the closest people to me. I would highlight the colleagues from the research group Simone Meroni (who gave me the first warming welcome), Francesca De Rossi, Jenny Baker, David Beynon, Katherine Hooper, and Trystan Watson. Nevertheless, my acknowledgment goes for everyone that made my experience so good and unique.

I do not want to forget acknowledging the support of concurrent doctoral students at Universitat Jaume I, such as Yessenia Jauregui and Fabrizio Guzzeta.

In the personal side, I especially acknowledge my girlfriend Lorena Galván Dibo for their patience and tremendous support in the late phases of my doctoral training. I also want to thank my parents for their economic support, which enabled me to undergo the doctoral studies. An important support for this doctoral period came from Andy Warner, who I thank all the good moments at lunchtime while exchanging English and Spanish. Finally, my closest friends also deserve an acknowledgment for their emotional support all along the thesis period, especially Pablo Martínez Blasi. 


\section{Contents}

Acknowledgments .......................................................................................... vii

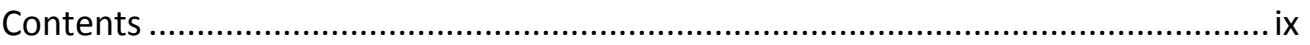

List of figures .......................................................................................

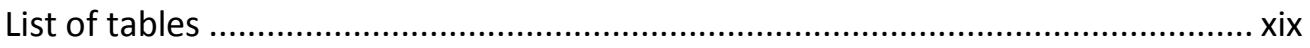

Abbreviations ...................................................................................................... xxiii

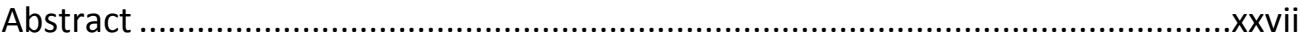

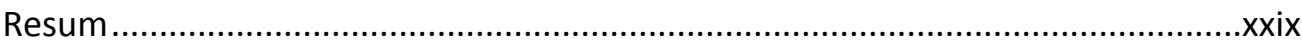

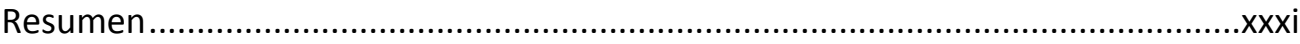

Graphical Abstract ...............................................................................xxxV

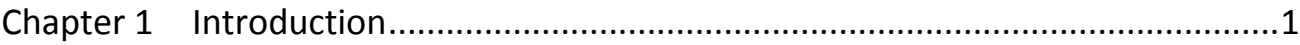

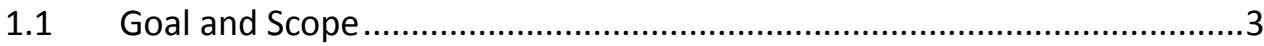

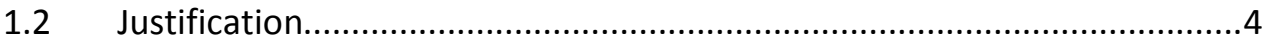

1.2.1 Renewable sources of energy as a solution .................................

1.2.2 Photovoltaics as a powerful source of energy .............................. 8

1.2.3 Emergence of halide perovskite as a promising photovoltaic material with outstanding outcomes. ......................................................................

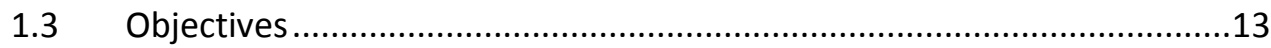

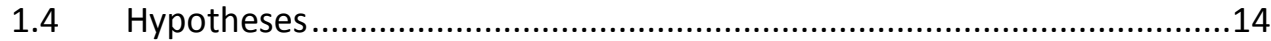

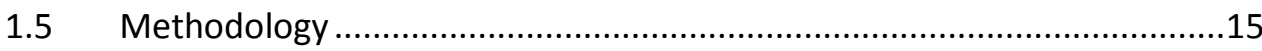

1.6 Structure of the dissertation .........................................................

1.6.1 Relative Impacts of Methylammonium Lead Triiodide Perovskite Solar Cells Based on Life Cycle Assessment...........................................................16

1.6.2 Evaluation of multiple cation/anion perovskite solar cells through life cycle assessment ............................................................................. 16

1.6.3 Halide perovskite photovoltaic modules: life cycle assessment of preindustrial production process.

Chapter 2 State of the art of studies evaluating the environmental and economic viability of photovoltaics based on halide perovskite.........................................19

2.1 Brief introduction to the state of the art .............................................21 
2.2 Prospective analyses applied to early development of laboratory scale PSCs 21

2.2.1 Analyses applied to compositional engineered PSCs ...................... 23

2.2.2 Summary of prospective analyses ................................................. 24

2.3 Environmental concerns posed by lead in PSCs ....................................... 24

2.3.1 LCA studies addressing the toxicity of PSCs ................................. 25

2.3.2 Empirical analyses of lead toxicity in perovskite ............................. 25

2.3.3 Substitution of lead to avoid its toxicity ......................................... 27

2.3.4 Summary of concerns posed by lead............................................. 28

2.4 Advancing towards large-scale production ........................................... 28

2.4.1 Theoretical studies towards PSCs commercialisation ...................... 29

2.4.2 Deposition processes suitable for large scale manufacturing .......... 30

2.4.3 Carbon stack configuration......................................................... 30

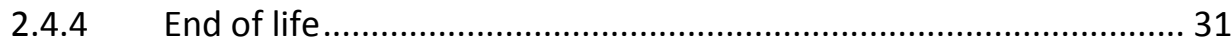

2.4.5 Summary of progress towards large scale production..................... 32

2.5 Pros and cons of perovskite PVs against other electricity producing

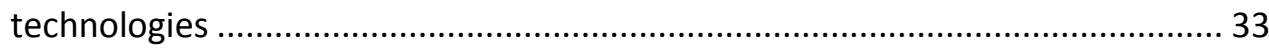

2.5.1 Perovskite tandems with other PV technologies ............................ 35

2.5.2 Summary of balancing PSC with other energy technologies............ 35

2.6 Cost analyses of perovskite solar cells ................................................... 36

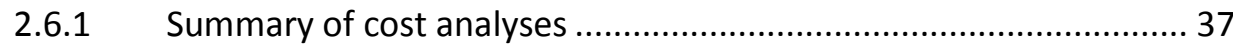

2.7 Summary of the state of the art of environmental studies applied to PSCs 37

Chapter 3 Relative Impacts of Methylammonium Lead Triiodide Perovskite Solar Cells Based on Life Cycle Assessment.................................................................. 39

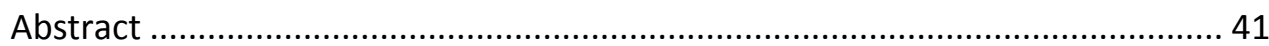

Graphical Abstract ............................................................................................ 41

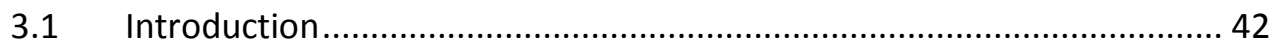

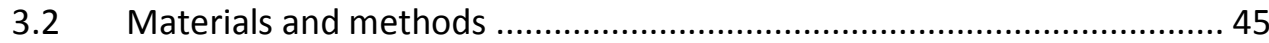

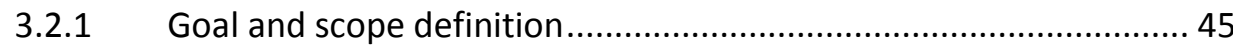

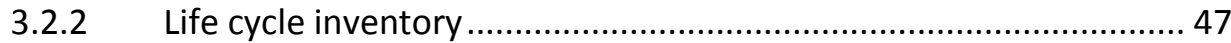




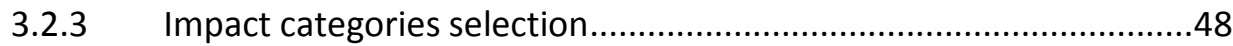

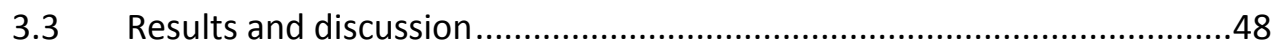

3.3.1 Environmental impact of the common system ................................48

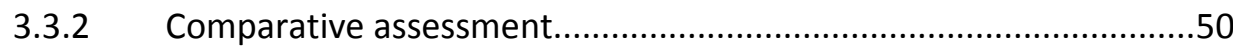

3.3.3 Human toxicity cancer payback time .............................................53

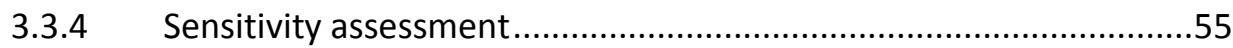

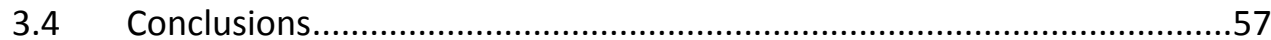

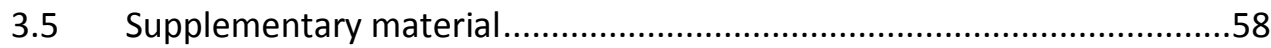

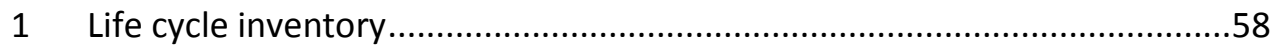

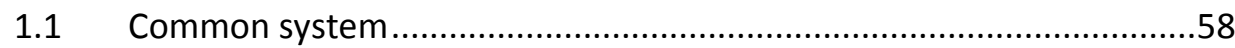

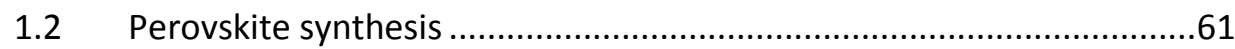

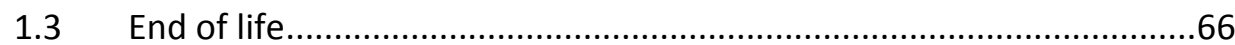

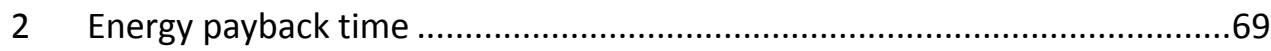

Chapter 4 Evaluation of multiple cation/anion perovskite solar cells through life

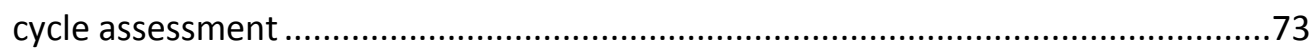

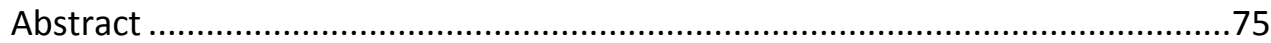

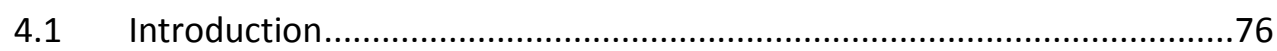

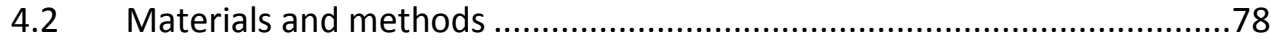

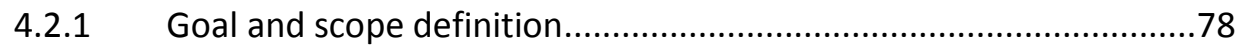

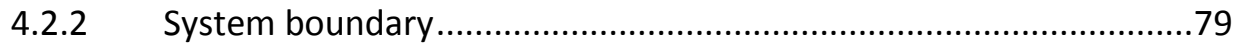

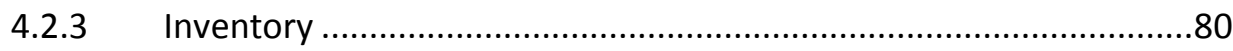

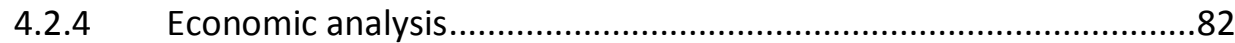

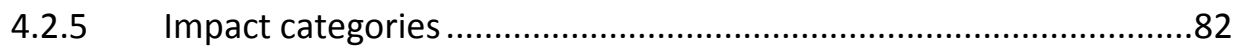

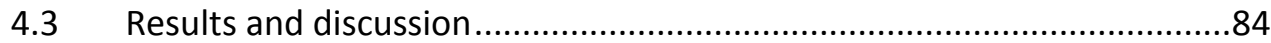

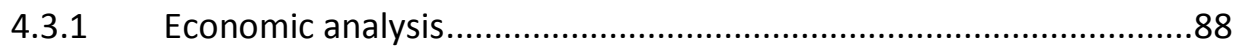

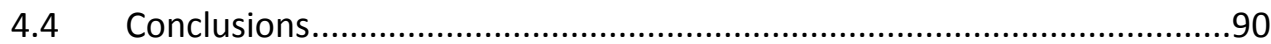

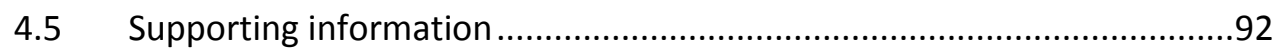

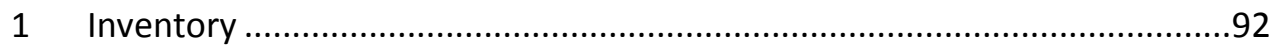

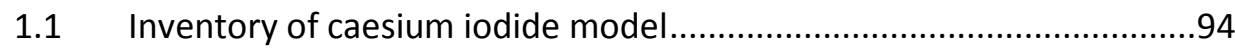

1.2 Inventory of formamidinium iodide model ..........................................95 
1.3 Inventory of methylammonium bromide model.................................. 96

1.4 Inventory of methylammonium iodide model .................................... 97

1.5 Inventory of lead iodide model ......................................................... 98

1.6 Inventory of lead bromide model....................................................... 99

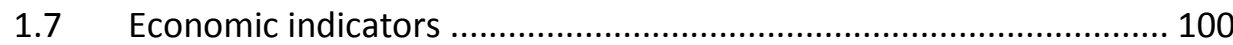

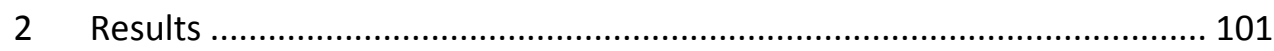

2.1 Sensitivity analysis .................................................................... 111

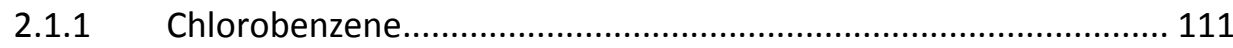

Chapter 5 Perovskite photovoltaic modules: life cycle assessment of preindustrial production process .......................................................................... 113

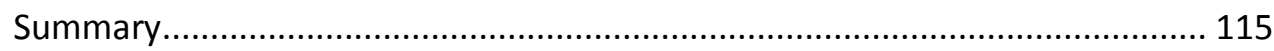

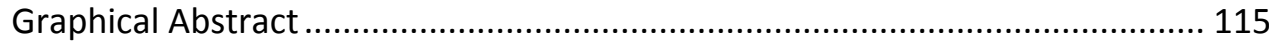

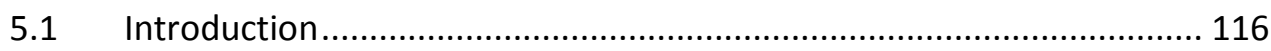

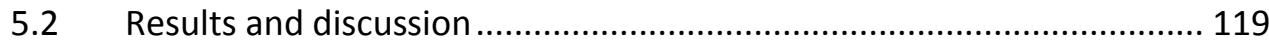

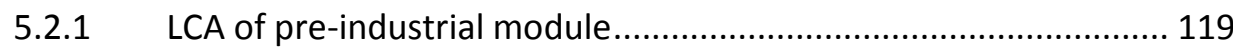

5.2.2 Ideality analysis........................................................................ 122

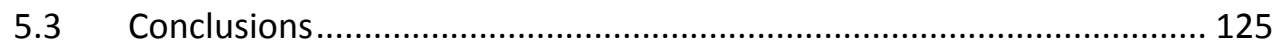

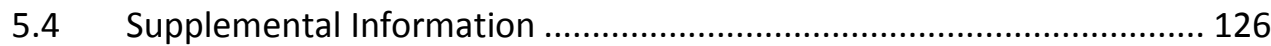

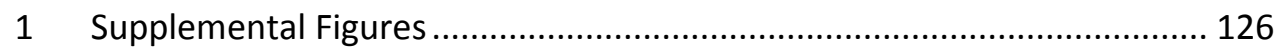

2 Supplemental Tables ....................................................................... 128

2.1 Perovskite module with a carbon stack configuration ........................ 128

2.2 Mesoporous PSC produced in the laboratory environment .............. 130

2.3 Ideal process of production of carbon stack perovskite modules...... 132

2.4 Inventory of ethyl cellulose model ................................................. 133

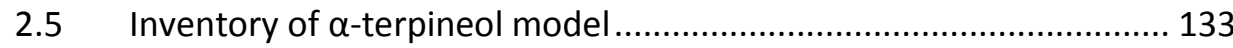

2.6 Inventory of titanium di-isopropoxide bis(acetylacetonate) model .. 134

2.7 Inventory of 5-ammonium valeric acid iodide .................................. 134

2.8 Inventory of 2-(2-butoxyethoxy) ethyl acetate model ....................... 135

2.9 Inventory of nitrocellulose model ................................................... 135

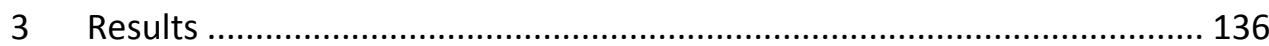




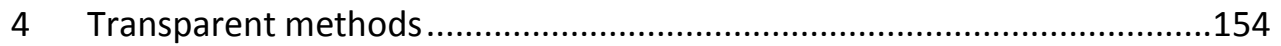

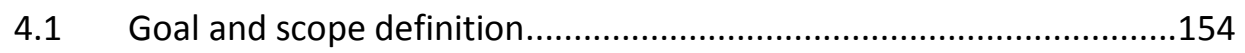

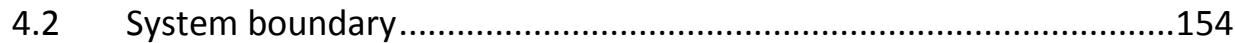

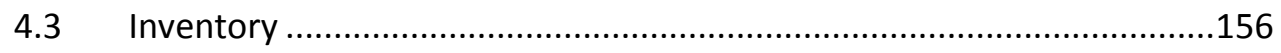

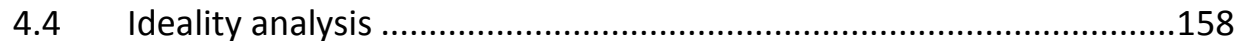

4.5 Life cycle inventory assessment ....................................................160

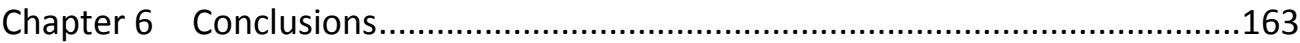

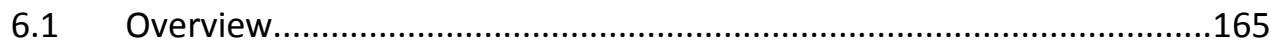

6.1.1 LCA applied to PSCs at an elementary stage of development ........165

6.1.2 LCA applied to four perovskite compositions improving key features of PSCs 166

6.1.3 LCA applied to a PV module based on perovskite at an advanced stage

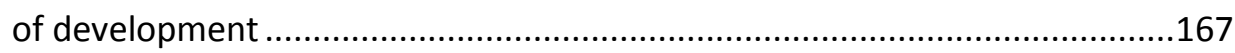

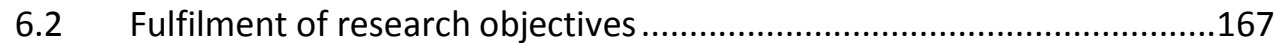

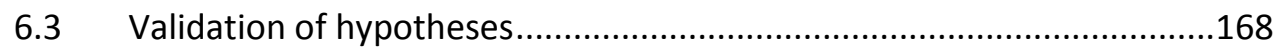

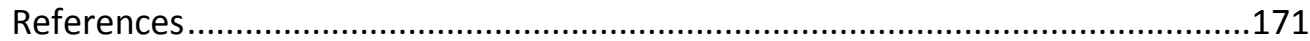

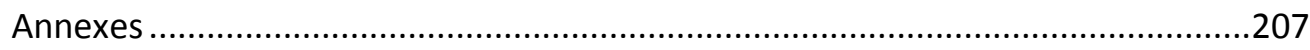





\section{List of figures}

Figure $1 \mathrm{Global}$ annual average $\mathrm{CO}_{2}$ concentration in parts per million from 500,000 $\mathrm{BC}$ to present [3]. Global annual average $\mathrm{CO}_{2}$ concentration is represented from the year 1000 to present in order to appreciate the $\mathrm{CO}_{2}$ emissions rise since the preindustrial era. Long-term trends in $\mathrm{CO}_{2}$ concentrations can be measured at highresolution using preserved air samples from ice cores.

Figure 2. World primary energy supply distribution sorted by source for the year 2017 [21].

Figure 3. Perovskite solar cells layers: 1) thin film planar perovskite layer and 2) embedded perovskite in the mesoporous layer. .43

Figure 4. System boundary of the PSCs. .46

Figure 5. Relative impacts of the common part of the four devices, perovskite layer that differs from device to device are excluded in this analysis. Each impact category is analyzed for the three different scenarios for the end of life. Scenario 1: residual landfill, Scenario 2: reuse and residual landfill and Scenario 3: reuse and recycling.

Figure 6. Specific impacts for scenario 1: a) Human toxicity cancer; b) Cumulative energy demand. Vertical axis is in logarithmic scale.

Figure 7. Specific relative impacts for scenario 2 vs. scenario1 (S2) and scenario 3 vs. scenario 1 (S3).

Figure 8. Time evolution of the human toxicity cancer: a) considering PCE from literature; b) considering 20\% efficiency and scenario 1 at EOL; c) considering $20 \%$ efficiency and scenario 3 at EOL.

Figure S9. Synthetic routes of a) Spiro-MeOTAD and b) FTO. Synthesis processes obtained from a database are inside a dashed box, whereas synthesis processes modelled herein are inside a solid box.

Figure S10. Synthesis routes for perovskite: a) from lead (II) chloride; b) from lead (II) iodide. Synthesis processes obtained from a database are inside a dashed box, whereas synthesis processes modelled herein are inside a solid box. 62

Figure S11. Scheme of the recycling process for scenario s3 67

Figure S12. Time evolution of the energy produced: a) considering the PCE from the literature, see Table S10; b) considering a $20 \%$ efficiency for all four devices and scenario 1 at EOL; c) considering 20\% efficiency for all four devices and scenario 3 at EOL 
Figure 13. System boundary of the steps involved in the deposition of the perovskite layer of a) deposition route of the multiple cation/anion perovskite through the antisolvent method and $b$ ) deposition route of the canonical perovskite through a simple spin-coating method. 79

Figure 14. Relative impacts of perovskite layer synthesis and deposition with proportions of $\mathrm{Cs}$ of $\mathrm{x}=0,0.05,0.10$ and 0.15 at the perovskite cationic position for multiple cation/anion $\boldsymbol{C s} \boldsymbol{x M A 0 . 1 7 F A 0 . 8 3 ( 1 - x ) P b I 0 . 8 3 B r 0 . 1 7 3}$ compared with the canonical perovskite for total impacts and without taking energy consumption into account. In X-axis are the environmental impact categories. .... 85

Figure 15. Relative impacts of materials for PSCs with proportions of caesium of $x=$ $0, x=0.05, x=0.10$ and $x=0.15$ at the perovskite cationic position. Impact categories: Global warming potential (GWP), Cumulative energy demand (CED), Human toxicity, cancer (HTC), and Human toxicity, non-cancer (HTNC).

Figure 16. Cost in euros of materials for the deposition of perovskite active layer each of the PSCs analised. Energy is not included in this analysis. 89

Figure 17. Equal cost payback time for the perovskite with $\mathrm{x}=0.1$ of caesium and canonical perovskite PSCs. 90

Figure S18. Distribution of impacts per type of flow for the most representative categories to assess PSCs.

Figure S19. Sensitivity analysis of chlorobenzene with three scenarios for the most determining impact categories for PSCs with antisolvent method.

Figure 20 Aggregated impacts of each layer of the carbon stack perovskite module, sorted by impact categories 119

Figure 21 Aggregated impacts of the carbon stack perovskite module, sorted by impact categories 121

Figure 22 Aggregated impacts of material inputs of the carbon stack perovskite module, sorted by impact categories

Figure 23 Ideality coefficient for the carbon stack module produced with a preindustrial process and the PSC produced with a process in the laboratory environment. The ideality coefficient quantifies how close a given fabrication procedure from the ideal process is, in percentage; its value is the result of dividing the impact of the ideal process by the impact of the process to compare. Relative impacts from pre-industrial module, PSC at laboratory scale and ideal process, sorted by impact categories and layers: a) anode + substrate, b) blocking and perovskite layer. See also Figure S24 and Figure S25 in the Supplemental Information 123 
Figure S24. Ideality coefficient for the carbon stack module produced with a preindustrial process and the PSC produced with a process in the laboratory environment. The ideality coefficient quantifies how close a given fabrication procedure from the ideal process is, in percentage; its value is the result of dividing the impact of the ideal process by the impact of the process to compare. In the vertical axis are the impact categories selected, related to Figure 23...................126

Figure S25. Relative impacts from pre-industrial module, PSC at laboratory scale and ideal process, sorted by impact categories and layers: anode + substrate, blocking and perovskite layer, related to Figure 23.

Figure S26. System boundary of the pre-industrial process of production of the carbon stack perovskite photovoltaic module, related to Figure 20 to Figure 23..155

Figure S27. Dimensional cross section of the perovskite solar module produced at a pre-industrial scale (right) and the perovskite solar cell produced at a laboratory scale (left), related to Figure 20 to Figure 23 .156 



\section{List of tables}

Table 1. Characteristics of the different PSCs analyzed. .46

Table 2. Impacts for the common system and specific for the four devices. 51

Table 3. Time evolution of the human toxicity cancer .54

Table 4. Sensitivity assessment: Relative HTC values per device for the deposition of the four specific layers respect to the HTC value of the most harmful device for labmeasured and industrial scenarios and absolute HTC values for the industrial scenario. .56

Table S5. LCl of the production process of the common system 59

Table S6. Electricity consumed per solar cell area for the deposition of the common layers.

.60

Table S7. Specific inputs and outputs for the production process of the four layers of perovskite

Table S8. Electricity consumed per solar cell area for the deposition of the four specific layers measured experimentally 66

Table S9. Inputs and outputs for each scenario of end of life 68

Table S10. Energy payback time .70

Table 11. Performance data of PSCs with perovskites containing three compounds in the cationic position [88] and the canonical perovskite [199] .80

Table 12. Stoichiometric coefficients of the reagents used for the syntheses of the perovskites compared. .81

Table 13. Inventory of chemicals used for the syntheses of the perovskites $(\mu \mathrm{g} / \mathrm{cm} 2)$. .81

Table 14. Inventory of electric consumption of devices used for perovskite mixture and deposition.

Table 15. List of impact categories, their abbreviations, units and methodologies in which they are included. .83

Table S16. Inventory of flows used for the perovskites analysed. 92

Table S17. Inventory for $1 \mathrm{~kg}$ of caesium iodide. 94

Table S18. Inventory for $1 \mathrm{~kg}$ of formamidinium iodide. 95

Table S19. Inventory for $1 \mathrm{~kg}$ of methylammonium bromide. .96 
Table S20. Inventory for $1 \mathrm{~kg}$ of methylammonium iodide

Table S21 Inventory for $1 \mathrm{~kg}$ of lead iodide.................................................... 98

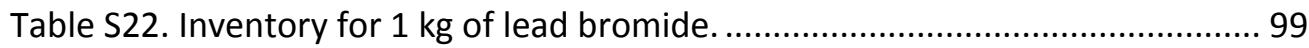

Table S23. Economic indicators of the reagents, solvents and electricity............ 100

Table S24. Impact results of 0\% caesium perovskite sorted by flows................... 101

Table S25. Impact results of 5\% caesium perovskite sorted by flows................... 103

Table S26. Impact results of 10\% caesium perovskite sorted by flows................ 105

Table S27. Impact results of 15\% caesium perovskite sorted by flows................. 107

Table S28. Impact results of canonical perovskite sorted by flows...................... 109

Table S29. Inventory of the carbon stack perovskite photovoltaic module, related to

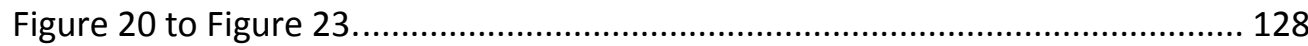

Table S30. Inventory of a mesoporous PSC produce in the laboratory environment, related to Figure 23. 130

Table S31. Inventory of the ideal process of production of the carbon stack perovskite module, related to Figure 23.

Table S32. Inventory for $1 \mathrm{~kg}$ of ethyl cellulose, related to Figure 20 to Figure 23.

Table S33. Inventory for $1 \mathrm{~kg}$ of $\alpha$-terpineol, related to Figure 20 to Figure $23 \ldots 133$

Table S34. Inventory for $1 \mathrm{~kg}$ of titanium di-isopropoxide bis(acetylacetonate), related to Figure 20 to Figure 23

Table S35. Inventory for $1 \mathrm{~kg}$ of 5-ammonium valeric acid iodide, related to Figure 20 to Figure 23

Table S36. Inventory for $1 \mathrm{~kg}$ of 2-(2-butoxyethoxy) ethyl acetate, related to Figure 20 to Figure 23.

Table S37. Inventory for $1 \mathrm{~kg}$ of nitrocellulose, related to Figure 20 to Figure 23. 135 Table S38. Environmental impacts results for the carbon stack produced with the pre-industrial process given per kWh of electricity produced, related to Figure 20 to Figure 23 136

Table S39. Results of the PSC produced with the laboratory scale method given per kWh of electricity produced given per kWh of electricity produced, related to Figure 23. 
Table S40. Results of the ideal process of production of a carbon stack perovskite

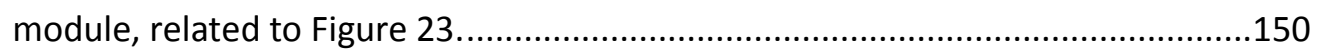

Table S41. Energy consumption of the carbon stack perovskite photovoltaic module produced in the pre-industrial process in comparison to the same module produced in the ideal industrial process, related to Figure 20 to Figure 23. 159

Table S42. List of impact categories, their abbreviations, units and methodologies in which they are included, related to Figure 20 to Figure 23.

161 

Abbreviations

Along the thesis the following abbreviations are used.

\begin{tabular}{|c|c|}
\hline Abbreviation & Meaning \\
\hline AD/ADP & $\begin{array}{l}\text { Mineral and Fossil resources depletion } \\
\text { potential/ Abiotic Depletion Potential }\end{array}$ \\
\hline ADPF & Abiotic Depletion Potential, fossil fuels \\
\hline AM1.5G & Standard solar irradiation \\
\hline AP & Acidification Potential \\
\hline AVAl & Ammonium Valerate Acid lodide \\
\hline $\mathrm{CB}$ & Chlorobenzene \\
\hline CED & Cumulative Energy Demand \\
\hline CIGS & Copper indium gallium selenide \\
\hline CML & $\begin{array}{l}\text { Institute of Environmental Sciences } \\
\text { impact assessment model }\end{array}$ \\
\hline CZTS & Copper zinc tin sulphide \\
\hline $\mathrm{C}-\mathrm{TiO}_{2}$ & Compact titania \\
\hline DMF & Dimethylformamide \\
\hline DMSO & Dimethylsulfoxide \\
\hline ETL/ETM & $\begin{array}{l}\text { Electron Transporting Layer / Electron } \\
\text { Transporting Material }\end{array}$ \\
\hline EOL & End of Life \\
\hline EP & Eutrophication Potential \\
\hline EPBT & Energy Payback Time \\
\hline EPBT20S1 & $\begin{array}{l}\text { Energy Payback Time considering an } \\
\text { efficiency of } 20 \% \text { and the end of life } \\
\text { scenario } 1\end{array}$ \\
\hline EPBT20S3 & $\begin{array}{l}\text { Energy Payback Time considering an } \\
\text { efficiency of } 20 \% \text { and the end of life } \\
\text { scenario } 3\end{array}$ \\
\hline EROEI & Energy Return on Energy Invested Ratio \\
\hline ET & Ecotoxicity \\
\hline FA/FAI & $\begin{array}{l}\text { Formamidinium ion/Formamidinium } \\
\text { iodide }\end{array}$ \\
\hline FET & Freshwater Ecotoxicity \\
\hline FTO & Fluor Tin Oxide \\
\hline GB/GBL & Y-Butyrolactone \\
\hline GHG & Greenhouse Gas \\
\hline GWP & $\begin{array}{l}\text { Global Warming Potential/Climate } \\
\text { Change Potential }\end{array}$ \\
\hline HFC & Hydrofluorocarbon \\
\hline
\end{tabular}




\begin{tabular}{|c|c|}
\hline Abbreviation & Meaning \\
\hline HTC & Human Toxicity, Cancer \\
\hline HTCPBT & Human Toxicity Cancer Payback Time \\
\hline HTCPBT20S1 & $\begin{array}{l}\text { Human Toxicity Cancer Payback Time } \\
\text { supposing a } 20 \text {-year lifetime and the } \\
\text { scenario } 1 \text { for the end of life }\end{array}$ \\
\hline HTCPBT20S3 & $\begin{array}{l}\text { Human Toxicity Cancer Payback Time } \\
\text { supposing a } 20 \text {-year lifetime and the } \\
\text { scenario } 3 \text { for the end of life }\end{array}$ \\
\hline HTL/HTM & $\begin{array}{l}\text { Hole Transporting Layer / Hole } \\
\text { Transporting Material }\end{array}$ \\
\hline HTN-C & Human Toxicity, Non-Cancer \\
\hline ILCD & $\begin{array}{l}\text { International Reference Life Cycle Data } \\
\text { System }\end{array}$ \\
\hline ITO & Indium Tin Oxide \\
\hline IPCC & $\begin{array}{l}\text { Intergovernmental Panel on Climate } \\
\text { Change }\end{array}$ \\
\hline LCA & Life Cycle Assessment \\
\hline LCOE & Levelized Cost of Energy \\
\hline LED & Light-emitting diode \\
\hline $\mathrm{MA} / \mathrm{MACl} / \mathrm{MAI}$ & $\begin{array}{l}\text { Methylammonium ion / } \\
\text { Methylammonium chloride / } \\
\text { Methylammonium iodide }\end{array}$ \\
\hline $\mathrm{m}-\mathrm{TiO}_{2}$ & Mesoporous titania \\
\hline $\mathrm{m}-\mathrm{ZrO}_{2}$ & Mesoporous zirconia \\
\hline $\mathrm{M}_{2.5}$ & $\begin{array}{l}\text { Fine particulate matter, with a diameter } \\
\text { of } 2.5 \mu \mathrm{m} \text { or less }\end{array}$ \\
\hline $\mathrm{NO}_{\mathrm{x}}$ & Nitrogen Oxides \\
\hline ODP & Ozone Layer Depletion Potential \\
\hline OPV & Organic Photovoltaics \\
\hline PAH & Polycyclic Aromatic Hydrocarbon \\
\hline $\mathrm{PCE} / \mathrm{n}$ & Power Conversion Efficiency / Efficiency \\
\hline PFC & Perfluorocarbon \\
\hline POP & Photochemical Oxidation Potential \\
\hline PSC & Perovskite Solar Cell \\
\hline PV & Photovoltaic \\
\hline RER & Europe in Ecoinvent database \\
\hline S1 & Scenario 1 \\
\hline S2 & Scenario 2 \\
\hline S3 & Scenario 3 \\
\hline
\end{tabular}




\begin{tabular}{|l|l|}
\hline Abbreviation & Meaning \\
\hline Spiro-MeOTAD & $\begin{array}{l}2,2 ', 7,7^{\prime}-\text { Tetrakis[N,N-di(4- } \\
\text { methoxyphenyl)amino]-9,9'- } \\
\text { spirobifluorene }\end{array}$ \\
\hline TiAcAc & $\begin{array}{l}\text { Titanium di-isopropoxide } \\
\text { bis(acetylacetonate) }\end{array}$ \\
\hline USEtox & $\begin{array}{l}\text { UNEP-SETAC toxicity impact assessment } \\
\text { model }\end{array}$ \\
\hline VOC & Volatile Organic Compound \\
\hline WDP & Water Depletion Potential \\
\hline
\end{tabular}





\begin{abstract}
An increasing concentration of greenhouse gases and pollutants in the Earth's atmosphere endangers survival of humans and ecosystems. Recently, a series of summits gathered world political leaders to tackle the challenge of alleviating these threatens to an extent in which human life on Earth is guaranteed. Besides, the fossil energy sources are found to be in serious risk of depletion. These issues highlight the necessity of changing the energy model that nowadays powers societies, mostly based on fossil fuels. The most promising alternative to the current model is based on renewable energy sources, in which photovoltaics play an important role.
\end{abstract}

Among photovoltaic technologies, recently emerged a new class with halide perovskite as the main material. Perovskite solar cells promise top efficiencies produced through a simple manufacturing process. However, their development faces diverse shortcomings since their emergence, such as low lifetime and risk of toxicity. This thesis aims to assist the development of the novel photovoltaic technology based on halide perovskite towards commercialisation, in terms of sustainability. Life Cycle Assessment is used as tool for this purpose. Further details of the justification and the goal and scope of this thesis, together with the objectives, the hypotheses, the methodology and the structure are given in Chapter 1.

The state of the art of the developments of perovskite photovoltaics in terms of sustainability are described in the Chapter 2. A review of the environmental impacts generated by perovskite solar cells at the early days of the technology through prospective life cycle assessment is presented. Results of studies treating the toxicity caused by lead present in halide perovskites are also described. A discussion of Life Cycle Assessment studies dealing with perovskite photovoltaics processes and devices in a more advanced technology readiness is included. Studies contrasting perovskite photovoltaics with other photovoltaic technologies are also discussed. Studies about the cost of are finally treated in the review. A subsection highlights the relation of the studies exposed in each section with the objectives of the thesis. $A$ final summary of these subsection is exposed at the end of chapter.

In the subsequent chapters the main body of the thesis is presented as a compendium of three articles. At the beginning of the development of halide perovskite photovoltaics, different cell architectures and assembly processes were developed at laboratory scale. In Chapter 3, the environmental performance of such initial developments is assessed through life cycle assessment. A comparison of three different perovskite deposition methods and two cell architectures is performed. Environmental impacts of the common layers of the four devices evaluated are found to be the highest. However, the sequential deposition method for perovskite 
and the mesoporous configuration result more detrimental than the rest. Three end of life scenarios are designed from methods reported in the literature and are evaluated. Reusing and recycling the devices at the end of life diminishes the environmental impacts.

Improved stability, reproducibility and efficiency is achieved by combining methylammonium cation with formamidinium and caesium in the perovskite composition, together with different halides in the anionic position. The environmental impacts of four perovskites combining these cations and anions deposited in lab-scale solar cells is compared in Chapter 4. The environmental impacts of a plain methylammonium lead iodide perovskite are also determined to stablish a benchmark. Perovskites combining different cations and anions show worse environmental impacts because of the impacts generated by the lead halide reagents and the energy consumed for the deposition. However, for the abiotic depletion category the methylammonium lead iodide perovskite has a higher impact because it uses more amount of lead iodide. Finally, an estimation of the cost of each of the perovskites treated is presented.

Further progression of the technology entails improving perovskite photovoltaics manufacturing at pilot scale, in larger sizes. A pilot-scale manufacturing process, called in this thesis pre-industrial, produces perovskite solar modules in a carbon stack configuration. This manufacturing process is evaluated in terms of environmental performance in Chapter 5. Their environmental impacts are contrasted with those of an ideal manufacturing process, which is simulated from this pre-industrial process. The energy consumption for the deposition of the perovskite layer results the most detrimental impact, which highlights the necessity of decreasing the energy consumption for a more sustainable commercialisation of the technology.

Finally, the conclusions of the thesis are presented in Chapter 6, comprising the main conclusions arising from the three previous chapters. Herein, it is also exposed a description of how the objectives of the thesis are reached and how the hypotheses are verified or rejected. 


\section{Resum}

La creixent concentració de gasos d'efecte hivernacle i compostos contaminants en l'atmosfera de la Terra posen en greu perill la supervivència d'essers humans i ecosistemes. Recentment, s'han reunit líders polítics d'arreu del món en una sèrie de cimeres per tal d'intentar minorar aquestes amenaces de manera que la vida de l'esser humà a la Terra estiga garantida. Addicionalment, els recursos fòssils d'energia es troben en risc seriós d'esgotament. Aquests problemes recalquen la importància de canviar el model energètic que a dia de huí cobreix les necessitat energètiques de les nostres societats, el qual es basa majoritàriament en combustibles fòssils. L'alternativa més prometedora a l'actual model es basa en fonts d'energia renovable, entre les quals l'energia fotovoltaica juga un paper important.

Entre les tecnologies fotovoltaiques, recentment ha sorgit una nova classe amb perovskita d'halogen com a material principal. Les cèl-lules solars de perovskita prometen eficiències d'alta gama, mentre es produeixen mitjançant un procés simple. No obstant això, el seu desenvolupament afronta diverses falles des que van emergir. Entre aquestes falles es troben baix temps de vida útil i risc de toxicitat. L'objectiu d'aquesta tesi és la d'ajudar en el desenvolupament d'aquesta tecnologia fotovoltaica novella basada en perovskita d'halogen de camí a ser comercialitzada, des del punt de vista de sostenibilitat. L'Anàlisi del Cicle de Vida s'usa com a ferramenta per a aquest propòsit. Al Capítol 1 s'hi poden trobar més detalls de la justificació i de l'objectiu i abast d'aquesta tesi, juntament amb els objectius, hipòtesis, metodologia i estructura.

Els antecedents del desenvolupament de la tecnologia fotovoltaica de perovskita des del punt de vista de la sostenibilitat es descrit al Capítol 2. Es presenta una revisió dels impactes mediambientals generats per les cèl-lules solars de perovskita a les beceroles de la tecnologia mitjançant Anàlisi del Cicle de Vida prospectiu. També es descriuen els resultat dels estudis que tracten la toxicitat causada pel plom present als dispositius fotovoltaics de perovskita d'halogen. S'hi inclou una discussió dels estudis d'Anàlisi del Cicle de Vida que tracten processos i dispositius fotovoltaics de perovskita en un estat més avançat de disponibilitat tecnològica. S'hi analitzen una sèrie d'estudis que comparen la tecnologia fotovoltaica de perovskita amb altres tecnologies fotovoltaiques. A l'últim punt de la revisió s'hi tracten estudis de cost. Una subsecció recalca la relació dels estudis descrits en cada secció amb els objectius de la tesi. Estes subseccions són resumides en una secció al final del capítol.

En els següents capítols es presenta el cos principal de la tesi com a compendi de tres articles. A les beceroles del desenvolupament dels dispositius fotovoltaics de perovskites d'halogen, diferents arquitectures de cèl-lula i processos d'acoblament 
foren desenvolupats a escala de laboratori. En el Capítol 3, la conducta mediambiental d'aquests desenvolupaments inicials s'avalua mitjançant Anàlisi del Cicle de Vida. S'hi comparen tres mètodes de deposició de perovskita i dues arquitectures de cèl/lula diferents. Els impactes mediambientals de les capes comunes en els quatre dispositius avaluats s'identifiquen com als més alts. No obstant això, el mètode de deposició seqüencial i la configuració mesoporosa resulten més perjudicials que la resta. Tres escenaris de final de vida s'hi dissenyen a partir de mètodes reportats en la literatura i s'hi avaluen. Reutilitzar i reciclar els dispositius al final de la vida útil disminueix els impactes mediambientals.

S'aconsegueix major estabilitat, reproductibilitat i eficiència quan es combinen cations metilamoni amb cations formamidini i cesi en una mateixa composició de perovskita, juntament amb halògens diferents en la posició aniònica. Es comparen els impactes mediambientals de quatre perovskites que combinen aquests cations $i$ anions depositat en cèl-lules de escala de laboratori al Capítol 4. Els impactes mediambientals de la perovskita de metilamoni plom plana també s'hi determinen per tal d'establir un punt de referència. Les perovskites que combinen cations $i$ anions diferent mostren pitjors impactes mediambientals a causa dels impactes generats pels halurs de plom y l'energia consumida per la deposició. No obstant això, per a la categoria d'esgotament de recursos abiòtics, la perovskita de iodur de metilamoni plom té un impacte major a causa de l'ús d'una major quantitat de iodur de plom. Finalment, s'hi presenta una estimació del cost de cadascuna de les perovskites tractades.

Una major progressió de la tecnologia implica millorar la producció de dispositius fotovoltaics de perovskita a escala pilot, en grandàries majors. Un procés de manufactura a escala pilot, anomenat preindustrial en aquesta tesi, produeix mòduls solars de perovskita en configuració apilament de carboni. La conducta mediambiental d'aquest procés de manufactura s'avalua al Capítol 5 . Els seus impactes mediambiental s'hi contrasten amb aquells d'un procés de manufactura ideal, simulat a partir d'aquest procés preindustrial. El consum d'energia per a la deposició de la capa de perovskita resulta l'impacte més perjudicial, la qual cosa recalca la necessitat de disminuir el consum d'energia per tal d'abastar una comercialització de la tecnologia més sostenible.

Finalment, les conclusions de la tesi es presenten en el Capítol 6, les quals consten de les principals conclusions dels tres capítols previs. També s'exposa aquí una descripció de com els objectius de la tesi s'abasten i com les hipòtesis es verifiquen $o$ es refusen. 


\section{Resumen}

La creciente concentración de gases de efecto invernadero y compuestos contaminantes en la atmósfera de la Tierra ponen en grave peligro la supervivencia de seres humanos y ecosistemas. Recientemente, se han reunido líderes de todo el mundo en una serie de cimas para intentar menguar estas amenazas de manera que la vida del ser humano en la Tierra esté garantizada. Adicionalmente, los recursos fósiles de energía se encuentran en riesgo serio de agotamiento. Estos problemas recalcan la importancia de cambiar el modelo energético que hoy en día cubre las necesidades energéticas de nuestras sociedades, el cual se basa mayoritariamente en combustibles fósiles. La alternativa más prometedora al actual modelo se basa en fuentes de energía renovable, entre las cuales la energía fotovoltaica juega un papel importante.

Entre las tecnologías fotovoltaicas, recientemente ha surgido una nueva clase con perovskita de halógeno como material principal. Las células solares de perovskita prometen eficiencias de alta gama, mientras se producen mediante un proceso simple. Sin embargo, su desarrollo afronta varias fallas desde que emergieron. Entre estas fallas se encuentran un bajo tiempo de vida útil y riesgo de toxicidad. El objetivo de esta tesis es el de ayudar en el desarrollo de esta tecnología fotovoltaica nobel basada en perovskita de halógeno en su camino a la comercialización, desde el punto de vista de la sostenibilidad. El Análisis del Ciclo de Vida se usa como herramienta para tal propósito. En el Capítulo 1 se pueden encontrar más detalles de la justificación y del objetivo y alcance de esta tesis, juntamente con los objetivos, hipótesis, metodología y estructura.

Los antecedentes del desarrollo de la tecnología fotovoltaica de perovskita desde el punto de vista de la sostenibilidad se describen en el Capítulo 2. Se presenta una revisión de los impactos medioambientales generados por las células solares de perovskita en los inicios de la tecnología mediante Análisis del Ciclo de Vida prospectivo. También se describen los resultados de los estudios que tratan la toxicidad causada por el plomo presente en los dispositivos fotovoltaicos de perovskita de halógeno. Se incluye una discusión de los estudios de Análisis del Ciclo de Vida que tratan procesos y dispositivos fotovoltaicos de perovskita en un estado más avanzado de disponibilidad tecnológica. Se analizan una serie de estudios que comparan la tecnología fotovoltaica de perovskita con otras tecnologías fotovoltaicas. En el último punto de la revisión se tratan estudios de costes. Una subsección recalca la relación de los estudios descritos en cada sección con los objetivos de la tesis. Estas subsecciones son resumidas en una sección al final del capítulo. 
En los siguiente capítulos se presenta el cuerpo principal de la tesis como un compendio de tres artículos. En los inicios del desarrollo de los dispositivos fotovoltaicos de perovskitas de halógeno, diferentes arquitecturas de célula y procesos de ensamblaje se desarrollaron a escala de laboratorio. En el Capítulo 3, la conducta medioambiental de estos desarrollos iniciales se evalúa mediante Análisis del Ciclo de Vida. Se comparan tres métodos de deposición de perovskita y dos arquitecturas de célula diferentes. Los impactos medioambientales de las capas comunes en los cuatro dispositivos evaluados se identifican como los más altos. Sin embargo, el método de deposición secuencial y la configuración mesoporosa resultan más perjudiciales que el resto. Tres escenarios de final de vida se diseñan a partir de métodos reportados en la literatura y se evalúan. Reutilizar y reciclar los dispositivos al final de su vida útil disminuye los impactos medioambientales.

Se consigue mayor estabilidad, reproducibilidad y eficiencia cuando se combinan cationes metilamonio con cationes formamidinio y cesio en una misma composición de perovskita, juntamente con halógenos diferentes en la posición aniónica. Se comparan los impactos medioambientales de cuatro perovskitas que combinan estos cationes y aniones depositados en células de escala de laboratorio en el Capítulo 4. Los impactos medioambientales de la perovskita de metilamonio plomo llana también se determinan para establecer un punto de referencia. Las perovskitas que combinan cationes $y$ aniones diferentes muestran peores impactos medioambientales debido a de los impactos generados por los haluros de plomo y la energía consumida por la deposición. Sin embargo, para la categoría de agotamiento de recursos abióticos, la perovskita de yoduro de metilamonio plomo tiene un impacto mayor debido al uso de una mayor cantidad de yoduro de plomo. Finalmente, se presenta una estimación del coste de cada una de las perovskitas tratadas.

Una mayor progresión de la tecnología implica mejorar la producción de los dispositivos fotovoltaicos de perovskita a escala piloto, en tamaños mayores. Un proceso de manufactura a escala piloto, denominado preindustrial en esta tesis, produce módulos solares de perovskita en configuración apilamiento de carbono. La conducta medioambiental de este procesó de manufactura se evalúa en el Capítulo 5. Sus impactos medioambientales se contrastan con aquellos de un proceso de manufactura ideal, simulado a partir de este proceso preindustrial. El consumo de energía para la deposición de la capa de perovskita resulta el impacto más perjudicial, lo cual recalca la necesidad de disminuir el consumo de energía para alcanzar una comercialización de la tecnología más sostenible.

Finalmente, las conclusiones de la tesis se presentan en el Capítulo 6, las cuales constan de las principales conclusiones de los tres capítulos previos. También se 
expone una descripción de como los objetivos de la tesis se alcanzan y como las hipótesis se verifican o se rechazan. 



\section{Graphical Abstract}

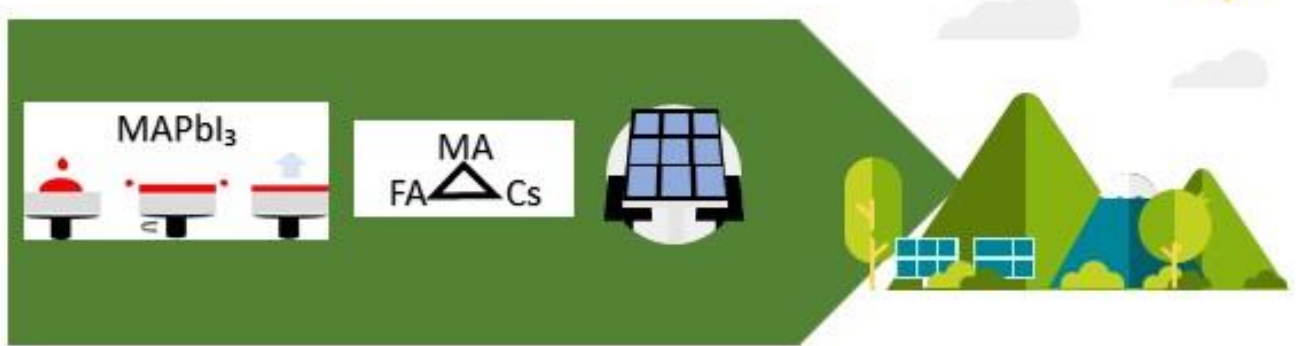



Chapter 1 Introduction 



\subsection{Goal and Scope}

The present thesis aims to assist decision-making of researchers in charge of the development of the novel halide perovskite technology for photovoltaics (PV) from the most elementary state towards commercialisation, in environmental terms. The assistance consists in evaluating the environmental impacts produced during the life cycle of these devices in order to provide guidance to researchers of this particular field. In particular, the readiness levels of this PV technology covered by this thesis range from laboratory to pilot plant. The tool used to analyse the environmental impacts of this technology is Life Cycle Assessment (LCA). The halide perovskites studied in this thesis are principally methylammonium lead halide perovskites. Some additional reagents with which enhance the performance parameters of this elementary formula such as caesium iodide, formamidinium iodide (FAI) and 5ammonium valerate acid iodide (AVAl) are also considered. Halide perovskite layer depositions analysed are spin-coating, "anti-solvent" method and infiltration. 


\subsection{Justification}

Since the beginning of civilisations energy consumption becomes a vital issue for people's survival. So much so that energy availability establishes the prosperity level and technological development of a given civilisation. In modern times, energy is elementary to sustain the exponential technological growth that notably commands our societies. However, it is among the main responsible assets of the environmental crisis that threats our societies.

For instance, usage of an immoderate amount of energy coming from fossil fuels is behind the global warming effect, which whether not stopped will certainly bring irreversible changes that pose a menace to life on Earth as we know it [1]. Carbon dioxide $\left(\mathrm{CO}_{2}\right)$ is the most pernicious responsible of the global warming effect in the Earth's atmosphere. Methane $\left(\mathrm{CH}_{4}\right)$, nitrous oxide $\left(\mathrm{N}_{2} \mathrm{O}\right)$, perfluorocarbons (PFCs), hydrofluorocarbons (HFCs), sulphur hexafluoride $\left(\mathrm{SF}_{6}\right)$ and nitrogen trifluoride $\left(\mathrm{NF}_{3}\right)$ are also included in the list of responsible gases of the climate change according to the Kyoto protocol [2]. As shown in Figure 1, $\mathrm{CO}_{2}$ is present in our atmosphere with a concentration of $411.44 \mathrm{ppm}$, an unprecedented level far larger than the historical record of 300 ppm less than 350,000 years ago, and even larger than its previous concentration to the last ice age [3]. As a result, average global temperature has roughly risen 1 or 1.2 o $\mathrm{C}$ since 1850 [4,5]. Adverse and even fatal consequences of this average global temperature rise are manifold; namely extreme weather events, disrupted water systems, rise of sea level and altered crop growth [6]. In turn, our societies may witness an increase in deaths and plagues, unbreathable air, poisoned oceans, food scarcity, perpetual economic collapse and permanent war [7].

Most of $\mathrm{CO}_{2}$ emissions are generated since the start of the industrial era, with $5 \mathrm{Gt}$ $\mathrm{CO}_{2} \mathrm{yr}^{-1}$ emitted in 1950, $22 \mathrm{Gt} \mathrm{CO}_{2} \mathrm{yr}^{-1}$ emitted in 1990 and roughly $36 \mathrm{Gt} \mathrm{CO}_{2} \mathrm{yr}^{-1}$ emitted nowadays [5]. In terms of Greenhouse Gases (GHG), emissions increased an average of $1.3 \% \cdot \mathrm{yr}^{-1}$ from 1970 to 2000 and $2.2 \% \cdot \mathrm{yr}^{-1}$ from 2000 to 2010, until GHG emissions reached $49 \mathrm{Gt} \mathrm{CO}_{2}$ eq $\mathrm{yr}^{-1}$ in 2010 [1]. The Paris Agreement reached in 2015 by 175 political leaders mainly aimed to limit the global temperature rise this century well below $2 \circ \mathrm{C}$ respect pre-industrial levels, besides pursuing efforts to limit this rise even below 1.5 으 [8]. The Intergovernmental Panel on Climate Change (IPCC) recently recommended to target limiting a rise of $1.5 \circ \mathrm{C}$ out of pre-industrial levels as many of the adverse impacts of climate change will still come at the 1.5 o $\mathrm{C}$ mark [9]. For the 1.5 o $\mathrm{C}$ scenario, if peak happens in $2019 \mathrm{CO}_{2}$ emissions cannot surpass a budget of $600 \mathrm{Gt} \mathrm{CO}_{2}$ (from 2018 to 2100 or reaching a net-zero $\mathrm{CO}_{2}$ emissions), without any negative GHG emission technology $[10,11]$. Under the same 
conditions but for the 2-으 scenario, the maximum $\mathrm{CO}_{2}$ emissions possible increases to a budget of $1200 \mathrm{Gt} \mathrm{CO}_{2}$ [10].

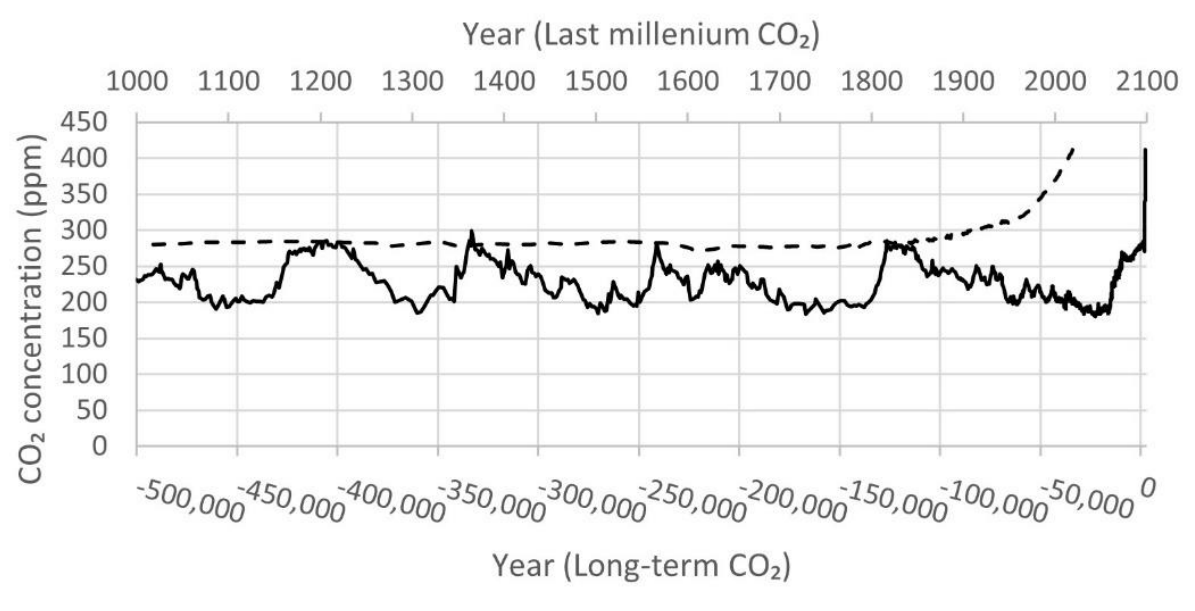

- Long-term $\mathrm{CO}_{2} \quad$ - - - - Last millenium $\mathrm{CO}_{2}$

Figure $1 \mathrm{Global}$ annual average $\mathrm{CO}_{2}$ concentration in parts per million from 500,000 BC to present [3]. Global annual average $\mathrm{CO}_{2}$ concentration is represented from the year 1000 to present in order to appreciate the $\mathrm{CO}_{2}$ emissions rise since the pre-industrial era. Long-term trends in $\mathrm{CO}_{2}$ concentrations can be measured at high-resolution using preserved air samples from ice cores.

Air pollution, with severe negative impacts in our health, also represents another menace to our environment caused by the exorbitant usage of energy from fossil fuels [12-14]. Aerosols possess the ability to travel vast distances, with hazardous pathways originating from highly industrial regions such as Asia $[15,16]$. This is again risking the most vulnerable sectors of population, such as the poor and the future generations [14]. Pollutants such as polycyclic aromatic hydrocarbons (PAH), fine particulate matter $\left(\mathrm{M}_{2.5}\right)$, black carbon, mercury, $\mathrm{SO}_{2}$, nitrogen oxides $\left(\mathrm{NO}_{\mathrm{x}}\right)$ and volatile organic compounds (VOCs), forming ground-level ozone $\left(\mathrm{O}_{3}\right)$, are responsible of multiple health impacts such as infant mortality, low birth weight, allergy, asthma, neurodevelopmental disorders and cancer [17]. Overall, the World Health Organization stated that air-pollution (both indoor and outdoor) is a public health emergency [18].

A third consequence of the usage of non-renewable energy resources to power our societies affects our world by depleting those resources. Specially, economies of countries with a poor availability of those resources in their domains can be the most damaged [19]. In 2018, 97 million barrels of oil were consumed each day around the globe, accounting for all types of oil [20]. Oil is the most required source of primary 
energy because it is almost the unique fuel in the transport sector thanks to its high

Energy Returned on Energy Invested (EROEI) ratio and its versatility. For instance, $31.8 \%$ of the energy consumed in the world during 2017 came from oil [21]. This percentage includes oil consumption in manifold sectors such as industry, the beforementioned transport, residential, commercial and public services, agriculture/forestry, fishing or non-energy. It contributed to generate electricity with a $3.7 \%$ in 2018 [20].

The rate of availability of non-renewable energy sources theoretically resembles the bell curve relationship with time $[22,23]$. Experts claim that we have already overtaken the oil zenith $[24,25]$. Therefore, the amount of oil supplied is foreseen to decrease progressively in the coming years, which may cause a row of severe price spikes [26], which in turn become economic recessions, until its eventual fall.

Reliance in other non-renewable sources is also improbable. Currently, coal is used for residential and agricultural purposes, in the cement and metallurgy industries, and for electricity and heat production. Its contribution to the production of electricity had the largest share of $37.04 \%$ in 2018 [20]. However, its contribution to the supply of primary energy was the second largest for 2017 with a share of $27.1 \%$ [21]. According to other projections, the zenith of coal could have been already occurred or will have been occurred in the following years [27].

Natural gas is principally used for residential and industrial purposes. Although in smaller amount, it is also used for commercial and public services, non-energy and transport purposes. Natural gas contributed to the global primary energy supply with a $22.2 \%$ in 2017 [21], being the lowest contributor among fossil fuels. Nonetheless, it was the second most important fuel used to produce electricity in 2018 , accounting for a $22.22 \%$ out of the total [20]. The feasibility of exploiting natural gas will ultimately be determined by the remaining amount to use, which is optimistically estimated to last for 50.9 years, that is between 2068 and 2069, where unconventional gases are supposed to be included [28].

A last non-renewable source of energy is uranium. Its contribution to the primary energy production in the world was 4.9\% [21]. Uranium's rate of production may have already reached the zenith [29] or it may peak between 2025 and 2040.

\subsubsection{Renewable sources of energy as a solution}

Renewable sources of energy guarantee the entire population unlimited provision of the energy currently needed to power our societies. In addition, usage of current technologies that convert the energy from renewable sources to energy that humans can handle significantly reduces the GHG emissions respect conventional fuels, even 
when the former has been mostly manufactured with the latter [30]. Besides, these technologies have the capacity to diminish the emission of pollutants to the environment [31]. Although it is not a flawless option, a thorough transition to a system capable to supply energy based on renewable sources is one of the few solutions available to this threefold challenge [32,33].

The levelized cost of energy for technologies that use renewable sources is currently competitive respect conventional technologies fed by non-renewable sources. For instance, the unsubsidised levelized cost of electricity of conventional sources (coal, nuclear, gas peaking, and gas combined cycle) ranges from 44 to $199 \$ / \mathrm{MWh}$, whereas that from renewable resources (Solar PV on residential, commercial and industrial rooftop, Thin Film PV utility scale, and Wind Power) ranges from 28 to 242 $\$ / M W h$ [34]. At global scale, a completely renewable electricity mix can be feasible, restricted with some possible constraints [35].

Power technologies reliant on fossil fuels are currently predominant worldwide as demonstrated by a superior demand thereof in 2017 for primary energy, depicted in Figure 2. In addition, the main energetic output of energy stemming from renewable sources is electricity, produced in the most presently deployed windmills, water reservoirs and PV fields. In 2017, nearly 585 EJ were globally supplied, out of which around 97 EJ were supplied via electricity; among which 4 EJ from PVs, 4 EJ from wind power, $14 \mathrm{EJ}$ from hydropower and $4 \mathrm{EJ}$ from other renewable energy technologies [21,36]. Accepting that power infrastructures are an asset hard to massively renew, switching to a worldwide system of infrastructures powered by renewable sources represents a challenge.

A successful transition to a post-carbon energy system will also require an increasement of primary energy from non-renewable sources for at least a couple of decades [37]. However, this last requirement is also constrained by the temperature rise ceiling of $2 \stackrel{\circ}{\circ}$ [8], which limits $\mathrm{CO}_{2}$ emissions to $1160 \mathrm{Gt}$ [10]. Ultimately, decreasing the energy demand at a global scale is deemed to be an inexorable measure to overcome peak oil [38-40].

Another critical aspect about the viability of a full energy transition to a post-carbon energy system is the scarcity of the materials used to manufacture some energy technologies capable to transform energy from renewable sources. In the case of PV, while this is not a major problem for 1st PV generation based on silicon, it is the case for 2nd PV generation due to usage of highly scarce materials such as indium, gallium, selenium or tellurium. Conventional crystalline Si PV, recently overcame the criticality issues arising from the usage of silver as cathode, replacing it by metallised copper [41]. Meanwhile, caesium is a potential component of PVs based on 
perovskite, whose availability may be threatened as reserves are mostly controlled by a single country [42]. Not only PVs contain critical raw materials, concentrated solar power relies on silver for its mirrors, which is a limiting material [43].

- Coal

- Oil

" Natural gas

n Nuclear

- Hydro

- Biofuels

- Other renewables

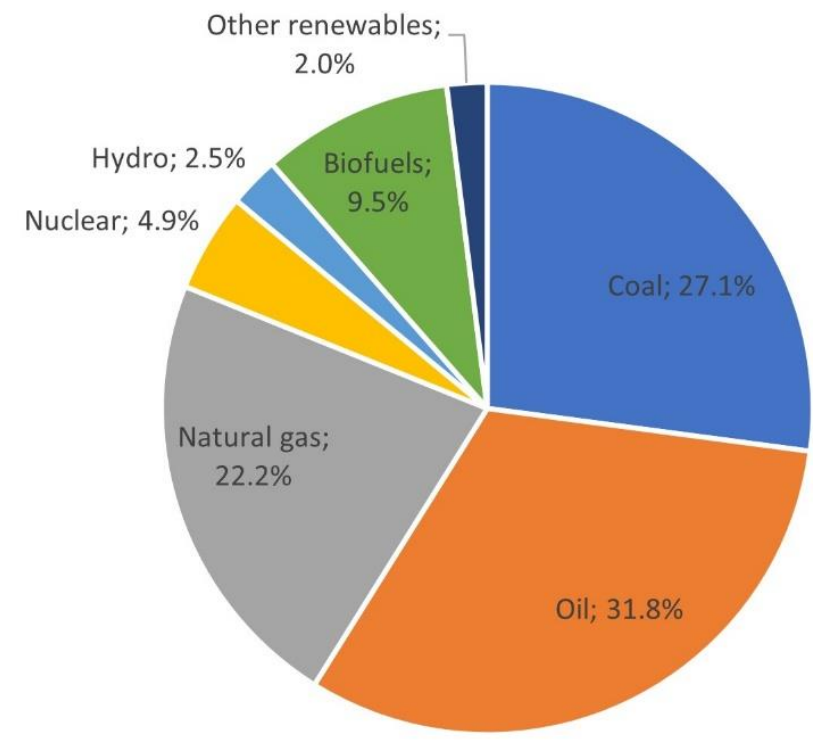

Figure 2. World primary energy supply distribution sorted by source for the year 2017 [21].

\subsubsection{Photovoltaics as a powerful source of energy}

Earth receives from the sun approximately $432 \mathrm{EJ}$ in one hour, out of which $18 \mathrm{EJ}$ per hour are reflected off from the surface and lost into space [44]. Despite the fact that this amount of energy is available to be directly converted to usable electric energy by PVs, nowadays this power technology is just converting about 4 EJ per year [20]. Converting all this incident energy would suppose nearly 158 thousand EJ per year, which greatly exceeds the 585 EJ of primary energy consumed in 2017 [21]. This fact makes solar power technologies converting incident sunlight into usable electric energy, hence PVs, powerful candidates to ease the environmental issues derived from the present system of energy production. However, the potential of PVs to provide electricity to our societies in a post-carbon energy system is limited by the theorical Shockley-Queisser limit of efficiency to which single-junction PV devices are subject to [45]. This theoretical limit is very low, limiting single-junction solar cells with a restricted bandgap range $(0.94 \mathrm{eV}$ to $1.60 \mathrm{eV})$ can theoretically surpass an efficiency of $30 \%$ under standard conditions [46]. 
There currently exist different PV types, which present different characteristics and different levels of technological maturity. Crystalline Si PVs represent the most deployed type with $95.5 \%$ of the market share [47], because it presents moderately high operating efficiencies between $20 \%$ and $22 \%$ [48], and constitutes the so called 1st PV generation. On the other hand, synthesising pure silicon for this type of cells is highly energy-demanding $[49,50]$, which lowers the EROEl. Furthermore, it is a highly optimised technology, which leaves little margin for enhancing the efficiency [51]. An advantage of this technology in a large production scenario is that it can be entirely produced with relatively abundant materials, as silver cathodes can be replaced by copper [41].

Thin-film PV types possess the remaining $4.5 \%$ of the market share, according to production data of 2017 [47], forming the 2nd PV generation. This type of PV technology needs less energy in the manufacture process, which may enhance their EROEI [52,53]. However, among the absorbing materials used for this technology, large-scale production of CdTe and Copper indium gallium selenide (CIGS) cells are constrained by the scarcity of Te and In raw materials [35]. The highest efficiency for a single-junction device belongs to GaAs absorbing material [54], despite its Ga content also supposes a bottleneck for large-scale deployment [55]. In contrast, amorphous- and nano-silicon thin-film technologies do not present this bottleneck provided that the Indium Tin Oxide compound in the electrode is substituted by ZnO [55]. Alternatively, by tuning these chalcogenide materials, promising absorbing materials are obtained [56]. Absorbing materials with similar optoelectronic properties could be deposited consuming a comparable amount of energy to that of CdTe and CIGS, without risking their large-scale deployment $[57,58]$.

Contribution of other technologies to the market share is marginal, namely multijunction PVs and emerging technologies. Multi-junction present the highest efficiency at the expense of a more complex manufacturing cost [59], which increases the initial energetic investment. A remarkable maximum efficiency of $86.8 \%$ is stablished for multi-junction devices with multiple stacks [60], which can possibly lower their EROEI. Emerging technologies consume relatively low energy for their production [61], while the absorbing material is made from abundant materials. However, they are not currently commercialised because of diverse shortcomings, such as low efficiencies or low stability.

\subsubsection{Emergence of halide perovskite as a promising photovoltaic material with outstanding outcomes.}

Among all the types of currently-existing PV technologies, those based on halide perovskite raise much interest among the scientific community, as they offer high 
efficiencies at a low cost [62]. In roughly a decade since hybrid organic inorganic methylammonium lead halides in a perovskite crystal arrangement were discovered as a promising absorbing material for dye-sensitized solar cells [63], their record efficiency for a little area cell is positioned at 25.5\% [64]. This efficiency is comparable to that of already commercialised PV technologies with the highest efficiencies, such as crystalline silicon, CIGS, CdTe and GaAs [65].

A second pillar standing for their potentiality is that they can be manufactured through solution-processing, which is a simple and cost-effective process of production [66]. Halide perovskite solar cells (PSC) whose perovskite has been deposited through solution-processing require low temperatures to be manufactured [67]. Therefore, if deposition of other high energy-demanding layers such as $\mathrm{TiO}_{2}$ is avoided, PV devices manufactured with this process present a diminished energy consumption [68].

A myriad of methods can be used to deposit the halide perovskite layer, encompassing laboratory scale and large scale methods [69]. This process also enables to deposit the absorbing material onto a flexible substrate, which makes PSC suitable for an enhanced amount of purposes [70,71]. In addition, low amounts of material are required to form the cell, as thicknesses of the absorbing layer are within a range of hundreds of nanometres due to the large absorption coefficient of halide perovskites [72].

Stability was one of the first drawbacks of PSC, as they were initially operative only tens of minutes until perovskite dissolved in the liquid electrolyte [73]. This problem was partly solved when the liquid electrolyte was replaced by a solid hole transporting material, quickly enhancing the stability to $500 \mathrm{~h}$ in those days $[74,75]$. Although this problem still remains as the most important challenge of PSC towards commercialisation [76], paramount advances in that sense have nevertheless been achieved. Thus far, the longest lifespan for PSCs is superior to 9,000 $\mathrm{h}$ [77] and 10,000 h [78].

Reliable and standard stability tests are also crucial for PSCs towards commercialisation [79]. For the moment, IEC61215:2016 tests originally intended for crystalline silicon cells recently replaced the specific tests for thin-film solar cells IEC61646:2008 [80], despite not being the most appropriate assessment [81]. The cell lifetime is proposed as the time that solar cells retain at least $80 \%$ of their initial efficiency [82]. Recently, the amount of energy that a PSC produces during the first day has been proposed as a benchmark so as to account for the diurnal efficiency variation [83]. 
Several factors affect stability of PSC, namely damp, heat, oxygen, light and electrical bias [84]. Rectifying structural stability of PSCs issues, while producing them with a low environmental burden, do not pose a significant challenge [85]. For instance, enhancing the PSCs temperature to $330 \mathrm{~K}$, which is within its operational temperature range, to produce the black perovskite phase change may produce a self-healing effect on their structure [86]. Another approach consists in depositing the perovskite layer using an optimised mixture of solvents which enhances the uniformity and density of the perovskite layer leading to hysteresis-free devices [87]. Combining different cations to synthesise the halide perovskite has been proven to improve significantly both efficiency and stability [88]. Despite the fact that this last approach is estimated to be detrimental for the environment [89], improvements in the synthesis procedures of some key precursors could reduce this impact. Additionally, introducing PbS nanoplatelets in a FA-based perovskite matrix enhances the stability of its optoelectronic properties, while also improving its reproducibility [90].

Optimising the interlayers is another manner to improve the stability of PSCs while not implying an additional toxicity burden [85]. Instead of Spiro-MeOTAD, which was the first to replace the highly unstable liquid electrolyte, the usage of transition metal oxides is examined as hole transporting layers to enhance the stability [91,92]. On the other hand, carbon based interlayers suppose a low-cost approach to increase the stability [93], which can be placed in various positions into the stack [94]. In particular, a carbon stack structure replaces precious metals in the electrode [95], while sacrificing the hole transporting layer [96,97]. Apart from presenting relatively high efficiencies and stabilities, the environmental impacts generated during its production reveal a clear candidate structure to become commercialised [98]. A last approach falling into the interlayers engineering is stacking $2 D / 3 D$ perovskite layers, as the successful combination of ammonium valerate acid and methylammonium reflects, producing stabilities above 1 year [78].

A prominent technic to ensure enduring PSCs preventing them from photo-oxidation and decomposition is to shield them with an encapsulation [99]. From glass [100] to a variety of polymers [101] can act as a barrier to protect PSCs, each one of them presenting different physical properties. Recently, a PSC sealed with a low-cost polymer/glass pressure-tight encapsulation passed the IEC61215:2016 Damp Heat and Humidity Freeze tests [102]. Apart from protecting the PSC device from the environment, a metal-organic framework polymer composite sealant has the ability to prevent the lead from leaking into the environment [103]. Other polymeric materials such as $P, P^{\prime}$-di(2-ethylhexyl)methanediphosphonic acid and ethylenediamine tetra(methylene phosphonic acid blended with poly(ethylene 
oxide) have also been proven as an useful barrier to retain lead of PSCs from leaking into the environment [104].

Other interesting features of halide perovskites are that they can be tailored according to the application on purpose $[105,106]$. Therefore, perovskite's bandgap can be tuned to match with other PV technologies in a multi-junction stack [107]. It is even possible to combine two perovskite types in a tandem cell [108]. Alternatively, they have demonstrated a great potential when combined with the traditional monocrystalline $\mathrm{Si}$, reaching a record efficiency of $29,5 \%$, which is slightly higher than that of GaAs thin-film [64]. 


\subsection{Objectives}

The beforementioned goal of this thesis is to assist the research community to sustainably conduct the PSCs development towards their final commercialisation. The present thesis addresses the specific objectives listed below:

1. To provide information about the environmental performance of PSCs at an elementary state of development, while making available original inventories of their life cycle.

1.1. To apply LCA to three of the most promising PSCs assembly processes at laboratory scale; comprising spin-coating of 3:1 ( $\left.\mathrm{MAl}^{\mathrm{PbCl}} \mathrm{Pb}_{2}\right)$ perovskite, spin-coating of 1:1 (MAl:Pbl$\left.{ }_{2}\right)$, and sequential deposition of 1:1 (MAl:Pbl $\left.{ }_{2}\right)$.

1.2. To apply LCA to two of the most common perovskite layer configurations used for PSCs, which are planar and mesoporous.

1.3. To apply LCA to a halide perovskite deposition method useful at laboratory scale that needs the usage of an additional solvent.

2. To provide information about the environmental performance of different halide perovskite compositions intended to improve stability, reproducibility and efficiency of PSCs, while making available original inventories of their life cycle.

2.1. To apply LCA to four different perovskite compositions containing caesium, formamidinium and methylammonium as cations; also iodide and bromide as anions.

2.2. To compare these four multication perovskite compositions with a canonical methylammonium lead iodide perovskite.

3. To provide information about the environmental performance of a PV device based on halide perovskite at a pre-industrial development stage, while making available original inventories of their life cycle.

3.1. To apply LCA to a pre-industrial production process of a large area carbonstack photovoltaic module based on halide perovskite.

3.2. To evaluate the level of optimisation of this pre-industrial process in terms of a newly defined ideality coefficient.

3.3. To evaluate the environmental performance of three end-of-life scenarios for PSCs from recycling methods proposed in the literature. 


\subsection{Hypotheses}

The research conducted in the present thesis pursues to provide a response to the subsequently described hypotheses.

1. As PSCs are a promising PV technology because, among other advantages, their assembly needs relatively little energy, the environmental impacts arising from this input are not expected to be remarkable.

2. In line with the results of previous toxicity analyses to the lead content of PSCs, it is not expected to pose such a hazard to reject its usage.

3. Due to the amount of materials used to produce PSCs is marginal, the time of functioning of the PSCs necessary to offset the toxicity generated to produce them is relatively low.

4. End-of-life scenarios are expected to improve the environmental performance of the life cycle of PSCs as their materials are reused and recycled.

5. The "anti-solvent" perovskite deposition method is expected to increase the environmental impacts because it uses an additional amount of an organic solvent.

6. The price of the canonical halide perovskite is expected to be lower than the multication halide perovskite for the former uses more ordinary reagents.

7. The pre-industrial production process is expected to notably improve the environmental performance respect the laboratory scale process. 


\subsection{Methodology}

The methodology followed in the present thesis is as exposed below:

The first step to perform the studies included in this thesis consists of an extensive literature review to find the latest trends in the research field of the PSCs. From this review, the most recent materials and techniques employed to produce the PSCs are extracted. Once these are known, a study to evaluate their environmental performance can be proposed, with the intention of providing guidance to researchers to improve them from a sustainable point of view. In addition, works with similar intention are reviewed so as to obtain ideas, with which support our proposed study.

After the literature revision process, the study proposal is further developed. An outline comprising the goal and scope, together with the system boundary is made. A selection of the environmental categories according to product to evaluate is also plotted. From this outline, the necessary models of the inputs and outputs of the proposed system are searched in the Ecoinvent and International Reference Life Cycle Data System (ILCD) databases using SimaPro software. These models that are not available in the databases, must be modelled from other studies. When their inventory is not found in other studies a search of information to model their inventory must be made. In parallel, the amounts of each of the inputs and outputs must be gathered in the system inventory. From the system inventory and the models of the materials and process involved into it, a simulation of the environmental performance of the PSCs or related materials thereof during their life cycle is executed. Therefore, the environmental impacts of the categories selected are obtained.

Once the results are known, an evaluation of them is performed. The impacts of each category are compared among different devices, materials or parts of a device. These results are finally exposed in a manuscript, supported with some comments about them. 


\subsection{Structure of the dissertation}

The present thesis is divided into 6 chapters. Apart from the introduction in Chapter 1 and a state-of-art about the supporting studies to the development of PSCs (into which LCA studies applied to PSCs are found) in Chapter 2, the thesis is organised as a series of articles published in peer-reviewed research journals. The post-print version of a total of 3 articles appears in the main body of this thesis. A final chapter includes the general conclusions of the thesis and some suggestions for future research. The overall conclusions reached in this thesis are exposed in Chapter 6. A summary of the chapters forming the principal body of this thesis is described below.

\subsubsection{Relative Impacts of Methylammonium Lead Triiodide Perovskite Solar Cells Based on Life Cycle Assessment}

In Chapter 3, the environmental performance of four promising PSCs assembly processes at laboratory scale is evaluated through LCA from cradle to grave. The four resulting devices comprise three planar PSCs where halide perovskite is deposited through three different methods, and a mesoporous PSC where perovskite is deposited through one of the methods used for the planar PSCs. The three deposition methods encompass 1 ) spin-coating of a mixture of reagents including lead chloride and an excess of methylammonium iodide, 2) spin-coating of an equimolar mixture of precursors, and 3) deposition of reagents solution through a two-step process. The three end-of-life scenarios assessed comprise the following fates after PSC devices use stage: disposal in a residual landfill, reuse and final disposal in a residual landfill, and reuse and recycling. In addition, a new environmental indicator is proposed, which represents the time of functioning of the PSC necessary to offset the toxicity generated during its production.

\subsubsection{Evaluation of multiple cation/anion perovskite solar cells through life cycle assessment}

In Chapter 4, the environmental performance of four PSCs using different halide perovskite compositions containing multiple cations and anions as absorbing layer is evaluated through LCA. The cations considered in this study are Cs, FA and methylammonium (MA), whereas the anions are iodide and bromide, by far the most extended combinations used in the development of PSCs. The "anti-solvent" method of deposition of perovskite is considered in these four devices because of its improved efficiency and stability results. Additionally, the environmental performance of these four devices is compared with that of a PSC using a canonical perovskite, methylammonium lead iodide, as absorbing layer. This conventional device is considered to be deposited via spin-coating. The environmental 
performance of layers other than the absorbing layer are not counted because they are considered similar for all five devices. The study is supplemented with an economical assessment of the reagents used for each halide perovskite composition.

\subsubsection{Halide perovskite photovoltaic modules: life cycle assessment of pre-industrial production process}

In Chapter 5, the environmental performance of a large area PV module based on perovskite is subject to LCA. The process of production of this PV module is considered suitable for being produced at large scale, because the techniques/equipment used in its production and the carbon mesoporous architecture of the device are so considered. From the so-called pre-industrial production process used for this PV module, an ideal process of production is simulated in order to establish a benchmark with which test its technological development in terms of environmental performance. A process with the same intention is simulated from a laboratory scale process extracted from the study exposed in Chapter 3. A comparison of the relation of both pre-industrial and laboratory scale processes with their own ideal process is analysed to verify that the technology is progressing appropriately, from a sustainable point of view. 

Chapter 2 State of the art of studies evaluating the environmental and economic viability of photovoltaics based on halide perovskite 



\subsection{Brief introduction to the state of the art}

As halide perovskite solar cells (PSCs) are conceived to directly generate electricity from the sunlight energy, their main advantage lays in the fact that they can generate electricity for a wide variety of purposes from a renewable source, without generating neither emissions nor residues in the process. However, are not the whole of a product impacts solely generated during its use stage, but during the entire life cycle. Although devices based on perovskite are produced via a relatively simple process, it becomes necessary to verify that impacts generated during their whole life cycle are acceptable.

In the present chapter, the current state of the art of the studies evaluating the environmental and economic viability of photovoltaics (PVs) based on halide perovskites is described. In the second section (2.2), prospective analyses supporting the development of PSCs at their most fundamental state of development are summarised. The environmental evaluation of an improvement in the composition of halide perovskite is also included in this section. In the third section (2.3), special attention is given to the toxicity of lead. The different approaches through which the toxicity of lead is tackled are included in this section. Such approaches comprise the Life Cycle Assessment (LCA) studies, the empirical analyses, and the analyses of its substitution. The environmental and economic performance of PSCs in an advanced state of development is evaluated in the fourth section (2.4). Theoretical studies about their commercialisation, suitable perovskite deposition processes, the carbon stack configuration, and their end of life are the topics treated in this section. The pros and cons of perovskite PVs versus other PV technologies is discussed in the fifth section (2.5), with a special part addressing tandems with perovskite. The analyses treating the cost viability of PVs based on perovskite are discussed in the sixth section (2.6). Each section is finished with a brief summary, contrasting the main findings encountered in the described studies. At the end of the chapter (2.7), a last section summarises the studies performed in the literature from all the sections described above.

\subsection{Prospective analyses applied to early development of laboratory scale PSCs}

With the goal of evaluating the environmental impacts along the entire life cycle of PSCs at an elementary state of development in mind, LCA emerges as the most appropriate tool. This goal emerges as a starting point on the way of providing guidance about the environmental performance of the developers of a novel technology such as PSCs. However, inherent complications to apply it arise from the 
incipient state of development of PSCs technology, increasing the uncertainty of the LCA outcomes. Several pitfalls are identified as responsible of these difficulties. For instance, there is a low availability of data of the fate, transport and toxicity of the novel involved substances [109]. Nevertheless, a few years after the arrival of PSCs, the first LCA studies about this technology were performed. Although, some of the prospective LCA studies on PSCs are developed using inventories from a reduced number of studies [53].

In the previously described context, the first LCA study was focused in comparing two lab-scale perovskite layer deposition processes, which are solution- and vapourbased processes [110]. As a result, halide perovskite was vapour deposited onto a normal configuration device and spin-coated onto an inverted configuration device. Results of this work reveal that the principal environmental hotspots are the perovskite layer and the electricity required for the production. Authors conclude that there is a lack of strong reasons to dismiss perovskite to produce PV devices.

A subsequent LCA evaluated PSCs where the halide perovskite is deposited with a sequential method, in which the $\mathrm{Pbl}_{2}$ reagent is spin-coated whereas $\mathrm{MAl}$ is dipped [111]. The main goal of this study was to compare two devices using $\mathrm{TiO}_{2}$ and $\mathrm{ZnO}$ as an electron transporting layer (ETL). The gold cathode, the energy used to deposit it through thermal evaporation, the Indium tin oxide (ITO) glass substrate and the organic solvents are found the most detrimental inputs for the production of both PSCs.

A third LCA study evaluated a device where halide perovskite is deposited through the same two-step deposition method [112]. Although this PSC differs when it comes to the interlayers, as it has an ETL composed with titanium dioxide nanotubes and a liquid hole transporting layer (HTL). PSCs inherited this type of HTL from dyesensitized solar cells, but it was soon identified as an instability inducer, and so replaced it with the solid-state HTL [62]. This study finds the organic solvents and the energy used during the device production as the main sources of environmental impact.

After these abovementioned studies were published, the present thesis was initiated in order to contribute to the development of laboratory-scale PSCs, while also providing the manufacturing inventories of some substances to the field. Therefore, the Chapter 3 of this thesis reports an LCA study where the environmental performance of four laboratory-scale PSCs are compared [113]. In these four devices, three of the most common laboratory-scale PSC assembly routes back then are included, together with the two of the most usual PSC configurations. The outcomes 

photovoltaics based on halide perovskite

of the study point out that the majority of the impact generated by the four devices stem from the energy consumption and the gold cathode.

\subsubsection{Analyses applied to compositional engineered PSCs}

From then on, several LCA studies applied to PSCs were focused on analysing new perovskite compositions to mainly improve their performance properties stability, reproducibility, and efficiency. The principal difference in their composition supposed the introduction of formamidinium (FA) and caesium cations, totally replacing the conventional methylaminium (MA) cation. For instance, introducing FA cation boosted its power conversion efficiency (PCE) above 20\% [114]. Through the so-called compositional engineering, researchers sought improving the PCE and stabilising the perovskite phase [115]. Both properties were also improved while tuning the perovskite's bandgap, by combining Cs with FA in the cationic mixture [116]. Recently, the stability was further optimised by introducing $\mathrm{Rb}$ to the perovskite composition [117].

The first LCA study of the kind contrasts from cradle to grave the environmental impacts of distinct halide perovskite compositions, each in a single device [118]. This study includes three perovskite compositions with each of those three cations, together with a perovskite combining I and $\mathrm{Cl}$ anions. This study attributes the higher consumption of embodied energy and mass of $\mathrm{MAPbl}_{3}$ and $\mathrm{FAPbl}_{3}$ devices to the system manufacturing stage. Usage of gold for the cathode, alongside to usage of organic solvents to clean the Fluor Tin Oxide (FTO) and the perovskite layer are responsible of most of the environmental impact generated during the manufacturing stage.

Also including the end-of-life stage in the system, an additional work compared a conventional $\mathrm{MAPbl}_{3} \mathrm{PSC}$ with a proposed $\mathrm{Cs}_{x} \mathrm{FA}_{1-\mathrm{x}} \mathrm{Pbl}_{3-\gamma} \mathrm{Br}_{\gamma} \mathrm{PSC}$ [119]. For the Cs-FAcontaining PSC, copper and CUSCN are used for the cathode and the HTL, respectively. Most of the environmental impact is attributed to the gold cathode for the conventional module. Meanwhile, most of the environmental impact generated by the proposed module is caused by the FTO layer. Substituting the gold cathode by for instance copper is considered as a necessary step towards commercialisation of PSCs.

When FA and MA cations are combined the stability of the overall perovskite is preserved whereas the efficiency is enhanced above $18 \%[115,120]$. By further adding Cs, perovskites' stability and reproducibility is improved [88]. Therefore, an LCA study presented in the Chapter 4 of the present thesis compares different proportions of these cations in a sole $\mathrm{Cs}_{\mathrm{x}}\left[\mathrm{MA}_{0.17} \mathrm{FA}_{0.83}\right]_{1-\mathrm{x}} \mathrm{Pb}\left[\mathrm{l}_{0.83} \mathrm{Br}_{0.17}\right]_{3}$ perovskite 
with a canonical $\mathrm{MAPbl}_{3}$ perovskite [89]. The multicationic perovskites are deposited through the anti-solvent method, whereas the canonical perovskite is deposited through spin-coating. All the compositions are intended to be the absorbing layer of a PSC, the rest of layers of the PSC are however excluded from the system because they are similar. Perovskites combining the three cations get the worst environmental results because of the usage of both chlorobenzene as a solvent for the anti-solvent deposition and $\mathrm{FAl}$ as reagent. $\mathrm{Pbl}_{2}$ reagent generates the most pernicious impact for all perovskite compositions.

\subsubsection{Summary of prospective analyses}

After the discovery of the fact that perovskite holds excellent photoconversion properties, a reduced number of prospective LCA studies were performed to evaluate this technology in an incipient state [110-112]. In these studies, scarce configurations and production methods typical of laboratory environment are evaluated. Few additional inventories were generated in these preliminary studies [53]. With the objective of evaluating further configurations and production methods whilst providing their inventories, the Chapter 3 of this thesis evaluates the most likely successful lab-scale configurations and deposition methods to provide relevant information about their environmental performance to researchers [113].

An important improvement in the photoconverting properties of halide perovskites achieved modifying its composition is evaluated in subsequent LCA studies. Two LCA studies tackle this improvement by evaluating halide perovskite compositions with the innovative cations separated or barely combined [118,119]. Results of these studies are aligned with those evaluating PSCs with just MA as cation. They provide limited extra information about the environmental burden of the beneficial halide perovskite composition. With the objective of evaluating several halide perovskite compositions presenting the optoelectronic benefits attributed while providing their inventories, an LCA study of the three cations combined is presented in the Chapter 4 of this thesis [89].

\subsection{Environmental concerns posed by lead in PSCs}

Lead is a controversial element owing to its capacity to mimicry essential elements once it enters the human body [121]. Despite its extended use in the ancient times, its use is currently restricted in a crucial market for PVs as it is the European Union [122]. A methylammonium lead iodide perovskite layer with $0.6 \mu \mathrm{m}$ of thickness contain roughly $0.8 \mathrm{~g}$ of lead [123], which is more than $32 \%$ and $0.13 \%$ of lead by weight in the perovskite layer and in the whole PSC, respectively. Such lead content could have a detrimental influence in consumers acceptance [124]. As a result, 
State of the art of studies evaluating the environmental and economic viability of photovoltaics based on halide perovskite

understanding lead of PSCs toxicity behaviour has essential consequences on the final commercialisation of this technology.

\subsubsection{LCA studies addressing the toxicity of PSCs}

The concern surrounding PSCs lead content concentrates part of the research attention. Few LCA studies focused on evaluating the toxicity of lead in PSCs are found in the literature [118,125-127]. Nevertheless, an important number of the LCA studies about PSCs mention in their conclusions that the toxicity risk posed by lead is of low relevance $[110,111,113,128-130]$, among which the Chapter 3 of this thesis is found.

Two of the LCA studies focusing on the toxicity of lead in PSCs compare impacts of lead in PV devices based on perovskite with those of the electricity from the grid $[125,126]$. In both studies the production of electricity from perovskite PV devices results beneficial.

The other two LCA studies of this kind compare lead with tin in halide perovskite devices. The first of both studies compares the environmental performance of a representative tin-based PSC with two lead-based PSCs [127]. These two lead-based PSCs had been deeply evaluated previously elsewhere [110]. Authors conclude that if lead is treated carefully at the end of life its use would generate a little environmental impact.

The second LCA study of this kind, contrasts the environmental impact of a tin-based PSC with that of four lead-based PSCS [118]. The tin-based halide perovskite contained MA as cation, with a given proportion of $\mathrm{Br}$ and $\mathrm{I}$ as anions. Tin-based PSC did not have the most pernicious environmental impacts. Meanwhile, neither lead nor tin represents a major environmental impact because of the little amount of them used.

\subsubsection{Empirical analyses of lead toxicity in perovskite}

As it happens with other PV technologies, such as GaAs or CdTe, commercial deployment of PSCs poses a critical concern because its toxicity. In principle, a proper encapsulation is vital to protect the environment from the toxic substances contained in the cell [131]. However, agents of diverse nature can liberate these toxic species into the environment, ranging from a simple rain falling on a damaged module to natural disasters. From now on, these latter agents are expected to occur at an increased frequency due to the climate change. Therefore, scientists from diverse research fields performed relevant studies to contribute with empirical results to shed light on the consequences of widely using leaded PSCs. 
A relevant number of these studies is gathered in a recent review, that covers PSCs apart from other PV technologies [132]. The review finds relatively few studies addressing the toxicity generated by the potential leachates of PSCs, which considers insufficient. More data about the environmental consequences of leachates is then necessary to perform more accurate studies on the impact to the environment and health. In line with a conclusion of a previous study [131], authors propose considering the worst-case scenario in the event of spillage, when designing PV devices and regulatory policies.

A study compares the environmental impacts of lead- and tin-based halide perovskites through exposition of perovskite degradation products to the model organism Zebrafish [133]. These organisms are chosen for the test because of their capacity to provide precise details about the mechanisms of toxicology of chemicals [134]. Their results disprove the common belief that tin-based perovskites are a completely satisfactory option compared with leaded perovskites.

The chance of failure and leakage of perovskite's lead into the soil or groundwater in the event of rain is experimentally analysed [135]. In the experimental setup, PSCS are rinsed with water poured to substrates, which are later weighted before and after rinsing to determine the captured perovskite. The $\mathrm{Pb}$ content is determined by measuring the effluent water by inductively coupled plasma mass spectrometry analysis. Results reveal that rain on PSCs with a damaged encapsulation irreversibly decomposes the perovskite, whose lead inevitably penetrates the environment. Authors minimise the consequences of the penetration of lead into the environmental, whether it spreads in the groundwater or it is absorbed by the soil. Attaching water impermeable interlayers to the absorbing layer is recommended to mitigate these consequences.

On the other hand, a study analyses the consequences beyond leaded perovskites infiltrating the soil, by exposing Mentha spicata plants to the perovskite leachate [123]. The importance of this analysis lays behind the responsibility of plants in introducing soil pollutants into the food chain. Findings in this study reveal that leakage of lead present in perovskites can penetrate plants 10 times more effectively than other lead contaminants, making it severely pernicious. Authors oppose current assumptions when claiming that the considered linear proportionality of the environmental impact from lead to its concentration is a mistake. As a result, the current limit of lead concentration of $0.1 \%$ imposed to homogeneous materials in electronic devices may be insufficient. They also recommend completely removing lead from perovskite. 
Whereas the previous study from $\mathrm{Li}$ et al [123] considers any encapsulation technology ineffective to prevent lead leaks to a safe extent, several studies propose encapsulations that retain most of the lead in PSCs. A recent study proposes an encapsulation based on epoxy resin with enhanced mechanical strength and able to self-heal after damaged [136]. Thanks to these properties it significantly decreases the lead leakage rate respect the glass cover with ultraviolet-cured resin placed at the PSC edges. In case the water is already polluted with lead from PSCs, a lead scavenger based on a ferric organic acid as lead absorbent embedded into a porous polydopamine scaffold is proven under simulated rain contaminated with a damaged PSC [103]. It demonstrated to maintain lead concentrations in water below drinkable levels. After estimating its cost, authors conclude that its cost is not expected to impede its incorporation in commercial PSCs.

Besides rainwater, other agents pose a real risk of polluting the environment with lead after reaching a PSC. For example, fire probably is the most pernicious because it can liberate lead into the atmosphere, presenting an acute health hazard for the surroundings. A study tested PSC in tandem with silicon under a simulated fire event

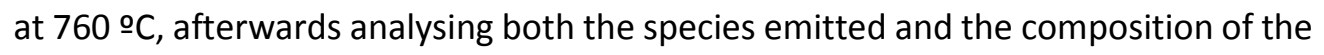
remains [137]. Authors find that perovskite degrades into $\mathrm{Pbl}_{2}$, which in turn oxidises and evaporates, reaching the environment unless a glass encapsulation captures the oxidised species, preventing their release into the environment. However, as described above, an epoxy-resin-based encapsulation prevents more effectively lead leakages than the glass based one in case of rain.

\subsubsection{Substitution of lead to avoid its toxicity}

Additionally, several researchers try to replace the lead in PSCs with alternative metallic cations. Among the candidate elements to substitute lead we can find bismuth [138], germanium [139], cuprum [140], antimony [141] or tin [86]. However, lead-free perovskites are a minority as they still present low efficiencies [142]. Snbased perovskite solar cells are the perovskite lead-free PV devices exhibiting the highest performance, surpassing $13 \%$ efficiency [143]. However, $\mathrm{Pb}^{2+}$ present excellent structural and electronical properties that make difficult waiving its usage [144]. Therefore, a promising alternative to reduce the toxicity of PSCs is partially replacing lead with these elements [144].

In line with this, under the premise that lead-containing perovskites have no commercial future, a summary of the progress of low-lead halide perovskites is exposed along with the necessary criteria to replace lead in perovskites [145]. Authors consider tin, germanium, bismuth, antimony, indium, and transition metals $(\mathrm{Cu}, \mathrm{Mn})$ as substitutes for low-lead perovskites, from which the former is the most 
promising. Despite the low efficiencies and stabilities achieved thus far with these nontoxic substitutes, authors are confident that lead-free perovskites have a high potential to replace lead without compromising their efficiency and stability. This stance is supported by the empirical study where Mentha spicata plants are exposed to leaked lead from PSCs [123]. Authors conclude therein that tin-based perovskites are safer than lead-based perovskites.

In contrast, the conclusions of some previously herein exposed studies analysing the suitability of elements replacing lead in PSCs state that this replacement does not necessarily entail a diminished toxicity. For instance, the exposure of PSCS to zebrafish organisms reveals that the tin-based decomposition product $\mathrm{Snl}_{2}$ generates a higher lethal response than the lead-based one $\mathrm{Pbl}_{2}$, because a higher acidification of the media [133].

The results of this study are in line with that of a previous LCA study comparing leadwith tin-based PSCs, presenting a higher impact for the latter in the terrestrial ecotoxicity category [127]. Therein, several strategic disadvantages are ascribed to the tin perovskite device, such as its higher cost, its lower availability, and its higher production concentration. These handicaps are not offset by favourable environmental impacts, which are even one order of magnitude larger for terrestrial ecotoxicity and global warming potential. This latter LCA study concluded that tinbased PSCs need a breakthrough in the PCE in order to suppose an alternative to replace lead.

\subsubsection{Summary of concerns posed by lead}

Some of the first LCA studies indirectly tackle the issue of lead's toxicity $[110,111,128-130]$. They clearly point out that lead is not a significant concern. This issue is deemed as essential for commercialisation purposes. Among these LCA studies, Chapter 3 also provides information about this issue while evaluates the most likely successful lab-scale configurations and deposition methods with halide perovskites containing lead [113]. Nevertheless, several LCA studies aiming to evaluate lead's toxicity can be found in the literature [118,125-127].

\subsection{Advancing towards large-scale production}

On their way to commercialisation, PSCs possess a low-cost production and high PCEs as advantage. As previously described in section 1.2.3, their stability embodies a key obstacle towards their commercialisation. Further attributes must be considered to transfer PSCs from laboratory-scale to large-scale production, such as large area, high throughput, reproducibility, cost performance and low toxicity [146]. 

photovoltaics based on halide perovskite

Despite the difficulty it entails, several deposition processes are being investigated to fabricate large-area PSCs $[147,148]$. Some of these processes can enable PSCs being produced at large scale while achieving high throughput, high costperformance, and high reproducibility [149-152]. The most recent attempt of producing large area PV modules based on perovskite achieved an aperture area 802 $\mathrm{cm}^{2}$ with a PCE of $16.09 \%$ [153].

\subsubsection{Theoretical studies towards PSCs commercialisation}

Several theoretical studies evaluate the suitability of PV devices based on perovskite commercialisation. These are valuable studies as they mostly analyse the viability of PSCs as a commercial technology. A prospective technical and economic assessment about the large scale manufacturing an incipient PSCs technology was one of the firsts of the kind to be published [154]. It declines the possibility of this technology of substituting commercial monocrystalline silicon. Authors base their conclusion in five key considerations for a successful commercial PSCs manufacturing. These are the need of a high uniform PCE (which should be higher than $30 \%$ for PSCs), the problem of series resistance in large area performance, the toxicity stemming from their lead content, their low stability, and the need of a cost of ownership lower than that of the well-optimised conventional Si PVs. They also find perovskite inappropriate for its inclusion in tandems.

After more development is achieved for PSCs, several technoeconomic analyses were performed on simulated PSCs manufacturing processes [155-158]. Among them, a technoeconomic analysis scrutinised a module configuration with high potential to be manufacturable because of including inexpensive materials and highthroughput deposition techniques [158]. The module is manufactured by sputtering the electrodes made of $\mathrm{Al}$ and Indium Tin Oxide, alongside screen-printing the charge transport layers ( $\mathrm{NiO}$ and $\mathrm{ZnO}$ ) and the perovskite. However, including In as raw material could be disadvantageous for a commercial PV technology because its supply is not ensured in the timespan of a couple of decades [159]. The study concludes that despite some remaining issues to be addressed, PSCs can become a low-cost leader.

Finally, a critical review analyses the current state of single junction and multiple junction PV devices based on perovskite [160]. This work tries to highlight the key challenges of halide perovskite to move from laboratory scale production to industrial scale production. It considers a wide variety of deposition techniques such as blade coating, slot die, spray, inkjet printing, screen printing, roll to roll, electrodepositon, and vapour-based deposition techniques. However, this review omits the carbon stack [96], together with the flash infrared annealing as 
configuration and annealing method highly suitable for large scale production. This review concludes that the electricity necessary to produce the PSCs is the principal contributor to the overall impacts. Authors of this review recommend further investigation of the toxic threats arising from an accidental spillage of the perovskite in PSCs. They also suggest that a proper recycling process for PSCs would notably improve their sustainability when produced at large scale.

\subsubsection{Deposition processes suitable for large scale manufacturing}

Applying LCA to support upscaling of a laboratory scale generates results with high uncertainty [161]. Nevertheless, several LCA studies were recently published with this goal. The first LCA handling this matter compares both co-evaporation and spray deposition methods for the perovskite layer, which present a high potential to be used in a large-scale arrangement [130]. Between both deposition processes, spray deposition results the least energy consuming, which then generates lower environmental impacts for most of the categories.

Also evaluating perovskite deposition methods amenable to large scale manufacturing, a notable improvement in the annealing step of the perovskite is evaluated through LCA [162]. It consists in a novel deposition method using infrared rays to anneal the perovskite layer of a planar device in just 1.2 seconds. After comparing its environmental performance with that of a conventional annealing, results demonstrate that the novel flash infrared annealing method present one order of magnitude lower environmental impacts respect a conventional process using an anti-solvent. Therefore, it is undoubtedly more adequate for large scale production, not only for its lower environmental impact but also for its lower cost. The fact that through this method the annealing can be performed outside a glove box is another advantage for large-scale production [163].

\subsubsection{Carbon stack configuration}

In terms of configuration, the carbon stack configuration has a great potential to be produced at large scale [96]. One of the reasons behind this is the elimination of the expensive cathode, often precious metals as gold or silver, which is replaced by carbon. Another important advantage of this configuration is the elimination of the HTL layer, usually composed of Spiro-MeOTAD, which is also expensive and decreases the stability of the whole device [164]. In this configuration, the deposition of titania, zirconia and carbon interlayers can be achieved via screen-printing, whereas the perovskite can be uniformly infiltrated in the stack with a robotic dispenser [165]. Large-area carbon-stack modules are manufactured through this process [166]. The environmental performance of this configuration is somehow 
evaluated in several cradle-to-gate LCA studies described in the following paragraphs $[98,130,167]$.

The same LCA study that compares two amenable-to-commercialisation perovskite deposition methods, includes in the comparison a spray-deposited HTL-free carbon electrode device, which has fundamental features of a carbon stack device [130]. The results reveal that the carbon stack device presents lower environmental impacts in all categories, except for marine eutrophication due to the organic inputs. Ecotoxicity is the category where the carbon stack device has the lowest impact, because of the avoidance of the HTL layer deposition.

Appearing in the Chapter 5 of this thesis, a pre-industrial process to produce perovskite PV modules using the carbon stack configuration (with a mesoporous titania and zirconia layers) is analysed via LCA and compared to a simulated ideal production process [98]. The energy consumption during the deposition of the perovskite layer (heating up the precursors and annealing) has a predominant contribution to the overall impact. Nonetheless, results confirm that this process is considered of great potential to be implemented at large scale. Further reduction of the energy consumption during the production process is necessary in order to optimise its environmental impacts. After contrasting all layers of the module with the ideal process, the titania blocking layer and the perovskite layer present the highest potential to be optimised.

Although not using deposition methods capable to be applied in large scale processes for the perovskite and electrons transport layer, another LCA study compared two planar (with $\mathrm{SnO}_{2}$ ) and mesoporous (with $\mathrm{TiO}_{2}$ ) variants within a carbon stack configuration [167]. This work finds the process of deposition and patterning of FTO as the most energy demanding, and as a result the most pernicious. This result contrasts with those of previous studies, where some assumptions of energy consumption during FTO cleaning and production are missing, according to authors claim. Again, low stability is found as a major obstacle in order to PSCs to be competitive in the PVs market.

\subsubsection{End of life}

For the sustainability of any PV technology, an adequate end of life of each module is mandatory. An increase of the recyclability of traditional PV technologies [168], as long as clear and efficient recycling methods for the emerging PV technologies is essential for the expected deployment thereof. Some studies addressing this aspect can be found in the literature. 
In one of these studies, some important environmental, regulatory and practical aspects that may arise from PSCs dismantling are discussed [124]. Authors of this study warn that if highly efficient and simple reuse and recycling processes are not stablished, we can eventually have large PVs waste volumes with a time span of 20 or 30 years, representing a 10\% (60 million tons) of all e-waste produced globally.

Several methods of producing PSCs from disposed materials have already been proposed. For instance, a clean process to recover the lead from disposed car batteries is proposed [169]. Lead iodide obtained by this method has similar material characteristics to that stemming from virgin lead. Also addressed to optimise the usage of lead, another study reports a method to recycle until $99.8 \%$ of the lead in PSCs, using deep eutectic solvents [170]. Other studies present clean solutions to extend the lifetime of the perovskite absorbing layer in PSCs [171,172]. The lifetime of PSCs can also be extended by dismantling them and recovering the principal components $[173,174]$.

In the study presented in Chapter 3 of the present thesis [113], two end-of-life scenarios for PSCs evaluate a recycling process where the principal layers are separated and reused. Both end-of-life scenarios are designed from recycling processes reported in the bibliography $[175,176]$. The recycling process proposed significantly diminishes the toxicity impact.

\subsubsection{Summary of progress towards large scale production}

On the way of PV devices based on halide perovskite towards commercialisation, their feasibility to be produced at industrial scale is preliminarily evaluated through technoeconomic analyses $[154,158]$. A review of LCA studies applied to PSCs tries to highlight the challenges that PSCS can encounter on their way to industrialisation [160]. Several studies apply LCA to PSCs with the intention of supporting their upscaling, by evaluating spray deposition perovskite deposition method [130], and flash infrared annealing method [162]. The carbon-stack configuration has a great potential for commercialisation [96]. With the objective of evaluating halide perovskite photovoltaic devices at an advanced readiness level while providing the resulting inventories, the Chapter 5 of this thesis performs a LCA to a carbon-stack halide perovskite module production process [98].

Due to the importance of a proper end of life for a sustainable commercialisation of the halide perovskite PVs, various studies address this aspect [124]. A handful of methods are proposed to diminish impacts of PSCs at their end of life, such as recovering lead [169,170], as well as the main components of PSCs [171-174]. Among these LCA studies, the Chapter 3 of this thesis contributes to these 
propositions by evaluating three end of life scenarios, in two of which some materials are recovered [113].

\subsection{Pros and cons of perovskite PVs against other electricity producing technologies}

In order to support perovskite-based PVs development towards commercialisation, conducting a benchmark analysis with other PV technologies, among which there is already commercial PV technologies, is an important step. In principle, PV devices based on perovskite are considered a beneficial technology for human's health and the environment because they are a clean energy technology of assembled abundant raw materials with a simpler production process based on solution processing. However, the scientific community must pay some attention to their life cycle impacts on these compartments in comparison to other technologies with the same purpose in order to ensure such benefits. To date little work done in line with this is found in the literature.

The first work in this line compares the benefits of perovskite in a tandem cell in terms of reduced greenhouse gas (GHG) emissions and their enhanced risk of lead emissions to those of the grid electricity mix, mostly based on fossil fuels [126]. LCA methodology is used for the analysis. The study demonstrates that consuming electricity from the grid generates a higher impact than that of using electricity stemming from the tandem perovskite-silicon. A currently unrealistic lifetime of 25 years is used in the analysis. Nevertheless, the results are favourable to the perovskite-silicon tandem even when a 2-year lifetime is considered.

Also analysing the impact of lead in comparison with that of three representative U.S. electricity grid mixes, a study concludes that using PSCs to obtain electricity diminishes lead emissions respect that generated consuming electricity from the grid, assuming $17 \%$ of efficiency [125]. An unrealistic lifetime of 20 years is also assumed. Authors of this work recommend to direct research efforts to develop energy-efficient PSCs production processes.

A recent review also deals with the comparation of PSCs with commercial PV technologies [53]. PSCs at a laboratory scale, tandem configuration and industrial scale simulated are included in the study. Despite the uncertainty found for the energy consumption in the production processes of PSCs, they are environmentally advantageous when compared with Silicon PVs on 1-kWp basis.

Despite the scarce number of studies addressing this matter, some extra assessments can be found in several studies whose main goal is not comparing 
impacts of PSCs with those of other energy technologies. These LCA studies on PSCs chiefly contrast the results with that of traditional PV technologies [53]. In agreement with this, one of the first LCA studies applied to PSCs compares their environmental performance with that of existing $\mathrm{PV}$ technologies, in terms of the energy payback time (EPBT) and the $\mathrm{CO}_{2}$ emission factor [111]. Various types of $\mathrm{Si}$ PVs, CdTe and Organic PVs are used as references. Conclusions of this work underline the potential that PSCs possess as an environmentally sustainable electricity generation technology due to its shorter EPBT in comparison with the rest of the existing PV technologies.

A second LCA study applied to a lab-scale PSC using a liquid electrolyte contrasts the environmental performance of the PSC analysed therein with that of other PV technologies [112]. Besides the PV technologies compared in the previous study, dye-sensitized and amorphous silicon PVs are included in the analysis. The energy used for the manufacturing, the GHG emissions and the EPBT are the parameters used for the comparison. As the manufacturing energy is smaller, whereas the GHG emissions and the EPBT are comparable, authors predict a promising commercial future for PSCs.

A LCA study analysing three PSCs produced with processes amenable to large-scale manufacturing compares them with the commercial PV technologies mono-Si, poly$\mathrm{Si}$, amorphous-Si, CdTe and CIS [130]. A shorter lifetime assumed for the three PSCS (5 years for PSCs against 30 years for the rest of technologies) generates higher impacts per kWh for the PSCs respect the commercial technologies, making them environmentally uncompetitive. When impacts were normalised using the mono-Si as a reference, these of PSCs result from $10 \%$ to $30 \%$ lower than the mono-Si reference, although higher than the rest of PV technologies analysed.

Also analysing two carbon stack mesoporous and planar devices, a recent LCA study contrasts them with mono-Si, poly-Si and CdTe commercial PV technologies [167]. The comparison is performed in terms of the EPBT and GHG emissions. As in the previous described studies, EPBT is lower for PSCs than for the commercial PV technologies. However, the GHG emissions are more detrimental for both carbonstack PSCs owing to an assumed lifetime of 5 years. Authors determine that planar and mesoscopic PSCs need a lifetime of 8 and 10 years respectively to reach GHG emission similar to those of commercial PV technologies.

A last LCA study applied to two PSCs, one presenting MA and the other presenting Cs and FA as cations, contrasted their environmental impacts with those of a large group of PV technologies [119]. The EPBT and the GHG emissions are used as a reference for the comparison. The outcomes again present a shorter EPBT for PSCs 
in comparison to the other PV technologies, whereas the GHG emissions per kWh for PSCs are higher than the commercial PV technologies because of a shorter 3-year lifetime.

In a technoeconomic analysis to PSCs, authors conclude that they could become a low-cost leader in the PVs market provided that their stability issues are solved [158].

\subsubsection{Perovskite tandems with other PV technologies}

Due to the maturity state of current commercial PV technologies, among which monocrystalline-Si has the highest market share, it is not easy for an emerging PV technology to penetrate the market. Therefore, the combination of halide perovskite with this technology in tandems perovskite-silicon is under research. Several LCA studies are published addressing this matter.

For instance, a LCA analysis from cradle to grave about three Si-perovskite tandems using $\mathrm{Au}, \mathrm{Ag}$ and $\mathrm{Al}$ as an electrode is performed [177]. Authors underline that the ability of perovskite to transmit both electricity and light after failure enables the silicon layer to continue functioning, which emerges as essential to improve their environmental performance.

Further PV technologies such as Copper indium gallium selenide (CIGS), Copper zinc tin sulphide (CZTS) and mono-Si in tandem configuration with perovskite are evaluated through LCA from cradle to grave [178]. The whole energy used to produce these tandems (from 549 to $3000 \mathrm{MJ} / \mathrm{m}^{2}$ ) is recovered in 7 months for the former tandem, while the latter recovers it in 12 months. These results are expected to improve as tandems technology matures.

A prospective LCA study with 2025 as a time horizon compares the environmental performance of a perovskite-Si tandem with a Si based solar cell and a PSC [179]. Results again confirm that the tandem perovskite-Si is beneficial for the environment, recommending proper encapsulation to avoid the risk posed by the perovskite layer.

\subsubsection{Summary of balancing PSC with other energy technologies}

The suitability of PSCs as a clean energy technology is insufficiently evaluated by contrasting their environmental performance with that of other energy technologies. It is compared to four electricity grid mixes with a high share of fossil fuels in two different approaches $[125,126]$. In addition, a review contrasts PSCs with commercial PV technologies [53]. The rest of the comparisons with PV technologies are done as a supplementary assessment. In these comparisons other PV 
technologies are compared with lab-scale PSC devices $[111,112]$, with PSCs with perovskites containing MA, FA and Cs cations [119], and with PSCs more prone to industrialisation $[130,167]$.

Perovskite has also a high potential to be combined with other PV technologies in a tandem configuration. Three studies evaluate the environmental performance of tandems with Si [177,179], CIGS [178] and CZTS [178] through LCA, whose conclusions agree on that the combination is environmentally beneficial.

\subsection{Cost analyses of perovskite solar cells}

Besides technical aspects, the cost of a certain technology has direct consequences on their commercial fate. It is therefore important evaluating the cost of PSCs while they are under development. Studies oriented towards evaluating the cost of PV devices based in perovskite can also be found in the literature. An evaluation of the Levelized Cost of Energy (LCOE) is conducted for a perovskite module made from low-cost materials and a high efficiency perovskite module [155]. If their efficiency and lifetime exceed a $12 \%$ and 15 years, respectively, LCOE of PSCs can compete with that of traditional energy sources, according to this study results.

Moreover, cost of PSCs is analysed for glass rigid substrate PSCs produced with a large-scale process [156]. Not only is the module considered in these studies, but also the costs of auxiliary equipment, maintenance, and labour to install it. Assumptions and calculation methodology taken to estimate the LCOE in this study match those of a previous estimation on PVs in the United States [180]. Polymer flexible substrate PSCs produced with Roll-to-Roll technique costs are also analysed, detailing how the production is modelled [157]. Chief conclusions of these studies remark LCOE would be competitive for both types, provided that efficiencies of $18 \%$ and $15 \%$ are achieved, together with 20 years and 15 years of lifetime, respectively.

As halide perovskite also has a great commercial potential coupling with crystalline silicon in tandem modules, an evaluation of the economic viability of these devices under the influence of perovskite degradation is published [181]. According to authors of this study, competitiveness of perovskite/silicon tandem devices is conditioned to a maximum perovskite yearly degradation of $2 \%$ and a maximum additional cost of $50 \%$ respect to a single silicon module.

Alternatively, the economic feasibility of PSCs to be produced with low capital cost equipment is explored considering a carbon stack configuration [182]. This possibility is of interest for developing countries, where processes with low initial investment would enable its production. Results of this study reject the idea of expensive and 
specific equipment is essential for PSCs production, even though cost of imported pastes such as zirconia represents a key challenge. Authors conclude that further research to replace zirconia with e.g., alumina is necessary.

\subsubsection{Summary of cost analyses}

The cost of deployed PSCs is lightly evaluated. The LCOE of PSCS is evaluated by considering a halide perovskite PV module produced from low-cost materials [155]. The cost competitiveness of PSCs is evaluated in devices where halide perovskite is deposited onto a rigid substrate [156], as well as onto a flexible substrate [157]. The cost of coupling halide perovskite with crystalline $\mathrm{Si}$ in tandem modules is evaluated [181]. Finally, the cost of the equipment necessary to produce PSCs is explored [182].

\subsection{Summary of the state of the art of environmental studies applied to PSCs}

Research to support the development of PSCs starts from the lowest level of readiness until the highest achieved readiness level. Therefore, since halide perovskite photovoltaics arose, some studies mostly using LCA as a tool analyse the environmental performance of different configurations and materials used at laboratory scale [110-112]. Among these LCA studies, the Chapter 3 of this thesis provides an assessment of the widest variety of lab-scale configurations and deposition methods [113]. An improvement in the perovskite chemistry that boosted the efficiency of PSCs and the stability by introducing MA, FA and Cs as cations is also evaluated through LCA $[118,119]$. The Chapter 4 of this thesis evaluates for the first time different combination of those three cations [89].

In parallel, the toxicity risk posed by the lead content of halide perovskites is evaluated in several studies. This topic is commented in most of the pioneer LCA studies $[110,111,128-130]$, among which the Chapter 3 of this thesis is included [113]. Nevertheless, this issue is treated in a more straightforward way in several LCA studies [118,125-127].

As PSCs technology improved, technoeconomic studies analyse the way of PSCs towards industrialisation [154,158]. Additionally, LCA studies treat production methods approaching industrialisation $[130,160,162]$. The Chapter 5 of this thesis provides a LCA study of a carbon-stack halide perovskite PV module produced in a pilot plant [98]. Several proposals to implement an improved end of life for a clean commercialisation of PSCs are provided and evaluated by few studies [169-174]. The Chapter 3 contributes to this aspect with an evaluation of two recovery routes of the PSC materials [113]. 
A balance of the environmental advantages and disadvantages of PSCS respect to other energy technologies is poorly addressed in the literature. Environmental impacts of PSCs are contrasted with those of four current electricity grid mixes $[125,126]$, and with commercial PV technologies [53]. Furthermore, some comparisons of PSCs with other PV technologies are included in LCA studies as a supplement $[111,112,119,130,167]$. The potential of halide perovskites to combine with other PV technologies in a tandem configuration is analysed in three studies [177-179].

The costs of producing halide perovskite PV devices is also treated in the literature. The LCOE of a low-cost module [155] and two devices with glass [156]and flexible [157] substrates are estimated. Costs of combining halide perovskites with Si PV in tandems [181], and the cost of the necessary equipment to produce PSCs are also analysed [182]. 


\section{Chapter 3 Relative Impacts of}

Methylammonium Lead Triiodide Perovskite Solar Cells Based on Life Cycle Assessment 



\section{Abstract}

The environmental performance of four different device assembly procedures based on hybrid halide perovskite solar cell (PSC) were assessed from cradle to grave using life cycle assessment (LCA) methodology. In addition, a new environmental indicator was defined to measure the time evolution of an impact category, specifically in this case, human toxicity cancer payback time. PSCs procedures accounted for the probably three more used basic recipes for laboratory perovskite deposition: 1) spin coating of stoichiometric precursor solution, 2) spin coating of precursor solution using lead chloride precursor and 3) the two-step deposition method. Also, the two most widely used substrate configurations (planar and mesoporous substrate) were considered. LCA included three realistic scenarios for the end of life: 1) residual landfill, 2) reuse and residual landfill and 3) reuse and recycling. The remaining variable parameters to assemble the device were fixed in common for all four devices, which were the major responsible of the whole PSC impact. Lead of PSCS had no significant contribution in environmental impacts. Beyond shared procedure steps, impacts generated by the two-step method and the use of mesostructured type substrate were higher. End of life scenario with reuse and recycling improved the toxicity impact categories.

\section{Graphical Abstract}

\section{Common relative impacts}

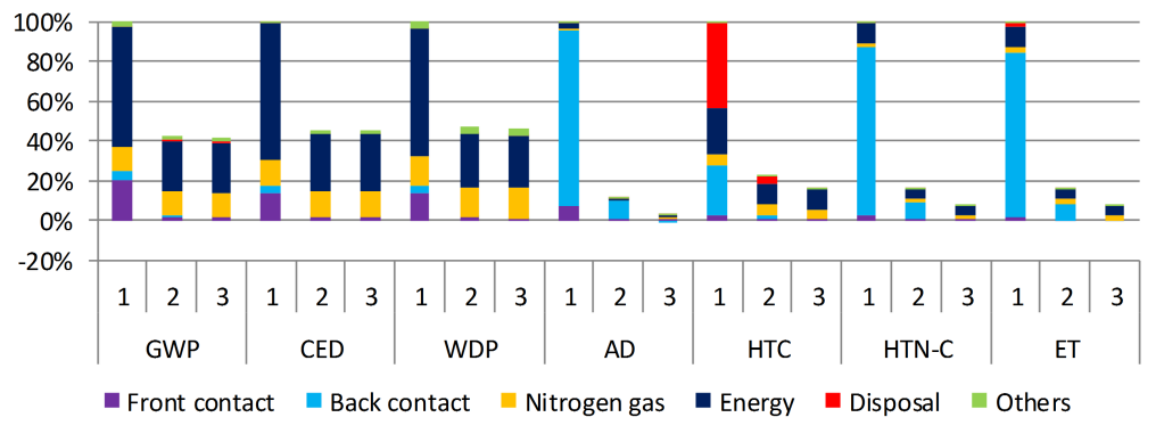




\subsection{Introduction}

Perovskite solar cells (PSCs) have emerged as a very efficient type of solar cells for the last few years. As yet, they have shown efficiencies $(\eta)$ over $20 \%$ on thin film cells $[183,184]$. Besides, it is expected they reach as high efficiencies as first-generation (25.3\% for a single crystal Si non-concentrator cell) and second-generation (22.6\% for a Copper indium gallium selenide (CIGS) cell) solar cells do, even overstepping their efficiencies in a nearby future [62]. Owing to its versatility and the possibility of tailoring its energy band gap, perovskite also has a high potential to be combined with other materials to form a tandem device, thus reaching higher efficiencies [107]. For instance, an efficiency of $27 \%$ of a tandem of perovskite combined with Si was reported [185]. However, for a final implantation of this technology, demonstration of long-term stability will be needed. Moreover, a technical and economical assessment of PSCs states that there are some limitations when manufacturing them at large scale [154]. Although stability should still be proven over a broad range of conditions [62], promising results have already been delivered [186].

One of the main concerns of PSCs is that the hybrid organic-inorganic perovskite most commonly used (with general formula $\mathrm{MAPbX}_{3}$, where $\mathrm{MA}=$ methylammonium and $\mathrm{X}=\mathrm{I}, \mathrm{Br}$ ) contains significant quantities of lead. $\mathrm{Pb}$ is a toxic substance whose intake in the human body causes damage through mimicry of essential ions such as $\mathrm{Ca}, \mathrm{Zn}$ and Fe [121,131]. Furthermore, its use is restricted by the European Restriction of Hazardous Substances Directive [122]. Encapsulation of PSCs, to impede contact with moisture and oxygen to improve stability [97], could be a solution for the toxicity issue in order to contain possible $\mathrm{Pb}$ leachates. Besides the toxicity of this element, the $\mathrm{Pb}$ extraction consists of a high-temperature process over 1400 으, which generates greenhouse gases and dangerous fumes as byproducts [187]. Consequently, further solutions should be found in order to decrease the environmental impacts of the preparation of PSCs $[133,169]$.

Solar cells employing hybrid halide perovskite as light harvester material are mainly composed either a) by a thin film perovskite layer, known as planar configuration or b) by the perovskite deposited onto a mesoporous scaffold. The light harvesting layer is sandwiched between a hole transporting material (HTM) and an electron transporting material layer (ETM), see Figure 3. Once the charges are photogenerated in the perovskite, the ETM separates selectively the electrons to the front contact, and the HTM layer transports the holes to the back contact. Both layers are important to ensure a high performance of the cell, although different architectures are possible [188]. The most currently used material for the HTM is the Spiro- 
MeOTAD, initially synthesized for incorporating in multilayer light-emitting diodes (LED) $[189,190]$, later it was used in solid state dye sensitized solar cell as HTM [191]. A compact layer of $\mathrm{TiO}_{2}$ is widely used as ETM which is formed in most of the cases through the hydrolysis of the titanium isopropoxide [192]. In PSCs, the front contact or light side is generally the transparent conductive oxide $\mathrm{SnO}_{2}: \mathrm{F}$ (FTO), because of its high transparency in the visible region and its low resistivity at room temperature of the order of $1 \Omega \mathrm{cm}$ [193]. Meanwhile, the back contact extracting contact may be made of silver [194], gold [195] or aluminum [67], among others.
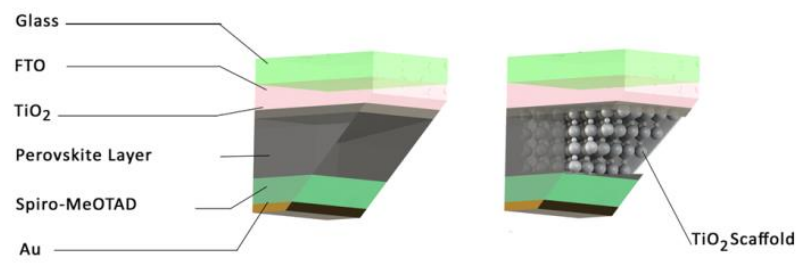

Figure 3. Perovskite solar cells layers: 1) thin film planar perovskite layer and 2) embedded perovskite in the mesoporous layer.

In order to lead the manufacture of this promising technology of PSCs to a more sustainable state, as it is still under development at lab-scale, life cycle assessment (LCA) methodology should be applied. In this regard, few works have been done thus far $[110,118,127,129-131,133,154,177]$. Amongst them, special emphasis should be given to the work of Espinosa et al. [110], in which two important deposition methods (spin-coating and vapor-deposition) were compared. With each deposition method, a different architecture (normal and inverted) was produced and assessed from cradle to gate. Gong et al. [111] compared two PSCs with different ETM $\left(\mathrm{TiO}_{2}\right.$ scaffold vs ZnO thin film), back contact (gold vs silver) and front contact (fluorine doped tin oxide vs indium tin oxide). This study was the first to include the disposal stage into its system boundary. Zhang et al. [112] evaluated a PSC based on titanium dioxide nanotubes through LCA methodology with data obtained from laboratoryscale. Alternatively, Celik et al. [130] evaluated a comparison of co-evaporation and spray perovskite deposition methods, which are more amenable to manufacturing, rather than laboratory specific deposition methods dipping and spinning. Recently, a perovskite/Si was assessed through LCA from cradle to grave [177] contrasting several combinations of materials for the back electrode ( $\mathrm{Au}, \mathrm{Ag}$ and $\mathrm{Al}$ ) and HTM (Spiro-MeOTAD vs PEDOT:PSS). Finally, five different perovskites were compared using $\mathrm{Cs}$, formamidinium (FA), and MA for the monovalent cationic position; $\mathrm{Pb}$ and $\mathrm{Sn}$ for the cationic position; and combinations of $\mathrm{I}^{-}, \mathrm{Br}^{-}$and $\mathrm{Cl}^{-}$for the anionic position [118]. 
The aim of our work was to conduct a comprehensive LCA of four different devices of PSCs from cradle to grave $[196,197]$, selecting likely the most broadly considered. Although the best efficiencies have been reached using perovskites with mixtures of organic cations $\left(\mathrm{MA}^{+}\right.$and $\mathrm{FA}^{+}$) and halides $\left(\mathrm{I}^{-}\right.$and $\left.\mathrm{Br}^{-}\right)[114,198]$, for the sake of clarity and simplicity, we just considered the most extended $\mathrm{CH}_{3} \mathrm{NH}_{3} \mathrm{Pbl}_{3}$ halide perovskite as light absorbing material and three basic recipes of perovskite deposition: 1) spin coating of stoichiometric precursor solution of $\mathrm{PbCl}_{2}$ and methylammonium iodide (MAI) in 1:3 molar ratio, that we call Device 1 hereafter [72]; 2) spin coating of precursor solution of $\mathrm{Pbl}_{2}$ and $\mathrm{MAl}$, Device 2 hereafter [199]; and 3) the two step method deposition, which implies the dipping of a spin coated $\mathrm{Pbl}_{2}$ film into a MAI solution (Device 3 hereafter) [75]. Also, for the preparation method of spin coating of precursor solution of $\mathrm{Pbl}_{2}$ and $\mathrm{MAl}$, the two most widely used substrate types (planar and with mesoporous $\mathrm{TiO}_{2}$ scaffold) were considered, the device with mesoporous substrate is called Device 4 [200]. The remaining variables parameters, as substrate, contacts, ETM and HTM, to assemble the device were fixed in common for all four types of devices, and correspond to the most commonly used in PSCs field, see Table 1. Due to the unreliable nature of the amount of electricity consumed in the laboratory environment for a real industrial scenario, an uncertainty analysis was performed for the most energy consuming processes.

For the first time, we dipped into three possible scenarios of recycling of the PSCS, which could significantly improve their lifetime, see Table 1. In scenario 1, PSCs was inertized and deposited in a residual landfill. The other two scenarios were aimed by recent researches about the potential regeneration of PSCs $[175,176]$ and they two differ in their potential treatment at the end of the last regenerative cycle: landfilling in scenario 2 or recycling in scenario 3.

By means of the power conversion efficiencies (PCE) provided in the bibliography relative to each perovskite solar cell preparation studied $[72,75,199,200]$, the lifetime at which each PSC produces just as much energy as necessary to manufacture it (in laboratory environment) was determined. Further analyses were performed considering that all four devices were prepared with an efficiency of $20 \%$ with different scenarios of end of life. Finally, a similar assessment was made to compare the payback time of the human toxicity impact category on the four PSC devices analyzed during their potential lifetime. This latter human toxicity cancer payback time analysis was contrasted with a similar analysis for established photovoltaic technologies. 


\subsection{Materials and methods}

\subsubsection{Goal and scope definition}

This study was intended to lay on the table the environmental aspects of the most promising ways through which lead halide perovskite solar cells can be conducted. Four different perovskite-based devices were considered, see Table 1 . The four different analyzed devices presented different light harvesting layer but the other parts of the cell were common. We considered a glass with FTO deposited via sputtering. On FTO, a compact layer of $\mathrm{TiO}_{2}$, deposited via spin-coating worked as ETM. The next layer was the perovskite, prepared following three different procedures, and considering both planar and mesoporous $\mathrm{TiO}_{2}$ scaffold configurations, see Table 1. Spin-coated Spiro-MeOTAD on top of perovskite layer was used as HTM. Finally, Au electrode was subsequently evaporated on the top of the HTM, see Figure 3. This common system shared the same impacts and they were relatively very high, as we discuss below. To analyze deeply the differences within the four cells, the common system was isolated and on one hand the environmental assessment of the common parts was performed and on the other hand, the environmental assessment of the four devices focused on their differences was also implemented.

All four devices present common layers prepared in the same way and using the same materials while the difference is the light absorbing perovskite deposition and method and configuration.

The study was performed on laboratory prepared solar cells. This fact allowed us to directly measure the consumptions during the solar cell preparation process. Despite this approach, we consider that important consequences for a future upscaling an implementation in an industrial environment can be extracted from this work. Functional unit was $1 \mathrm{~cm}^{2}$ of active surface area, assigning, for a first study, to each kind of device the efficiency reported in the literature under standard solar irradiation (AM1.5G), which depends on the type of perovskite solar cell preparation $[72,75,199,201]$. All devices had an active cell area of $4 \mathrm{~cm}^{2}$ and a cell's substrate area of $25 \mathrm{~cm}^{2}$. A general description of the system boundary of the four different devices is illustrated on Figure 4. 
Chapter 3

Table 1. Characteristics of the different PSCs analyzed.

\begin{tabular}{lll}
\hline Specific layers & & \\
Device & Perovskite deposition method & Configuration \\
\hline Device 1 & Spin-coating 3:1 & Planar \\
Device 2 & Spin-coating 1:1 & Planar \\
Device 3 & Spin-coating + dipping & Planar \\
Device 4 & Spin-coating 1:1 & Mesoporous \\
\hline Common layers & & \\
Layer name & Material & Deposition method \\
\hline Substrate + Front contact & Glass/FTO & Sputtering \\
ETM & TiO 2 & Spin-coating \\
HTM & Spiro-MeOTAD & Spin-coating \\
Back contact & Gold & Thermal evaporation \\
\hline End of life scenarios & & \\
Scenario & Number of uses & EOL treatment \\
\hline Scenario 1 & 1 & Landfill \\
Scenario 2 & 10 & Landfill \\
Scenario 3 & 10 & Recycling \\
\hline
\end{tabular}

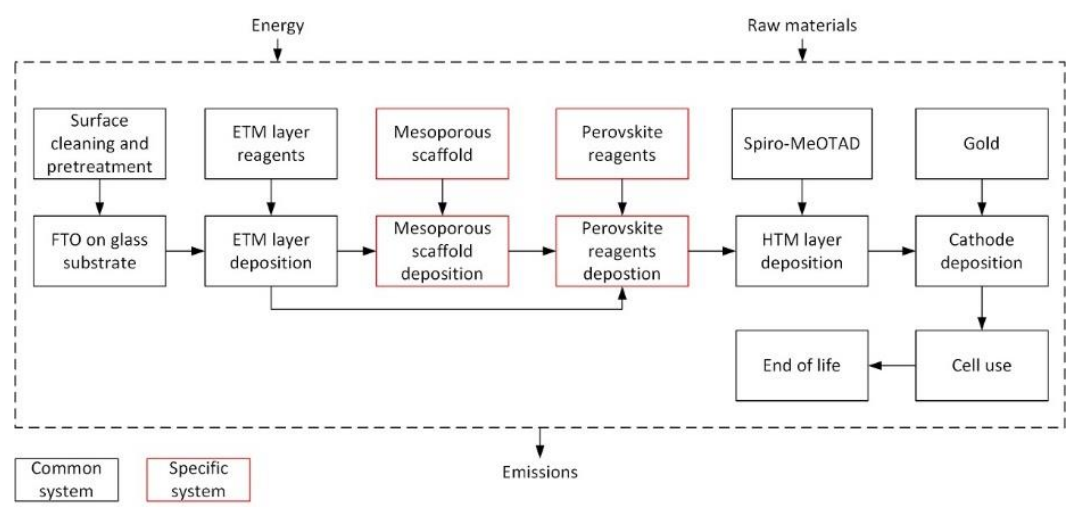

Figure 4. System boundary of the PSCs. 


\subsubsection{Life cycle inventory}

Life cycle inventory included PSCs synthesis, cell use and end of life. Most inventory data were provided directly from our lab measures, see Supplementary material for synthesis details and life cycle inventories of the common system and the specific layers of perovskite.

Physical characteristics and other inventory data were obtained from literature $[72,74,75,199,201-204]$. The energy consumption needed in each step of the PSCs preparation was experimentally established by measuring the electric consumption. However, on those cases where the power consumption could not be measured, such as the FTO sputtering, vapor-deposition process and the use of glovebox, the data was obtained from the literature $[203,204]$ and the devices design characteristics. The environmental impacts generated by the electric consumption were calculated from the medium voltage production in Europe (RER data set of Ecoinvent database) [205]. Nitrogen gas consumption of the glove box, both for the PSC production process and for the reagents synthesis, was obtained from literature [110]. The contribution of transportation of every material of the inventory was obtained from the distance between the supplier and the manufacturing location, taking as reference our laboratory location.

While using the solar cells to cleanly convert sunlight to electricity, there is not any type of harm to the environment. Therefore, at this stage it is important to convert as much energy as possible to environmentally recover the energy invested in the manufacturing of the solar cell. This aim can be improved by enhancing the PCE, because the higher the PCE is, the lesser the EPBT. In the same manner, high PCE values are also important to produce as much electricity as possible to enable the covering of the energetic worldwide demand. Another way of converting more electricity entails increasing the lifetimes of PSCs to obtain more energy from one single device. Currently, lifetimes of PSCs are below 1 month, which is far from a desirable time. This is the reason behind the fact that stability of PSCs must be improved, leading more efforts towards this issue.

Three scenarios were considered for the end of life, see Table 1 and the Supplementary material for their life cycle inventories. As well as in the $\mathrm{LCl}$ of the production process of the PSCs, some layers were considered common for the four devices, thus, the corresponding perovskite layers were considered specific of each device. A consequential approach was applied to model the benefits of recycling. This means that by-products of the disposal process are assumed to substitute a product manufactured by alternative means and that the environmental impacts thereby avoided are credited to the system under study [206], see Table S9 of the 
Supplementary material. Life cycle inventory of the residual landfilling of each waste fraction and incineration of the non-hazardous wastes were modelled with the tool provided by Doka [207].

\subsubsection{Impact categories selection}

Lead is a toxic substance whose use is restricted by the European Restriction of Hazardous Substances Directive. For this reason, toxicity was one of the most significant impact categories to be assessed. UNEP-SETAC toxicity (USEtox) model [208] is according with Hauschild et al. [209], Pizzol et al. [210], etc., the best among existing characterization models for toxicity. The three impact categories of USEtox model were selected: human toxicity, cancer effects (HTC); human toxicity, noncancer effects (HTN-C) and ecotoxicity (ET).

The solar cells considered used other metals like Pd, Sn, Au, etc. (as part of the cell or involved in the preparation of the cell materials), and also fossil fuels (for energy, transport and as raw materials for synthesis of other compounds). The model CML 2002 [211], from the Institute of Environmental Sciences (CML), is one of the best among existing characterization models for scarcity [209]. To show the consumption of mineral resources, energy and water, the environmental impact of abiotic depletion potential was selected with the division into mineral and fossil resources depletion potential (AD) and water depletion potential (WDP).

The cumulative energy demand (CED) was also selected for an ease energy comparisons. CED assessment was based on the method published by Ecoinvent ${ }^{\circledR}$ [212] and expanded within the SimaPro ${ }^{\circledR}$ software application.

Finally, the most important impact categories related with energy were also important. Global warming (GWP) is the most frequent impact category in life cycle assessments of energy. At midpoint level, Climate Change baseline model of 100 years of the Intergovernmental Panel on Climate Change (IPCC) is the reference model [213]. The version of USEtox, scarcity model of CML and climate change of the IPCC included in the International Reference Life Cycle Data System (ILCD) [214] were used. ILCD and CED are incorporated within the SimaPro ${ }^{\circledR}$ 8.0.3.14 software.

\subsection{Results and discussion}

\subsubsection{Environmental impact of the common system}

Table 2 and Figure 5 present the results of the environmental impacts of the common system equal in the four devices analyzed, whose associated inputs and outputs are the same for all of them. The results in Figure 5 are presented for the three end of 
life scenarios assessed. In order to make the results comparable, each impact category is related to the values for scenario 1 . These results allow readers to identify the hotspots of a PSC not taking into account the specific systems impact. In the category others of Figure 5 are included the inputs/outputs with values lower than $5 \%$ in every impact category (ETM, HTM, transportation, process outputs and inputs to reuse the devices). It has to be noticed that use phase is not included.

\section{Common relative impacts}

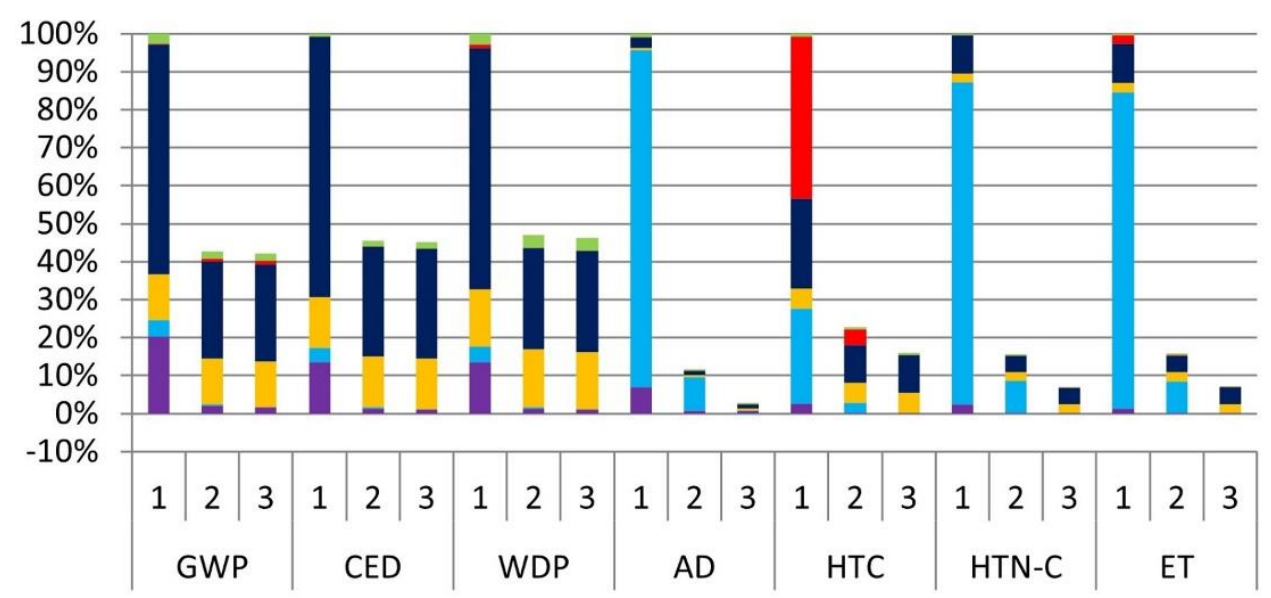

Front contact $\square$ Back contact $\square$ Nitrogen gas $\square$ Energy $\square$ Disposal $\square$ Others

Figure 5. Relative impacts of the common part of the four devices, perovskite layer that differs from device to device are excluded in this analysis. Each impact category is analyzed for the three different scenarios for the end of life. Scenario 1: residual landfill, Scenario 2: reuse and residual landfill and Scenario 3: reuse and recycling.

The results showed the predominant impact of back contact for mineral and fossil depletion, human toxicity non-cancer and ecotoxicity. Back contact was made of gold, whose extraction procedure releases many toxic chemicals to the environment (cyanide and mercury, among others) and consumes many natural resources [215217]. In scenario 3 , the impact reductions were significant as a consequence of its reuse and recycling. Although to a lesser extent, the impacts for these categories of the back contact were also reduced in the scenario 2 thanks to its reuse.

Laboratory production of PSC required high electric energy consumption. Burdens of electricity production [218-220] were the main hotspots in global warming, cumulative energy demand and water depletion. The front contact and the nitrogen gas contributed to these three impact categories as well, due to the high energy consumption during their production. Energy consumption was also notably present on toxicity impact categories. 
The fact that the Au impact was predominant for the common system is in line with the results obtained by Gong et al. [111]. As the impacts of the common system were much higher (Table 2) than the impacts of the perovskite layer, the impacts produced by $\mathrm{Au}$ and also the energy consumption can be considered predominant on the whole cell. However, for Gong et al. [111], life cycle energy inventory was lower and in consequence climate change and cumulative energy demand impact categories were lower.

Disposal has not been usually included in LCA of perovskites, except in Gong et al. [111], however disposal of the common part was responsible of about $40 \%$ in HTC impact category for scenario 1 . Reuse with final disposal or recycling reduced every impact category in different rate. Two groups of impact categories with different behaviors were observed. Global warming, cumulative energy demand and water depletion were included in the first group, in which values for scenario 2 and scenario 3 were almost the same, they were $42-47 \%$ respect values of scenario 1 . Decision about disposal or recycling at the end of the ten reuses was not significant for these impact categories.

Mineral and fossil depletion and toxicity impact categories were included in the second group, in which values for scenario 2 were decreased to 15.7 respect scenario $1(A D)$ and the reduction was even higher in scenario 3 (the highest improvement was for $A D$, values decreased to $2.8 \%$ ). Recycling for these impact categories was clearly favored at EOL.

\subsubsection{Comparative assessment}

Table 2 includes the impacts of the non-common part (i.e., perovskite layer and $\mathrm{TiO}_{2}$ mesoporous layer for Device 4) of each type of perovskite solar cell in the seven impact categories selected for scenario 1 . The percentages of contribution of each specific system in respect to contribution of the common system were calculated to help to visualize the specific weight for each device.

The results of Table 2 show that, in every case, impacts of the specific part of each device type were much lower than impacts of the common system, shared by all four different devices analyzed. A larger number and amount of common inputs may justify such results, even though the specific part contains $\mathrm{Pb}$. Furthermore, the high impact produced by the back contact and the energy consumption in the common part may overshadow the contribution of all the specific parts. Interestingly, the fact that specific parts had a lower impact in all of the impact categories suggests that $\mathrm{Pb}$ content of the perovskite solar cells does not currently constitute a concerning hotspot, in good agreement with J. Zhang et al. [112] and N. Espinosa et al. [110]. 
Relative Impacts of Methylammonium Lead Triiodide Perovskite Solar Cells Based on Life Cycle Assessment

Table 2. Impacts for the common system and specific for the four devices.

\begin{tabular}{|c|c|c|c|c|c|c|}
\hline Category & Unit & $\begin{array}{c}\text { Common } \\
\text { system }\end{array}$ & $\begin{array}{c}\text { Specific for } \\
\text { Device1 }\end{array}$ & $\begin{array}{c}\text { Specific for } \\
\text { Device } 2 \\
\end{array}$ & $\begin{array}{c}\text { Specific for } \\
\text { Device } 3\end{array}$ & $\begin{array}{c}\text { Specific for } \\
\text { Device } 4\end{array}$ \\
\hline \multirow[t]{2}{*}{ GWP } & $\mathrm{kg} \mathrm{CO}{ }_{2} \mathrm{eq}$ & $3.5410^{-2}$ & $5.1710^{-4}$ & $6.6410^{-4}$ & $1.3610^{-2}$ & $9.5110^{-3}$ \\
\hline & $\%$ & - & 1.44 & 1.84 & 27.81 & 21.19 \\
\hline \multirow[t]{2}{*}{ CED } & MJ & $6.4910^{-1}$ & $1.0710^{-2}$ & $1.3810^{-2}$ & $2.8310^{-1}$ & $1.9710^{-1}$ \\
\hline & $\%$ & - & 1.62 & 2.08 & 30.36 & 23.33 \\
\hline \multirow[t]{2}{*}{ WDP } & $\mathrm{m}^{3}$ water eq & $2.0810^{-4}$ & $3.5010^{-6}$ & $4.2110^{-6}$ & $8.3910^{-5}$ & $5.8810^{-5}$ \\
\hline & $\%$ & - & 1.65 & 1.98 & 28.73 & 22.04 \\
\hline \multirow[t]{2}{*}{$A D$} & $\mathrm{~kg} \mathrm{Sb}$ eq & $3.2010^{-6}$ & $3.4610^{-9}$ & $3.2510^{-9}$ & $5.7410^{-8}$ & $4.1110^{-8}$ \\
\hline & $\%$ & - & 0.11 & 0.10 & 1.76 & 1.27 \\
\hline \multirow[t]{2}{*}{ HTC } & CTUh & $6.4910^{-9}$ & $3.6710^{-11}$ & $4.7210^{-11}$ & $9.7010^{-10}$ & $6.7710^{-10}$ \\
\hline & $\%$ & - & 0.56 & 0.72 & 13.00 & 9.44 \\
\hline \multirow[t]{2}{*}{ HTN-C } & CTUh & $5.4810^{-8}$ & $1.3610^{-10}$ & $1.7410^{-10}$ & $3.5610^{-9}$ & $2.4910^{-9}$ \\
\hline & $\%$ & - & 0.25 & 0.32 & 6.11 & 4.34 \\
\hline \multirow[t]{2}{*}{ ET } & CTUe & 1.30 & $3.710^{-3}$ & $4.2010^{-3}$ & $8.6210^{-2}$ & $6.0110^{-2}$ \\
\hline & $\%$ & - & 0.5 & 0.32 & 6.23 & 4.43 \\
\hline
\end{tabular}

Impacts generated by Devices 3 and 4 were much higher than impacts generated by Devices 1 and 2, as a consequence of more complex processes involved and higher energetic consumption. A closer comparison between Devices 1 and 2 showed that impacts were slightly higher for Device 2 in all the categories except in mineral and fossil depletion impact category where Device 2 contribution was vaguely lower. The reason behind the higher impact in almost all categories was a more quantity of energy and reagents consumption.

Continuing with the specific systems of the different devices, a comprehensive evaluation of their inputs is presented in Figure 6 for human toxicity cancer and cumulative energy demand impact categories and for scenario 1. Impacts are divided in perovskite layer, energy consumption, disposal at EOL and others (transportation, process outputs and scaffold for the Device 4). 

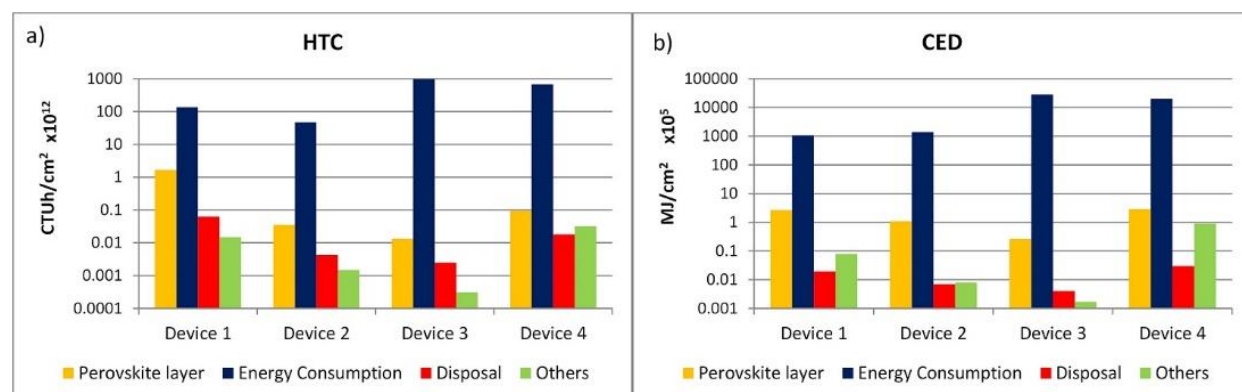

Figure 6. Specific impacts for scenario 1: a) Human toxicity cancer; b) Cumulative energy demand. Vertical axis is in logarithmic scale.

Figure 6 shows that the energy consumption in solar cell synthesis is quite prominent, with few orders of magnitude higher in all of the categories. For this reason, vertical axis is represented in logarithmic scale. Again, this fact proved that energy consumption was the main responsible of most of the impacts generated producing a PSC. This result is in agreement with previous works (Zhang et al. [112] and N. Espinosa et al. [110]) and opposite to that of Asif et al. [154]. Energy consumption is a hotspot to be improved substantially in industrial production.

Figure 6a focuses on the results of human toxicity cancer, a potential critical impact category as a consequence of the toxicity of lead. Considering the specific systems of the PSCs and excluding the energy consumption, Device 3 had the lowest impact thanks to it used the least amount of perovskite and the least amount of solvents. Such impact was mostly due to the $\mathrm{Pb}$ content of the perovskite. However, this specific impact due to the lead content was 1-2 orders of magnitude lower than the originated from the common system; consequently the content of $\mathrm{Pb}$ could not be considered the main source of human toxicity cancer of PSCs.

Another worth-focusing impact category for this study was CED. Figure 6b compares the inputs of the four PSC Devices. Again, excluding the energy consumption, Device 3 had the smallest impact and the perovskite layer predominated in the impact of the four Devices. Though, this time the impact was mostly generated by iodide production. CED was used to estimate the energy payback time for the four devices (included in the Supplementary material), the analysis reflected that Devices 3 and 4 (using two step deposition method and $\mathrm{TiO}_{2}$ scaffold respectively) can just compete in terms of energy payback time if they can provide higher efficiency than Devices 1 and 2, and even in that case, the stability of the device had to be long enough to allow the surpass.

The analysis of advantages or disadvantages of reuse with final disposal or final recycling is shown in Figure 7. The relative impacts of the specific part for scenarios 
2 and 3 versus scenario 1 are represented in a way that the value $100 \%$ indicates no change regardless scenario 1 . Impacts of the common part were not included. If a scenario of reuse was followed, Device 4 was the only one with significant improvement in all impact categories, due to the benefits of reusing the scaffold. Moreover, Device 4 can also compete respect energy payback time with Devices 1 and 2 if a recycling approach is followed (energy payback time included in the Supplementary material).

This fact allowed us to conclude that reuse and recycling the $\mathrm{Pb}$ content of perovskites had no significant improvement in environmental impacts, although lead must always be safely disposed and avoid accidentals spillages. Taking into account all the PSC, reuse and recycling improved the environmental impacts due to the recovery of the materials present in the back contact and front contact, and the recovery of $\mathrm{TiO}_{2}$.

\section{Specific relative impacts, Scenarios 2 \& 3 vs Scenario 1}

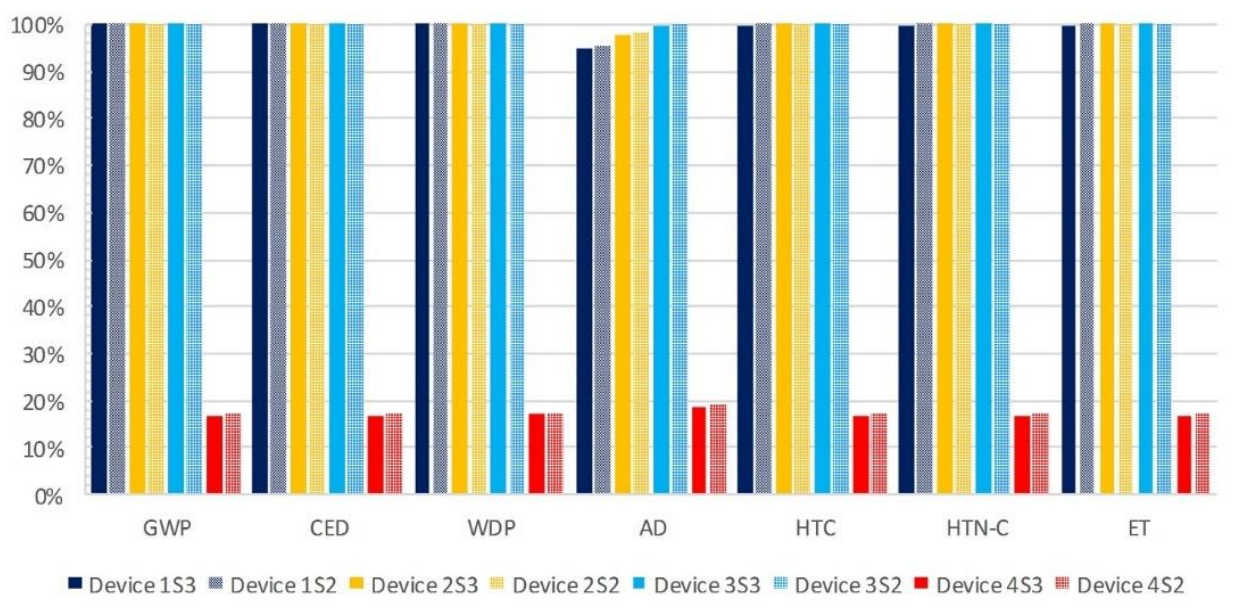

Figure 7. Specific relative impacts for scenario 2 vs. scenario1 (S2) and scenario 3 vs. scenario 1 (S3).

\subsubsection{Human toxicity cancer payback time}

A similar assessment as that made for the energy payback time (included in the Supplementary material) was made to compare the time evolution of human toxicity cancer category impact or human toxicity cancer payback time, called here HTCPBT (Table 3 and Figure 8). Similar assessments should be performed with the rest of the impact categories. At the beginning, each device had the human toxicity cancer impact value corresponding to the materials and production phase. This impact 
category diminished as the solar cell produces energy, avoiding conventional electric power consumption. Concretely, the production of $1 \mathrm{MJ}$ of electricity (medium voltage, production RER, at grid) avoided $9.92 \cdot 10^{-9}$ CTUh.

Table 3. Time evolution of the human toxicity cancer.

\begin{tabular}{lcccc}
\hline & Device 1 & Device 2 & Device 3 & Device 4 \\
\hline $\begin{array}{l}\text { Initial HTC } \\
\text { (CTUh/cm }{ }^{2} \text { ) }\end{array}$ & $6.5310^{-9}$ & $6.5410^{-9}$ & $7.4610^{-9}$ & $7.1510^{-9}$ \\
$\begin{array}{l}\text { HTCPBT (years) } \\
\begin{array}{l}\text { HTCPBT20S1 } \\
\text { (years) }\end{array}\end{array}$ & 10.98 & 12.05 & 9.53 & 11.15 \\
$\begin{array}{l}\text { HTCPBT20S3 } \\
\text { (years) }\end{array}$ & 6.26 & 6.27 & 7.15 & 6.86 \\
\hline
\end{tabular}

HTCPBT was estimated with the PCE from the literature. HTCPBT20S1 and HTCPBT20S3 were calculated considering an efficiency of the device of $20 \%$ and scenario 1 and scenario 3, respectively, at EOL.

The initial impact sets the position of each solar cell for smaller lifetimes, whilst the efficiency determines directly proportional the slope of the line to set the position of each type for larger lifetimes. While Device 1, 2 and 4 lasted approximately 11-12 years to recover the initial impact generated to produce them, Device 3 lasted approximately 9.5 years, if the efficiencies extracted from literature were considered. Also, this device avoided more human toxicity impact from the 6th year than the rest of solar cell types studied.

When efficiencies of $20 \%$ were considered for all four devices, the time they lasted to reach a negative human toxicity impact was obviously shorter. In a recycling approach and for the same efficiency, Figure $8 \mathrm{c}$ ), human toxicity cancer payback time for Device 3 almost doubled the value for the other three devices, conversely, Device 4 presented similar values with Devices 1 and 2 .

In order to make the HTCPBT analysis more straightforward to the readers, a comparison of established photovoltaic technologies is provided herein. The HTC impact of diverse established photovoltaic technologies is reported in some works [221-224]. For instance, the HTCPBT of PSCs is compared in this work with Organic photovoltaics (OPV) [222].

Here, the HTCPBT analysis was similarly performed as for the four PSCs studied in this work. For the purpose of estimating HTCPBT scores, the HTC impacts and efficiencies of OPV was taken from the work of Espinosa et al [222]. In contrast to the data in this manuscript, the efficiency and the inventory utilized for the analysis 
of established photovoltaic technologies correspond to modules instead of cells. Moreover, contrary to established photovoltaic technologies, PSCs of this study are produced in a laboratory environment, where they are not optimized as the common system of this manuscript evidences. These facts generate uncertainty to this analysis. Thanks to a $1.1 \%$ of efficiency for the OPV and an initial HTC impact of 2.21 $10^{-10} \mathrm{CTUh} / \mathrm{cm}^{2}$, this analysis reveals that the HTC generated during the life cycle of the OPV is recovered from 3.85 years, by avoiding usage of electricity from the grid.
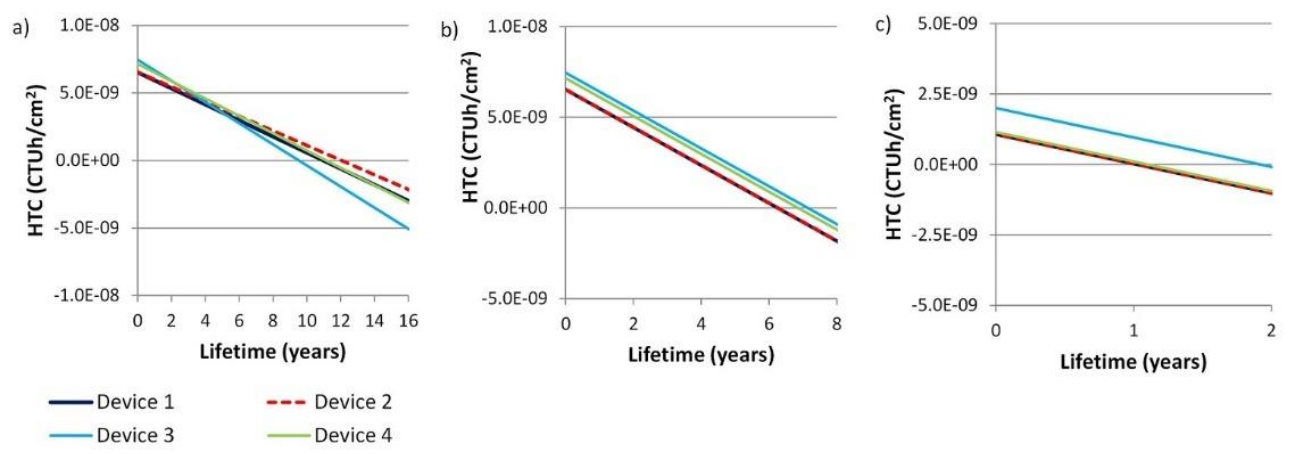

Figure 8. Time evolution of the human toxicity cancer: a) considering PCE from literature; b) considering $20 \%$ efficiency and scenario 1 at EOL; c) considering $20 \%$ efficiency and scenario 3 at EOL.

This HTCPBT result clearly display that PSCs are worse than OPV. The reason behind this outcome is a shorter initial HTC, despite the lower efficiency. It is worth mention that in spite of the low HTCPBT of OPV of 3.85 years, it is still higher than current OPV lifetimes, which is inferior to 2 years [222].

\subsubsection{Sensitivity assessment}

As clearly depicted in Figure 5 and Figure 6, energy supposes the most detrimental flow by far. At a certain distance, it is followed by the nitrogen gas consumption. Therefore, it is expected that a reduction in these flows can modify the results. Either it can decrease the overall impact or alter which is the most adverse device.

Bearing in mind that the energy was measured experimentally from laboratory equipment whereby the energetic consumption is not optimized. Therefore, it is predicted that in an industrially produced device the energy consumed will decrease. In order to estimate the energy consumed in such industrial scenario the thermodynamic processes that the solar cell undergoes during its production were considered. Moreover, a complete thermal isolation of the system was supposed for the estimation. In order to analyze which device is the most harmful in a theoretical industrial scenario, a reduction in the energy usage of the specific system was simulated. In particular, five steps of the deposition of perovskite procedure were 
perceived as the most energy consuming, where the reduction was implemented. As shown in Table S8 of the Supplementary material, they are four annealing treatments practiced after the deposition of each reagent in device 3 , and another annealing treatment after the deposition of the scaffold in device 4 . These processes generally consume one order of magnitude more energy than the rest. It is important to mention that the actual electricity consumption might be somewhere between the electricity measured experimentally and that estimated via thermodynamic phenomena. After obtaining the thermodynamically necessary energy for these treatments, its impact was added to the impact of the rest of impacts that have remained constant. The energy was estimated from the specific heat of the materials involved [225-228], along with the conditions at which the treatments were performed, as the energy spent to heat the materials was solely considered and no energy losses during the treatments were assumed. In order to show the outcomes of the drop in energy consumption, the relative HTC impact in the theoretical industrial scenario and the same impact in the scenario of electricity measured in laboratory equipment respect to the impact of the most pernicious device for each scenario were calculated. These results are presented in percentages for the four devices in Table 4 together with the absolute values of the HTC impact of the theoretical industrial scenario.

Table 4. Sensitivity assessment: Relative HTC values per device for the deposition of the four specific layers respect to the HTC value of the most harmful device for lab-measured and industrial scenarios and absolute HTC values for the industrial scenario.

\begin{tabular}{lcccc}
\hline & Device 1 & Device 2 & Device 3 & Device 4 \\
\hline Relative lab-measured HTC (\%) & 4 & 5 & 100 & 70 \\
Relative industrial HTC (\%) & 20 & 26 & 34 & 100 \\
Industrial HTC (CTUh/cm ${ }^{2}$ ) & $3.6710^{-11}$ & $4.7210^{-11}$ & $6.3010^{-11}$ & $1.8510^{-10}$ \\
\hline
\end{tabular}

The results in Table 4 show that the most adverse device moved from Device 3 to Device 4 in the new theoretical industrial scenario, as Device 3 present the most relevant impact drop. Thanks to this impact decreasing for Device 3 together with the increasing of Device 1 and Device 2, these three devices impact is more similar for the theoretical industrial approach. Overall, from absolute values a significant reduction of HTC impact of the specific system of Device 3 and Device 4 is observed in comparison to the HTC scores in Table 2. In spite of the fact that differences in HTC impacts among devices were reduced relevantly, Device 3 and Device 4 keep presenting the most adverse HTC in respect to Device 1 and Device 2. Furthermore, with the reduction in consumption analyzed is not expected the overall impact of devices to decrease, because as the specific system is still lower than that of the 
common system. Among all devices studied, Devices 3 and 4 present the best efficiency results; hence it could be worth addressing an environmental improvement of their life cycle.

\subsection{Conclusions}

The environmental performance of four different laboratory-produced lead halide perovskite photovoltaic devices, with quite common and extended configurations was assessed from cradle to grave using life cycle assessment methodology. These procedures accounted for the three most commonly used basic recipes of perovskite deposition: 1) spin coating of precursor solution within excess of chloride, 2) spin coating of stoichiometric precursor solution and 3) the two-step method deposition. The two most widely used cell configurations (planar and mesoporous) were considered. Furthermore, three scenarios for the end of life were assessed: 1) residual landfill, 2) reuse and residual landfill and 3) reuse and recycling. As far as we know it is the first time that such detailed analysis is performed for the end of life, and it has a significant effect in the energy and human toxicity cancer payback times.

Common system of the four solar cell devices was the major responsible of the impact of the whole PSC. Lead was not among the main current concerns of the use of PSCs, contrary to the most extended assumption that the lead contained in the perovskite is the main responsible of the impacts of PSC. This was so even for a theoretical industrial estimated case where the electricity consumption was diminished.

Considering the four analyzed devices with the same efficiency, Devices 1 and 2 had lower energy and human toxicity cancer payback times. Devices fabricated by the two-step method (Device 3) or using $\mathrm{TiO}_{2}$ scaffold (Devices 4) can only compete in these categories in a scenario where they had higher efficiency and long enough stability in order to overcome the initial higher production cost and human toxicity generated during their fabrication. In addition, devices using $\mathrm{TiO}_{2}$ scaffold were specially benefited with recycling at EOL, achieving energy and human toxicity cancer payback times' equivalents to devices fabricated by the one step method.

PSCs constitute a promising technology to produce energy from the sunlight owing to their low cost and high performances, although much work has to be done in order to upscale, reduce energy consumption during production and moreover, PSCs have to increase their stability, which will play a key role to make them feasible for the massive production. 


\subsection{Supplementary material}

\section{Life cycle inventory}

\subsection{Common system}

The whole process of production of the four PSCs compared herein had common layers (FTO, ETM, HTM and Au electrode) which were the same for the four analyzed devices. Firstly, FTO substrates, which were composed of a glass substrate with an FTO layer, were cleaned before the $\mathrm{TiO}_{2}$ compact layer deposition. This procedure consists in etching a part of the FTO layer with metallic zinc and hydrochloric acid, subsequent cleaning with $2 \%$ hallmanex detergent and water, sonicating in isopropanol and acetone, washing with ethanol and finally treatment with ozone plasma. The titanium dioxide compact layer was deposited by spin-coating at 2000 rpm for 1 minute, a mildly solution of titanium isopropoxide [192] in ethanol. Next, it was heated at $120 \stackrel{\circ}{\circ}$ for 10 minutes and annealed at 450 o $C$ for 4 hours. Isopropanol and ethanol vapours were emitted to the atmosphere, where the former was generated as a side-product of the reaction. The HTM layer was made of Spiro-MeOTAD which was deposited by spin-coating for 30 seconds at $4000 \mathrm{rpm}$. Gold was used for the back contact which was deposited by thermal evaporation. Moreover, the whole process of production of PSCs had more common inputs, including nitrogen gas, its transport burdens, and the electricity consumed by glove box. These inputs were necessary in order to maintain a proper inert atmosphere required for some of the preparation procedures.

The inventory of the common system is listed in Table S5 along with transportation and electricity consumed during their processing. These energies consumed for the deposition of each layer of the common system are itemized in Table S6. SpiroMeOTAD $[229,230]$ and FTO $[193,231]$ synthetic routes are shown in Figure S9. The inventory of other reagents and materials employed for the processing of the perovskite solar was taken from Ecoinvent database [205]. 
Table S5. $\mathrm{LCl}$ of the production process of the common system

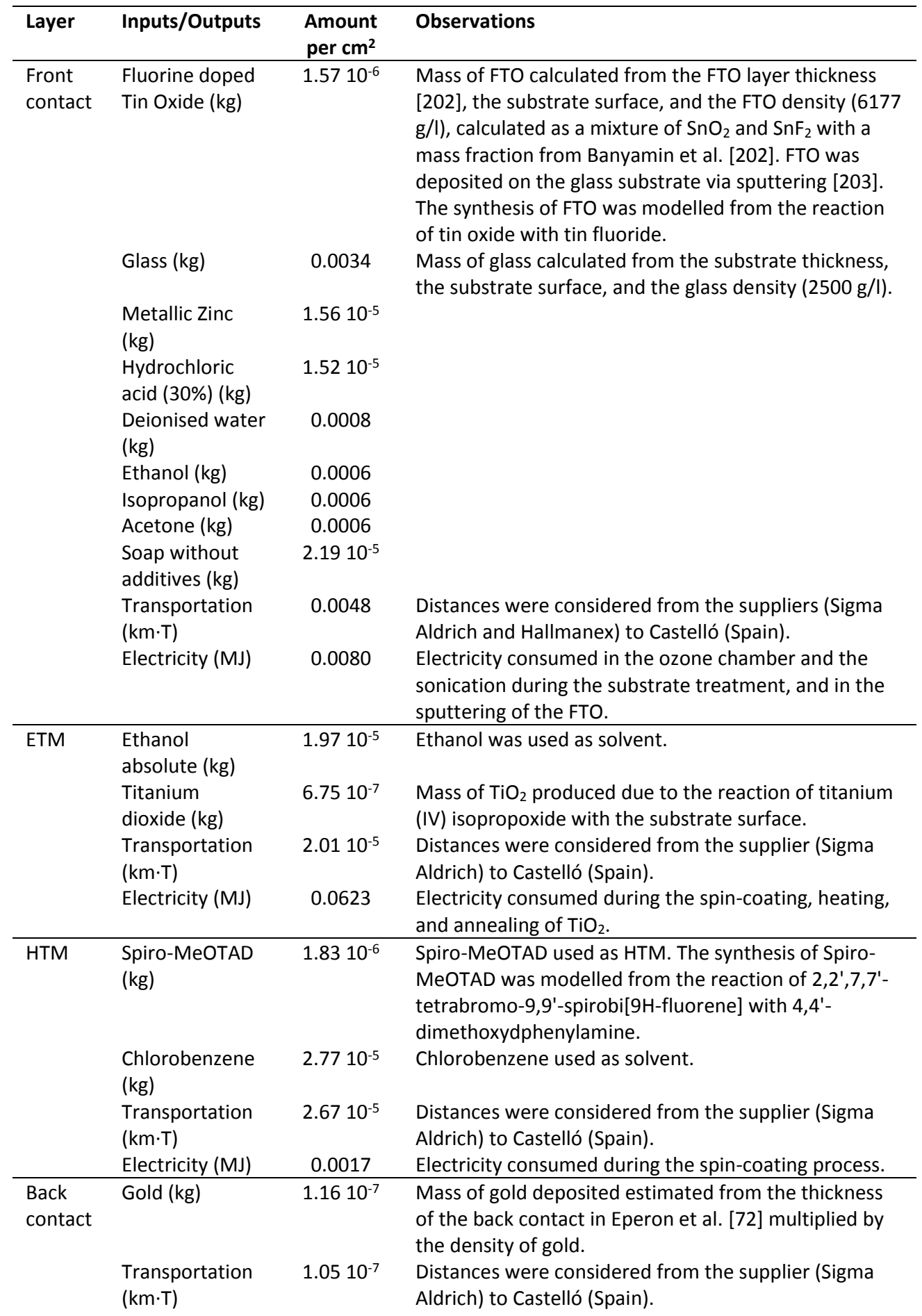




\begin{tabular}{|c|c|c|c|}
\hline & Electricity (MJ) & 0.0286 & $\begin{array}{l}\text { Gold thermal evaporation electrical consumption } \\
\text { estimated from mean device powers from García- } \\
\text { Valverde et al. [204], and process times. }\end{array}$ \\
\hline \multirow[t]{3}{*}{$\begin{array}{l}\text { Glove } \\
\text { box }\end{array}$} & $\begin{array}{l}\text { Nitrogen gas } \\
(\mathrm{kg})\end{array}$ & 0.0098 & $\begin{array}{l}\text { Nitrogen consumption estimated from data in } \\
\text { Espinosa et al. [110]. }\end{array}$ \\
\hline & $\begin{array}{l}\text { Transportation } \\
(\mathrm{km} \cdot \mathrm{T})\end{array}$ & 0.0008 & $\begin{array}{l}\text { Distances were considered from the supplier (Praxair) } \\
\text { to Castelló (Spain). }\end{array}$ \\
\hline & Electricity (MJ) & 0.0533 & $\begin{array}{l}\text { Electrical consumption estimated from data in García- } \\
\text { Valverde et al. [204]. }\end{array}$ \\
\hline \multirow[t]{8}{*}{$\begin{array}{l}\text { Process } \\
\text { outputs }\end{array}$} & $\begin{array}{l}\text { Emissions - } \\
\text { Ethanol (kg) }\end{array}$ & $6.1710^{-4}$ & $\begin{array}{l}\text { Emissions to air due to the use of ethanol for the FTO } \\
\text { cleaning process. }\end{array}$ \\
\hline & $\begin{array}{l}\text { Emissions - } \\
\text { Isopropanol (kg) }\end{array}$ & $6.1310^{-4}$ & $\begin{array}{l}\text { Emissions to air due to the use of isopropanol for the } \\
\text { FTO cleaning process. }\end{array}$ \\
\hline & $\begin{array}{l}\text { Emissions - } \\
\text { Acetone }(\mathrm{kg})\end{array}$ & $6.1810^{-4}$ & $\begin{array}{l}\text { Emissions to air due to the use of acetone for the FTO } \\
\text { cleaning process. }\end{array}$ \\
\hline & $\begin{array}{l}\text { Emissions - } \\
\text { Ethanol (kg) }\end{array}$ & $1.9710^{-5}$ & $\begin{array}{l}\text { Emissions to air due to the use of ethanol for the ETM } \\
\text { layer. }\end{array}$ \\
\hline & $\begin{array}{l}\text { Emissions - } \\
\text { Nitrogen }(\mathrm{kg})\end{array}$ & $9.8010^{-3}$ & $\begin{array}{l}\text { Emissions to air due to the use of nitrogen for the } \\
\text { glove box. }\end{array}$ \\
\hline & $\begin{array}{l}\text { Emissions - Zinc } \\
(\mathrm{kg})\end{array}$ & $9.8010^{-3}$ & $\begin{array}{l}\text { Emissions to water due to the use of zinc for the FTO } \\
\text { cleaning process. }\end{array}$ \\
\hline & $\begin{array}{l}\text { Emissions - } \\
\text { Chloride (kg) }\end{array}$ & $9.8010^{-3}$ & $\begin{array}{l}\text { Emissions to water due to the use of chloride for the } \\
\text { FTO cleaning process. }\end{array}$ \\
\hline & $\begin{array}{l}\text { Chlorobenzene } \\
(\mathrm{kg})\end{array}$ & $2.7710^{-5}$ & $\begin{array}{l}\text { Incinerated in a municipal solid waste incineration } \\
\text { plant. Impacts modelled with the work of Doka [207]. }\end{array}$ \\
\hline
\end{tabular}

Table S6. Electricity consumed per solar cell area for the deposition of the common layers.

\begin{tabular}{|c|c|c|c|}
\hline Layer & Process step & $\begin{array}{l}\text { Electricity } \\
\left(\mathrm{MJ} / \mathrm{cm}^{2}\right)\end{array}$ & Observations \\
\hline \multirow[t]{3}{*}{$\begin{array}{l}\text { Front } \\
\text { contact }\end{array}$} & FTO sputtering & 0.0024 & $\begin{array}{l}\text { Sputtering of the FTO onto the glass substrate energy } \\
\text { obtained from Tsang et al. [203]. }\end{array}$ \\
\hline & Sonication & 0.0047 & It was measured experimentally. \\
\hline & Ozone chamber & 0.0009 & It was measured experimentally. \\
\hline \multirow[t]{3}{*}{ ETM } & $\begin{array}{l}\text { Spin-coating } \\
\text { (2000 rpm, } 1 \\
\text { min) }\end{array}$ & 0.0016 & It was measured experimentally. \\
\hline & $\begin{array}{l}\text { Heating }(120 \circ \mathrm{C} \text {, } \\
10 \mathrm{~min})\end{array}$ & 0.0102 & It was measured experimentally. \\
\hline & $\begin{array}{l}\text { Annealing ( } 450 \\
\text { o- C, } 45 \mathrm{~min} \text { ) }\end{array}$ & 0.0505 & It was measured experimentally. \\
\hline HTM & $\begin{array}{l}\text { Spin-coating } \\
\text { (4000 rpm, } 30 \mathrm{~s})\end{array}$ & 0.0017 & It was measured experimentally. \\
\hline $\begin{array}{l}\text { Back } \\
\text { contact }\end{array}$ & $\begin{array}{l}\text { Thermal } \\
\text { evaporation }\end{array}$ & 0.0286 & $\begin{array}{l}\text { It was estimated from the equipment features and the } \\
\text { time of operation. }\end{array}$ \\
\hline \multirow[t]{2}{*}{ General } & Globe box & 0.0533 & $\begin{array}{l}\text { Two glove boxes are considered. Its energy } \\
\text { consumption was obtained from Garcia-Valverde et al. } \\
{[204] \text {. }}\end{array}$ \\
\hline & Total & 0.1539 & \\
\hline
\end{tabular}




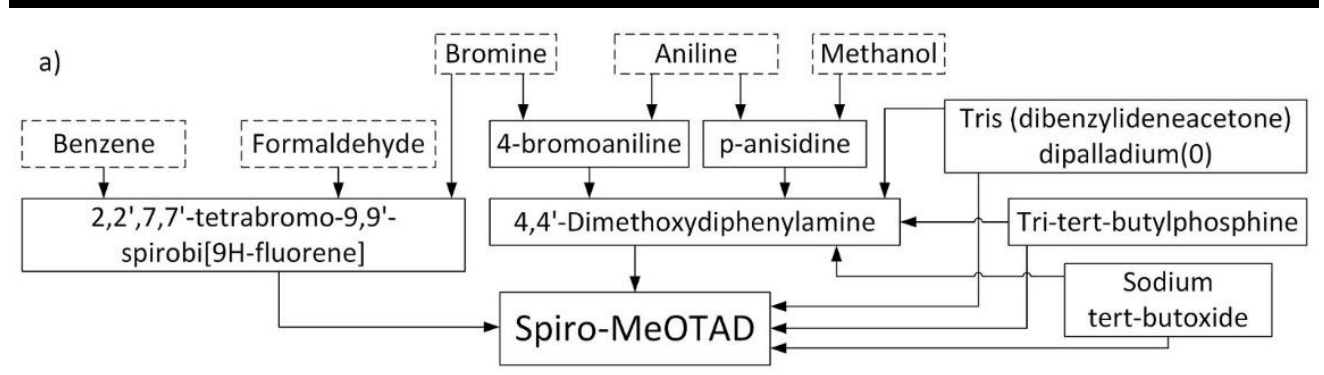

b)

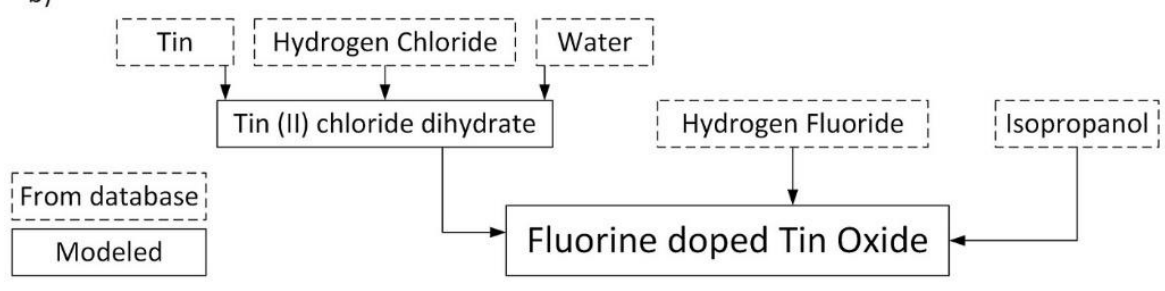

Figure S9. Synthetic routes of a) Spiro-MeOTAD and b) FTO. Synthesis processes obtained from a database are inside a dashed box, whereas synthesis processes modelled herein are inside a solid box.

\subsection{Perovskite synthesis}

In this paper, three different ways to synthesize $\mathrm{CH}_{3} \mathrm{NH}_{3} \mathrm{Pbl}_{3}$ perovskite were considered. Specific inputs and outputs of the four types of perovskite solar cells analyzed in this work are summarized in Table S7. To support this information, the energy consumed in every step involved in the production of the specific layers of the four PSCs is detailed in Table S8. Briefly, Device 1 was produced considering the method developed by Snaith and coworkers [72], although some modifications were applied. The perovskite layer was deposited by spin-coating MAI and $\mathrm{PbCl}_{2}$ with 3:1 molar ratio in anhydrous $\mathrm{N}, \mathrm{N}$-dimethylformamide (DMF). This reaction produces 1 part of $\mathrm{CH}_{3} \mathrm{NH}_{3} \mathrm{Pbl}_{3}$ and releases 2 parts of methylammonium chloride (MACl) to the atmosphere. To produce 1 mole of $\mathrm{MAI}$, a reaction of 1 mole of hydrogen iodide in aqueous solution with 1 mole of methylamine was considered. None other compounds were produced through this reaction. The inventory of production of 1 mole of $\mathrm{PbCl}_{2}$ was composed of 1 mole of chlorine and 1 mole of lead, with none other output. See Figure S10a, for a scheme of the synthesis routes for perovskite using this method. The deposition process of the perovskite synthesized from $\mathrm{PbCl}_{2}$ consisted of a prior 5-second time spin-coating at $500 \mathrm{rpm}$ of the reagents mixture i.e., $\mathrm{MAl}$ and $\mathrm{PbCl}_{2}$ in $\mathrm{DMF}$ - and 60-second time spin-coating at $2000 \mathrm{rpm}$. The sample was then heated at 100 ㅇ C for 60 minutes in a drying oven. In Table S7 the inventory of this perovskite can be seen. Along with these data, the energy per solar cell consumed in each step of the process of its deposition is displayed in Table S8. 
Device 2 was based on the work of Park and coworkers [74]. It is important to notice that their method was not precisely followed. Here a mixture of 1 mole of MAl with 1 mole of $\mathrm{Pbl}_{2}$ was dissolved in $y$-butyrolactone to form the perovskite, without any by-product formation. Inventory of MAI was made considering the same reaction and the same reagents with water as a solvent. For the synthesis of 1 mole of $\mathrm{Pbl}_{2}, 1$ mole of $\mathrm{Pb}$ and 1 mole of iodine were considered, with no by-products release. See Figure S10b for a scheme of the synthesis routes for perovskite using this method. In Device 2, the synthetic process comprised a stirring of the reagents mixture - i.e., $\mathrm{MAl}$ and $\mathrm{Pbl}_{2}$ in $\mathrm{\gamma}$-butyrolactone - for 30 minutes at $70{ }^{\circ} \mathrm{C}$. The mixture was spincoated firstly at $500 \mathrm{rpm}$ for $5 \mathrm{~s}$ and secondly at $2000 \mathrm{rpm}$ for $60 \mathrm{~s}$. After that, the perovskite was heated at $100 \stackrel{\circ}{ } \mathrm{C}$ for 60 minutes in a drying oven. Process inventory data and energy consumption for each step of it are shown in Table S7 and Table S8, respectively.

a)
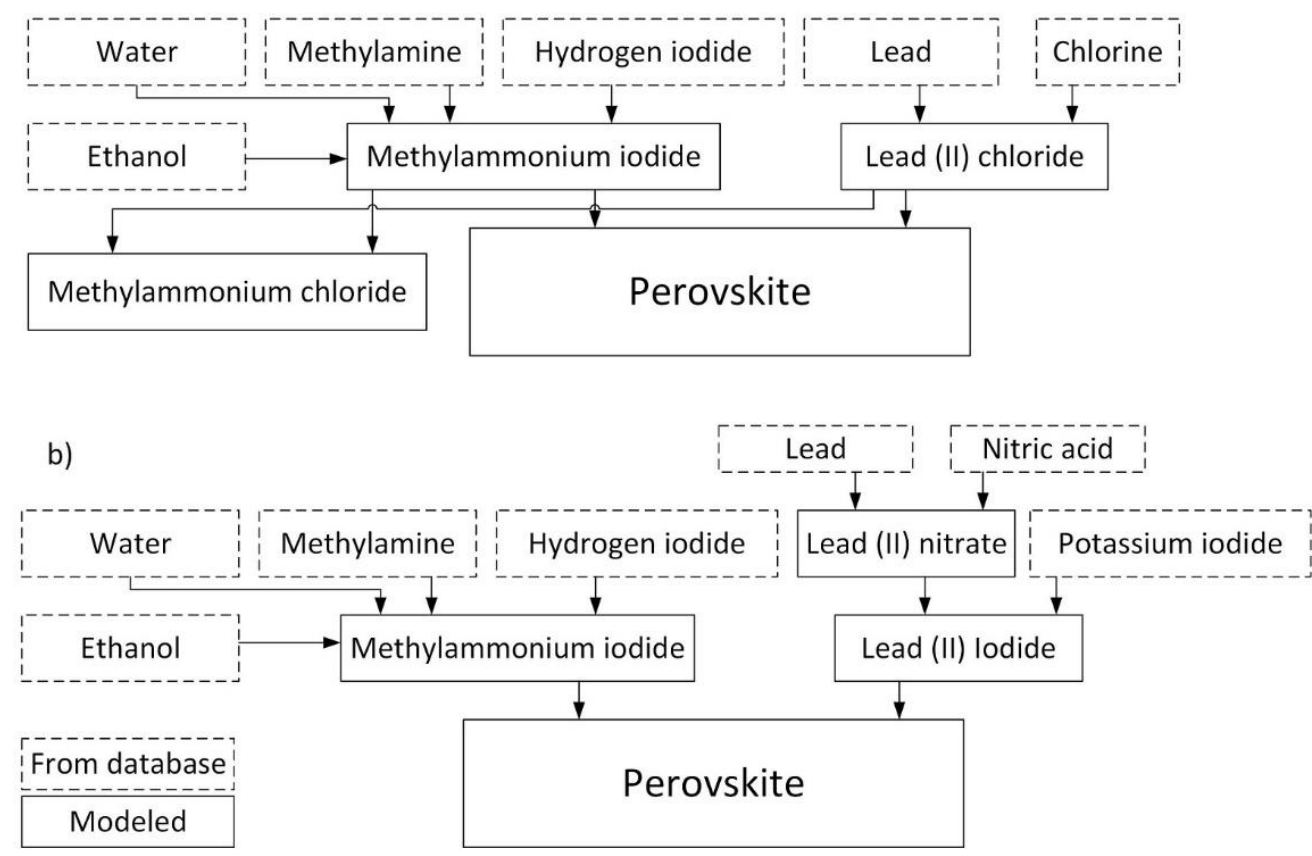

Figure S10. Synthesis routes for perovskite: a) from lead (II) chloride; b) from lead (II) iodide. Synthesis processes obtained from a database are inside a dashed box, whereas synthesis processes modelled herein are inside a solid box. 
Device 3 used the same reagents than Device 2; however the deposition method was different for that device. In Device 3 perovskite was deposited by a two-step method developed by Gratzel and coworkers [75] with some variations. A solution of $\mathrm{Pbl}_{2}$ in DMF is stirred at $70 \stackrel{\circ}{ } \mathrm{C}$ for 30 minutes. The following step was the spin-coating of that mixture for 5 and 20 seconds at 500 and $6000 \mathrm{rpm}$, respectively. Then, the sample was heated at $40{ }^{\circ} \mathrm{C}$ for 3 minutes and at $100{ }^{\circ} \mathrm{C}$ for 10 minutes. The sample was then dipped for 1 minute in a mixture of MAI and cleared in isopropanol for 30 $\mathrm{s}$ afterwards. After that, the sample was spin-coated for $5 \mathrm{~s}$ at $500 \mathrm{rpm}$, for $10 \mathrm{~s}$ at

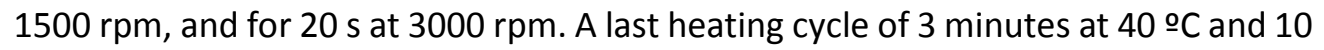
minutes at $100 \stackrel{\circ}{ } \mathrm{C}$ was applied to the perovskite. Table S7 shows the inventory of the perovskite deposited by the two-step methodology. In addition, Table S8 details the energy consumed in each step.

Table S7. Specific inputs and outputs for the production process of the four layers of perovskite

\begin{tabular}{|c|c|c|c|c|}
\hline Device & Layer & Inputs/Outputs & $\begin{array}{l}\text { Amount } \\
\text { per } \mathrm{cm}^{2}\end{array}$ & Observations \\
\hline \multirow[t]{5}{*}{ Device 1} & Perovskite & $\begin{array}{l}\text { Methylammonium } \\
\text { lead triiodide }(\mathrm{kg})\end{array}$ & $1.9010^{-7}$ & $\begin{array}{l}\text { Mass of perovskite calculated from } \\
\text { the thickness of the layer in Eperon } \\
\text { et al. [72], the active surface area } \\
\text { and the } \alpha \text {-perovskite density in } \\
\text { Stoumpos et al. [232]. The } \\
\text { synthesis of methylammonium lead } \\
\text { triiodide was modelled according } \\
\text { to Figure S10a. }\end{array}$ \\
\hline & & $\begin{array}{l}\mathrm{N}, \mathrm{N}- \\
\text { Dimethylformamide } \\
(\mathrm{kg})\end{array}$ & $3.2910^{-7}$ & $\begin{array}{l}\mathrm{DMF} \text { used as solvent calculated } \\
\text { from a concentration of } 0.88 \mathrm{M} \text { of } \\
\mathrm{PbCl}_{2} \text { and } 2.64 \mathrm{M} \text { of } \mathrm{CH}_{3} \mathrm{NH}_{3} \mathrm{l} \text {. }\end{array}$ \\
\hline & & $\begin{array}{l}\text { Transportation } \\
(\mathrm{km} \cdot \mathrm{T})\end{array}$ & $5.0810^{-7}$ & $\begin{array}{l}\text { Distances measured from the } \\
\text { supplier (Sigma Aldrich) to Castelló } \\
\text { (Spain) }\end{array}$ \\
\hline & & Electricity (MJ) & 0.0037 & $\begin{array}{l}\text { Electricity consumed during } \\
\text { perovskite deposition by the spin- } \\
\text { coater and the convective oven. }\end{array}$ \\
\hline & & $\begin{array}{l}\text { Waste - } \\
\text { Dimethylformamide } \\
(\mathrm{kg})\end{array}$ & $5.9810^{-11}$ & $\begin{array}{l}\text { Incinerated in a municipal solid } \\
\text { waste incineration plant. Impacts } \\
\text { modelled with the work of Doka } \\
\text { [207]. }\end{array}$ \\
\hline Device 2 & Perovskite & $\begin{array}{l}\text { Methylammonium } \\
\text { lead triiodide }(\mathrm{kg})\end{array}$ & $6.8710^{-8}$ & $\begin{array}{l}\text { Mass of perovskite calculated from } \\
\text { the thickness of the layer in Kim et } \\
\text { al. [74], the porosity in Listorti et al. } \\
\text { [195], the active surface area and } \\
\text { the } \alpha \text {-perovskite density in } \\
\text { Stoumpos et al. [232]. The } \\
\text { synthesis of methylammonium lead } \\
\text { triiodide was modelled according } \\
\text { to Figure S10b. }\end{array}$ \\
\hline
\end{tabular}




\begin{tabular}{|c|c|c|c|c|}
\hline & & v-butyrolactone $(\mathrm{kg})$ & $1.0310^{-7}$ & $\begin{array}{l}\nu \text {-butyrolactone used as solvent, } \\
\text { calculated from } 40 \text { wt\% of reagents } \\
\text { in the solution [199]. }\end{array}$ \\
\hline & & $\begin{array}{l}\text { Transportation } \\
(\mathrm{km} \cdot \mathrm{T})\end{array}$ & $1.5610^{-7}$ & $\begin{array}{l}\text { Distances measured from the } \\
\text { supplier (Sigma Aldrich) to Castelló } \\
\text { (Spain). }\end{array}$ \\
\hline & & Electricity (MJ) & 0.0048 & $\begin{array}{l}\text { Electricity consumed during } \\
\text { perovskite deposition by the spin- } \\
\text { coater, hot plate, stirrer, and the } \\
\text { convective oven. }\end{array}$ \\
\hline & & v-butyrolactone $(\mathrm{kg})$ & $1.0310^{-7}$ & $\begin{array}{l}\text { Incinerated in a municipal solid } \\
\text { waste incineration plant. Impacts } \\
\text { modelled with the work of Doka } \\
\text { [207]. }\end{array}$ \\
\hline \multirow[t]{7}{*}{ Device 3} & Perovskite & $\begin{array}{l}\text { Methylammonium } \\
\text { lead triiodide (kg) }\end{array}$ & $4.0110^{-8}$ & $\begin{array}{l}\text { Mass of perovskite calculated from } \\
\text { the thickness of the layer in } \\
\text { Burschka et al. [75], the porosity in } \\
\text { Listorti et al. [195], the active } \\
\text { surface area and the } \alpha \text {-perovskite } \\
\text { density in Stoumpos et al. [232]. } \\
\text { The synthesis of methylammonium } \\
\text { lead triiodide was modelled } \\
\text { according to Figure S10b. }\end{array}$ \\
\hline & & $\begin{array}{l}\text { Dimethylformamide } \\
(\mathrm{kg})\end{array}$ & $5.9810^{-11}$ & $\begin{array}{l}\text { DMF used as solvent of lead (II) } \\
\text { iodide calculated from a solute } \\
\text { concentration of } 1.082 \mathrm{M} \text {. }\end{array}$ \\
\hline & & Isopropanol (kg) & $1.2910^{-9}$ & $\begin{array}{l}\text { Isopropanol used as solvent of } \\
\text { methylammonium iodide } \\
\text { calculated from a solute } \\
\text { concentration of } 0.05 \mathrm{M} \text {. }\end{array}$ \\
\hline & & $\begin{array}{l}\text { Transportation } \\
(\mathrm{km} \cdot \mathrm{T})\end{array}$ & $3.7610^{-8}$ & $\begin{array}{l}\text { Distances measured from the } \\
\text { supplier (Sigma Aldrich) to Castelló } \\
\text { (Spain). }\end{array}$ \\
\hline & & Electricity (MJ) & 0.0977 & $\begin{array}{l}\text { Electricity consumed during the } \\
\text { lead (II) iodide deposition and the } \\
\text { perovskite layer post-treatment by } \\
\text { the spin-coater, the stirrer, and the } \\
\text { hot plate. }\end{array}$ \\
\hline & & $\begin{array}{l}\text { Emissions - } \\
\text { Isopropanol (kg) }\end{array}$ & $1.2910^{-9}$ & $\begin{array}{l}\text { Emissions to air due to the } \\
\text { volatilization of Isopropanol during } \\
\text { the deposition process. }\end{array}$ \\
\hline & & $\begin{array}{l}\text { Waste - } \\
\text { Dimethylformamide } \\
(\mathrm{kg})\end{array}$ & $5.9810^{-11}$ & $\begin{array}{l}\text { Incinerated in a municipal solid } \\
\text { waste incineration plant. Impacts } \\
\text { modelled with the work of Doka } \\
\text { [207]. }\end{array}$ \\
\hline Device 4 & Scaffold & $\begin{array}{l}\text { Titanium dioxide } \\
(\mathrm{kg})\end{array}$ & $1.0910^{-7}$ & $\begin{array}{l}\text { Mesoporous } \mathrm{TiO}_{2} \text { used as scaffold } \\
\text { calculated from the thickness of } \\
\text { the mesoporous } \mathrm{TiO}_{2} \text { layer in Ball } \\
\text { et al. [201], its porosity in Listorti et } \\
\text { al. [195], the active surface area, } \\
\text { and the titania density. }\end{array}$ \\
\hline
\end{tabular}




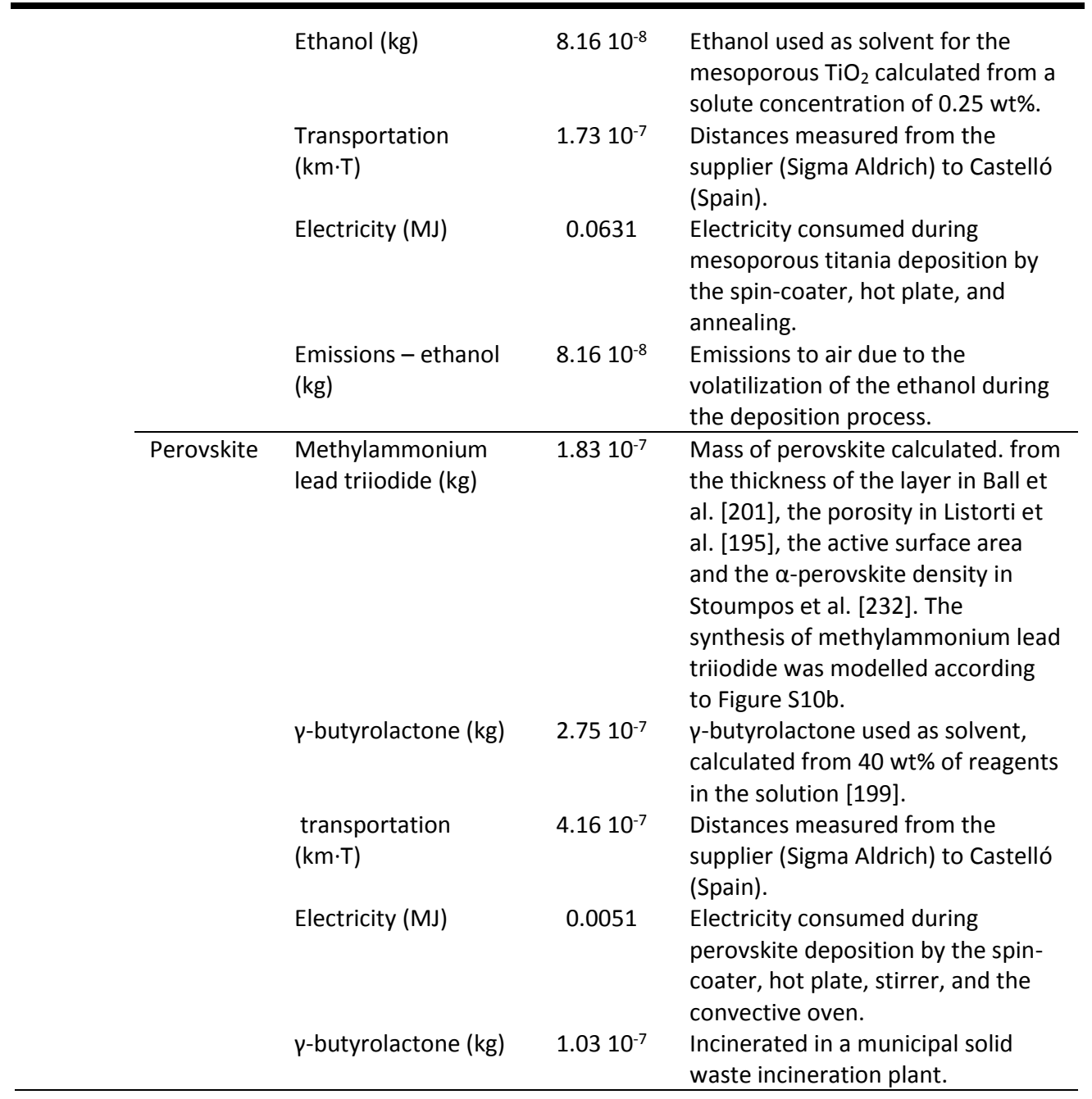

Finally for Device 4, a similar perovskite deposition process and a similar inventory of reagents that the one used for Device 2 was employed, but now the perovskite was deposited into a $400 \mathrm{~nm}$ thick scaffold of mesoporous $\mathrm{TiO}_{2}[200,201]$. In order to lay the scaffold, a mixture of $\mathrm{TiO}_{2}$ in ethanol was firstly spin-coated for $60 \mathrm{~s}$ at 4000

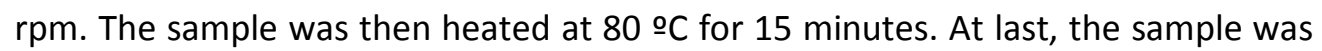
annealed for 4 hours at 450 ㄷ. In order to deposit the perovskite into the scaffold a mixture of methylamine iodide and lead (II) iodide in $\psi$-butyrolactone was stirred for

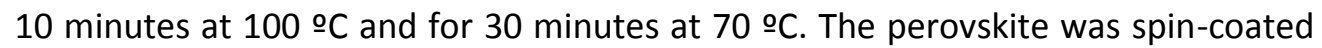

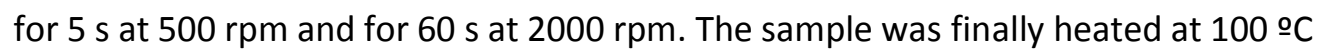
for 60 minutes in a drying oven. That inventory is shown in Table S7, in which scaffold and perovskite inputs are differentiated. Furthermore, the energy consumed in each step of this process is listed in Table S8. The amount of transportation and the 
electricity is calculated for common and specific systems (Table S5 and Table S7, respectively).

Table S8. Electricity consumed per solar cell area for the deposition of the four specific layers measured experimentally.

\begin{tabular}{|c|c|c|}
\hline Layer & Process step & $\begin{array}{l}\text { Electricity Observations } \\
\left(\mathrm{MJ} / \mathrm{cm}^{2}\right)\end{array}$ \\
\hline \multirow[t]{3}{*}{ Device 1} & Spin-coating (500 rpm, $5 \mathrm{~s}$ ) & 0.0001 \\
\hline & Spin-coating (2000 rpm, $60 \mathrm{~s}$ ) & 0.0016 \\
\hline & Heating (100 9 C, $60 \mathrm{~min})$ & 0.0020 \\
\hline \multirow[t]{4}{*}{ Device 2} & Stirring (70 9 C, $30 \mathrm{~min})$ & 0.0011 \\
\hline & Spin-coating (500 rpm, $5 \mathrm{~s}$ ) & 0.0001 \\
\hline & Spin-coating (2000 rpm, $60 \mathrm{~s}$ ) & 0.0016 \\
\hline & Heating (100 ㄷ, $60 \mathrm{~min}$ ) & 0.0020 \\
\hline \multirow[t]{10}{*}{ Device 3} & 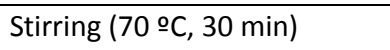 & 0.0043 \\
\hline & Spin-coating (500 rpm, $5 \mathrm{~s}$ ) & 0.0001 \\
\hline & Spin-coating (6000 rpm, $20 \mathrm{~s}$ ) & 0.0006 \\
\hline & Annealing ( $40 \stackrel{\circ}{ } \mathrm{C}, 3 \mathrm{~min})$ & 0.0074 \\
\hline & Annealing (100 $9 \mathrm{C}, 10 \mathrm{~min})$ & 0.0385 \\
\hline & Spin-coating (500 rpm, $5 \mathrm{~s}$ ) & 0.0001 \\
\hline & Spin-coating (1500 rpm, $10 \mathrm{~s})$ & 0.0003 \\
\hline & Spin-coating (3000 rpm, $20 \mathrm{~s}$ ) & 0.0005 \\
\hline & Annealing ( $40 \cong \mathrm{C}, 3 \mathrm{~min})$ & 0.0074 \\
\hline & Annealing (100 $9 \mathrm{C}, 10 \mathrm{~min})$ & 0.0385 \\
\hline \multirow{3}{*}{$\begin{array}{l}\text { Device } 4 \\
\text { (Titania } \\
\text { scaffold) }\end{array}$} & Spin-coating (4000 rpm, $60 \mathrm{~s}$ ) & 0.0033 \\
\hline & Heating ( $80 \stackrel{\circ}{ } \mathrm{C}, 15 \mathrm{~min})$ & 0.0092 \\
\hline & Annealing (450 $9 \mathrm{C}, 4 \mathrm{~h}$ ) & 0.0505 \\
\hline \multirow{5}{*}{$\begin{array}{l}\text { Device } 4 \\
\text { (Perovskite) }\end{array}$} & Stirring $(100 \stackrel{\circ}{ } \mathrm{C}, 10 \mathrm{~min})$ & 0.0004 \\
\hline & Stirring (70 9 C, $30 \mathrm{~min})$ & 0.0011 \\
\hline & Spin-coating (500 rpm, $5 \mathrm{~s}$ ) & 0.0001 \\
\hline & Spin-coating (2000 rpm, $60 \mathrm{~s}$ ) & 0.0016 \\
\hline & Heating (100 ㄷ, $60 \mathrm{~min})$ & 0.0020 \\
\hline
\end{tabular}

\subsection{End of life}

In Scenario 1, it was supposed all materials were used once and inertized waste was deposited in a residual landfill. In scenario 2, Spiro-MeOTAD and perovskite layer were removed through a selective dissolution process with polar aprotic solvents (DMF) $[175,176]$. This process, shown in Figure S11, is capable of dissolving PSCs such that the Au electrodes, the front contact and ETM layer are separated through the dissolution of the perovskite layers. Park and coworkers [176] found that the 
recycling of PSCs can be executed based on the removal of trihalide perovskite materials and that a small amount of $\mathrm{Pb}$ residue has a negligible effect on the ability to reuse the front contact and ETM layer. Through this method the original power conversion efficiency (15\%) is retained at least over 10 regeneration cycles. In scenario 2, part of the initial materials were reused nine times, at the end of the $10^{\text {th }}$ use, the PSC was inertized and deposited in a residual landfill. The removal of lead from a polar aprotic solvent was performed with solvent extraction (diethyl-ether) and sent to be recycled. In the three scenarios, non-hazardous wastes were incinerated. In scenario 3 , at the end of the $10^{\text {th }}$ use, DMF was added again and the separated inorganic materials were sent to be recycled, see Figure S11.

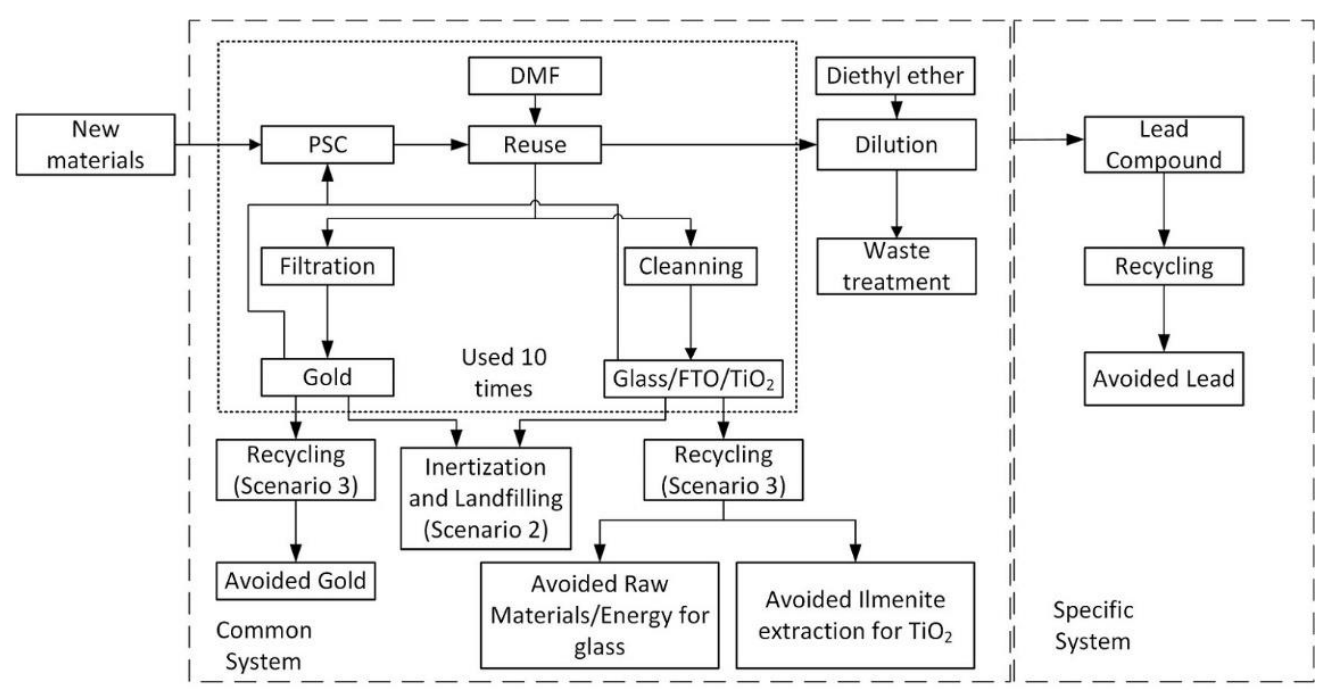

Figure S11. Scheme of the recycling process for scenario s3. 
Table S9. Inputs and outputs for each scenario of end of life

\begin{tabular}{|c|c|c|c|}
\hline Scenario & System & Inputs/Outputs & Observations \\
\hline \multirow[t]{3}{*}{ S1 } & Common & Disposal & $\begin{array}{l}\text { Glass/ FTO/TiO } / \text { Spiro-MeOTAD /Gold, inertized } \\
\text { with cement and disposed in a residual landfill. } \\
\text { Impacts were modelled with the work of Doka } \\
\text { [207]. }\end{array}$ \\
\hline & \multirow[t]{2}{*}{ Specific } & $\begin{array}{l}\text { Methylammonium } \\
\text { lead triiodide }\end{array}$ & $\begin{array}{l}\text { Inertized with cement and disposed in a residual } \\
\text { landfill. Impacts were modelled with the work of } \\
\text { Doka [207]. }\end{array}$ \\
\hline & & Scaffold - $\mathrm{TiO}_{2}$ & $\begin{array}{l}\text { Scaffold in Device 3. Inertized with cement and } \\
\text { disposed in a residual landfill. Impacts were } \\
\text { modelled with the work of Doka [207]. }\end{array}$ \\
\hline \multirow[t]{8}{*}{ S2 } & \multirow[t]{5}{*}{ Common } & $\begin{array}{l}\mathrm{N}, \mathrm{N}- \\
\text { Dimethylformamide }\end{array}$ & $\begin{array}{l}\text { About } 10^{-4} \mathrm{~kg} / \mathrm{cm}^{2} \text { of DMF to dilute Perovskite } \\
\text { and Spiro-MeOTAD. The rest was reused } 9 \text { times } \\
\text { after the initial use }[175,176] . \text { DMF was added } 9 \\
\text { times. }\end{array}$ \\
\hline & & Gold & $\begin{array}{l}\text { After addition of DMF, gold from back-contact } \\
\text { was filtered and reused } 9 \text { times [176]. Finally, it } \\
\text { was inertized with cement and disposed in a } \\
\text { residual landfill, according to the work of Doka } \\
\text { [207]. }\end{array}$ \\
\hline & & Glass/FTO/TiO 2 & $\begin{array}{l}\text { After addition of DMF, front contact and ETM } \\
\text { were cleaned and reused } 9 \text { times }[175,176] . \\
\text { Finally, they were inertized with cement and } \\
\text { disposed in a residual landfill, according to the } \\
\text { work of Doka [207]. }\end{array}$ \\
\hline & & Diethyl-ether & $\begin{array}{l}\text { About } 10^{-3} \mathrm{~kg} / \mathrm{cm}^{2} \text { to precipitate lead compounds } \\
\text { [176]. }\end{array}$ \\
\hline & & Disposal & $\begin{array}{l}\text { Afterwards the last use, the cell was landfilled. } \\
\text { Waste composed by the dilution of DMF, ether } \\
\text { and Spiro-MeOTAD was treated by incineration, } \\
\text { according to the work of Doka [207]. }\end{array}$ \\
\hline & \multirow[t]{3}{*}{ Specific } & Scaffold - $\mathrm{TiO}_{2}$ & $\begin{array}{l}\text { After addition of DMF, scaffold was cleaned } 9 \\
\text { times [176]. Finally, it was inertized with cement } \\
\text { and disposed in a residual landfill, according to } \\
\text { the work of Doka [207]. }\end{array}$ \\
\hline & & Lead compounds & $\begin{array}{l}\text { After addition of diethyl-ether, lead compounds } \\
\text { were precipitated and recycled during } 9 \text { uses, at } \\
10^{\text {th }} \text { use it was landfilled with the rest of the cell. } \\
\text { Benefits of recycling were modelled as avoided } \\
\text { "lead, from combined metal production, at } \\
\text { beneficiation" [205]. }\end{array}$ \\
\hline & & Disposal & $\begin{array}{l}\text { Organic waste composed by the decomposition } \\
\text { of perovskite after addition of diethyl-ether. It is } \\
\text { treated by incineration, according to the work of } \\
\text { Doka [207]. }\end{array}$ \\
\hline S3 & Common & $\begin{array}{l}\mathrm{N}, \mathrm{N}- \\
\text { Dimethylformamide }\end{array}$ & $\begin{array}{l}\text { About } 10^{-4} \mathrm{~kg} / \mathrm{cm}^{2} \text { of DMF to dilute Perovskite } \\
\text { and Spiro-MeOTAD. The rest was reused } 9 \text { times } \\
\text { after the initial use }[175,176] \text {. DMF was added } 10 \\
\text { times, the last one was to separate different } \\
\text { materials to be recycled. }\end{array}$ \\
\hline
\end{tabular}




\begin{tabular}{|c|c|c|}
\hline & Gold & $\begin{array}{l}\text { After addition of DMF, gold from back-contact } \\
\text { was filtered and reused } 9 \text { times [176]. Finally, it } \\
\text { was recycled. Benefits were modelled as "Gold, } \\
\text { primary, at refinery" [205] with a recycling rate of } \\
0.6895 \text {. }\end{array}$ \\
\hline & Glass/FTO/TiO 2 & $\begin{array}{l}\text { After addition of DMF, front contact and ETM } \\
\text { were cleaned and reused } 9 \text { times }[175,176] . \\
\text { Finally, they were recycled. Benefits were } \\
\text { modelled as avoided raw materials and energy } \\
\text { reduction for glass [233] and avoided "ilmenite, } \\
54 \% \text { titanium dioxide, at plant" [205] for } \mathrm{TiO}_{2} \text {. }\end{array}$ \\
\hline & Diethyl-ether & $\begin{array}{l}\text { About } 10^{-3} \mathrm{~kg} / \mathrm{cm}^{2} \text { to precipitate lead compounds } \\
\text { [176]. }\end{array}$ \\
\hline & Disposal & $\begin{array}{l}\text { Waste composed by the dilution of DMF, ether } \\
\text { and Spiro-MeOTAD. It was treated by } \\
\text { incineration, according to the work of Doka } \\
\text { [207]. }\end{array}$ \\
\hline Specific & Scaffold - $\mathrm{TiO}_{2}$ & $\begin{array}{l}\text { After addition of DMF, scaffold was cleaned } 9 \\
\text { times [176]. Finally, it was recycled. Benefit was } \\
\text { modelled as avoided "ilmenite, } 54 \% \text { titanium } \\
\text { dioxide, at plant" [205]. }\end{array}$ \\
\hline & Lead compounds & $\begin{array}{l}\text { After addition of diethyl-ether, lead compounds } \\
\text { were precipitated and recycled. Benefits of } \\
\text { recycling were modelled as avoided "lead, from } \\
\text { combined metal production, at beneficiation" } \\
\text { [205]. }\end{array}$ \\
\hline & Disposal & $\begin{array}{l}\text { Organic waste composed by the decomposition } \\
\text { of perovskite after addition of diethyl-ether. It } \\
\text { was treated by incineration, according to the } \\
\text { work of Doka [207]. }\end{array}$ \\
\hline
\end{tabular}

\section{Energy payback time}

One of the aims of the research in the solar cells field entails achieving a solar cell with an energy payback time as short as possible.

Table S10 includes three energy payback times for each device. EPBT was obtained from the cumulative energy demand values of the four devices. For this estimation, the power conversion efficiency of each cell was obtained from the literature $[72,75,199,201]$. EPBT20S1 was calculated using a PCE of $20 \%$ and scenario 1 , and EPBT20S3 was estimated with PCE $20 \%$ and scenario 3. In all cases, it was supposed an average of 4 hours of full sun illumination per day and no degradation at all of solar cell performance along the complete life cycle were considered. Stability issues are without any doubt one of the greatest challenges facing this technology. Longtime stability likely will require a change in the perovskite composition, respect the $\mathrm{MAPbl}_{3}$ analyzed in this work, and an efficient encapsulation, not considered in this work. 
The Device with the lowest energy payback time in all cases was Device 1 . This value was a consequence of lesser amount of energy consumption in the production of the cell. On the other hand, Device 4 had the highest EPBT (with the PCE from literature), although it had higher efficiency than Devices 1 and 2. When the same efficiency of $20 \%$ was considered Device 3 had the highest EPBT20 for both EOL scenarios.

Table S10. Energy payback time

\begin{tabular}{lcccc}
\hline & Device 1 & Device 2 & Device 3 & Device 4 \\
\hline PCE (\%) & $11.4[72]$ & $10.4[199]$ & $15.0[75]$ & $12.3[201]$ \\
CED (MJ/cm ${ }^{2}$ ) & 0.66 & 0.66 & 0.93 & 0.84 \\
EPBT (years) & 11.00 & 12.12 & 11.81 & 13.03 \\
EPBT20S1 (years) & 6.27 & 6.30 & 8.86 & 8.01 \\
EPBT20S3 (years) & 2.88 & 2.91 & 5.47 & 3.09 \\
\hline
\end{tabular}

EPBT was estimated with PCE from literature. EPBT20S1 was calculated considering an efficiency of the device of $20 \%$ and scenario 1 . EPBT20S3 was calculated considering an efficiency of the device of $20 \%$ and scenario 3.

In order to go more deeply into the parameters of production and recovering of energy, a time evolution of the energy is presented in Figure S12. In this evaluation, each PSC type starts its lifetime with the energy invested on its production as a debt so that it is negative. As the perovskite solar cell produces energy, it gets back this energy until it reaches the EPBT, from where it produces net and clean energy. It is important to highlight that current stability reported for PSCs is much lower and it should be drastically increased to attain this lifetime.

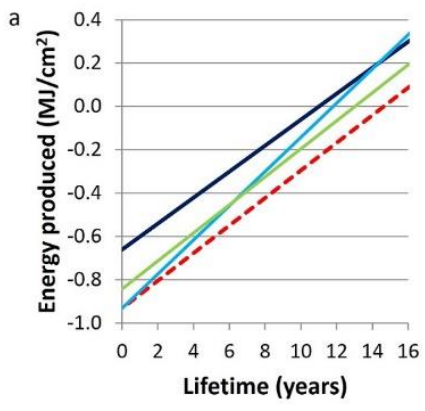

$\begin{array}{ll}\text {-Device } 1 & \text {--- Device } 2 \\ \text { Device } 3 & \text { - Device } 4\end{array}$
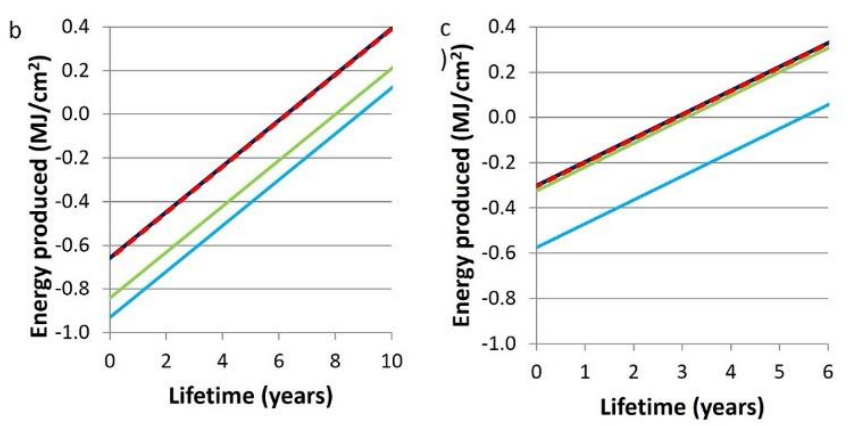

Figure S12. Time evolution of the energy produced: a) considering the PCE from the literature, see Table S10; b) considering a 20\% efficiency for all four devices and scenario 1 at EOL; c) considering $20 \%$ efficiency for all four devices and scenario 3 at EOL.

This analysis reflected that Devices 3 and 4 (using two step deposition method and $\mathrm{TiO}_{2}$ scaffold respectively) can just compete in terms of energy payback time if they 
can provide higher efficiency than Devices 1 and 2, and even in that case, the stability of the device has to be long enough to allow the surpass. Moreover, Device 4 can also compete with Devices 1 and 2 if a recycling approach is followed.

Given the unrealistic characteristic of energy payback time outcomes, it is worth emphasizing that lab PSCs were considered here, and further device upscaling and massive production will undoubtedly significantly decrease the energy payback time. Additionally, it has to be noticed the significant reduction of time in PBT20S3 as a consequence of reuse and recycling at EOL. As other mature renewable energy technologies have EPBTs lower than 3 years [61], all these results allow to consider that perovskite solar cells will have a very low EPBT in an industrial scenario, especially if cell reutilization and recycling is implemented. 

Chapter 4 Evaluation of multiple cation/anion perovskite solar cells through life cycle assessment 



\section{Abstract}

After the great initiation of perovskite as a photovoltaic material, laboratory efficiencies similar to other photovoltaic technologies already commercialised have been reached. Consequently, recent research interests on perovskite solar cells try to address the stability improvement as well as make its industrialisation possible. Record efficiencies in perovskite solar cells (PSCs) have been achieved using as active material a multiple cation/anion perovskite by combining methylammonium (MA) and formamidinium (FA), but also $\mathrm{Cs}$ cation and $\mathrm{I}$ and $\mathrm{Br}$ as anions, materials that also have demonstrated a superior stability. Herein, the environmental performance of the production of such perovskite films was evaluated via life cycle assessment. Our study points out that multiple cation/anion perovskite films show major detrimental environmental impacts for all categories assessed, except for abiotic depletion potential, when they are compared with a canonical perovskite $\mathrm{MAPbl}_{3}$. In addition, a closer analysis of the materials utilised for the synthesis of the different multiple cation perovskites compositions revealed that lead halide reagents and chlorobenzene were the most adverse compounds in terms of impact. However, the former is used in all the perovskite compositions and the later can be avoided by the use of alternative fabrication methods to anti-solvent. To this extent, FAl, with the current synthesis procedures, is the most determining compound as it significantly increases the impacts and the cost in comparison with MAI. A further economic analysis, exposed that multiple cation perovskites need a significantly higher photoconversion efficiency to produce the same payback times than canonical perovskite. 


\subsection{Introduction}

Perovskite solar cells (PSCs) have experienced an unprecedented rise since they were discovered in 2009 [63] and constitute a promising technology to collect energy from sun in the near future. Fundamental reasons of such success are an easy and cheap deposition of perovskite combined with efficiencies (PCE) comparable to those of the most expensive monocrystalline silicon solar cells [62]. For now, perovskite compositions, solvents and deposition processes are under optimisation $[114,115,234]$. However, in order to produce them at a large scale, stability and reproducibility issues must be overcome $[78,186,235,236]$.

Thus far, much research on PSCs has been oriented towards compositional engineering [114,115,234,237]. Perovskites with outstanding photovoltaic properties have a distinctive structure, composed by three atoms according to the formula $A B X_{3}$, where $A$ corresponds to a monovalent organic/inorganic cation, $B$ corresponds to a divalent inorganic cation (commonly $\mathrm{Pb}$ ) and $\mathrm{X}$ corresponds to $\mathrm{a}$ halide anion ( $\mathrm{Cl}, \mathrm{Br}$ and $\mathrm{I})$. As for the monovalent cationic position (A), the most efficient perovskite compositions introduce formamidinium (FA) cation along with the traditional methylammonium (MA) cation and also $\mathrm{Br}$ partially substitutes I anion [114,115,238-241] with published efficiencies as high as 22.1\% [234]. Recently, a caesium inorganic monovalent cation has shown also good results when combined with MA and FA in the perovskite structure. Actually, the three cations combined performed an enhanced power conversion efficiency (PCE) of $21.1 \%$ [88]. Not only that, but high reproducibility was achieved and the efficiency after $250 \mathrm{~h}$ was found quite stable, performing an efficiency of $18 \%$.

Lately, the so-called anti-solvent method has been used extensively to deposit high quality perovskite layers $[88,198,241,242]$. This method is implemented into the conventional spin-coating method, which can use Dimethylformamide (DMF), dimethylsulfoxide (DMSO) or $\mathrm{p}$-butyrolactone (GBL) as solvents for perovskite precursors. What makes this method different is the addition of a drop of a nonpolar solvent as chlorobenzene (CB) into the mixture during the spin-coating stage in order to force the formation of nucleation centres.

Chemical and optoelectronic properties of the three cations are notably different. On one hand, band gap of $\mathrm{FAPbl}_{3}$ is closer to the theoretical optimum [45]. Yet, pure $\mathrm{FAPbl}_{3}$ presents low structural stability at room temperature as a disadvantage $[232,238]$, thus needing $\mathrm{MAPbl}_{3}$ to reach a fair balance between efficiency and stability. On the other hand, inclusion of Cs enhances the stability of $\mathrm{Br}$ PSCs $[243,244]$. However, caesium iodine perovskites forming $\mathrm{CsPbl}_{3}$ could provide a band 
gap of $1.73 \mathrm{eV}$, which is relatively close to the aforementioned theoretical optimum, but its bulk perovskite phase is solely stable at temperatures above $300 \stackrel{\circ}{\circ}$ [245].

Apparently, combining MA and FA cations also combines their advantages while avoids their disadvantages. Nevertheless, a PSC with FA and Cs has been reported with enhanced thermal and humidity stability [246]. Cs assists the crystallisation of FA faster and more effectively than MA does, due to a superior size difference.[88] Although Cs may be deemed a low abundant element, its presence on earth crust is comparable to other large-scale produced elements like Sn [243], thus demonstrating that usage of Cs is feasible. Indeed, the sufficient abundance in Earth's crust of Cs compared with the rest of the elements is illustrated in the chart elaborated by the U.S. Geological Survey [247]. Furthermore, Cs concentration in the Earth's crust is signally larger than that of other elements already used in photovoltaics, namely cadmium, tellurium, selenium or indium.

Environmental analyses of PSCs via life cycle assessment (LCA) methodology have been reported to ensure an environmentally safer PSCs development and assist PSCs technology growth while respecting the environment $[110-112,127,130]$. Recently, a comparison of PSCs with silicon solar cells and a tandem with both perovskite and silicon was implemented [177]. Furthermore, the four most common methods to produce PSCs were environmentally revised by us [113]. This study also assessed a PSCs regeneration method previously proposed $[175,176]$ applied to the four production methods considered.

Other studies addressed the inclusion of Cs and FA in PSCs. For instance, a LCA was individually applied to the whole life cycle of modules of five different types of perovskite, such as $\mathrm{MAPbl}_{2} \mathrm{Cl}, \mathrm{MAPbl}_{3}, \mathrm{FAPbl}_{3}, \mathrm{CsPbl}_{3}, \mathrm{MASnl}_{3-\mathrm{B}} \mathrm{Br}_{\mathrm{x}}[118]$. In this work, $\mathrm{MAPbl}_{3}$ and $\mathrm{FAPbl}_{3}$ arose as the most harmful perovskites. However, results of the comparison of perovskites were clouded by the rest of the layer forming devices, such as the cathode and the anode made of fluorine-doped tin oxide (FTO). Another study collated a conventional $\mathrm{MAPbX}_{3}$ and a more stable $\mathrm{CsFAPbX}_{3}$ with other photovoltaic technologies [119].

The aim of this work is to evaluate the ongoing trend of compositional engineering in PSCs through LCA from cradle to gate. Therefore, the focus is solely set on the perovskite layer. Furthermore, as layers apart from perovskite layer would be roughly the same for every PSC studied, focusing the comparison on perovskite layer is more meaningful. By isolating the perovskite layer, clear results of the environmental performance of the different compositions of perovskites combining the three Cs, FA and MA cations, as well as the reagents that contain them, are obtained here for the first time. Herein, the four compositions reported on the 
manuscript of Saliba et al [88] are contrasted with a canonical $\mathrm{MAPbl}_{3}$ perovskite synthesised and deposited according to Noh et al [199]. As a consequence, the corresponding deposition methods for each type of perovskite are also contrasted. For a more realistic determination of the energy consumption, it has been directly measured for the preparation of cells at laboratory scale. Energy used in the method to synthesise multiple cation/anion perovskite was obtained by measuring the consumption in a laboratory environment. On the other hand, the energy consumption for the synthesis of canonical perovskite was taken from our previous study, based also in the direct measurement. [113]. Furthermore, the usage of materials for the synthesis of the multiple cation/anion perovskite is analysed to find the responsible compounds of the four compositions impact. A final economic analysis of the materials complements this assessment. Together with the economic cost of the materials, this analysis presents an economic payback time analysis of the materials used for the synthesis of all perovskites. Outcomes of this study are intended to support scientific community to develop PSCs with the highest efficiencies and stabilities in a safe and environmentally respectful way, thus fulfilling one of the objectives of this technology. Thereby, after this study PSCs are expected to be one step closer to industrial scale production.

\subsection{Materials and methods}

\subsubsection{Goal and scope definition}

Fundamental research on PSC is mainly focusing on the efficiency enhancement and on the increase of long-term stability. This study is intended to assist researchers in the realm of perovskite-based photovoltaics on issues less investigated but significantly important for the further development of an industrial technology as the effect of composition in cell impacts and cost. For this purpose, four different combinations of the inorganic cation Cs with the most used organic cations FA and $\mathrm{MA}$ using $\mathrm{Br} / \mathrm{I}$ anions were compared with the canonical $\mathrm{MAPbl}_{3}$ perovskite. Impacts generated by the perovskite layer were assessed from cradle to gate using LCA as tool. A functional unit of $1 \mathrm{~cm}^{2}$ of PSC was chosen as representative for the comparison of several compositions of perovskite. It is very important to highlight that, this work solely assesses the perovskite layer deposited, as the rest of the layers (substrate, electron and hole selecting contacts...) are considered to be similar for all the analysed cases and for that reason excluded from the LCA [248,249]. A detailed effect of these other parts of the cell can be found in our previous LCA study [113]. The corresponding efficiencies and lifetimes of the PSCs (Table 11) made of the five combinations of perovskite were extracted from the works in which their syntheses are reported $[88,199]$. 


\subsubsection{System boundary}

In order to compare the environmental performance of the highly efficient and more stable multiple cation/anion perovskite with a canonical perovskite, an LCA was conducted from cradle to gate. Therefore, the steps of the life cycle of PSCs included from the extraction of raw materials to the deposition of the perovskite layer. As in this work just the perovskite layer is studied, the system ends when every step concerning the deposition of the perovskite layer is accounted. Although perovskite is synthesised generally in a nitrogen glove box, its energetic consumption and the nitrogen it uses is dismissed, as it participates in both synthesis processes. Thereby, the deposition methods modelled for this work are described in Figure 13.

a)

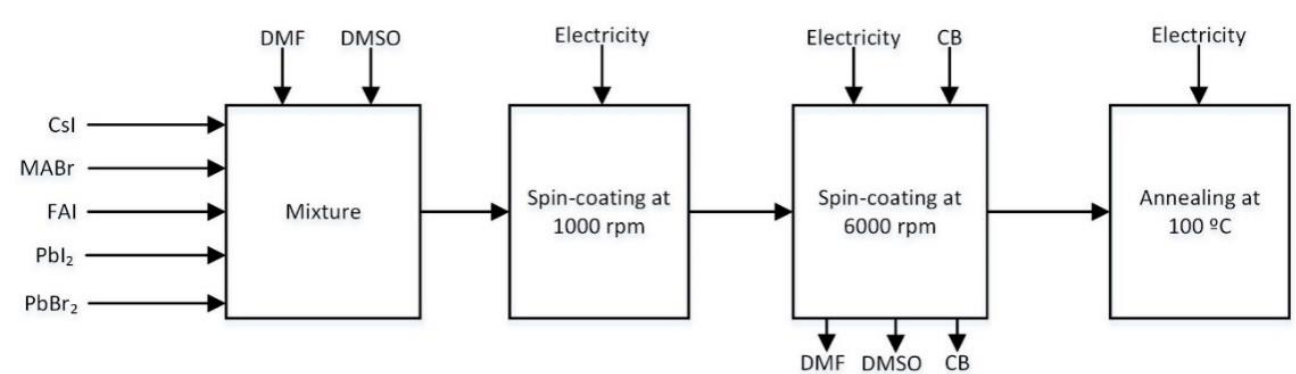

b)

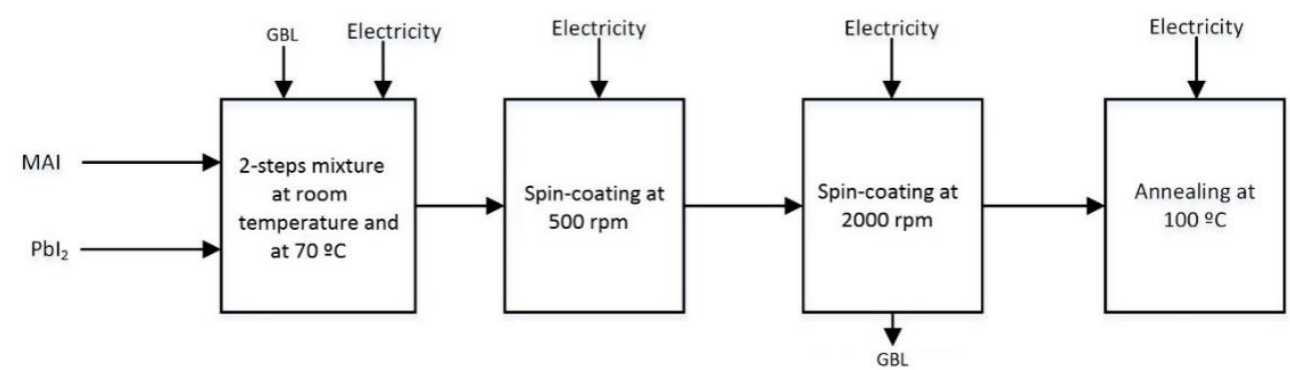

Figure 13. System boundary of the steps involved in the deposition of the perovskite layer of a) deposition route of the multiple cation/anion perovskite through the anti-solvent method and $b$ ) deposition route of the canonical perovskite through a simple spin-coating method.

As well as in the work of Saliba et al [88], a deposition with the anti-solvent method was simulated, which is illustrated in Figure 13a. This method cannot easily be upscaled for industrial applications [250], however we have decided to include it due to its extended use and to determine its impact from the point of view of LCA. In this study, for a perovskite deposition with anti-solvent we consider a first step of spin- 
coating at $1000 \mathrm{rpm}$ for $10 \mathrm{~s}$ of the reagents with a mixture of (4:1) DMF and DMSO in volume. This step was followed by another spin-coating step at $6000 \mathrm{rpm}$ for $20 \mathrm{~s}$, in which $100 \mu \mathrm{l}$ of CB were dropped onto the mixture $5 \mathrm{~s}$ before the end of the step. Lastly, the substrate was annealed for $1 \mathrm{~h}$ at 100 ㅇ. Energy consumption was directly measured from laboratory devices.

The deposition of the canonical perovskite, which is depicted in Figure 13b, comprised a first stirring of the mixture of $\mathrm{MAl}$ and $\mathrm{Pbl}_{2}$ reagents in $\mathrm{GBL}$ at room temperature for 10 minutes and 30 minutes at 70 으. Then, the mixture was spincoated at 500 for $5 \mathrm{~s}$ and $2000 \mathrm{rpm}$ for $60 \mathrm{~s}$. Finally, the film was heated for 60 minutes at 100 으. This procedure was extracted from our previous assessment [113].

\subsubsection{Inventory}

Herein, combinations of the three cations and two anions follow a general formula $\left(C s_{x}\left[M A_{0.17} F A_{0.83}\right]_{(1-x)} P b\left[I_{0.83} B r_{0.17}\right]_{3}\right)$, which reached efficiencies around $20 \%$ and a good stability during $250 \mathrm{~h}$ [88], as shown in Table 11 . As well as in the manuscript, the four combinations used herein were $x=0,0.05,0.10$ and 0.15 , where consequently $\mathrm{x}=0$ just containing $\mathrm{MA}$ and $\mathrm{FA}$, the combination used for the currently published PSC record [234]. According to that, the resulting stoichiometric coefficients of each precursor used for the synthesis are clarified in Table 12. As for the canonical perovskite an even mixture of $\mathrm{MAl}$ and $\mathrm{Pbl}_{2}$ were considered [199], known for being a general recipe from the early days of PSCs.

Table 11. Performance data of PSCs with perovskites containing three compounds in the cationic position [88] and the canonical perovskite [199].

\begin{tabular}{|c|c|c|c|c|c|}
\hline & 0.00 & 0.05 & 0.10 & 0.15 & Canonical \\
\hline PCE (\%) & 16.8 & 18.6 & 19.1 & 14.6 & 10.4 \\
\hline Stability $(\mathrm{h})$ & 100 & $250(18 \%)^{*}$ & - & - & - \\
\hline
\end{tabular}

*After $250 h$ the efficiency dropped to $18 \%$

Most of the inputs were calculated from datasets in Ecoinvent [212], namely electricity, transport, solvents and most of the reagents. However, FAI and CsI production processes could not be found in databases, it was therefore modelled from information in literature. In particular, the synthesis of FAI was modelled from several reactions with hydrogen cyanide, hydroxylamine, acetic acid and hydroiodic acid as reagents $[114,251,252]$. At the same time, Csl was modelled from a process of recovery of Cs from pollucite with sulphuric acid and hydroiodic acid as reagents [253]. In addition, the characterisation factor of Cs for abiotic depletion potential category was obtained from two different methods to contrast them. The most 
utilised characterisation factor in this work was extracted from literature [254,255]. For the sake of presenting a comparison, an updated factor was estimated based on data from 2017 [256,257], according to the methodology description [254].

Table 12. Stoichiometric coefficients of the reagents used for the syntheses of the perovskites compared.

\begin{tabular}{|c|c|c|c|c|c|c|}
\hline Composition & Csl & FAI & $\mathrm{MABr}$ & $\mathrm{MAI}$ & $\mathrm{Pbl}_{2}$ & $\mathrm{PbBr}_{2}$ \\
\hline 0.00 & 0.0000 & 0.8300 & 0.1700 & - & 0.8300 & 0.1700 \\
\hline 0.05 & 0.0500 & 0.7885 & 0.1615 & - & 0.8258 & 0.1743 \\
\hline 0.10 & 0.1000 & 0.7470 & 0.1530 & - & 0.8215 & 0.1785 \\
\hline 0.15 & 0.1500 & 0.7055 & 0.1445 & - & 0.8173 & 0.1828 \\
\hline Canonical & - & - & - & 1.0000 & 1.0000 & - \\
\hline
\end{tabular}

From the stoichiometric coefficients (Table 12) and the amount of perovskite, the amount of each reagent was obtained, which are reported in Table 13. The mass of perovskite was calculated by multiplying the perovskite's density [232] by the volume of perovskite deposited in the cell. The volume was obtained by multiplying $25 \mathrm{~cm}^{2}$ of substrate area and $500 \mathrm{~nm}$ of thickness of perovskite layer, which were assumed.

Table 13. Inventory of chemicals used for the syntheses of the perovskites $(\mu \mathrm{g} / \mathrm{cm} 2)$.

\begin{tabular}{|l|c|c|c|c|c|}
\hline Reagents/Solvents & 0.00 & 0.05 & 0.10 & 0.15 & Canonical \\
\hline $\mathrm{CSI}$ & 0 & 4.38 & 8.76 & 13.1 & \\
\hline $\mathrm{FAI}$ & 48.1 & 45.7 & 43.3 & 40.9 & \\
\hline $\mathrm{MABr}$ & 6.42 & 6.09 & 5.77 & 5.45 & \\
\hline $\mathrm{MAI}$ & & & & & 52.4 \\
\hline $\mathrm{PbI}_{2}$ & 129 & 128 & 128 & 127 & 152 \\
\hline $\mathrm{PbBr}_{2}$ & 21.0 & 21.6 & 22.1 & 22.6 & \\
\hline $\mathrm{DMF}$ & 799 & 791 & 783 & 774 & \\
\hline $\mathrm{DMSO}$ & 233 & 230 & 228 & 226 & \\
\hline $\mathrm{CB}$ & & \multicolumn{7}{|c|}{4440} & & 307 \\
\hline $\mathrm{GBL}$ & & & & & \\
\hline
\end{tabular}

The electric consumption of multiple cation/anion perovskite used in the steps detailed in Figure 13 was experimentally determined. The inventory of overall 
electricity usage for the two methods is shown in Table 14. During mixture and annealing steps 16 devices processed simultaneously were assumed.

Table 14. Inventory of electric consumption of devices used for perovskite mixture and deposition.

\begin{tabular}{|l|c|c|}
\hline Step & $\begin{array}{c}\text { Anti-solvent } \\
\text { method }\left(\mathrm{J} / \mathrm{cm}^{2}\right)\end{array}$ & $\begin{array}{c}\text { Conventional } \\
\text { method }\left(\mathrm{J} / \mathrm{cm}^{2}\right)\end{array}$ \\
\hline Mixing & 36 & 171 \\
\hline Spin-coating $(500 \mathrm{rpm})$ & & 20 \\
\hline Spin-coating $(1000 \mathrm{rpm})$ & 144 & \\
\hline Spin-coating $(2000 \mathrm{rpm})$ & & 252 \\
\hline Spin-coating $(6000 \mathrm{rpm})$ & 288 & \\
\hline Annealing & 1647 & 1647 \\
\hline Total energy consumption & 2115 & 2090 \\
\hline
\end{tabular}

Finally, there are two classes of inventory flows left to account for. These are the amount of transportation and the outputs released during the deposition. The amount of transportation was obtained from the distance of the supplier to Castello (Spain), where the laboratories are located. Solvent releases during perovskite deposition were assumed to be similar to the amounts of solvent used. A complete inventory is described in the Supporting information Table S16, Table S17, Table S18, Table S19, Table S20, Table S21 and Table S22.

\subsubsection{Economic analysis}

An additional economic analysis was performed in order to support the environmental assessment. For this analysis, chemicals for the synthesis and deposition of perovskite were only considered as transport price is embedded into chemicals' price. The energy consumption flow was not included in the economic analysis due to the great uncertainty of its measurement. Furthermore, the process outputs were supposed void of economic cost. The price in euros of each input was calculated from the amount of each used and its retail price from the main suppliers. Further details are provided in the Supporting information Table S23.

\subsubsection{Impact categories}

For a comprehensive and thorough comparison, eleven impact categories were chosen, in which the most developed impact models and the most representative categories were rendered, see Table 15. Seven of this group of categories are included in the CML baseline V3.02 [254,258]. These categories are Abiotic depletion 
(ADP), Abiotic depletion fossil fuels (ADPF), Global warming (GWP), Ozone layer depletion (ODP), Photochemical oxidation (POP), Acidification (AP) and Eutrophication (EP). From these categories, one of the most significant for measuring the environmental performance of a solar energy collector device is Global warming, as one of the main benefits of energy stemming from such devices is the mitigation of greenhouse effect. Nonetheless, the other categories enlisted represent a broad panoply of the most concerning categories which must be taken into consideration in order to avoid environmental charge transference, from Global warming category to these categories.

Additionally, four determining categories were chosen. From the Cumulative energy demand method (CED) [212], the total cradle-to-gate energy invested in the perovskite layer is obtained by adding cumulative energies obtained from sources renewable and non-renewable. This category allows contrasting the energy invested to produce it with the energy obtained from it. Owing to the concerning content of lead in PSCs, it is necessary to introduce into the assessment the impact categories Human toxicity cancer (HTC), Human toxicity non-cancer (HTNC) and Freshwater ecotoxicity (FET) from USEtox V1.04 method.[208]

CML, CED and USEtox methods are incorporated within the SimaPro ${ }^{\circledR}$ 8.0.3.14 software [259]. In this manuscript, abbreviations listed in Table 15 are used to name the selected impact categories.

Table 15. List of impact categories, their abbreviations, units and methodologies in which they are included.

\begin{tabular}{|c|c|c|c|}
\hline Category & Abbreviation & Unit & Methodology \\
\hline Abiotic depletion potential & ADP & kg Sb eq & \multirow{7}{*}{ CML baseline V3.02 } \\
\hline Abiotic depletion potential, fossil fuels & ADPF & MJ & \\
\hline Climate change potential & GWP & $\mathrm{kg} \mathrm{CO}{ }_{2} \mathrm{eq}$ & \\
\hline Ozone layer depletion potential & ODP & kg CFC-11 eq & \\
\hline Photochemical oxidation potential & POP & $\mathrm{kg} \mathrm{C}_{2} \mathrm{H}_{4} \mathrm{eq}$ & \\
\hline Acidification potential & AP & $\mathrm{kg} \mathrm{SO}_{2} \mathrm{eq}$ & \\
\hline Eutrophication potential & EP & $\mathrm{kg} \mathrm{PO}_{4}{ }^{3-} \mathrm{eq}$ & \\
\hline Cumulative energy demand & CED & MJ & $\begin{array}{c}\text { Cumulative energy } \\
\text { demand V1.09 }\end{array}$ \\
\hline Human toxicity, cancer effects & HTC & CTUh & \multirow{3}{*}{ Usetox V1.04 } \\
\hline Human toxicity, non-cancer effects & HTNC & CTUh & \\
\hline Freshwater ecotoxicity & FET & CTUe & \\
\hline
\end{tabular}




\subsection{Results and discussion}

The environmental impact of multiple cation/anion perovskite were compared with the environmental impact of a canonical perovskite, in Figure 14. These outcomes comprise the environmental impacts generated from the materials extraction until the PSC is manufactured, although considering just the effect of perovskite layer as it has been previously commented in section 4.2 . The results are plotted in percentage considering the impact of the composition with the largest impact as $100 \%$, been this composition the multiple cation/anion perovskite with $\mathrm{x}=0$, i.e. $M A_{0.17} F A_{0.83} P b\left[I_{0.83} \mathrm{Br}_{0.17}\right]_{3}$, for every category but ADP. Alongside with the total impacts including the impact originated by the energy consumption for the preparation of the perovskite layer, results without accounting the energy consumption are also plotted in Figure 14. Energy consumption for the preparation of PSCs at lab scale has been directly measured and in fact it rules most of the impact as can be appreciated in the distribution of impacts per type of flow Figure S18. The contribution of energy consumption to the total impact will undoubtedly decrease with the industrial up-scaling process. Consequently, in order to take into account the direct impact of the materials themselves the impact without taking into account the energy consumption have been also calculated and represented in Figure 14.

Outcomes of the comparison of environmental impacts of the four compositions of perovskite containing $\mathrm{Cs}, \mathrm{FA}, \mathrm{MA}, \mathrm{I}$ and $\mathrm{Br}$ with the canonical perovskite, which is composed of just MA and I, are quite homogeneous for all categories, except for ADP category. In general, they show that multiple cation/anion perovskite compositions are more harmful than canonical perovskite, except for ADP where canonical perovskite impact surpasses that of multiple cation/anion perovskites.

A comprehensive table with the absolute outcomes of the five different perovskite composition here compared is available in the Supporting information, Table S24, Table S25, Table S26, Table S27 and Table S28. In addition, the impact distribution of the flows of inputs and outputs of the process of the perovskite synthesis and deposition is presented in the Supporting information, see Figure S18. Total impact results for multiple cation/anion perovskite impacts are very analogous among them. Approximately, the canonical perovskite impact supposes just a $92 \%$ of the multiple cation/anion perovskite with $\mathrm{x}=0$ impact, which is the most harmful among triple cation perovskites for all categories. This fact is true except for ODP, POP and EP categories, where canonical perovskite supposes a $77 \%, 75 \%$ and $87 \%$ of the $x=0$ perovskite, respectively. The little deviation stems from a slightly larger impact of multiple cation/anion perovskites reagent and energy consumption. 


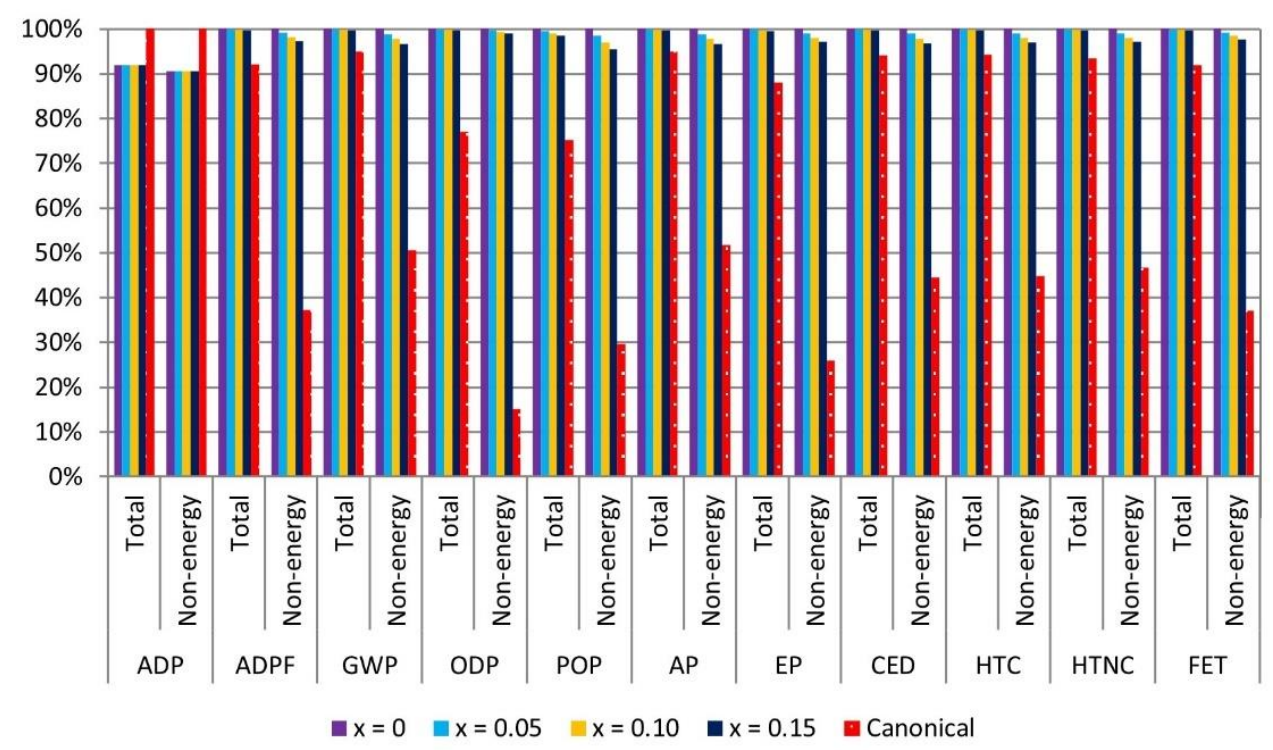

Figure 14. Relative impacts of perovskite layer synthesis and deposition with proportions of Cs of $x=0$, $0.05,0.10$ and 0.15 at the perovskite cationic position for multiple cation/anion $C s_{x}\left[M A_{0.17} F A_{0.83}\right]_{(1-x)} P b\left[I_{0.83} B r_{0.17}\right]_{3}$ compared with the canonical perovskite for total impacts and without taking energy consumption into account. In $\mathrm{X}$-axis are the environmental impact categories.

However, for ADP category impact multiple cation/anion perovskite is predominant, supposing roughly a $92 \%$ respect to the canonical perovskite impact. The reason behind this lies on the fact that the main responsible group of inputs of the impact of ADP category are the synthesis reagents, mainly $\mathrm{Pbl}_{2}$, whose impact is bigger for the canonical perovskite. There is a little difference of impact amongst multiple cation/anion perovskites, as the amount of synthesis reagents used is identical. Generally, for this category energy consumption is not as determinant as for the rest of categories. Although Cs impact is negligible for ADP category and unappreciable for the rest of the categories, its ADP characterisation factor (ADPF) needs a revision because it might be outdated. Due to the ADPF utilised for this study is taken from literature of 2002 [254,255], ADPF was updated to 2017 [256,257]. Further details about the updating can be seen in the Supporting information.

Nevertheless, the impact due to the different materials and processed employed in the fabrication of multiple cation/anion perovskites in comparison with canonical perovskite is evident when energy consumption is not considered in the total impacts, see Figure 14. $M A_{0.17} F A_{0.83} P b\left[I_{0.83} B r_{0.17}\right]_{3}$ is the most harmful perovskite, the impact of multiple cation/anion perovskites decreases as the content of Cs increases. However, with variations that do not differ more than a $5 \%$ for any 
category. On the other hand, the impacts of canonical perovskite is just $15-55 \%$ of the impact of $M A_{0.17} F A_{0.83} P b\left[I_{0.83} \mathrm{Br}_{0.17}\right]_{3}$ perovskite, the most harmful one, depending on the impact category except for ADP where the canonical perovskite has more impact, for the reason previously commented.

Figure 14 clearly reflect that the canonical perovskite is significantly less harmful than the multiple cation/anion perovskite when energy use is not considered. A closer and more precise view of the contributions of the reagents and the solvents for the deposition of the here studied compositions of multiple cation/anion perovskite in comparison to the canonical perovskite is detailed in Figure 15. In this analysis, the most determining categories to assess PSCs are selected, which are GWP, CED, HTC and HTNC.

Lead reagents are among the most pernicious compounds. For HTC and HTNC categories, $\mathrm{Pbl}_{2}$ is the major contributor to the overall impact, which is attributed to the larger quantity of it, used for the synthesis of the perovskites. However similar impact is produced by the $\mathrm{Pbl}_{2}$ in canonical samples that by the sum of the impacts originated by $\mathrm{Pbl}_{2}$ plus $\mathrm{PbBr}_{2}$ in multiple cation/anion perovskite layers. The huge differences in the impacts among multiple cation/anion and canonical perovskite layers are due to the use in the formers of $C B$ in the anti-solvent method and FAI instead of $\mathrm{MAl}$, where the latest generates less impacts. $\mathrm{CB}$ used for the anti-solvent method has a slightly lower impact for HTC and HTNC impacts. However, for GWP and $C E D$ categories $C B$ is responsible of the highest contribution to the overall impact, where $\mathrm{Pbl}_{2}$ is the second most contributing compound. The great contribution of $\mathrm{CB}$ stems from the fact that its amount used is the highest among all compounds, despite its little impact per $\mathrm{kg}$ in comparison with $\mathrm{Pbl}_{2}$. Impact improvements of a possible optimisation of $C B$ are analysed in the supplementary information. Results of this analysis disclose that despite the reductions in chlorobenzene usage, except for the ADP category, overall impacts of multiple cation/anion perovskites would not reach the impact extent of the canonical perovskite shown in Figure 15. The up-scaling of anti-solvent technology to move from lab scale cell to large substrates is not straightforward at all from the technological point of view [250]. Here we show that anti-solvent method also has an important deleterious effect on the impacts generated and consequently should be exchanged by a lower impact method in the future commercialization of perovskites. 


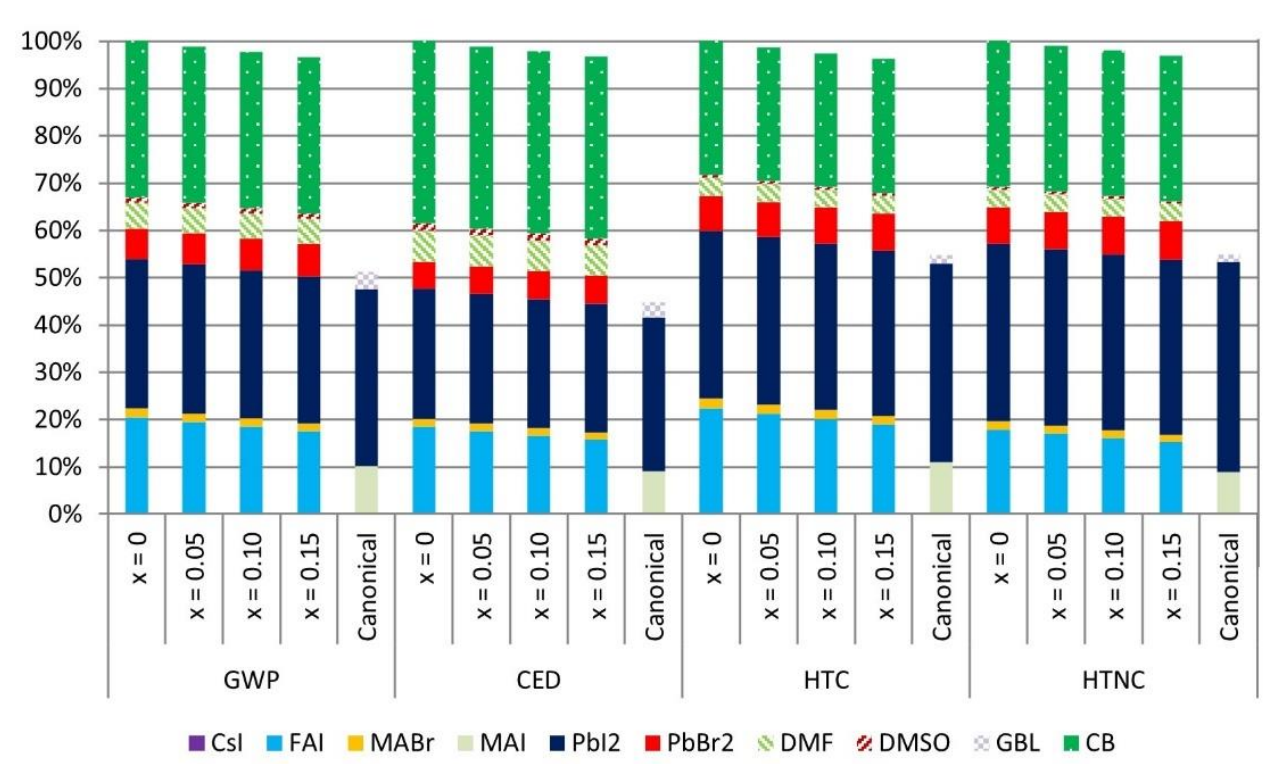

Figure 15. Relative impacts of materials for PSCs with proportions of caesium of $x=0, x=0.05, x=$ 0.10 and $x=0.15$ at the perovskite cationic position. Impact categories: Global warming potential (GWP), Cumulative energy demand (CED), Human toxicity, cancer (HTC), and Human toxicity, noncancer (HTNC).

Among the reagents that supply the three cations, FAl emerges as the most adverse, which is also the reagent that mostly varies along compositions and therefore the reagent that eventually determines the result. Most of its impact stems from the energy used to synthesise it, as its synthesis from hydroiodic acid and formamidine acetate is performed in laboratory environment. In particular, the most detrimental step of this process is a final treatment in a vacuum oven at 60 으 for $24 \mathrm{~h}$ [114]. By reducing the operational time of this treatment impacts of multiple cation/anion perovskite would not decrease as much as those of the canonical perovskite. Nonetheless, for GWP, CED, HTC and HTNC categories, impact of FAl is less adverse than that of the cation supplier reagent for canonical perovskite (MAI) when this operational time goes below 6 hours.

Meanwhile, contribution of $\mathrm{MABr}$ is vague and contribution of Csl is not visible due to a little amount of them is used. Alongside with the fact that more amount of FAI is used for the synthesis of multiple cation/anion perovskite, its impact per $\mathrm{kg}$ of reagent is the highest of the three reagents that supply cations, making the $M A_{0.17} F A_{0.83} P b\left[I_{0.83} B r_{0.17}\right]_{3}$ perovskite the most harmful, where the impact is reduced when $\mathrm{x}$ increases due to the fact that less FAI is used as it is partially substituted by Csl. 
Usage of solvents produces a considerable lesser impact respect to the reagents. DMF solvent causes a superior impact than DMSO, both considerably inferior to that of $\mathrm{CB}$. In contrast to preceding works [111,118], perovskite deposition solvent impacts are generally of trivial magnitude. This statement is true provided that $C B$ would not be treated as such since it satisfies the extra function of removing solvents used for the deposition. $\mathrm{DMF}, \mathrm{PbBr}_{2}$ and $\mathrm{Csl}$ are the only flows whose impact increases with the Cs content. Meanwhile, the remaining flows impact decreases with the amount of Cs. Moreover, CB impact remains constant due to its amount does not vary along the different compositions.

\subsubsection{Economic analysis}

In order to complement the analysis of four multiple cation/anion perovskites with the canonical $\mathrm{MAPbl}_{3}$ perovskite, the economic consequences of the usage of reagents and solvents for the perovskites deposition are analysed in Figure 16. For this analysis, use of energy flow is dismissed owing to an unrealistic usage in laboratory environment. In this economic analysis the cost in euros of each reagent and solvent is obtained from its amount used and its retail price, see Table S23 for further details. Note the economic analysis here reported are for cells at lab scale and just considering the cost of the perovskite layer. This fact makes that the cost here reported are overestimated considering a future industrial application. However, it provides important clues about which parts are mostly affecting the final price.

In Figure 16, the canonical perovskite arises as the most economical type by virtue of the lesser quantity of compounds used. The principal compound behind the higher cost of multiple cation/anion perovskites in comparison with the canonical composition is the FAI. In fact, cost of multiple cation/anion perovskites is roughly $\cdot 1 € / \mathrm{m}^{2}$ higher than that of multiple cation/anion perovskite, which matches approximately with the cost of FAI. Furthermore, this difference decreases with the Cs content used favoured by the subsequent reduction in the cost of FAI. Among multiple cation/anion perovskites the cheapest composition is the $x=0.15$ with the highest content of Cs and consequently the lowest of FA. Despite the determining character of FAl and its highest cost per mass unit, $\mathrm{Pbl}_{2}$ with the second highest cost per mass unit is the most expensive reagent used in all the composition, however in multiple cation/anion perovskite the cost is slightly mitigated by the introduction of $\mathrm{Br}$ anion and the consequent use of $\mathrm{PbBr}_{2}$ precursor, significantly cheaper than $\mathrm{Pbl}_{2}$, see Table S23. DMF and DMSO solvents cost is lower than the CB cost, nonetheless this three compounds cost is neither important nor determining for the total cost. 


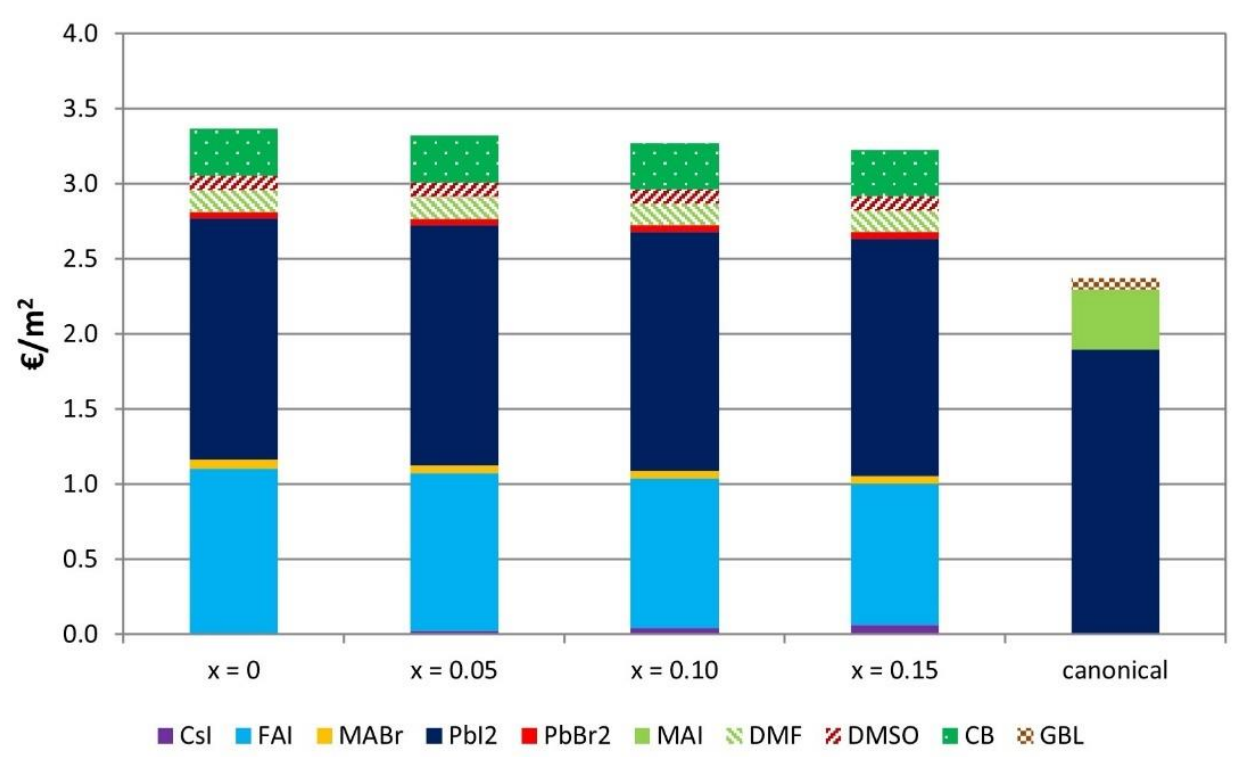

Figure 16. Cost in euros of materials for the deposition of perovskite active layer each of the PSCs analysed. Energy is not included in this analysis.

Given that PSCs can be an economic source from the energy generated, a cost payback time analysis was performed for the perovskite layer. Due to the canonical perovskite arises as the lower cost perovskite layer respect to the rest of perovskites here analysed, the payback time will be lower for canonical perovskite if the efficiencies of the cells are similar. Multiple cation/anion perovskite can only have the same payback time by an increase of cell efficiency. In Figure 17, the efficiency of a multiple cation/anion perovskite with $\mathrm{x}=0.10$ (the perovskites with the highest reported efficiency in Table 1), left axis, is plotted against the efficiency of perovskite canonical cell in order that both present the same payback time. It has been calculated considering the perovskite layer cost, see Figure 16 , and the price of $1 \mathrm{MJ}$ of electricity in Spain and the assumption of a solar constant of $1 \mathrm{~kW} / \mathrm{m}^{2}$. This analysis calculates the efficiency that should have the perovskite with $x=0.10$ of Cs to recover the money invested on its synthesis and deposition in the same time than the canonical perovskite does. The difference between the efficiencies of multiple cation/anion and canonical perovskite to get the same payback time is represented by the right axis in Figure 17, to facilitate the comprehension of this analysis. 


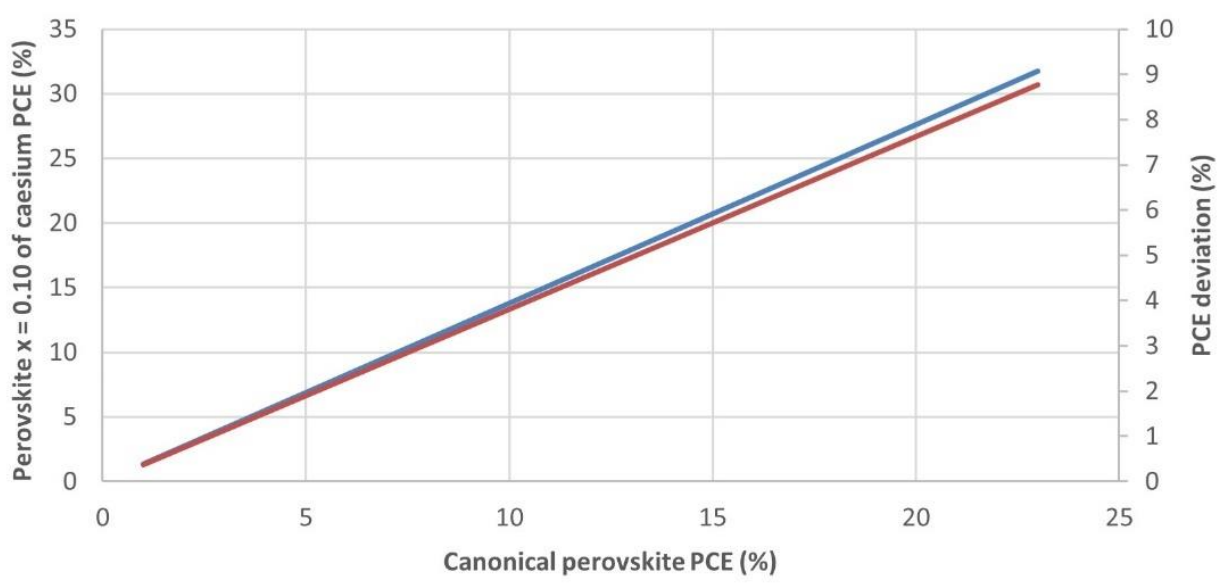

- Equivalent cost payback efficiency of perovskite with $\mathrm{x}=0.10$ of caesium PCE (\%)

Deviation between canonical perovskite and its cost payback equivalent for the perovskite with $\mathrm{x}=0.10$ of caesium $(\%)$

Figure 17. Equal cost payback time for the perovskite with $\mathrm{x}=0.1$ of caesium and canonical perovskite PSCs.

The payback cost analysis in Figure 17 reveals that the efficiency necessary to recover the money invested in the synthesis and deposition of a canonical perovskite with and efficiency of $16 \%$, for a perovskite with $x=0.10$ of Cs is similar the current published efficiency record of $22.1 \%$ [234], i.e. the efficiency of multiple cation/anion perovskite has to be 1.38 the efficiency of the canonical perovskite to make equal the payback cost.

\subsection{Conclusions}

The outcomes of the comparison of four perovskites containing Cs, formamidinium and methylammonium as cation and $\mathrm{I}$ and $\mathrm{Br}$ as anions to the canonical perovskite with methylammonium cation and just I as anion expose that multiple cation/anion perovskites are harmful for all the impact categories analysed except for abiotic depletion potential (ADP). The impact of multiple cation/perovskite is even more pronounced if the energy used in the cell fabrication is not considered. Two are the main reasons of the higher impact of multiple cation/anion perovskites: The use of the anti-solving method and the utilization of FAI precursor. This work points out that the anti-solving method, that produce outstanding results at lab scale, is not adequate for industrial implementation. The reason behind this is not only owing to technical difficulties of its implementation on larger substrate sizes, but also to the increase of impacts. On the other hand, FA cation is present in the efficiency record 
PSCs $[114,115,234,237]$. Nevertheless, the FAl chemical used in the multiple cation/anion perovskites synthesis significantly increases the impacts. Moreover, it is the most expensive precursor causing an important increase of the cell cost in comparison with canonical devices using just MA as monovalent cation. The current synthesis of this precursor needs to be optimised in order to reduce these impacts and cost. In contrast, the partial substitution of $\mathrm{I}$ by $\mathrm{Br}$ anions has positive consequences as it has practically no effect in terms of impact, nonetheless reducing the device cost, as $\mathrm{PbBr}_{2}$ is remarkably cheaper than $\mathrm{Pbl}_{2}$. The future utilisation of multiple cation/anion in the industrialisation of perovskite process needs a detailed and balanced study of not only efficiency but also impact and cost. For example, here we highlight that a canonical $\mathrm{MAPb}_{3}$ with $16 \%$ efficiency will be more attractive for industrialisation, as long as it can be prepared with enough stability, than multication cells with FA and with the current published record efficiency of $22.1 \%$ as both present the same payback time but the former exhibits reduced impacts. 


\subsection{Supporting information}

\section{Inventory}

The inventory of triple cation perovskites was extracted from the work in which all their compositions are reported [88]. Meanwhile, the canonical perovskite inventory was modelled from the manuscript of Noh et al [199]. Inventories of the five perovskites are shown in Table S16.

Table S16. Inventory of flows used for the perovskites analysed.

\begin{tabular}{|c|c|c|c|c|c|c|c|}
\hline Name & $\begin{array}{l}\text { Value for } \\
0 \% \\
\text { caesium } \\
\text { perovskite }\end{array}$ & $\begin{array}{c}\text { Value for } \\
5 \% \\
\text { caesium } \\
\text { perovskite }\end{array}$ & $\begin{array}{c}\text { Value for } \\
10 \% \\
\text { caesium } \\
\text { perovskite }\end{array}$ & $\begin{array}{l}\text { Value for } \\
15 \% \\
\text { caesium } \\
\text { perovskite }\end{array}$ & $\begin{array}{l}\text { Value for } \\
\text { canonical } \\
\text { perovskite }\end{array}$ & Unit & Observations \\
\hline \multicolumn{8}{|c|}{ Reagents } \\
\hline Csl & $0.00 \mathrm{E}+00$ & $4.38 \mathrm{E}-06$ & $8.76 \mathrm{E}-06$ & $1.31 \mathrm{E}-05$ & & $\mathrm{~g} / \mathrm{cm}^{2}$ & $\begin{array}{l}\text { Detailed inventory } \\
\text { in Table S17 }\end{array}$ \\
\hline FAI & $4.81 \mathrm{E}-05$ & 4.57E-05 & 4.33E-05 & 4.09E-05 & & $\mathrm{g} / \mathrm{cm}^{2}$ & $\begin{array}{l}\text { Detailed inventory } \\
\text { in Table S18 }\end{array}$ \\
\hline $\mathrm{MABr}$ & $6.42 \mathrm{E}-06$ & $6.09 \mathrm{E}-06$ & 5.77E-06 & $5.45 \mathrm{E}-06$ & & $\mathrm{~g} / \mathrm{cm}^{2}$ & $\begin{array}{l}\text { Detailed inventory } \\
\text { in Table S19 }\end{array}$ \\
\hline MAI & & & & & $5.24 \mathrm{E}-05$ & $\mathrm{~g} / \mathrm{cm}^{2}$ & $\begin{array}{l}\text { Detailed inventory } \\
\text { in Table S20 }\end{array}$ \\
\hline $\mathrm{Pbl}_{2}$ & $1.29 \mathrm{E}-04$ & $1.28 \mathrm{E}-04$ & $1.28 \mathrm{E}-04$ & $1.27 \mathrm{E}-04$ & $1.52 \mathrm{E}-04$ & $\mathrm{~g} / \mathrm{cm}^{2}$ & $\begin{array}{l}\text { Detailed inventory } \\
\text { in Table S21 }\end{array}$ \\
\hline $\mathrm{PbBr}_{2}$ & $2.10 \mathrm{E}-05$ & $2.16 \mathrm{E}-05$ & $2.21 \mathrm{E}-05$ & $2.26 \mathrm{E}-05$ & & $\mathrm{~g} / \mathrm{cm}^{2}$ & $\begin{array}{l}\text { Detailed inventory } \\
\text { in Table S22 }\end{array}$ \\
\hline \multicolumn{8}{|c|}{ Solvents } \\
\hline DMF & 7.99E-04 & 7.91E-04 & $7.83 \mathrm{E}-04$ & 7.74E-04 & & $\mathrm{g} / \mathrm{cm}^{2}$ & $\begin{array}{l}\text { DMF solvent from } \\
\text { Ecoinvent } \\
\text { database [260] }\end{array}$ \\
\hline DMSO & $2.33 \mathrm{E}-04$ & $2.30 \mathrm{E}-04$ & $2.28 \mathrm{E}-04$ & $2.26 \mathrm{E}-04$ & & $\mathrm{~g} / \mathrm{cm}^{2}$ & $\begin{array}{l}\text { DMSO solvent } \\
\text { from Ecoinvent } \\
\text { database [260] }\end{array}$ \\
\hline CB & \multicolumn{4}{|l|}{$4.44 \mathrm{E}-03$} & & $\mathrm{~g} / \mathrm{cm}^{2}$ & $\begin{array}{l}\text { CB solvent from } \\
\text { Ecoinvent } \\
\text { database [260] }\end{array}$ \\
\hline GBL & & & & & $3.07 E-04$ & $\mathrm{~g} / \mathrm{cm}^{2}$ & $\begin{array}{l}\text { GBL solvent from } \\
\text { Ecoinvent } \\
\text { database }[260]\end{array}$ \\
\hline \multicolumn{8}{|c|}{ Outputs } \\
\hline $\begin{array}{l}\text { Emissions } \\
\text { - DMF }\end{array}$ & 7.99E-04 & 7.91E-04 & $7.83 E-04$ & 7.74E-04 & & $\mathrm{g} / \mathrm{cm}^{2}$ & $\begin{array}{l}\text { Emissions to air } \\
\text { due to } \\
\text { evaporation of } \\
\text { DMF solvent }\end{array}$ \\
\hline $\begin{array}{l}\text { Emissions } \\
\text { - DMSO }\end{array}$ & $2.33 \mathrm{E}-04$ & $2.30 \mathrm{E}-04$ & $2.28 \mathrm{E}-04$ & $2.26 \mathrm{E}-04$ & & $\mathrm{~g} / \mathrm{cm}^{2}$ & $\begin{array}{l}\text { Emissions to air } \\
\text { due to } \\
\text { evaporation of } \\
\text { DMSO solvent }\end{array}$ \\
\hline
\end{tabular}


Evaluation of multiple cation/anion perovskite solar cells through life cycle assessment

\begin{tabular}{|c|c|c|c|c|c|c|c|}
\hline $\begin{array}{l}\text { Emissions } \\
-\mathrm{CB}\end{array}$ & \multicolumn{4}{|l|}{ 4.44E-03 } & & $\mathrm{g} / \mathrm{cm}^{2}$ & $\begin{array}{l}\text { Emissions to air } \\
\text { due to } \\
\text { evaporation of } \mathrm{CB} \\
\text { solvent }\end{array}$ \\
\hline $\begin{array}{l}\text { Emissions } \\
\text { - GBL }\end{array}$ & & & & & $3.07 E-04$ & $\mathrm{~g} / \mathrm{cm}^{2}$ & $\begin{array}{l}\text { Emissions to air } \\
\text { due to } \\
\text { evaporation of } \\
\text { GBL solvent }\end{array}$ \\
\hline \multicolumn{8}{|c|}{ Amount of transportation } \\
\hline $\begin{array}{l}\text { Transport } \\
\text {, lorry > } \\
16 \mathrm{t}\end{array}$ & $2.71 \mathrm{E}-06$ & $2.70 \mathrm{E}-06$ & $2.70 \mathrm{E}-06$ & $2.69 \mathrm{E}-06$ & $2.20 \mathrm{E}-07$ & $\mathrm{tkm} / \mathrm{cm}^{2}$ & $\begin{array}{l}\text { Distances } \\
\text { considered from } \\
\text { suppliers to } \\
\text { Castelló (Spain) }\end{array}$ \\
\hline \multicolumn{8}{|c|}{ Use of energy } \\
\hline $\begin{array}{l}\text { Electricity } \\
\text {, low } \\
\text { voltage }\end{array}$ & $2.12 \mathrm{E}-03$ & & & & $2.09 E-03$ & $\mathrm{MJ} / \mathrm{cm}^{2}$ & $\begin{array}{l}\text { European } \\
\text { electricity mix } \\
\text { from Ecoinvent } \\
{[260]}\end{array}$ \\
\hline
\end{tabular}




\subsection{Inventory of caesium iodide model}

The recovery of caesium from pollucite ore was modelled according to a method in which the raw pollucite is digested with sulphuric acid [253]. Its inventory is shown in Table S17. The caesium iodide supplier was abcr GmbH in Pontevedra (Spain). Its distance to Castelló (Spain) is $974 \mathrm{~km}$.

Table S17. Inventory for $1 \mathrm{~kg}$ of caesium iodide.

\begin{tabular}{|c|c|c|}
\hline Name & Value & Unit \\
\hline \multicolumn{3}{|l|}{ Materials/fuels } \\
\hline Sulphuric acid & 754.989 & g \\
\hline Lime & 431.677 & g \\
\hline lodine & 488.434 & g \\
\hline Hydrogen & 3.849 & $\mathrm{~g}$ \\
\hline Water, deionised & 10271.291 & $\mathrm{~g}$ \\
\hline Pollucite Ore & 1694.725 & $\mathrm{~g}$ \\
\hline \multicolumn{3}{|l|}{ Electricity/heat } \\
\hline Heat, natural gas, $<100 \mathrm{~kW}$ & 3.58 & $\mathrm{kWh}$ \\
\hline Electricity, low voltage & 0.027 & $\mathrm{kWh}$ \\
\hline Crushing, rock & 1694.725 & $\mathrm{~g}$ \\
\hline Chemical plant, organics & $4 \mathrm{E}-10$ & $p$ \\
\hline \multicolumn{3}{|l|}{ Emissions to air } \\
\hline Water & 9924.884 & $\mathrm{~g}$ \\
\hline \multicolumn{3}{|l|}{ Emissions to water } \\
\hline Aluminium oxide & 196.222 & $\mathrm{~g}$ \\
\hline Silicon dioxide & 925.045 & $\mathrm{~g}$ \\
\hline Sodium hydroxide & 303.988 & $\mathrm{~g}$ \\
\hline Aluminium oxide & 196.222 & $\mathrm{~g}$ \\
\hline \multicolumn{3}{|l|}{ Waste to treatment } \\
\hline Waste gypsum (waste treatment) & 1325.342 & $\mathrm{~g}$ \\
\hline
\end{tabular}




\subsection{Inventory of formamidinium iodide model}

The inventory of formamidinium iodide was modelled from three reactions in which hydrogen cyanide, hydroxylamine, acetic acid and hydroiodic acid are involved $[114,251,252]$. It is shown in Table S18.The formamidinium iodide supplier was Dyesol Limited in Manchester (United Kingdom). Its distance to Castelló (Spain) is $2013 \mathrm{~km}$.

Table S18. Inventory for $1 \mathrm{~kg}$ of formamidinium iodide.

\begin{tabular}{|c|c|c|}
\hline Name & Value & Unit \\
\hline \multicolumn{3}{|l|}{ Materials/fuels } \\
\hline Hydrogen cyanide & 157.153 & $\mathrm{~g}$ \\
\hline Hydroxylamine & 192.068 & $\mathrm{~g}$ \\
\hline Acetic anhydride & 296.825 & $\mathrm{~g}$ \\
\hline Hydrogen & 5.815 & $\mathrm{~g}$ \\
\hline lodine & 737.919 & $\mathrm{~g}$ \\
\hline Water, deionised & 423.965 & $\mathrm{~g}$ \\
\hline Diethyl ether & 101.588 & $\mathrm{~g}$ \\
\hline Methanol & 838.438 & $\mathrm{~g}$ \\
\hline Chemical plant, organics & $4 \mathrm{E}-10$ & $p$ \\
\hline \multicolumn{3}{|l|}{ Electricity/heat } \\
\hline Electricity, low voltage & 197.79 & $\mathrm{kWh}$ \\
\hline \multicolumn{3}{|l|}{ Emissions to air } \\
\hline Diethyl ether & 101.588 & $\mathrm{~g}$ \\
\hline Methanol & 838.438 & $\mathrm{~g}$ \\
\hline \multicolumn{3}{|l|}{ Emissions to water } \\
\hline Water & 476.3 & $\mathrm{~g}$ \\
\hline Acetic acid & 349.189 & $\mathrm{~g}$ \\
\hline
\end{tabular}




\subsection{Inventory of methylammonium bromide model}

In Table S19, the methylammonium bromide inventory was modelled according to a reaction of methylamine and hydrobromic acid [242]. The methylammonium bromide supplier was Dyesol Limited in Manchester (United Kingdom). Its distance to Castelló (Spain) is $2013 \mathrm{~km}$.

Table S19. Inventory for $1 \mathrm{~kg}$ of methylammonium bromide.

\begin{tabular}{|l|c|l|}
\hline Name & Value & Unit \\
\hline Materials/fuels & 277.023 & $\mathrm{~g}$ \\
\hline Methylamine & 8.936 & $\mathrm{~g}$ \\
\hline Hydrogen & 714.041 & $\mathrm{~g}$ \\
\hline Bromine & 415.535 & $\mathrm{~g}$ \\
\hline Methanol & 783.225 & $\mathrm{~g}$ \\
\hline Water, deionised & 11.103 & $\mathrm{~g}$ \\
\hline Ethanol & 10.033 & $\mathrm{~g}$ \\
\hline Diethyl ether & $4 \mathrm{E}-10$ & $\mathrm{p}$ \\
\hline Chemical plant, organics & 143.05 & $\mathrm{kWh}$ \\
\hline Electricity/heat & & \multicolumn{2}{|l|}{} \\
\hline Electricity, low voltage & 415.535 & $\mathrm{~g}$ \\
\hline Emissions to air & 783.225 & $\mathrm{~g}$ \\
\hline Methanol & 11.103 & $\mathrm{~g}$ \\
\hline Water & 10.033 & $\mathrm{~g}$ \\
\hline Ethanol & \\
\hline Diethyl ether &
\end{tabular}




\subsection{Inventory of methylammonium iodide model}

In Table S20, the methylammonium iodide inventory was modelled according to a reaction of methylamine and hydrobromic acid [199]. The formamidinium iodide supplier was Sigma Aldrich in Madrid (Spain). Its distance to Castelló (Spain) is 430 $\mathrm{km}$.

Table S20. Inventory for $\mathbf{1} \mathrm{kg}$ of methylammonium iodide.

\begin{tabular}{|l|c|l|}
\hline Name & Value & Unit \\
\hline Materials/fuels & 195.086 & $\mathrm{~g}$ \\
\hline Methylamine & 6.293 & $\mathrm{~g}$ \\
\hline Hydrogen & 798.621 & $\mathrm{~g}$ \\
\hline lodine & 292.629 & $\mathrm{~g}$ \\
\hline Methanol & 607.216 & $\mathrm{~g}$ \\
\hline Water, deionised & 8.733 & $\mathrm{~g}$ \\
\hline Ethanol & 7.892 & $\mathrm{~g}$ \\
\hline Diethyl ether & $4 \mathrm{E}-10$ & $\mathrm{p}$ \\
\hline Chemical plant, organics & & \\
\hline Electricity/heat & 90.87 & $\mathrm{kWh}$ \\
\hline Electricity, low voltage & & \\
\hline Emissions to air & 292.629 & $\mathrm{~g}$ \\
\hline Methanol & 607.216 & $\mathrm{~g}$ \\
\hline Water & 8.733 & $\mathrm{~g}$ \\
\hline Ethanol & 7.892 & $\mathrm{~g}$ \\
\hline Diethyl ether & &
\end{tabular}




\subsection{Inventory of lead iodide model}

In Table S21, the lead iodide inventory was modelled according to a reaction of lead nitrate and potassium iodide [261]. The lead iodide supplier was TCl Europe N.V. in Zwijndrecht (Belgium). Its distance to Castelló (Spain) is $1645 \mathrm{~km}$.

Table S21 Inventory for $\mathbf{1} \mathbf{~ k g}$ of lead iodide.

\begin{tabular}{|l|c|l|}
\hline Name & Value & Unit \\
\hline Materials/fuels & 449.449 & $\mathrm{~g}$ \\
\hline Lead, primary & 546.627 & $\mathrm{~g}$ \\
\hline Nitric acid, 50\% in $\mathrm{H}_{2} \mathrm{O}$ & 243.372 & $\mathrm{~g}$ \\
\hline Potassium hydroxide & 550.551 & $\mathrm{~g}$ \\
\hline lodine & $4 \mathrm{E}-10$ & $\mathrm{p}$ \\
\hline Chemical plant, organics & 114.4 & $\mathrm{kWh}$ \\
\hline Electricity/heat & 6.507 & $\mathrm{~g}$ \\
\hline Electricity, low voltage & \multicolumn{2}{|l|}{} \\
\hline Emissions to air & 39.045 & $\mathrm{~g}$ \\
\hline Hydrogen & 273.314 & $\mathrm{~g}$ \\
\hline Emissions to water & 434.257 & $\mathrm{~g}$ \\
\hline Water & \multicolumn{2}{|l|}{} \\
\hline Nitric acid
\end{tabular}




\subsection{Inventory of lead bromide model}

In Table S22, the lead bromide inventory was modelled according to a reaction of lead nitrate and potassium bromide [261]. The lead bromide supplier was TCI Europe N.V. in Zwijndrecht (Belgium). Its distance to Castelló (Spain) is $1645 \mathrm{~km}$.

Table S22. Inventory for $\mathbf{1}$ kg of lead bromide.

\begin{tabular}{|l|c|l|}
\hline Name & Value & Unit \\
\hline Materials/fuels & 564.565 & $\mathrm{~g}$ \\
\hline Lead, primary & 686.634 & $\mathrm{~g}$ \\
\hline Nitric acid, 50\% in $\mathrm{H}_{2} \mathrm{O}$ & 305.706 & $\mathrm{~g}$ \\
\hline Potassium hydroxide & 435.435 & $\mathrm{~g}$ \\
\hline Bromine & $4 \mathrm{E}-10$ & $\mathrm{p}$ \\
\hline Chemical plant, organics & \multicolumn{2}{|l|}{} \\
\hline Electricity/heat & 143.7 & $\mathrm{kWh}$ \\
\hline Electricity, low voltage & \multicolumn{2}{|l|}{} \\
\hline Emissions to air & 8.174 & $\mathrm{~g}$ \\
\hline Hydrogen & \multicolumn{2}{|l|}{} \\
\hline Emissions to water & 49.045 & $\mathrm{~g}$ \\
\hline Water & 545.483 & $\mathrm{~g}$ \\
\hline Nitric acid & 343.317 & $\mathrm{~g}$ \\
\hline Potassium bicarbonate & & \\
\hline
\end{tabular}




\subsection{Economic indicators}

The economic analysis was performed to support the information provided by the environmental analysis. In this analysis, prices of reagents and solvents were obtained from the most economical retail prices found in October 2017, which are described in Table S23.

Table S23. Economic indicators of the reagents, solvents and electricity.

\begin{tabular}{|l|c|c|}
\hline Economic indicator (reference unit) & Price $(\boldsymbol{\epsilon})$ & Supplier \\
\hline Electricity $(1 \mathrm{MJ})$ & 0.036 & Spanish network cost \\
\hline Caesium iodide $(1 \mathrm{~kg})$ & 480.00 & abcr \\
\hline Formamidinium iodide $(1 \mathrm{~kg})$ & 2299.49 & Dyesol \\
\hline Methylammonium Bromide $(1 \mathrm{~kg})$ & 879.76 & Dyesol \\
\hline Methylammonium lodide $(1 \mathrm{~kg})$ & 763.86 & Dyesol \\
\hline Lead Bromide $(1 \mathrm{~kg})$ & 199.80 & Sigma Aldrich \\
\hline Lead lodide $(1 \mathrm{~kg})$ & 1246.00 & Sigma Aldrich \\
\hline N,N-dimethylformamide $(1 \mathrm{~kg})$ & 18.05 & Right Price Chemicals \\
\hline Dimethyl sulfoxide $(1 \mathrm{~kg})$ & 42.60 & Sigma Aldrich \\
\hline Chlorobenzene $(1 \mathrm{~kg})$ & 7.00 & $\begin{array}{c}\text { Noah Technologies } \\
\text { Corporation }\end{array}$ \\
\hline Butyrolactone $(1 \mathrm{~kg})$ & 23.85 & Sigma Aldrich \\
\hline
\end{tabular}




\section{Results}

Absolute results sorted into types of flow for $0 \%$ caesium perovskite (Table S24), 5\% caesium perovskite (Table S25), 10\% caesium perovskite (Table S26), 15\% caesium perovskite (Table S27) and canonical perovskite (Table S28).

Table S24. Impact results of $0 \%$ caesium perovskite sorted by flows.

\begin{tabular}{|c|c|c|c|c|c|c|}
\hline & $\begin{array}{l}\text { ADP (kg } \\
\text { Sb eq) }\end{array}$ & ADPF (MJ) & $\begin{array}{l}\text { GWP (kg } \\
\mathrm{CO}_{2} \text { eq) }\end{array}$ & $\begin{array}{l}\text { ODP (kg } \\
\text { CFC-11 eq) }\end{array}$ & $\begin{array}{l}\mathrm{POP}(\mathrm{kg} \\
\mathrm{C}_{2} \mathrm{H}_{4} \text { eq) }\end{array}$ & $\begin{array}{l}\mathrm{AP}\left(\mathrm{kg} \mathrm{SO} \mathrm{S}_{2}\right. \\
\text { eq) }\end{array}$ \\
\hline Total & $3.83 E-09$ & 4.49E-03 & $3.41 \mathrm{E}-04$ & $2.10 \mathrm{E}-11$ & $9.16 \mathrm{E}-08$ & $1.64 \mathrm{E}-06$ \\
\hline Reagents & $3.23 \mathrm{E}-09$ & $2.10 \mathrm{E}-04$ & $1.64 \mathrm{E}-05$ & $9.14 \mathrm{E}-13$ & $1.16 \mathrm{E}-08$ & 8.37E-08 \\
\hline Csl & $0.00 \mathrm{E}+00$ & $0.00 \mathrm{E}+00$ & $0.00 E+00$ & $0.00 \mathrm{E}+00$ & $0.00 \mathrm{E}+00$ & $0.00 \mathrm{E}+00$ \\
\hline FAI & 8.99E-10 & 7.37E-05 & 5.57E-06 & $3.27 \mathrm{E}-13$ & $9.03 \mathrm{E}-09$ & $2.91 \mathrm{E}-08$ \\
\hline $\mathrm{MABr}$ & $2.10 \mathrm{E}-11$ & $6.77 \mathrm{E}-06$ & $5.18 \mathrm{E}-07$ & $2.92 \mathrm{E}-14$ & $5.31 \mathrm{E}-10$ & $2.48 \mathrm{E}-09$ \\
\hline $\mathrm{Pbl}_{2}$ & 2.19E-09 & $1.08 \mathrm{E}-04$ & $8.61 \mathrm{E}-06$ & $4.66 \mathrm{E}-13$ & $1.73 \mathrm{E}-09$ & $4.34 \mathrm{E}-08$ \\
\hline $\mathrm{PbBr}_{2}$ & $1.24 \mathrm{E}-10$ & 2.17E-05 & $1.74 \mathrm{E}-06$ & $9.11 \mathrm{E}-14$ & $3.48 \mathrm{E}-10$ & 8.77E-09 \\
\hline Solvents & $5.91 \mathrm{E}-11$ & $2.74 \mathrm{E}-04$ & $1.08 \mathrm{E}-05$ & 4.47E-12 & $1.96 \mathrm{E}-08$ & $4.52 \mathrm{E}-08$ \\
\hline DMF & $5.85 \mathrm{E}-12$ & $3.87 \mathrm{E}-05$ & $1.48 \mathrm{E}-06$ & $2.45 \mathrm{E}-13$ & $4.53 \mathrm{E}-10$ & $6.57 \mathrm{E}-09$ \\
\hline DMSO & $2.50 \mathrm{E}-11$ & $9.80 \mathrm{E}-06$ & $2.99 \mathrm{E}-07$ & $4.42 \mathrm{E}-14$ & $6.36 \mathrm{E}-11$ & $7.75 \mathrm{E}-10$ \\
\hline CB & $2.82 \mathrm{E}-11$ & $2.26 \mathrm{E}-04$ & 8.99E-06 & $4.18 \mathrm{E}-12$ & $1.91 \mathrm{E}-08$ & $3.78 \mathrm{E}-08$ \\
\hline $\begin{array}{l}\text { Process } \\
\text { outputs }\end{array}$ & $0.00 \mathrm{E}+00$ & $0.00 \mathrm{E}+00$ & $0.00 \mathrm{E}+00$ & $0.00 \mathrm{E}+00$ & $0.00 \mathrm{E}+00$ & $0.00 \mathrm{E}+00$ \\
\hline $\begin{array}{l}\text { Emissions - } \\
\text { DMF }\end{array}$ & $0.00 \mathrm{E}+00$ & $0.00 \mathrm{E}+00$ & $0.00 \mathrm{E}+00$ & $0.00 \mathrm{E}+00$ & $0.00 \mathrm{E}+00$ & $0.00 \mathrm{E}+00$ \\
\hline $\begin{array}{l}\text { Emissions - } \\
\text { DMSO }\end{array}$ & $0.00 \mathrm{E}+00$ & $0.00 \mathrm{E}+00$ & $0.00 \mathrm{E}+00$ & $0.00 \mathrm{E}+00$ & $0.00 \mathrm{E}+00$ & $0.00 \mathrm{E}+00$ \\
\hline Emissions - CB & $0.00 \mathrm{E}+00$ & $0.00 \mathrm{E}+00$ & $0.00 \mathrm{E}+00$ & $0.00 \mathrm{E}+00$ & $0.00 \mathrm{E}+00$ & $0.00 \mathrm{E}+00$ \\
\hline $\begin{array}{l}\text { Transport, } \\
\text { lorry }>16 \mathrm{t}\end{array}$ & $9.75 E-13$ & 5.31E-06 & $3.60 \mathrm{E}-07$ & $5.82 \mathrm{E}-14$ & $5.86 \mathrm{E}-11$ & $1.96 \mathrm{E}-09$ \\
\hline $\begin{array}{l}\text { Electricity, low } \\
\text { voltage }\end{array}$ & $5.40 \mathrm{E}-10$ & $4.00 \mathrm{E}-03$ & $3.13 E-04$ & $1.55 \mathrm{E}-11$ & $6.03 E-08$ & $1.51 \mathrm{E}-06$ \\
\hline
\end{tabular}


Chapter 4

Table S24 Bis. Impact results of $0 \%$ caesium perovskite sorted by flows.

\begin{tabular}{lccccc}
\hline & $\begin{array}{c}\text { EP (kg PO } \\
\text { eq) }\end{array}$ & CED (MJ) & HTC (CTUh) & HTNC (CTUh) & FET (CTUe) \\
\hline Total & $1.18 \mathrm{E}-06$ & $7.88 \mathrm{E}-03$ & $3.20 \mathrm{E}-11$ & $1.32 \mathrm{E}-10$ & $3.16 \mathrm{E}-03$ \\
\hline Reagents & $5.57 \mathrm{E}-08$ & $3.65 \mathrm{E}-04$ & $1.49 \mathrm{E}-12$ & $7.38 \mathrm{E}-12$ & $1.51 \mathrm{E}-04$ \\
\hline $\mathrm{Csl}$ & $0.00 \mathrm{E}+00$ & $0.00 \mathrm{E}+00$ & $0.00 \mathrm{E}+00$ & $0.00 \mathrm{E}+00$ & $0.00 \mathrm{E}+00$ \\
$\mathrm{FAl}$ & $1.76 \mathrm{E}-08$ & $1.26 \mathrm{E}-04$ & $4.93 \mathrm{E}-13$ & $2.04 \mathrm{E}-12$ & $4.89 \mathrm{E}-05$ \\
$\mathrm{MABr}$ & $1.60 \mathrm{E}-09$ & $1.18 \mathrm{E}-05$ & $4.66 \mathrm{E}-14$ & $1.91 \mathrm{E}-13$ & $4.49 \mathrm{E}-06$ \\
Pbl 2 & $3.03 \mathrm{E}-08$ & $1.89 \mathrm{E}-04$ & $7.86 \mathrm{E}-13$ & $4.28 \mathrm{E}-12$ & $8.07 \mathrm{E}-05$ \\
PbBr & $6.18 \mathrm{E}-09$ & $3.83 \mathrm{E}-05$ & $1.60 \mathrm{E}-13$ & $8.72 \mathrm{E}-13$ & $1.64 \mathrm{E}-05$ \\
\hline Solvents & $1.19 \mathrm{E}-07$ & $3.19 \mathrm{E}-04$ & $7.25 \mathrm{E}-13$ & $3.99 \mathrm{E}-12$ & $1.99 \mathrm{E}-04$ \\
\hline $\begin{array}{l}\text { DMF } \\
\text { DMSO }\end{array}$ & $7.10 \mathrm{E}-08$ & $4.49 \mathrm{E}-05$ & $8.52 \mathrm{E}-14$ & $4.17 \mathrm{E}-13$ & $9.34 \mathrm{E}-06$ \\
CB & $4.44 \mathrm{E}-10$ & $1.07 \mathrm{E}-05$ & $1.47 \mathrm{E}-14$ & $7.21 \mathrm{E}-14$ & $1.58 \mathrm{E}-06$ \\
\hline $\begin{array}{l}\text { Process } \\
\text { outputs }\end{array}$ & $4.74 \mathrm{E}-08$ & $2.63 \mathrm{E}-04$ & $6.26 \mathrm{E}-13$ & $3.50 \mathrm{E}-12$ & $1.88 \mathrm{E}-04$ \\
\hline $\begin{array}{l}\text { Emissions - } \\
\text { DMF }\end{array}$ & $0.00 \mathrm{E}+00$ & $0.00 \mathrm{E}+00$ & $4.66 \mathrm{E}-13$ & $1.93 \mathrm{E}-12$ & $4.00 \mathrm{E}-06$ \\
$\begin{array}{l}\text { Emissions - } \\
\text { DMSO }\end{array}$ & $0.00 \mathrm{E}+00$ & $0.00 \mathrm{E}+00$ & $0.00 \mathrm{E}+00$ & $1.45 \mathrm{E}-12$ & $2.37 \mathrm{E}-07$ \\
Emissions - CB & $0.00 \mathrm{E}+00$ & $0.00 \mathrm{E}+00$ & $0.00 \mathrm{E}+00$ & $0.00 \mathrm{E}+00$ & $9.08 \mathrm{E}-09$ \\
\hline $\begin{array}{l}\text { Transport, } \\
\text { lorry }>16 \mathrm{t}\end{array}$ & $0.00 \mathrm{E}+00$ & $0.00 \mathrm{E}+00$ & $4.66 \mathrm{E}-13$ & $4.84 \mathrm{E}-13$ & $3.76 \mathrm{E}-06$ \\
\hline $\begin{array}{l}\text { Electricity, low } \\
\text { voltage }\end{array}$ & $1.00 \mathrm{E}-06$ & $7.19 \mathrm{E}-03$ & $2.93 \mathrm{E}-11$ & $1.18 \mathrm{E}-10$ & $2.81 \mathrm{E}-03$ \\
\hline
\end{tabular}


Evaluation of multiple cation/anion perovskite solar cells through life cycle assessment

Table S25. Impact results of $\mathbf{5 \%}$ caesium perovskite sorted by flows.

\begin{tabular}{|c|c|c|c|c|c|c|}
\hline & $\begin{array}{l}\text { ADP (kg } \\
\text { Sb eq) }\end{array}$ & ADPF (MJ) & $\begin{array}{l}\text { GWP (kg } \\
\mathrm{CO}_{2} \text { eq) }\end{array}$ & $\begin{array}{l}\text { ODP (kg } \\
\text { CFC-11 eq) }\end{array}$ & $\begin{array}{l}\text { POP (kg } \\
\mathrm{C}_{2} \mathrm{H}_{4} \text { eq) }\end{array}$ & $\begin{array}{l}\mathrm{AP}\left(\mathrm{kg} \mathrm{SO} \mathrm{SO}_{2}\right. \\
\text { eq) }\end{array}$ \\
\hline Total & $3.83 \mathrm{E}-09$ & 4.49E-03 & $3.40 \mathrm{E}-04$ & $2.10 \mathrm{E}-11$ & $9.11 \mathrm{E}-08$ & $1.64 \mathrm{E}-06$ \\
\hline Reagents & $3.23 \mathrm{E}-09$ & $2.06 \mathrm{E}-04$ & $1.61 \mathrm{E}-05$ & $8.98 \mathrm{E}-13$ & $1.12 \mathrm{E}-08$ & $8.24 \mathrm{E}-08$ \\
\hline CsI & $5.36 \mathrm{E}-11$ & $2.21 \mathrm{E}-07$ & $1.66 \mathrm{E}-08$ & 2.57E-15 & $9.78 \mathrm{E}-12$ & 2.27E-10 \\
\hline FAI & $8.54 \mathrm{E}-10$ & $7.00 \mathrm{E}-05$ & $5.29 \mathrm{E}-06$ & $3.11 \mathrm{E}-13$ & $8.58 \mathrm{E}-09$ & $2.76 \mathrm{E}-08$ \\
\hline $\mathrm{MABr}$ & $2.00 \mathrm{E}-11$ & $6.43 \mathrm{E}-06$ & $4.92 \mathrm{E}-07$ & $2.78 \mathrm{E}-14$ & $5.05 \mathrm{E}-10$ & $2.35 \mathrm{E}-09$ \\
\hline $\mathrm{Pbl}_{2}$ & 2.17E-09 & 1.07E-04 & $8.56 \mathrm{E}-06$ & $4.64 \mathrm{E}-13$ & $1.72 \mathrm{E}-09$ & 4.32E-08 \\
\hline $\mathrm{PbBr}_{2}$ & $1.27 \mathrm{E}-10$ & $2.23 \mathrm{E}-05$ & $1.78 \mathrm{E}-06$ & $9.34 \mathrm{E}-14$ & $3.57 \mathrm{E}-10$ & 8.99E-09 \\
\hline Solvents & $5.87 \mathrm{E}-11$ & $2.74 \mathrm{E}-04$ & $1.08 \mathrm{E}-05$ & 4.47E-12 & $1.96 \mathrm{E}-08$ & $4.51 \mathrm{E}-08$ \\
\hline DMF & $5.79 \mathrm{E}-12$ & $3.83 \mathrm{E}-05$ & 1.47E-06 & $2.43 \mathrm{E}-13$ & 4.49E-10 & $6.50 \mathrm{E}-09$ \\
\hline DMSO & $2.47 \mathrm{E}-11$ & $9.70 \mathrm{E}-06$ & $2.96 \mathrm{E}-07$ & $4.38 \mathrm{E}-14$ & $6.30 \mathrm{E}-11$ & $7.67 \mathrm{E}-10$ \\
\hline CB & $2.82 \mathrm{E}-11$ & $2.26 \mathrm{E}-04$ & 8.99E-06 & $4.18 \mathrm{E}-12$ & $1.91 \mathrm{E}-08$ & $3.78 \mathrm{E}-08$ \\
\hline $\begin{array}{l}\text { Process } \\
\text { outputs }\end{array}$ & $0.00 \mathrm{E}+00$ & $0.00 E+00$ & $0.00 \mathrm{E}+00$ & $0.00 E+00$ & $0.00 \mathrm{E}+00$ & $0.00 E+00$ \\
\hline $\begin{array}{l}\text { Emissions - } \\
\text { DMF }\end{array}$ & $0.00 \mathrm{E}+00$ & $0.00 \mathrm{E}+00$ & $0.00 \mathrm{E}+00$ & $0.00 \mathrm{E}+00$ & $0.00 E+00$ & $0.00 \mathrm{E}+00$ \\
\hline $\begin{array}{l}\text { Emissions - } \\
\text { DMSO }\end{array}$ & $0.00 \mathrm{E}+00$ & $0.00 \mathrm{E}+00$ & $0.00 \mathrm{E}+00$ & $0.00 \mathrm{E}+00$ & $0.00 \mathrm{E}+00$ & $0.00 \mathrm{E}+00$ \\
\hline Emissions - $\mathrm{CB}$ & $0.00 E+00$ & $0.00 E+00$ & $0.00 \mathrm{E}+00$ & $0.00 E+00$ & $0.00 E+00$ & $0.00 \mathrm{E}+00$ \\
\hline $\begin{array}{l}\text { Transport, } \\
\text { lorry >16t }\end{array}$ & $9.73 \mathrm{E}-13$ & $5.30 \mathrm{E}-06$ & $3.59 \mathrm{E}-07$ & $5.81 \mathrm{E}-14$ & $5.85 \mathrm{E}-11$ & $1.95 \mathrm{E}-09$ \\
\hline $\begin{array}{l}\text { Electricity, low } \\
\text { voltage }\end{array}$ & $5.40 \mathrm{E}-10$ & $4.00 \mathrm{E}-03$ & $3.13 E-04$ & $1.55 \mathrm{E}-11$ & $6.03 E-08$ & $1.51 \mathrm{E}-06$ \\
\hline
\end{tabular}


Chapter 4

Table S25 Bis. Impact results of 5\% caesium perovskite sorted by flows.

\begin{tabular}{lccccc}
\hline & $\begin{array}{c}\text { EP (kg PO } \\
\text { eq) }\end{array}$ & CED (MJ) & HTC (CTUh) & HTNC (CTUh) & FET (CTUe) \\
\hline Total & $1.18 \mathrm{E}-06$ & $7.87 \mathrm{E}-03$ & $3.20 \mathrm{E}-11$ & $1.32 \mathrm{E}-10$ & $3.16 \mathrm{E}-03$ \\
\hline Reagents & $5.47 \mathrm{E}-08$ & $3.58 \mathrm{E}-04$ & $1.46 \mathrm{E}-12$ & $7.27 \mathrm{E}-12$ & $1.48 \mathrm{E}-04$ \\
\hline $\mathrm{Csl}$ & $1.39 \mathrm{E}-11$ & $2.38 \mathrm{E}-07$ & $4.35 \mathrm{E}-16$ & $3.24 \mathrm{E}-15$ & $5.94 \mathrm{E}-08$ \\
$\mathrm{FAl}$ & $1.67 \mathrm{E}-08$ & $1.20 \mathrm{E}-04$ & $4.69 \mathrm{E}-13$ & $1.94 \mathrm{E}-12$ & $4.65 \mathrm{E}-05$ \\
$\mathrm{MABr}$ & $1.52 \mathrm{E}-09$ & $1.12 \mathrm{E}-05$ & $4.43 \mathrm{E}-14$ & $1.81 \mathrm{E}-13$ & $4.27 \mathrm{E}-06$ \\
Pbl & $3.02 \mathrm{E}-08$ & $1.88 \mathrm{E}-04$ & $7.82 \mathrm{E}-13$ & $4.26 \mathrm{E}-12$ & $8.03 \mathrm{E}-05$ \\
PbBr & $6.34 \mathrm{E}-09$ & $3.93 \mathrm{E}-05$ & $1.64 \mathrm{E}-13$ & $8.94 \mathrm{E}-13$ & $1.68 \mathrm{E}-05$ \\
\hline Solvents & $1.18 \mathrm{E}-07$ & $3.18 \mathrm{E}-04$ & $7.24 \mathrm{E}-13$ & $3.98 \mathrm{E}-12$ & $1.99 \mathrm{E}-04$ \\
\hline $\begin{array}{l}\text { DMF } \\
\text { DMSO }\end{array}$ & $7.03 \mathrm{E}-08$ & $4.44 \mathrm{E}-05$ & $8.43 \mathrm{E}-14$ & $4.13 \mathrm{E}-13$ & $9.25 \mathrm{E}-06$ \\
CB & $4.39 \mathrm{E}-10$ & $1.06 \mathrm{E}-05$ & $1.46 \mathrm{E}-14$ & $7.14 \mathrm{E}-14$ & $1.56 \mathrm{E}-06$ \\
\hline $\begin{array}{l}\text { Process } \\
\text { outputs }\end{array}$ & $4.74 \mathrm{E}-08$ & $2.63 \mathrm{E}-04$ & $6.26 \mathrm{E}-13$ & $3.50 \mathrm{E}-12$ & $1.88 \mathrm{E}-04$ \\
\hline $\begin{array}{l}\text { Emissions - } \\
\text { DMF }\end{array}$ & $0.00 \mathrm{E}+00$ & $0.00 \mathrm{E}+00$ & $4.66 \mathrm{E}-13$ & $1.92 \mathrm{E}-12$ & $4.00 \mathrm{E}-06$ \\
$\begin{array}{l}\text { Emissions - } \\
\text { DMSO }\end{array}$ & $0.00 \mathrm{E}+00$ & $0.00 \mathrm{E}+00$ & $0.00 \mathrm{E}+00$ & $1.43 \mathrm{E}-12$ & $2.34 \mathrm{E}-07$ \\
Emissions - CB & $0.00 \mathrm{E}+00$ & $0.00 \mathrm{E}+00$ & $0.00 \mathrm{E}+00$ & $0.00 \mathrm{E}+00$ & $8.98 \mathrm{E}-09$ \\
\hline $\begin{array}{l}\text { Transport, } \\
\text { lorry }>16 \mathrm{t}\end{array}$ & $0.00 \mathrm{E}+00$ & $0.00 \mathrm{E}+00$ & $4.66 \mathrm{E}-13$ & $4.84 \mathrm{E}-13$ & $3.76 \mathrm{E}-06$ \\
\hline $\begin{array}{l}\text { Electricity, low } \\
\text { voltage }\end{array}$ & $1.00 \mathrm{E}-06$ & $7.19 \mathrm{E}-03$ & $2.93 \mathrm{E}-11$ & $1.18 \mathrm{E}-10$ & $2.81 \mathrm{E}-03$ \\
\hline
\end{tabular}


Evaluation of multiple cation/anion perovskite solar cells through life cycle assessment

Table S26. Impact results of $\mathbf{1 0 \%}$ caesium perovskite sorted by flows.

\begin{tabular}{|c|c|c|c|c|c|c|}
\hline & $\begin{array}{l}\text { ADP (kg } \\
\text { Sb eq) }\end{array}$ & ADPF (MJ) & $\begin{array}{l}\text { GWP (kg } \\
\mathrm{CO}_{2} \text { eq) }\end{array}$ & $\begin{array}{l}\text { ODP (kg } \\
\text { CFC-11 eq) }\end{array}$ & $\begin{array}{l}\text { POP (kg } \\
\mathrm{C}_{2} \mathrm{H}_{4} \text { eq) }\end{array}$ & $\begin{array}{l}\mathrm{AP}\left(\mathrm{kg} \mathrm{SO} \mathrm{SO}_{2}\right. \\
\text { eq) }\end{array}$ \\
\hline Total & $3.83 \mathrm{E}-09$ & $4.48 \mathrm{E}-03$ & $3.40 \mathrm{E}-04$ & $2.09 \mathrm{E}-11$ & $9.07 \mathrm{E}-08$ & $1.64 \mathrm{E}-06$ \\
\hline Reagents & $3.23 E-09$ & $2.02 \mathrm{E}-04$ & $1.59 \mathrm{E}-05$ & $8.83 E-13$ & $1.07 \mathrm{E}-08$ & $8.10 \mathrm{E}-08$ \\
\hline Csl & $1.07 \mathrm{E}-10$ & $4.41 \mathrm{E}-07$ & $3.33 E-08$ & $5.15 E-15$ & $1.96 \mathrm{E}-11$ & $4.54 \mathrm{E}-10$ \\
\hline FAl & 8.09E-10 & $6.64 \mathrm{E}-05$ & $5.01 \mathrm{E}-06$ & $2.95 \mathrm{E}-13$ & 8.13E-09 & $2.62 \mathrm{E}-08$ \\
\hline $\mathrm{MABr}$ & $1.89 \mathrm{E}-11$ & $6.09 \mathrm{E}-06$ & 4.66E-07 & $2.63 \mathrm{E}-14$ & $4.78 \mathrm{E}-10$ & $2.23 \mathrm{E}-09$ \\
\hline $\mathrm{Pbl}_{2}$ & $2.16 \mathrm{E}-09$ & 1.07E-04 & $8.52 \mathrm{E}-06$ & $4.61 \mathrm{E}-13$ & 1.71E-09 & 4.30E-08 \\
\hline $\mathrm{PbBr}_{2}$ & $1.30 \mathrm{E}-10$ & $2.28 \mathrm{E}-05$ & $1.82 \mathrm{E}-06$ & $9.56 \mathrm{E}-14$ & $3.66 \mathrm{E}-10$ & $9.21 \mathrm{E}-09$ \\
\hline Solvents & $5.84 \mathrm{E}-11$ & $2.73 \mathrm{E}-04$ & $1.07 E-05$ & $4.46 \mathrm{E}-12$ & $1.96 \mathrm{E}-08$ & $4.50 \mathrm{E}-08$ \\
\hline DMF & $5.73 \mathrm{E}-12$ & $3.79 \mathrm{E}-05$ & $1.45 \mathrm{E}-06$ & $2.40 \mathrm{E}-13$ & $4.44 \mathrm{E}-10$ & $6.43 \mathrm{E}-09$ \\
\hline DMSO & $2.45 \mathrm{E}-11$ & $9.60 \mathrm{E}-06$ & 2.93E-07 & $4.33 \mathrm{E}-14$ & $6.23 \mathrm{E}-11$ & $7.59 \mathrm{E}-10$ \\
\hline CB & $2.82 \mathrm{E}-11$ & $2.26 \mathrm{E}-04$ & 8.99E-06 & $4.18 \mathrm{E}-12$ & $1.91 \mathrm{E}-08$ & $3.78 \mathrm{E}-08$ \\
\hline $\begin{array}{l}\text { Process } \\
\text { outputs }\end{array}$ & $0.00 E+00$ & $0.00 E+00$ & $0.00 \mathrm{E}+00$ & $0.00 E+00$ & $0.00 E+00$ & $0.00 \mathrm{E}+00$ \\
\hline $\begin{array}{l}\text { Emissions - } \\
\text { DMF }\end{array}$ & $0.00 \mathrm{E}+00$ & $0.00 \mathrm{E}+00$ & $0.00 \mathrm{E}+00$ & $0.00 \mathrm{E}+00$ & $0.00 E+00$ & $0.00 E+00$ \\
\hline $\begin{array}{l}\text { Emissions - } \\
\text { DMSO }\end{array}$ & $0.00 \mathrm{E}+00$ & $0.00 \mathrm{E}+00$ & $0.00 \mathrm{E}+00$ & $0.00 \mathrm{E}+00$ & $0.00 \mathrm{E}+00$ & $0.00 \mathrm{E}+00$ \\
\hline Emissions - CB & $0.00 E+00$ & $0.00 E+00$ & $0.00 \mathrm{E}+00$ & $0.00 E+00$ & $0.00 E+00$ & $0.00 \mathrm{E}+00$ \\
\hline $\begin{array}{l}\text { Transport, } \\
\text { lorry }>16 \mathrm{t}\end{array}$ & $9.71 \mathrm{E}-13$ & $5.28 \mathrm{E}-06$ & $3.58 \mathrm{E}-07$ & $5.79 \mathrm{E}-14$ & $5.83 \mathrm{E}-11$ & $1.95 \mathrm{E}-09$ \\
\hline $\begin{array}{l}\text { Electricity, low } \\
\text { voltage }\end{array}$ & $5.40 \mathrm{E}-10$ & $4.00 \mathrm{E}-03$ & $3.13 E-04$ & $1.55 \mathrm{E}-11$ & $6.03 E-08$ & $1.51 \mathrm{E}-06$ \\
\hline
\end{tabular}


Chapter 4

Table S26 Bis. Impact results of $10 \%$ caesium perovskite sorted by flows.

\begin{tabular}{lccccc}
\hline & $\begin{array}{c}\text { EP (kg PO } \\
\text { eq) }\end{array}$ & CED (MJ) & HTC (CTUh) & HTNC (CTUh) & FET (CTUe) \\
\hline Total & $1.18 \mathrm{E}-06$ & $7.86 \mathrm{E}-03$ & $3.19 \mathrm{E}-11$ & $1.32 \mathrm{E}-10$ & $3.16 \mathrm{E}-03$ \\
\hline Reagents & $5.38 \mathrm{E}-08$ & $3.52 \mathrm{E}-04$ & $1.43 \mathrm{E}-12$ & $7.17 \mathrm{E}-12$ & $1.45 \mathrm{E}-04$ \\
\hline Csl & $2.78 \mathrm{E}-11$ & $4.76 \mathrm{E}-07$ & $8.70 \mathrm{E}-16$ & $6.48 \mathrm{E}-15$ & $1.19 \mathrm{E}-07$ \\
$\mathrm{FAl}$ & $1.58 \mathrm{E}-08$ & $1.14 \mathrm{E}-04$ & $4.44 \mathrm{E}-13$ & $1.83 \mathrm{E}-12$ & $4.40 \mathrm{E}-05$ \\
$\mathrm{MABr}$ & $1.44 \mathrm{E}-09$ & $1.06 \mathrm{E}-05$ & $4.19 \mathrm{E}-14$ & $1.72 \mathrm{E}-13$ & $4.05 \mathrm{E}-06$ \\
$\mathrm{PbI}_{2}$ & $3.00 \mathrm{E}-08$ & $1.87 \mathrm{E}-04$ & $7.78 \mathrm{E}-13$ & $4.24 \mathrm{E}-12$ & $7.99 \mathrm{E}-05$ \\
PbBr${ }_{2}$ & $6.49 \mathrm{E}-09$ & $4.02 \mathrm{E}-05$ & $1.68 \mathrm{E}-13$ & $9.15 \mathrm{E}-13$ & $1.73 \mathrm{E}-05$ \\
\hline Solvents & $1.17 \mathrm{E}-07$ & $3.18 \mathrm{E}-04$ & $7.23 \mathrm{E}-13$ & $3.98 \mathrm{E}-12$ & $1.99 \mathrm{E}-04$ \\
\hline $\begin{array}{l}\text { DMF } \\
\text { DMSO }\end{array}$ & $6.95 \mathrm{E}-08$ & $4.40 \mathrm{E}-05$ & $8.34 \mathrm{E}-14$ & $4.09 \mathrm{E}-13$ & $9.15 \mathrm{E}-06$ \\
CB & $4.35 \mathrm{E}-10$ & $1.05 \mathrm{E}-05$ & $1.44 \mathrm{E}-14$ & $7.07 \mathrm{E}-14$ & $1.55 \mathrm{E}-06$ \\
\hline $\begin{array}{l}\text { Process } \\
\text { outputs }\end{array}$ & $4.74 \mathrm{E}-08$ & $2.63 \mathrm{E}-04$ & $6.26 \mathrm{E}-13$ & $3.50 \mathrm{E}-12$ & $1.88 \mathrm{E}-04$ \\
\hline $\begin{array}{l}\text { Emissions - } \\
\text { DMF }\end{array}$ & $0.00 \mathrm{E}+00$ & $0.00 \mathrm{E}+00$ & $4.66 \mathrm{E}-13$ & $1.90 \mathrm{E}-12$ & $4.00 \mathrm{E}-06$ \\
\hline $\begin{array}{l}\text { Emissions - } \\
\text { DMSO }\end{array}$ & $0.00 \mathrm{E}+00$ & $0.00 \mathrm{E}+00$ & $0.00 \mathrm{E}+00$ & $1.42 \mathrm{E}-12$ & $2.32 \mathrm{E}-07$ \\
Emissions - CB & $0.00 \mathrm{E}+00$ & $0.00 \mathrm{E}+00$ & $0.00 \mathrm{E}+00$ & $0.00 \mathrm{E}+00$ & $8.89 \mathrm{E}-09$ \\
\hline $\begin{array}{l}\text { Transport, } \\
\text { lorry }>16 \mathrm{t}\end{array}$ & $0.00 \mathrm{E}+00$ & $0.00 \mathrm{E}+00$ & $4.66 \mathrm{E}-13$ & $4.84 \mathrm{E}-13$ & $3.76 \mathrm{E}-06$ \\
\hline $\begin{array}{l}\text { Electricity, low } \\
\text { voltage }\end{array}$ & $1.00 \mathrm{E}-06$ & $7.19 \mathrm{E}-03$ & $2.93 \mathrm{E}-11$ & $1.18 \mathrm{E}-10$ & $2.81 \mathrm{E}-03$ \\
\hline
\end{tabular}


Evaluation of multiple cation/anion perovskite solar cells through life cycle assessment

Table S27. Impact results of $15 \%$ caesium perovskite sorted by flows.

\begin{tabular}{|c|c|c|c|c|c|c|}
\hline & $\begin{array}{l}\text { ADP (kg } \\
\text { Sb eq) }\end{array}$ & ADPF (MJ) & $\begin{array}{l}\text { GWP (kg } \\
\mathrm{CO}_{2} \text { eq) }\end{array}$ & $\begin{array}{l}\text { ODP (kg } \\
\text { CFC-11 eq) }\end{array}$ & $\begin{array}{l}\text { POP (kg } \\
\mathrm{C}_{2} \mathrm{H}_{4} \text { eq) }\end{array}$ & $\begin{array}{l}\mathrm{AP}\left(\mathrm{kg} \mathrm{SO} \mathrm{SO}_{2}\right. \\
\text { eq) }\end{array}$ \\
\hline Total & $3.83 \mathrm{E}-09$ & $4.48 \mathrm{E}-03$ & $3.40 \mathrm{E}-04$ & $2.09 \mathrm{E}-11$ & $9.02 \mathrm{E}-08$ & $1.63 \mathrm{E}-06$ \\
\hline Reagents & $3.23 E-09$ & $1.99 E-04$ & $1.56 \mathrm{E}-05$ & $8.68 \mathrm{E}-13$ & $1.02 \mathrm{E}-08$ & 7.97E-08 \\
\hline Csl & $1.61 \mathrm{E}-10$ & $6.62 \mathrm{E}-07$ & 4.99E-08 & $7.72 \mathrm{E}-15$ & 2.93E-11 & $6.80 \mathrm{E}-10$ \\
\hline FAl & $7.64 \mathrm{E}-10$ & $6.27 \mathrm{E}-05$ & $4.74 \mathrm{E}-06$ & $2.78 \mathrm{E}-13$ & $7.68 \mathrm{E}-09$ & $2.47 \mathrm{E}-08$ \\
\hline $\mathrm{MABr}$ & 1.79E-11 & $5.75 \mathrm{E}-06$ & $4.40 \mathrm{E}-07$ & $2.49 \mathrm{E}-14$ & $4.52 \mathrm{E}-10$ & $2.11 \mathrm{E}-09$ \\
\hline $\mathrm{Pbl}_{2}$ & $2.15 \mathrm{E}-09$ & $1.06 \mathrm{E}-04$ & 8.47E-06 & $4.59 \mathrm{E}-13$ & 1.70E-09 & 4.27E-08 \\
\hline $\mathrm{PbBr}_{2}$ & $1.33 \mathrm{E}-10$ & $2.34 \mathrm{E}-05$ & $1.87 \mathrm{E}-06$ & $9.79 E-14$ & $3.74 \mathrm{E}-10$ & $9.43 \mathrm{E}-09$ \\
\hline Solvents & $5.81 \mathrm{E}-11$ & $2.73 \mathrm{E}-04$ & $1.07 E-05$ & $4.46 \mathrm{E}-12$ & $1.96 \mathrm{E}-08$ & 4.50E-08 \\
\hline DMF & $5.67 \mathrm{E}-12$ & $3.75 E-05$ & $1.44 \mathrm{E}-06$ & $2.38 \mathrm{E}-13$ & 4.39E-10 & $6.36 \mathrm{E}-09$ \\
\hline DMSO & $2.42 \mathrm{E}-11$ & $9.50 \mathrm{E}-06$ & $2.90 \mathrm{E}-07$ & 4.29E-14 & $6.17 E-11$ & $7.51 \mathrm{E}-10$ \\
\hline CB & $2.82 \mathrm{E}-11$ & $2.26 \mathrm{E}-04$ & 8.99E-06 & $4.18 \mathrm{E}-12$ & $1.91 \mathrm{E}-08$ & $3.78 \mathrm{E}-08$ \\
\hline $\begin{array}{l}\text { Process } \\
\text { outputs }\end{array}$ & $5.67 E-12$ & $3.75 E-05$ & $1.44 \mathrm{E}-06$ & $2.38 \mathrm{E}-13$ & $4.39 \mathrm{E}-10$ & $6.36 \mathrm{E}-09$ \\
\hline $\begin{array}{l}\text { Emissions - } \\
\text { DMF }\end{array}$ & $2.42 \mathrm{E}-11$ & $9.50 \mathrm{E}-06$ & $2.90 \mathrm{E}-07$ & $4.29 \mathrm{E}-14$ & $6.17 \mathrm{E}-11$ & $7.51 \mathrm{E}-10$ \\
\hline $\begin{array}{l}\text { Emissions - } \\
\text { DMSO }\end{array}$ & $2.82 \mathrm{E}-11$ & $2.26 \mathrm{E}-04$ & 8.99E-06 & $4.18 \mathrm{E}-12$ & $1.91 \mathrm{E}-08$ & $3.78 \mathrm{E}-08$ \\
\hline Emissions - CB & $5.67 \mathrm{E}-12$ & $3.75 E-05$ & $1.44 \mathrm{E}-06$ & $2.38 \mathrm{E}-13$ & $4.39 \mathrm{E}-10$ & $6.36 \mathrm{E}-09$ \\
\hline $\begin{array}{l}\text { Transport, } \\
\text { lorry >16t }\end{array}$ & $2.42 \mathrm{E}-11$ & $9.50 \mathrm{E}-06$ & $2.90 \mathrm{E}-07$ & $4.29 \mathrm{E}-14$ & $6.17 \mathrm{E}-11$ & $7.51 \mathrm{E}-10$ \\
\hline $\begin{array}{l}\text { Electricity, low } \\
\text { voltage }\end{array}$ & $5.40 \mathrm{E}-10$ & $4.00 \mathrm{E}-03$ & $3.13 \mathrm{E}-04$ & $1.55 \mathrm{E}-11$ & $6.03 \mathrm{E}-08$ & $1.51 \mathrm{E}-06$ \\
\hline
\end{tabular}


Chapter 4

Table S27 Bis. Impact results of $15 \%$ caesium perovskite sorted by flows.

\begin{tabular}{|c|c|c|c|c|c|}
\hline & $\begin{array}{c}\mathrm{EP}\left(\mathrm{kg} \mathrm{PO}_{4}{ }^{3-}\right. \\
\text { eq) }\end{array}$ & CED (MJ) & HTC (CTUh) & HTNC (CTUh) & FET (CTUe) \\
\hline Total & 1.17E-06 & $7.86 \mathrm{E}-03$ & 3.19E-11 & $1.31 \mathrm{E}-10$ & $3.15 \mathrm{E}-03$ \\
\hline Reagents & $5.29 E-08$ & $3.45 \mathrm{E}-04$ & $1.41 \mathrm{E}-12$ & $7.06 \mathrm{E}-12$ & $1.43 \mathrm{E}-04$ \\
\hline Csl & $4.16 \mathrm{E}-11$ & $7.14 \mathrm{E}-07$ & $1.30 \mathrm{E}-15$ & $9.72 \mathrm{E}-15$ & $1.78 \mathrm{E}-07$ \\
\hline FAI & $1.49 \mathrm{E}-08$ & 1.07E-04 & 4.19E-13 & $1.73 \mathrm{E}-12$ & $4.16 \mathrm{E}-05$ \\
\hline $\mathrm{MABr}$ & $1.36 \mathrm{E}-09$ & $1.00 \mathrm{E}-05$ & $3.96 \mathrm{E}-14$ & $1.62 \mathrm{E}-13$ & $3.82 \mathrm{E}-06$ \\
\hline $\mathrm{Pbl}_{2}$ & $2.99 \mathrm{E}-08$ & $1.86 \mathrm{E}-04$ & $7.74 \mathrm{E}-13$ & $4.22 \mathrm{E}-12$ & $7.95 \mathrm{E}-05$ \\
\hline $\mathrm{PbBr}_{2}$ & $6.65 \mathrm{E}-09$ & $4.12 \mathrm{E}-05$ & $1.72 \mathrm{E}-13$ & $9.37 \mathrm{E}-13$ & $1.77 \mathrm{E}-05$ \\
\hline Solvents & 1.17E-07 & 3.17E-04 & $7.22 \mathrm{E}-13$ & $3.97 \mathrm{E}-12$ & $1.99 \mathrm{E}-04$ \\
\hline DMF & $6.88 \mathrm{E}-08$ & $4.35 \mathrm{E}-05$ & $8.25 E-14$ & $4.04 \mathrm{E}-13$ & $9.05 \mathrm{E}-06$ \\
\hline DMSO & $4.30 \mathrm{E}-10$ & $1.03 \mathrm{E}-05$ & $1.43 \mathrm{E}-14$ & $6.99 \mathrm{E}-14$ & $1.53 \mathrm{E}-06$ \\
\hline $\mathrm{CB}$ & $4.74 \mathrm{E}-08$ & $2.63 \mathrm{E}-04$ & $6.26 \mathrm{E}-13$ & $3.50 \mathrm{E}-12$ & $1.88 \mathrm{E}-04$ \\
\hline $\begin{array}{l}\text { Process } \\
\text { outputs }\end{array}$ & $6.88 \mathrm{E}-08$ & 4.35E-05 & $8.25 \mathrm{E}-14$ & $4.04 \mathrm{E}-13$ & $9.05 \mathrm{E}-06$ \\
\hline $\begin{array}{l}\text { Emissions - } \\
\text { DMF }\end{array}$ & $4.30 \mathrm{E}-10$ & $1.03 \mathrm{E}-05$ & $1.43 \mathrm{E}-14$ & $6.99 \mathrm{E}-14$ & $1.53 \mathrm{E}-06$ \\
\hline $\begin{array}{l}\text { Emissions - } \\
\text { DMSO }\end{array}$ & $4.74 \mathrm{E}-08$ & $2.63 \mathrm{E}-04$ & $6.26 \mathrm{E}-13$ & $3.50 \mathrm{E}-12$ & $1.88 \mathrm{E}-04$ \\
\hline Emissions - $\mathrm{CB}$ & $6.88 \mathrm{E}-08$ & $4.35 \mathrm{E}-05$ & $8.25 \mathrm{E}-14$ & $4.04 \mathrm{E}-13$ & $9.05 E-06$ \\
\hline $\begin{array}{l}\text { Transport, } \\
\text { lorry }>16 \mathrm{t}\end{array}$ & $4.30 \mathrm{E}-10$ & $1.03 \mathrm{E}-05$ & $1.43 \mathrm{E}-14$ & $6.99 \mathrm{E}-14$ & $1.53 \mathrm{E}-06$ \\
\hline $\begin{array}{l}\text { Electricity, low } \\
\text { voltage }\end{array}$ & $1.00 \mathrm{E}-06$ & 7.19E-03 & $2.93 \mathrm{E}-11$ & $1.18 \mathrm{E}-10$ & $2.81 \mathrm{E}-03$ \\
\hline
\end{tabular}


Evaluation of multiple cation/anion perovskite solar cells through life cycle assessment

Table S28. Impact results of canonical perovskite sorted by flows.

\begin{tabular}{|c|c|c|c|c|c|c|}
\hline & $\begin{array}{l}\text { ADP (kg } \\
\text { Sb eq) }\end{array}$ & ADPF (MJ) & $\begin{array}{l}\text { GWP (kg } \\
\mathrm{CO}_{2} \text { eq) }\end{array}$ & $\begin{array}{l}\text { ODP (kg } \\
\text { CFC-11 eq) }\end{array}$ & $\begin{array}{l}\mathrm{POP}(\mathrm{kg} \\
\mathrm{C}_{2} \mathrm{H}_{4} \text { eq) }\end{array}$ & $\begin{array}{l}\mathrm{AP}\left(\mathrm{kg} \mathrm{SO}{ }_{2}\right. \\
\text { eq) }\end{array}$ \\
\hline Total & $3.75 \mathrm{E}-09$ & $1.06 \mathrm{E}-03$ & $8.24 \mathrm{E}-05$ & $4.23 \mathrm{E}-12$ & $2.25 \mathrm{E}-08$ & $3.97 \mathrm{E}-07$ \\
\hline Reagents & $3.63 \mathrm{E}-09$ & $1.63 \mathrm{E}-04$ & $1.29 \mathrm{E}-05$ & 7.17E-13 & 9.07E-09 & $6.44 \mathrm{E}-08$ \\
\hline MAI & $1.05 \mathrm{E}-09$ & $3.64 \mathrm{E}-05$ & $2.78 \mathrm{E}-06$ & $1.67 \mathrm{E}-13$ & 7.04E-09 & $1.33 \mathrm{E}-08$ \\
\hline $\mathrm{Pbl}_{2}$ & $2.58 \mathrm{E}-09$ & $1.27 \mathrm{E}-04$ & $1.01 \mathrm{E}-05$ & $5.50 \mathrm{E}-13$ & $2.04 \mathrm{E}-09$ & $5.12 \mathrm{E}-08$ \\
\hline Solvents (GBL) & $1.81 \mathrm{E}-12$ & $1.88 \mathrm{E}-05$ & $9.99 \mathrm{E}-07$ & $1.07 \mathrm{E}-13$ & $2.39 \mathrm{E}-10$ & 3.09E-09 \\
\hline $\begin{array}{l}\text { Process } \\
\text { outputs } \\
\text { (Emissions - } \\
\text { GBL) }\end{array}$ & $1.81 \mathrm{E}-12$ & $1.88 \mathrm{E}-05$ & $9.99 \mathrm{E}-07$ & $1.07 \mathrm{E}-13$ & $2.39 \mathrm{E}-10$ & $3.09 \mathrm{E}-09$ \\
\hline $\begin{array}{l}\text { Transport, } \\
\text { lorry }>16 \mathrm{t}\end{array}$ & $0.00 \mathrm{E}+00$ & $0.00 \mathrm{E}+00$ & $0.00 \mathrm{E}+00$ & $0.00 E+00$ & $0.00 \mathrm{E}+00$ & $0.00 \mathrm{E}+00$ \\
\hline $\begin{array}{l}\text { Electricity, low } \\
\text { voltage }\end{array}$ & $1.18 \mathrm{E}-10$ & $8.75 E-04$ & $6.85 \mathrm{E}-05$ & $3.40 \mathrm{E}-12$ & $1.32 \mathrm{E}-08$ & 3.30E-07 \\
\hline
\end{tabular}


Chapter 4

Table S28 Bis. Impact results of canonical perovskite sorted by flows.

\begin{tabular}{|c|c|c|c|c|c|}
\hline & $\begin{array}{c}\mathrm{EP}\left(\mathrm{kg} \mathrm{PO}_{4}{ }^{3-}\right. \\
\text { eq) }\end{array}$ & CED (MJ) & HTC (CTUh) & HTNC (CTUh) & FET (CTUe) \\
\hline Total & $2.65 \mathrm{E}-07$ & $1.88 \mathrm{E}-03$ & $7.62 \mathrm{E}-12$ & $3.21 \mathrm{E}-11$ & $7.46 \mathrm{E}-04$ \\
\hline Reagents & $4.42 \mathrm{E}-08$ & $2.85 \mathrm{E}-04$ & 1.17E-12 & $6.06 \mathrm{E}-12$ & 1.19E-04 \\
\hline MAI & $8.40 E-09$ & $6.25 \mathrm{E}-05$ & $2.45 \mathrm{E}-13$ & $1.01 \mathrm{E}-12$ & 2.37E-05 \\
\hline $\mathrm{Pbl}_{2}$ & $3.58 \mathrm{E}-08$ & $2.23 \mathrm{E}-04$ & $9.27 \mathrm{E}-13$ & $5.05 \mathrm{E}-12$ & $9.52 \mathrm{E}-05$ \\
\hline Solvents (GBL) & $1.29 \mathrm{E}-09$ & 2.17E-05 & $3.92 \mathrm{E}-14$ & $1.85 \mathrm{E}-13$ & $3.82 \mathrm{E}-06$ \\
\hline $\begin{array}{l}\text { Process } \\
\text { outputs } \\
\text { (Emissions - } \\
\text { GBL) } \\
\end{array}$ & $1.29 \mathrm{E}-09$ & $2.17 \mathrm{E}-05$ & $3.92 \mathrm{E}-14$ & $1.85 \mathrm{E}-13$ & $3.82 \mathrm{E}-06$ \\
\hline $\begin{array}{l}\text { Transport, } \\
\text { lorry }>16 \mathrm{t}\end{array}$ & $0.00 \mathrm{E}+00$ & $0.00 \mathrm{E}+00$ & $0.00 \mathrm{E}+00$ & $0.00 \mathrm{E}+00$ & $9.18 \mathrm{E}-06$ \\
\hline $\begin{array}{l}\text { Electricity, low } \\
\text { voltage }\end{array}$ & $2.20 \mathrm{E}-07$ & $1.57 \mathrm{E}-03$ & $6.41 \mathrm{E}-12$ & $2.59 \mathrm{E}-11$ & $6.14 \mathrm{E}-04$ \\
\hline
\end{tabular}


For the sake of providing assistance to find the most responsible type of flow of the impacts of perovskites, impacts are distributed per types of flow and compared in a diagram. Figure S18 presents the percentage of impact generated per type of inventory flow. It depicts the categories ADP, GWP, CED, HTC and HTNC, which represent the most crucial categories for the assessment of PSCs.

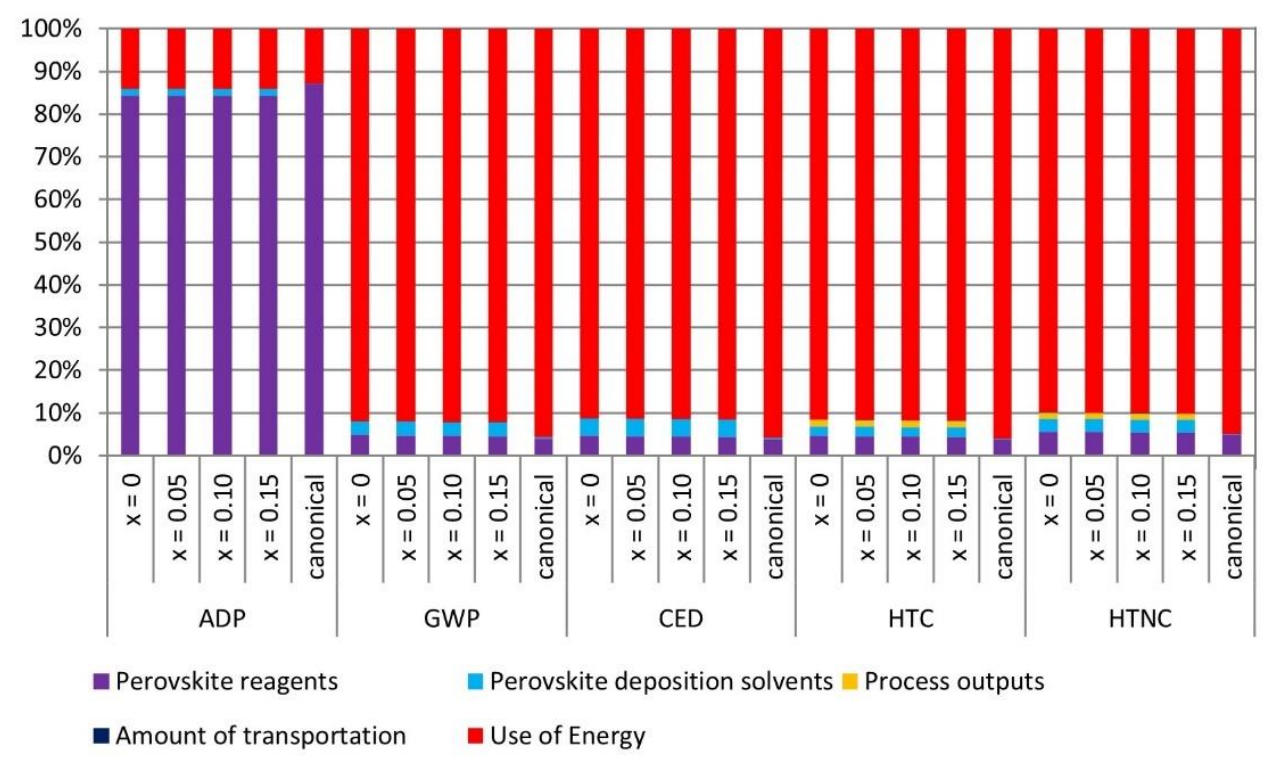

Figure S18. Distribution of impacts per type of flow for the most representative categories to assess PSCs.

From Figure S18, a general trend in which the energy used is the most harmful flow is observed, supposing more than $80 \%$ of the total. This circumstance occurs for all categories displayed, except for ADP category. Thus, for ADP perovskite reagents contribution exceeds an $80 \%$ and energy is the second most harmful type of flow. For the canonical perovskite, the contribution of energy to every category is superior. In respect to the contributions of triple cation perovskite, contribution of both perovskite reagents and solvents is little.

\subsection{Sensitivity analysis}

\subsubsection{Chlorobenzene}

Chlorobenzene mass is constant for multiple cation/anion perovskite compositions, because its amount does not depend on the composition. From the analysis in Figure 3 from the manuscript, its impact is notable in respect to the amounts of the rest of solvents, as chlorobenzene mass, which is one order of magnitude higher, added 
during the spin-coating step is not optimised. Furthermore, its use is specific of the anti-solvent method. Therefore, three scenarios were established to analyse the consequences of the usage of chlorobenzene for a proper removal of solvents during the spin-coating step. The three scenarios comprise a reference scenario where the amount of chlorobenzene used is not modified ( $100 \%$ scenario), a scenario where the amount of chlorobenzene is reduced to a $50 \%$ ( $50 \%$ scenario), and a scenario where the amount of chlorobenzene is completely eliminated ( $0 \%$ scenario). The purpose of the $50 \%$ scenario is to provide information about the benefits of reducing the dose of chlorobenzene used. At the same time, the purpose of the $0 \%$ scenario is to display the benefits of the conventional deposition method in comparison to the anti-solvent method, as the main difference of both methods is the usage of chlorobenzene to assist the removal of solvents. In Figure S19, the total impact of the perovskites for each scenario is shown divided by the total impact of the most detrimental scenario for the most determining categories for PSCs. As the most adverse outcomes belong to the perovskite without caesium content, only results of this perovskite are treated in this analysis.

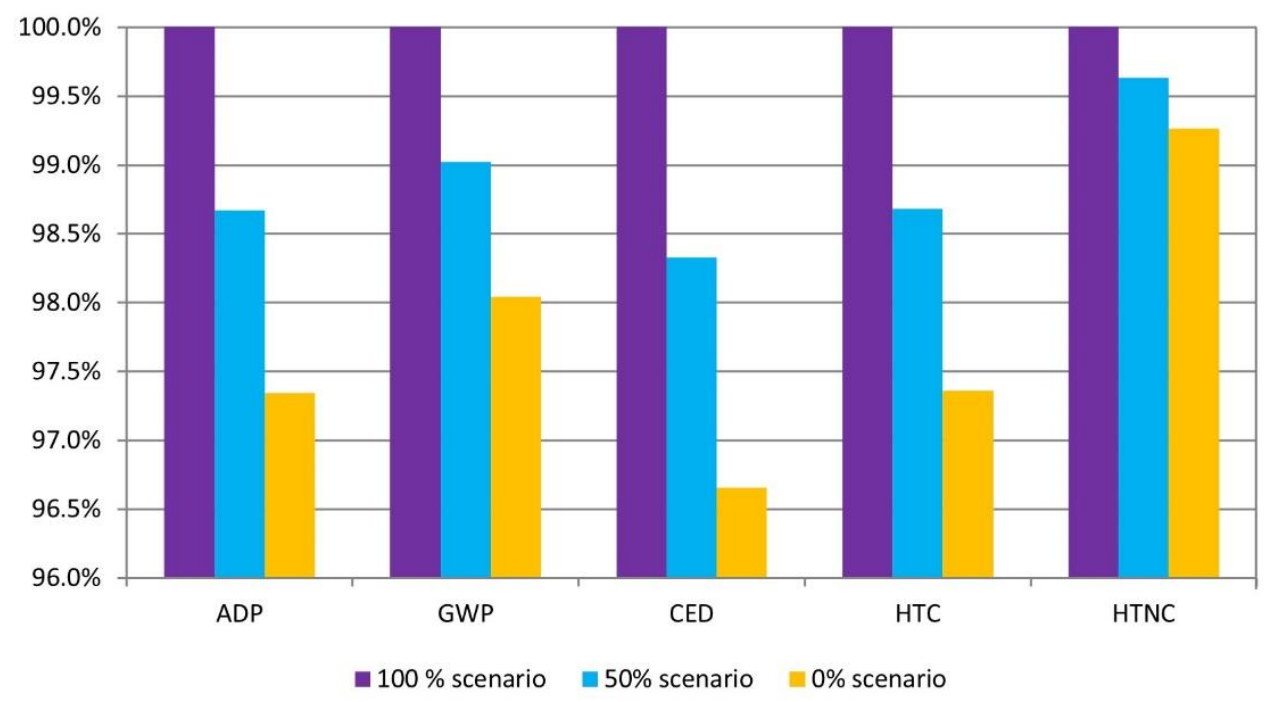

Figure S19. Sensitivity analysis of chlorobenzene with three scenarios for the most determining impact categories for PSCs with antisolvent method.

From the outcomes of the sensitivity analysis in Figure S19, a general reduction of the impacts is clearly observed. However, the most favourable scenario, which is always the $0 \%$ scenario, never declines below $96 \%$. Hence, this reduction does not suppose a relevant achievement, as except for ADP category, these reductions never decrease to the extent of canonical perovskite extent in Figure 14 from the manuscript. 


\section{Chapter 5 Perovskite photovoltaic modules: life cycle assessment of pre-industrial production process}





\section{Summary}

Photovoltaic devices based on perovskite materials have a great potential to become an exceptional source of energy, while preserving the environment. However, to enter the global market they require further development in order to achieve the necessary performance requirements. The environmental performance of a preindustrial process of production of a large area carbon stack perovskite module is analysed in this work through life cycle assessment (LCA). From the pre-industrial process an ideal process is simulated to establish a benchmark for a pre-industrial and a lab scale processes. Perovskite is shown to be the most harmful layer of the carbon stack module because of the energy consumed in the preparation and annealing of the precursor solution, and not by its $\mathrm{Pb}$ content. This work stresses the necessity of decreasing energy consumption during module preparation as the most effective way to reduce environmental impacts of PSCs.

\section{Graphical Abstract}

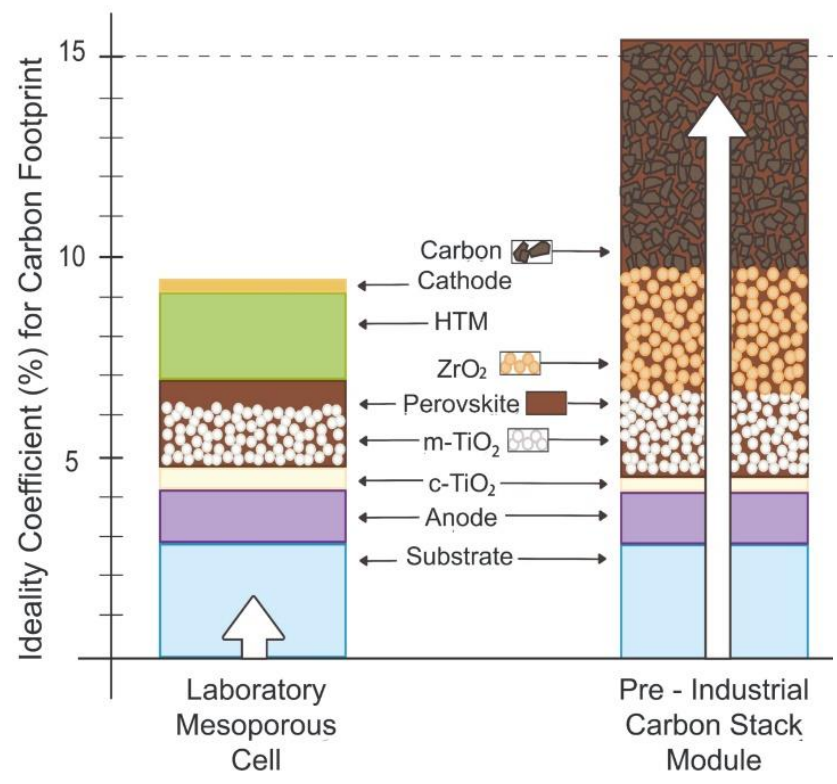




\subsection{Introduction}

Photovoltaics (PV) represent a potential technology to mitigate the climate change and other pollution consequences while obtaining energy to power human activity [262]. Nowadays, PV technologies based on halide perovskites have chiefly been developed at laboratory scale, where it has raised much interest among the scientific community [263]. Its development is addressed in multiple ways; decreasing costs of production, enhancing its poor lifespan, guaranteeing safety despite its lead content or substituting it for another less toxic element and producing them at industrial scale while maintaining high power conversion efficiency (PCE) [264-266]. Thus far, efficiencies have experienced a fast progression that over $20 \%$-efficient perovskite solar cell (PSC) have been obtained in several laboratories around the world $[228,230,256-259]$. Nevertheless, for bringing PSCs to commercialisation and launching them into the global market, as several companies aim to do [267-270], paramount parameters encompass low cost, large area, high throughput, high solarto-energy PCE, reproducibility, cost performance, long lifetime and low environmental impact [146].

The mainstream architecture and deposition techniques used in laboratories cannot be easily translated to larger substrates. For example, spin-coating or anti-solvent deposition methods present a large waste of material and a difficult implementation in large scale $[250,271]$, besides producing an increase of environmental impacts [89]. On the other hand, some materials used in several lab configurations such as Spiro-MeOTAD or Au should be avoided for their high cost, reduced stability and high environmental burden $[113,165]$. Consequently, new architectures have been investigated to overcome these limitations. Architectures where the perovskite is deposited through slot die [272-274], blade coating $[271,275,276]$ and solvent free pressure processing [277] are discarded because they still need an evaporated metal contact to complete the device or suffer from low efficiencies $(<5 \%)$. At the same time, a laminated device with a metal grid PEDOT:PSS cathode has been reported with efficiency over $10 \%[276,278,279]$, but the lifetime of this has not yet been proven. On the other hand, a large area module based on a fully printed mesoporous stack, using carbon as cathode, has been reported, exhibiting low cost, high throughput and high stability $[96,152,155]$. In this configuration, the use of the expensive and instable Spiro-MeOTAD and the use of gold are avoided. As such, it is viewed as one of the closest to commercialisation $[155,280]$. Perovskite is infiltrated into a semi conducting scaffold of mesoporous titania $\left(\mathrm{m}-\mathrm{TiO}_{2}\right)$, an insulating scaffold of mesoporous zirconia $\left(\mathrm{m}-\mathrm{ZrO}_{2}\right)$ and a cathode of carbon, whose porosity is crucial to control crystallisation of the perovskite over a large area [272]. Those layers are deposited through screen printing, which enables reproducibility in large area 
substrates $[281,282]$. Despite the fact that infiltration of the precursor solution is usually conducted manually, recently an automated system to deposit the perovskite with a robotic dispenser and a mesh has demonstrated more homogeneous depositions on large areas [165] and modules with active areas of up to $198 \mathrm{~cm}^{2}$ have been reported [166]. Furthermore, this configuration with a proper encapsulation exhibits outstanding lifetimes beyond one year [78]. By using different perovskite compositions in this carbon stack an efficiency close to $16 \%$ has been reached [283]. Yet, tuning the perovskite composition with formamidinium (FA), caesium, methylammonium (MA), iodide and bromide ions has proven adverse environmental consequences due to an increased amount of reagents [89]. Another advantage of the process is the usage of an ultra-fast annealing process with near infrared radiation technique [284]. However, in the structure fluorine-doped tin oxide (FTO) remains the most expensive material [235].

In addition to efficiency and cost issues, the environmental impact of the devices should be considered in the future implementation of this technology. The toxicity of lead embedded in perovskite remains one of the main concerns of PSCs since their early days $[146,235,285]$. Detrimental effects of $\mathrm{Pb}$ in the human body are notorious $[146,286]$. Its damaging activity consists in the mimicry of $\mathrm{Ca}, \mathrm{Zn}$ and Fe essential ions involved in biological processes [121,131]. Nonetheless, different studies assure that its presence in PSCs should not pose a restrictive concern for its commercialization $[126,135]$. In fact, emissions of Pb stemming from other established applications are higher than those related to PSCs; such as lead-acid batteries, crystalline solar cell panels (during its production) and weather-proofing lead sheets on roofs $[126,287]$. Still, PSCs embedded in consumer electronics or portable systems may find a barrier to the European market through the "RoHS Directive" [288], as it restricts the use of lead to $0.1 \%$ for homogeneous materials [124]. Several solutions to mitigate the detrimental effect of lead in PSCs have been proposed by the scientific community, such as designing safe production processes to prevent harmful consequences due to handling of $\mathrm{Pb}$ [126] and efficient recycling processes for $\mathrm{Pb}$ as well as for the rest of materials present in the solar cell $[124,169,285,289]$. In parallel, Pb-free PSCs are under development using either $\mathrm{Sn}$ or $\mathrm{Bi}$ as substitutes $[144,290,291]$, but their efficiencies are still quite low and benefits in the environment, derived from the usage of these elements instead of $\mathrm{Pb}$, are in doubt $[127,133]$.

A significant number of studies based on LCA have been conducted to support PSCs on its way to commercialisation. Some previous LCA studies, oriented towards the commercialisation of perovskite photovoltaic modules, evaluated some techniques suitable for low-cost manufacturing. For instance, an LCA analysing from cradle to gate two perovskite devices using spray and co-evaporation methods was reported 
[130]. In contrast, the first LCA applied to PSCs compared two deposition methods, spin-coating and evaporation [110]. Other LCAs likewise analyse laboratory scale devices to find weak points and possible improvements from an early stage of PSCS development $[111,113,128]$. Another LCA contrasting different configurations of Si/perovskite tandems concludes that the best configuration was Spiro-MeOTADfree and used Al instead of noble metals.[177] More analyses based on LCA contrast a handful of configurations of tandems with perovskite $[126,178,179,292]$. LCA has been directly applied to the perovskite layer to contrast various compositions combining different cations and anions [89]. Similarly, different PSCs containing different perovskite compositions are compared in two studies [118,119]. The substitution of $\mathrm{Pb}$ for $\mathrm{Sn}$ in the perovskite layer is also analysed in several studies $[127,133,292]$. To the best of our knowledge, an LCA study directly applied to an industrial process of production of large area photovoltaic modules based on perovskite has not been performed to date.

In this work, the environmental performance of a perovskite module, based on the carbon mesoporous stack architecture and produced with a pre-industrial process, is analysed via LCA, from cradle to gate, to determine the major environmental impacts of each manufacturing step. This pre-industrial process is intended to be a preliminary step towards commercialisation of perovskite modules. Remarkably, the energy consumptions of all equipment were directly measured and turned out to cause the most significant portion of environmental impact. The investigated process is based on a high-throughput process of production of a large area module (hereafter referred to as pre-industrial module), reported in a previous work [166], to which some alterations are implemented [152]. Usage of data stemming from a pre-industrial process provides a good approach of the environmental impact that will generate a real process. In addition, an ideal industrial process of production, based on the pre-industrial one (hereafter referred to as ideal module), is simulated (not directly measured) and environmentally assessed. In the ideal industrial process, energy consumption of some steps and usage of some materials are optimised with respect to those in the pre-industrial process, as it should be expected for the ideal implementation of a production line. We define an ideality coefficient that quantifies how close a given fabrication procedure from the ideal process is, in terms of environmental impacts. Finally, the progress attained by the large module produced via this pre-industrial process respect to a small PSC produced by means of the most extended laboratory scale process pertaining to a previous phase of development (hereafter referred to as lab-scale PSC) is illustrated via comparison of its ideality coefficient [113]. 


\subsection{Results and discussion}

\subsubsection{LCA of pre-industrial module}

Environment-wise, the production of a perovskite PV module with a carbon stack architecture (pre-industrial module) is scrutinised to elucidate which are its main weaknesses. For this purpose, the impact of each of the layers of the module is estimated for all the categories considered for this study, which is shown in Figure 20. Impacts of each layer are divided by the overall impact of the module. To make them comparable, impacts of each layer are aggregated per category. More information about how the environmental impacts are obtained can be found in the Transparent methods section, the Table S29, Table S32, Table S33, Table S34, Table S35, Table S36 and Table S37 in the Supplemental Information.

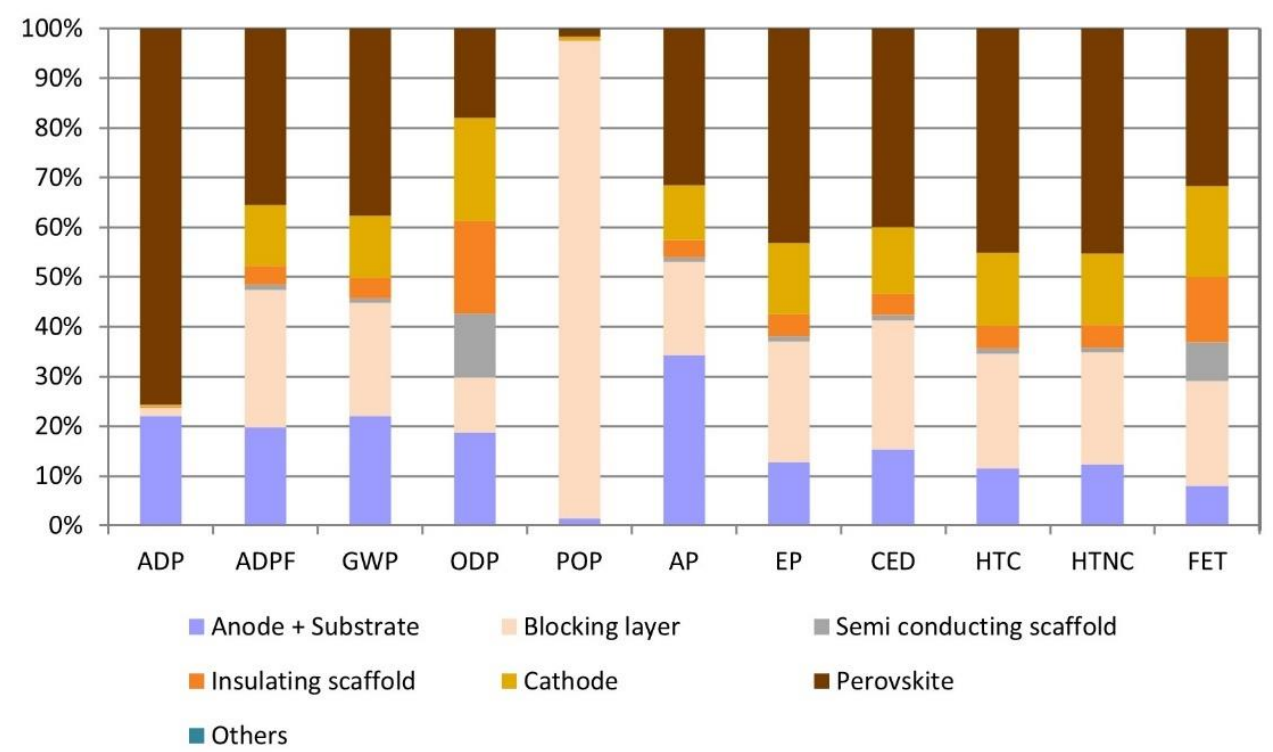

Figure 20 Aggregated impacts of each layer of the carbon stack perovskite module, sorted by impact categories

Distribution of impacts in Figure 20 exposes that the perovskite layer presents the biggest impact among all layers. Its contribution is superior to that of the rest of the layers, except in POP category. For most of the categories, the contribution of the perovskite layer is superior to $50 \%$. In contrast, for ODP, POP and AP categories, the impact of perovskite layer is below $50 \%$. Most of the impact of the perovskite layer stems from the use of energy flow, except for the ADP category where it mostly stems from the materials flow. Both heating up and annealing processes involved in the perovskite deposition contribute similarly to the impact. Both high consumptions 
originate from a forced convection generated to assist perovskite crystallisation during the annealing process and a process of heating of perovskite reagents carried out in a hot plate, which needs optimisation. Thus, a reduction of its impact should be among the next goals to improve the sustainability of the pre-industrial process. For instance, the amount of precursor reagents could be reduced with an automatic deposition using a robot and a mesh, instead of depositing it manually [165]. A

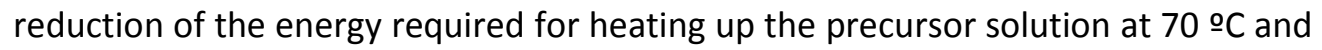
annealing the perovskite layer -e.g., via heat recovery and other methods for reducing the crystallisation time- would also be necessary.

For the POP category, the most adverse layer is the blocking layer, accounting for more than $90 \%$ of the total. For this category, the impact mostly stems from the emissions. The most harmful compound emitted is isopropanol. Impact of the blocking layer is also significant for the rest of the categories alongside the anode + substrate layer, whose contribution is above $10 \%$ in most of them. Use of energy and materials are the main responsible flows of their impact. Moreover, impact of the cathode is also noticeable.

To assist the analysis of the pre-industrial module, the distribution of impacts for each of the impact flow is depicted in Figure 21 for all categories. Materials, use of energy, amount of transportation and emissions flows are included in this analysis. Impacts of each flow are divided by the total impact to obtain the percentage of contribution.

When the impact of the four types of flows are compared in Figure 21, the use of energy results to be the most detrimental for ADPF, GWP, AP, EP, CED, HTC, HTNC and FET categories, varying between $69.1 \%$ to $90.2 \%$. As well as it happens in Figure 20 , impacts of those categories mainly stem from the perovskite layer, in particular from the heating up of the precursor solution and annealing of the film.

In contrast, for ADP and ODP the most harmful flow is materials, which ranges from $56.7 \%$ to $92.6 \%$. For ADP category, lead iodide reagent for the perovskite production is the most harmful material: its impact is one order of magnitude higher than MAI, two orders of magnitude higher than AVAl and three orders of magnitude higher than the solvent abutyrolactone (GBL). Meanwhile, for ODP the main material responsible for the impact is not as clear, since all layers contribute roughly the same. For the POP category, the contribution of emissions flow is higher than $90 \%$, due to the release of isopropanol used copiously as a carrier to enable the blocking layer deposition via spray. 


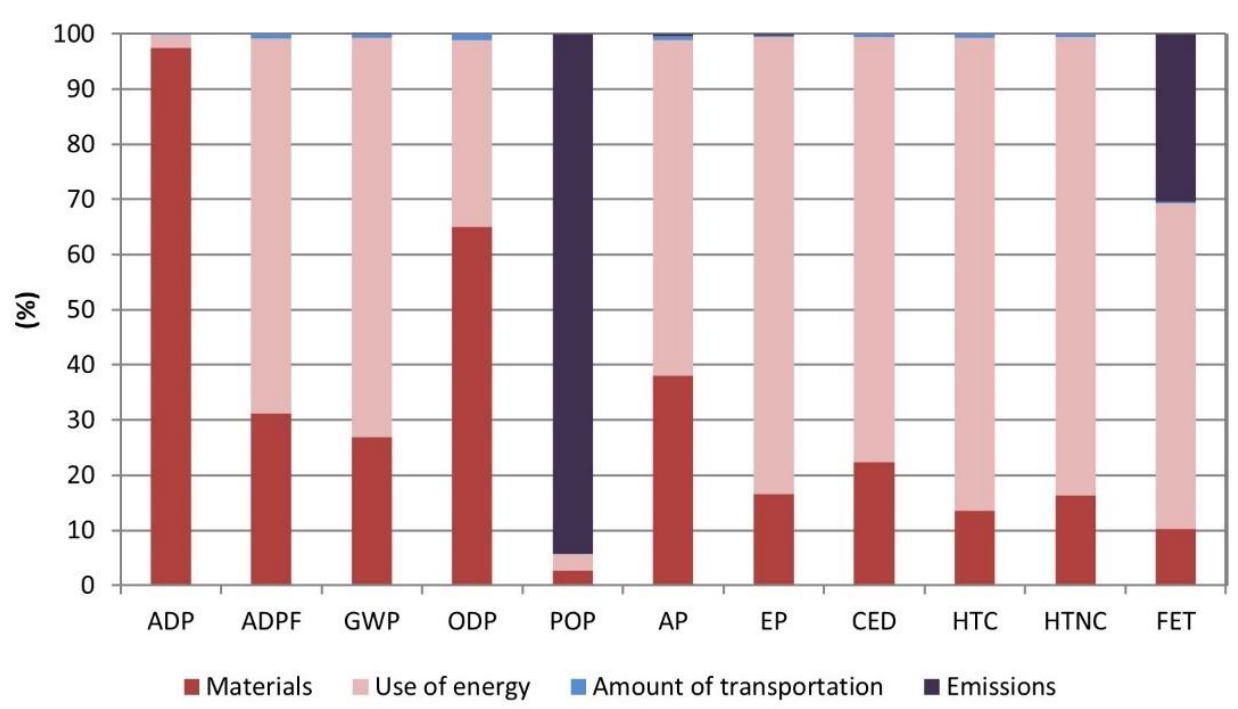

Figure 21 Aggregated impacts of the carbon stack perovskite module, sorted by impact categories

As materials chosen are an important concern for the production of PV devices and their impact is usually hidden by that of the use of energy flow, we focus on the materials used for the production of the pre-industrial module. The impact of each compound used is divided by the total impact of the materials flow and displayed in Figure 22, sorted by categories. As the impacts of some of the compounds depicted are too little to be appreciated in the chart, they are aggregated in a single group (Others), which comprises $\mathrm{TiAcAc}_{1} \mathrm{TiO}_{2}$, Ethylcellulose, 2-(2-butoxyethoxy) ethyl acetate, Nitrocellulose, AVAI, Polyethylene terephthalate, Zirconia and Carbon. On the other hand, contributions of the impact of FTO, glass substrate, isopropanol, $\alpha$ terpineol, $\mathrm{Pbl}_{2}, \mathrm{MAl}$ and $\mathrm{GBL}$ are shown individually.

The glass substrate, accounting for the largest fraction of the mass of the preindustrial module, represents the most detrimental material. Its contribution is above $43 \%$ for all categories, except for ADP (slightly below $20 \%$ ) and ODP. For ADP category, the most harmful material, contributing nearly $60 \%$ to this category, is the $\mathrm{Pbl}_{2}$ used as reagent for the perovskite synthesis. The reason behind such contribution lies in the fact that a big amount of it is used and its impact per kg is high. Isopropanol and $\alpha$-terpineol solvents have a significant contribution to the overall impact. Terpineol is especially detrimental for ODP category, where it represents nearly $67 \%$ of the total. On the other hand, mass of isopropanol used per $\mathrm{kWh}$ is the highest of all materials, i.e., $0.0908 \mathrm{~kg} / \mathrm{kWh}$. Impact of MAl is relatively modest except for ADP category, where represents more than 20\%. Moreover, GBL impacts are appreciable for every category. In consequence, the aggregate of 
compounds involved in the synthesis of perovskite $\left(\mathrm{Pbl}_{2}, \mathrm{MAl}, \mathrm{GBL}\right)$ is higher than $10 \%$ for ADP, GWP, EP, CED HTC, HTNC and FET. This fact reinforces the need for reducing the usage of reagents for the synthesis of perovskite as pointed out in the analysis in Figure 21.

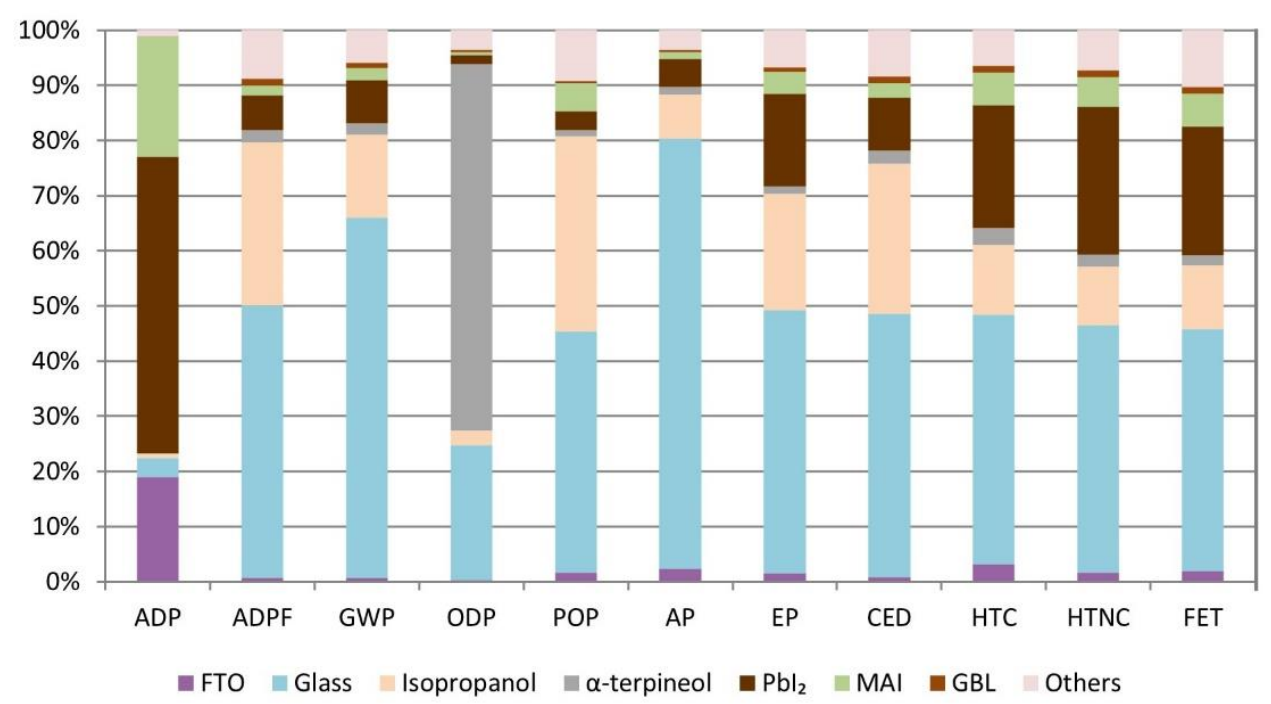

Figure 22 Aggregated impacts of material inputs of the carbon stack perovskite module, sorted by impact categories

\subsubsection{Ideality analysis}

Minimisation of material and energy consumption establishes the ideal scenario to decrease the environmental impacts caused by a device fabrication. Here, we define an ideality coefficient that quantifies how close a given fabrication procedure from the ideal process is, in percentage. Note that a technology requires an ideal coefficient as high as possible to reduce as much as possible the environmental impacts. However, no technological process can reach $100 \%$ ideality coefficient, as no technology can produce zero waste material and consume just the thermodynamic limit energy. This coefficient is depicted in percentages for both the pre-industrial module and the lab-scale PSC in Figure 23. Its value is the result of dividing the impact of the ideal process by the impact of the process to compare. For this analysis, the most fundamental categories are only used to ease its performance and thus its comprehension. As previously discussed and according to the data reported in Figure 20, the most concerning layers of the pre-industrial module are the anode + substrate, the blocking layer and the perovskite, so these are the only layers included in the analysis. In order to assess in great detail these layers, this analysis is combined with the relative impacts - sorted by type of flow - of both the 
carbon stack module produced at pre-industrial scale and the PSC produced at lab scale. The impact of each flow type pertaining to each layer is resized and aggregated to fit in the corresponding percentage of ideality coefficient. Results are sorted by device, by category and finally by layer, where those of the anode + substrate layer (a) are depicted from $0 \%$ to $100 \%$ and those of the blocking and perovskite layers (b) are depicted from $0 \%$ to $1 \%$. Further information about the obtaining of these outcomes can be found in Table S29 to Table S37 and in the Transparent methods section in the Supplemental Information.
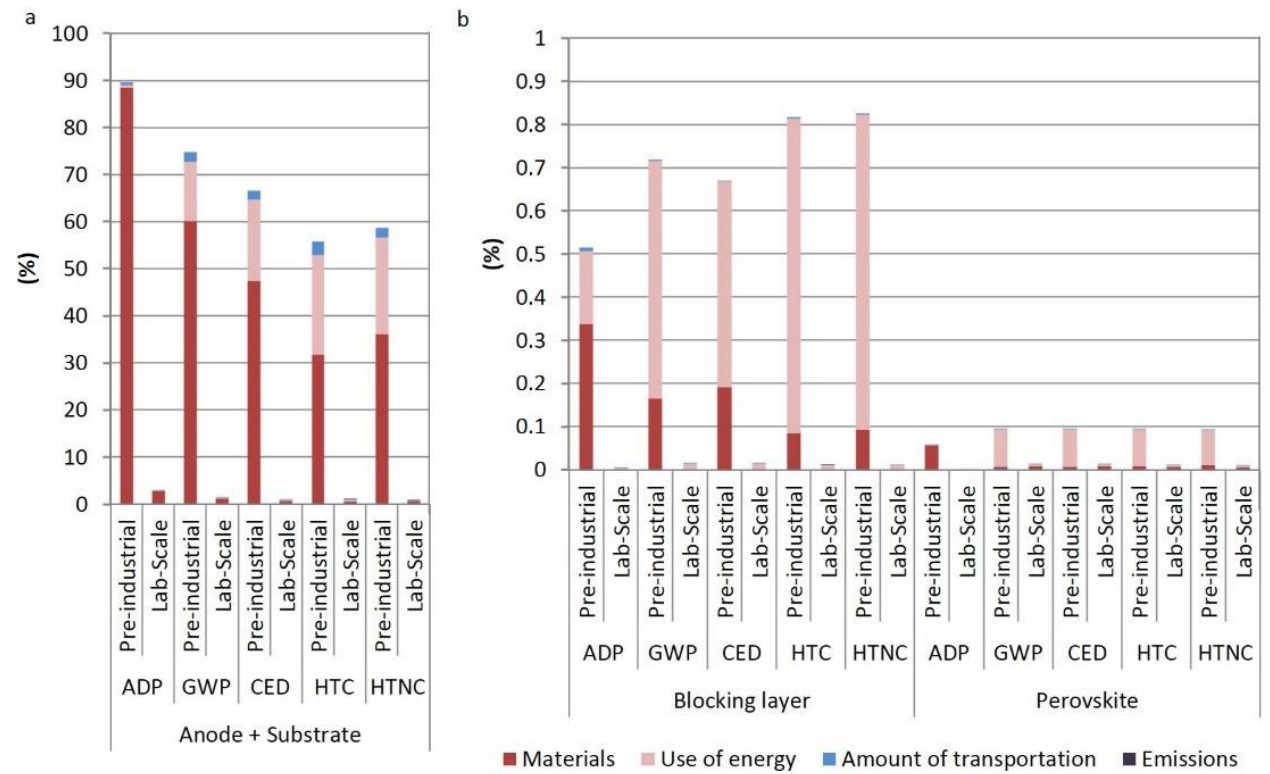

Figure 23 Ideality coefficient for the carbon stack module produced with a pre-industrial process and the PSC produced with a process in the laboratory environment. The ideality coefficient quantifies how close a given fabrication procedure from the ideal process is, in percentage; its value is the result of dividing the impact of the ideal process by the impact of the process to compare. Relative impacts from pre-industrial module, PSC at laboratory scale and ideal process, sorted by impact categories and layers: a) anode + substrate, b) blocking and perovskite layer. See also Figure S24 and Figure S25 in the Supplemental Information.

From the results in Figure 23, it is observed that the pre-industrial module significantly reduces all impacts, with ideality coefficients reaching values as high as $89.5 \%$ for ADP. In the anode + substrate layer the pre-industrial process reaches the highest ideality coefficients among the three layers analysed, where the preindustrial device ranges from $55.8 \%$ to $89.5 \%$. It is important to bear in mind that the step of cleaning has been removed for the anode + substrate with respect to the process performed in the laboratory, which is the cause of the reduction in the impact of this layer. Remarkably, impacts derived from anode + substrate layer of 
both pre-industrial and ideal processes are almost alike, indicating that further optimisation of the pre-industrial process should focus on blocking layer and especially perovskite layer. Theoretical optimisation of materials and energy in the ideal process is the reason why ideality coefficient of the pre-industrial process is not closer to the $100 \%$. The materials flow is the most responsible of the impact of the anode + substrate, followed by the energy for all categories except ADP. The high values of the ideality coefficient of the pre-industrial process contrast with those of the lab-scale PSC that do not surpass 3.0\% (about 30-fold lesser), which reinforces the progression made by the pre-industrial process for the anode + substrate layer.

Ideality coefficients for the blocking layer are significantly lower, ranging from $0.51 \%$ to $0.83 \%$ for the pre-industrial process, where the highest ideality coefficient pertains to the HTNC category. However, it is far from the ideal process, mostly due to the use of energy flow for the blocking layer. For the blocking layer, a significant optimisation of both materials and use of energy flows is recommended to improve ideality. For instance, depositing this layer by screen printing would result in an optimisation of TiAcAc solution and a decrease in the usage of energy, as it happens for the mesoporous layers in the pre-industrial process. Furthermore, a reduction in the thickness of the blocking layer to $8 \mathrm{~nm}$ is feasible, via electrophoretic deposition method, with a subsequent reduction in materials [293]. Other deposition methods such as spray-cast and semi-automatic spray pyrolysis might pose an alternative for industrial manufacture of the carbon-stack perovskite module $[294,295]$. For the labscale process, ideality coefficients fluctuate between $0.0043 \%$ and $0.0143 \%$, which are well below those of the pre-industrial one (about 58 -fold lesser). Therefore, for the blocking layer the pre-industrial process is less harmful, which highlights the advancement it has achieved.

In addition, results reveal that the process of deposition of perovskite is the least optimised, narrowly followed by the blocking layer. Its ideality coefficients vary between $0.06 \%$ for the ADP category and $0.09 \%$ for GWP, CED, HTC and HTNC categories. The highest amount of energy consumed for the pre-industrial process, to prepare the solution and to anneal the deposited layer, arises as the responsible of these striking results as use of energy is the most detrimental flow for this layer. Therefore, finding an alternative, such as heating with near infrared radiation $[152,284]$, especially for the annealing step, should be fundamental to reduce the impact of this process to that of the ideal process and get it off the ground. Alternatively, using other heating techniques needing shorter operational times such as NIR radiation [296,297], photonic flash-annealing [298] and high-temperatureshort-time annealing processes [299] could optimise the environmental performance of the perovskite layer. In comparison with those of the lab-scale PSC, 
ideality coefficient values of the pre-industrial device are notably higher (about 8fold bigger), despite the fact that both processes are far from ideality, pointing out the improvement already achieved. Overall outcomes of the study are provided in Table S38, Table S39 and Table S40 of the Supplemental Information.

\subsection{Conclusions}

A cradle-to-gate LCA of a pre-industrial process of production of a large area perovskite module based on a carbon stack architecture is assessed. An ideality coefficient is obtained to evaluate the level of optimisation of the pre-industrial module, which show overall encouraging results. This ideality coefficient of the preindustrial process is compared with that of a mesoporous structured PSC produced in the laboratory environment and with an extrapolated ideal situation in which material and energy consumption is minimized.

The perovskite layer is found to be the layer with the greatest impact on the preindustrial module, mainly due to the energy consumed in the preparation and annealing of the precursor solution, rather than the $\mathrm{Pb}$ content that raises a greater concern. This step is highly amenable to optimisation.

Ideality coefficients of the pre-industrial process show a significant improvement regarding environmental impacts for the most relevant layers, namely the FTO-glass substrate, the compact $\mathrm{TiO}_{2}$ blocking layer and the perovskite. While the first one generates low impacts, and it is already close to optimal, the energy consumption needed for the perovskite layer and for the blocking layer is still too high and must be reduced. 


\subsection{Supplemental Information}

\section{Supplemental Figures}

Ideality coefficient is defined in the Results and Discussion section of the main manuscript. In Figure S24 a wider analysis of the ideality coefficient is shown, which includes all the categories.

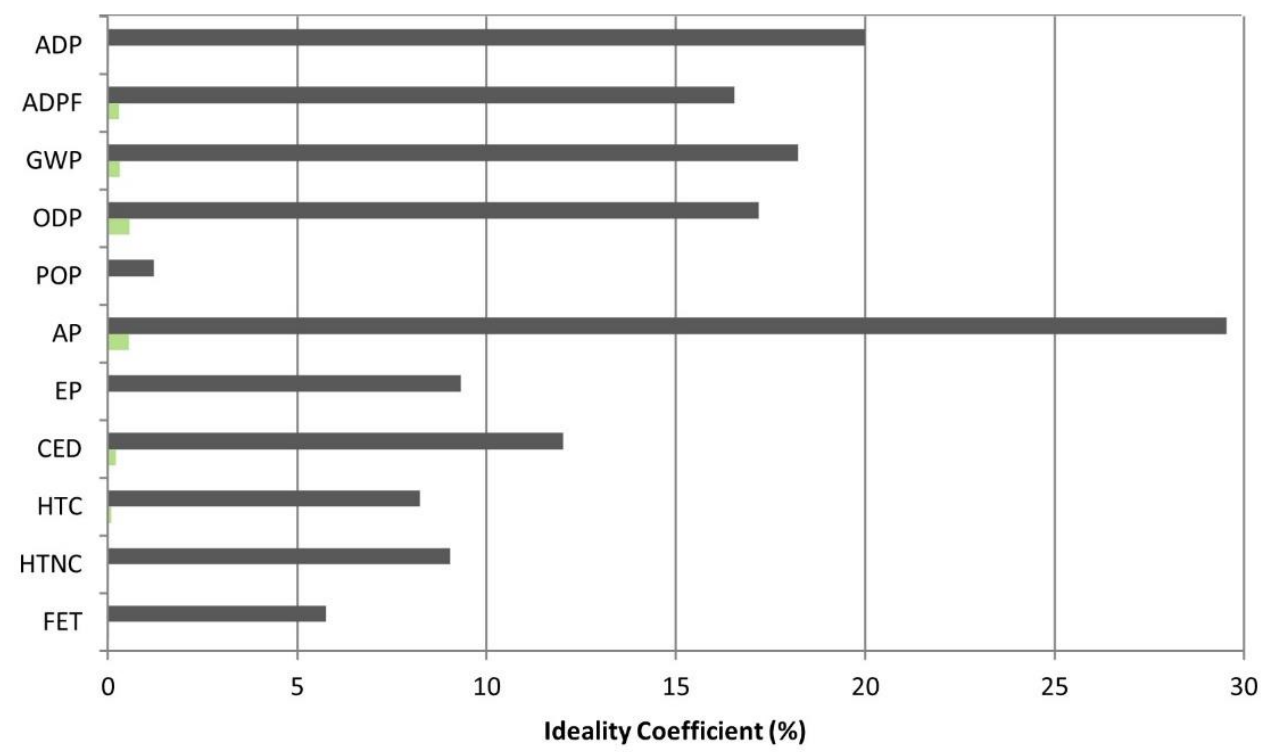

E Pre-industrial Carbon Stack $\quad$ Laboratory Mesosporous

Figure S24. Ideality coefficient for the carbon stack module produced with a pre-industrial process and the PSC produced with a process in the laboratory environment. The ideality coefficient quantifies how close a given fabrication procedure from the ideal process is, in percentage; its value is the result of dividing the impact of the ideal process by the impact of the process to compare. In the vertical axis are the impact categories selected, related to Figure 23.

In order to compare in great detail the carbon stack module produced at preindustrial scale, the PSC produced at lab scale and the module produced with the ideal process, relative impacts of these three devices are displayed in Figure S25. For this analysis, the most fundamental categories are only used to ease its performance and thus its comprehension. Outcomes of this chart are obtained by dividing the impact of each device by the maximum impact within the same category and the same layer. Afterwards, the impact of each flow type pertaining to each layer is resized and aggregated to fit in the corresponding percentage of relative impact. Results are sorted by device, by category and finally by layer. Moreover, impacts of 
the most harmful device within the same category and the same layer have a value of $100 \%$, whereas for the other two devices the percentage respect this device is shown. As previously discussed and according to the data reported in Figure 20 of the main manuscript, the most concerning layers of the pre-industrial module are the anode + substrate, the blocking layer and the perovskite, so these are the only layers included in the analysis.

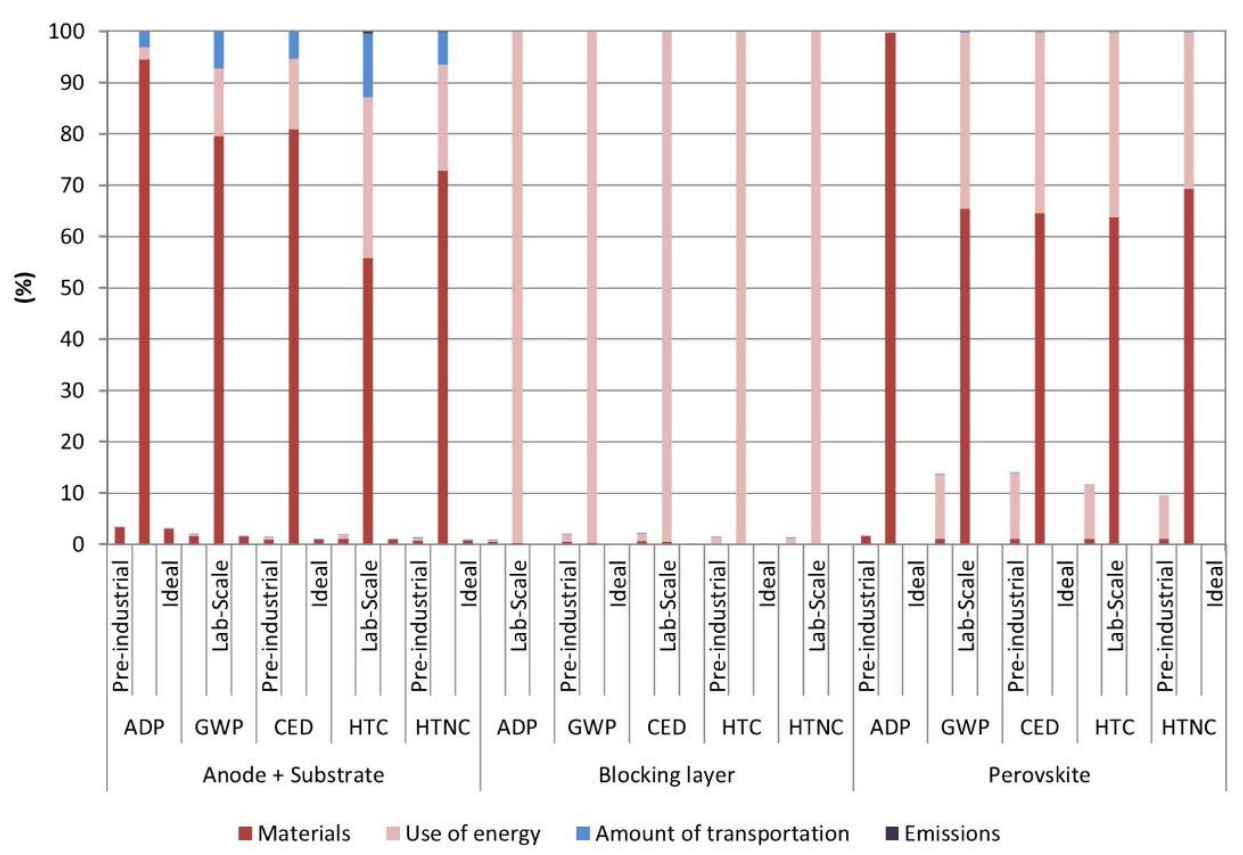

Figure S25. Relative impacts from pre-industrial module, PSC at laboratory scale and ideal process, sorted by impact categories and layers: anode + substrate, blocking and perovskite layer, related to Figure 23. 


\section{Supplemental Tables}

\subsection{Perovskite module with a carbon stack configuration}

Table S29. Inventory of the carbon stack perovskite photovoltaic module, related to Figure 20 to Figure 23.

\begin{tabular}{|c|c|c|c|}
\hline Layer & Input/Output & Amount & Unit \\
\hline \multirow{5}{*}{$\begin{array}{l}\text { Anode (FTO) } \\
+ \text { Substrate } \\
\text { (glass) }\end{array}$} & Fluorine doped Tin Oxide & 0.0211 & $\mathrm{~g} / \mathrm{kWh}$ \\
\hline & Glass & 27.0 & $\mathrm{~g} / \mathrm{kWh}$ \\
\hline & FTO sputtering, medium voltage & $1.18 \cdot 10^{-5}$ & $\mathrm{MJ} / \mathrm{kWh}$ \\
\hline & Laser substrate etching, medium voltage & 0.0466 & $\mathrm{MJ} / \mathrm{kWh}$ \\
\hline & Transportation burden by lorry & $7.48 \cdot 10^{-3}$ & $\mathrm{~km} \cdot \mathrm{T} / \mathrm{kWh}$ \\
\hline \multirow{7}{*}{$\begin{array}{l}\text { Blocking } \\
\text { layer }\end{array}$} & Titanium di-isopropoxide bis(acetylacetonate) & 0.488 & $\mathrm{~g} / \mathrm{kWh}$ \\
\hline & Isopropanol & 3.63 & $\mathrm{~g} / \mathrm{kWh}$ \\
\hline & Air compression & $7.97 \cdot 10^{-6}$ & $\mathrm{~m}^{3} / \mathrm{kWh}$ \\
\hline & $\begin{array}{l}\text { Annealing at } 550 \text { o } \mathrm{C} \text { for } 30 \mathrm{~min} \text { (allocated), medium } \\
\text { voltage }\end{array}$ & 0.217 & $\mathrm{MJ} / \mathrm{kWh}$ \\
\hline & Emissions - Acetylacetone & 0.796 & $\mathrm{~g} / \mathrm{kWh}$ \\
\hline & Emissions - Isopropanol & 3.79 & $\mathrm{~g} / \mathrm{kWh}$ \\
\hline & Transportation burden by lorry & $1.13 \cdot 10^{-3}$ & $\mathrm{~km} \cdot \mathrm{T} / \mathrm{kWh}$ \\
\hline \multirow{14}{*}{$\begin{array}{l}\text { Semi } \\
\text { conducting } \\
\text { scaffold }\end{array}$} & Titania nanoparticles & 0.0199 & $\mathrm{~g} / \mathrm{kWh}$ \\
\hline & Ethyl cellulose & 0.0100 & $\mathrm{~g} / \mathrm{kWh}$ \\
\hline & 2-(2-Butoxyethoxy) ethyl acetate & 0.0199 & $\mathrm{~g} / \mathrm{kWh}$ \\
\hline & Terpineol & 0.0586 & $\mathrm{~g} / \mathrm{kWh}$ \\
\hline & Screen printing, medium voltage & $7.72 \cdot 10^{-5}$ & $\mathrm{MJ} / \mathrm{kWh}$ \\
\hline & $\begin{array}{l}\text { Annealing at } 550 \text { o } \mathrm{C} \text { for } 30 \mathrm{~min} \text { (allocated), medium } \\
\text { voltage }\end{array}$ & $8.85 \cdot 10^{-3}$ & $\mathrm{MJ} / \mathrm{kWh}$ \\
\hline & Emissions - Titanium dioxide & $4.98 \cdot 10^{-3}$ & $\mathrm{~g} / \mathrm{kWh}$ \\
\hline & Emissions - Ethyl cellulose & $3.34 \cdot 10^{-3}$ & $\mathrm{~g} / \mathrm{kWh}$ \\
\hline & Emissions - 2-(2-Butoxyethoxy) ethyl acetate & 0.0199 & $\mathrm{~g} / \mathrm{kWh}$ \\
\hline & Emissions - Terpineol & 0.0586 & $\mathrm{~g} / \mathrm{kWh}$ \\
\hline & Emissions - Carbon dioxide & 0.0138 & $\mathrm{~g} / \mathrm{kWh}$ \\
\hline & Emissions - Water vapour & $4.95 \cdot 10^{-3}$ & $\mathrm{~g} / \mathrm{kWh}$ \\
\hline & Transportation burden by lorry & $2.49 \cdot 10^{-5}$ & $\mathrm{~km} \cdot \mathrm{T} / \mathrm{kWh}$ \\
\hline & Transportation burden by freight ship & $2.08 \cdot 10^{-3}$ & $\mathrm{~km} \cdot \mathrm{T} / \mathrm{kWh}$ \\
\hline \multirow{5}{*}{$\begin{array}{l}\text { Insulating } \\
\text { scaffold }\end{array}$} & Zirconia & 0.0401 & $\mathrm{~g} / \mathrm{kWh}$ \\
\hline & Ethyl cellulose & 0.0134 & $\mathrm{~g} / \mathrm{kWh}$ \\
\hline & Terpineol & 0.0802 & $\mathrm{~g} / \mathrm{kWh}$ \\
\hline & Screen printing, medium voltage & $7.72 \cdot 10^{-5}$ & $\mathrm{MJ} / \mathrm{kWh}$ \\
\hline & $\begin{array}{l}\text { Annealing at } 400 \text { o } \mathrm{C} \text { for } 30 \mathrm{~min} \text { (allocated), medium } \\
\text { voltage }\end{array}$ & 0.0460 & $\mathrm{MJ} / \mathrm{kWh}$ \\
\hline
\end{tabular}


Perovskite photovoltaic modules: life cycle assessment of pre-industrial production

process

\begin{tabular}{|c|c|c|c|}
\hline Layer & Input/Output & Amount & Unit \\
\hline & Emissions - Zirconium dioxide & 0.0100 & $\mathrm{~g} / \mathrm{kWh}$ \\
\hline & Emissions - Ethyl cellulose & $3.34 \cdot 10^{-3}$ & $\mathrm{~g} / \mathrm{kWh}$ \\
\hline & Emissions - Terpineol & 0.0802 & $\mathrm{~g} / \mathrm{kWh}$ \\
\hline & Emissions - Carbon dioxide & 0.0186 & $\mathrm{~g} / \mathrm{kWh}$ \\
\hline & Emissions - Water vapour & $6.65 \cdot 10^{-3}$ & $\mathrm{~g} / \mathrm{kWh}$ \\
\hline & Transportation burden by lorry & $1.63 \cdot 10^{-4}$ & $\mathrm{~km} \cdot \mathrm{T} / \mathrm{kWh}$ \\
\hline \multirow{12}{*}{ Cathode } & Carbon & 0.133 & $\mathrm{~g} / \mathrm{kWh}$ \\
\hline & Nitrocellulose & 0.0222 & $\mathrm{~g} / \mathrm{kWh}$ \\
\hline & Terpineol & 0.0667 & $\mathrm{~g} / \mathrm{kWh}$ \\
\hline & Screen printing, medium voltage & $7.72 \cdot 10^{-5}$ & $\mathrm{MJ} / \mathrm{kWh}$ \\
\hline & $\begin{array}{l}\text { Annealing at } 400 \stackrel{\circ}{ } \mathrm{C} \text { for } 30 \mathrm{~min} \text { (allocated), medium } \\
\text { voltage }\end{array}$ & 0.153 & $\mathrm{MJ} / \mathrm{kWh}$ \\
\hline & Emissions - Carbon & 0.0334 & $\mathrm{~g} / \mathrm{kWh}$ \\
\hline & Emissions - Nitrocellulose & $5.56 \cdot 10^{-3}$ & $\mathrm{~g} / \mathrm{kWh}$ \\
\hline & Emissions - Terpineol & 0.0667 & $\mathrm{~g} / \mathrm{kWh}$ \\
\hline & Emissions - Carbon dioxide & 0.0148 & $\mathrm{~g} / \mathrm{kWh}$ \\
\hline & Emissions - Water vapour & $3.54 \cdot 10^{-3}$ & $\mathrm{~g} / \mathrm{kWh}$ \\
\hline & Emissions - Nitrogen dioxide & $7.75 \cdot 10^{-3}$ & $\mathrm{~g} / \mathrm{kWh}$ \\
\hline & Transportation burden by lorry & $2.03 \cdot 10^{-5}$ & $\mathrm{~km} \cdot \mathrm{T} / \mathrm{kWh}$ \\
\hline \multirow{9}{*}{ Perovskite } & Lead lodide & 0.0525 & $\mathrm{~g} / \mathrm{kWh}$ \\
\hline & Methylammonium lodide & 0.0181 & $\mathrm{~g} / \mathrm{kWh}$ \\
\hline & 5-ammonium valeric acid iodide & $8.01 \cdot 10^{-4}$ & $\mathrm{~g} / \mathrm{kWh}$ \\
\hline & $\gamma$-butyrolactone & 0.135 & $\mathrm{~g} / \mathrm{kWh}$ \\
\hline & Precursor solution mixture, low voltage & $5.38 \cdot 10^{-3}$ & $\mathrm{MJ} / \mathrm{kWh}$ \\
\hline & Annealing at $50 \stackrel{\circ}{ } \mathrm{C}$ for $60 \mathrm{~min}$, medium voltage & 0.426 & $\mathrm{MJ} / \mathrm{kWh}$ \\
\hline & Emissions - Butyrolactone & 0.135 & $\mathrm{~g} / \mathrm{kWh}$ \\
\hline & Transportation burden by lorry & $4.86 \cdot 10^{-5}$ & $\mathrm{~km} \cdot \mathrm{T} / \mathrm{kWh}$ \\
\hline & Transportation burden by freight & $3.95 \cdot 10^{-4}$ & $\mathrm{~km} \cdot \mathrm{T} / \mathrm{kWh}$ \\
\hline \multirow{2}{*}{ Others } & Screen (polyethylene terephthalate) & $1.05 \cdot 10^{-3}$ & $\mathrm{~g} / \mathrm{kWh}$ \\
\hline & Transportation burden by lorry & $3.75 \cdot 10^{-7}$ & $\mathrm{~km} \cdot \mathrm{T} / \mathrm{kWh}$ \\
\hline
\end{tabular}




\subsection{Mesoporous PSC produced in the laboratory environment}

Just as it is considered for the carbon stack module, the active area is obtained by applying the fill factor, which determines the percentage of active area in respect of the overall area. This active area is then used to convert the amount of all inputs and outputs as a function of the unit of $1 \mathrm{kWh}$.

Table S30. Inventory of a mesoporous PSC produce in the laboratory environment, related to Figure 23.

\begin{tabular}{|c|c|c|c|}
\hline Layer & Input/Output & Amount & Unit \\
\hline \multirow{17}{*}{$\begin{array}{l}\text { Anode (FTO) } \\
+ \text { Substrate } \\
\text { (glass) }\end{array}$} & Fluorine doped Tin Oxide & 0.562 & $\mathrm{~g} / \mathrm{kWh}$ \\
\hline & Glass & 695 & $\mathrm{~g} / \mathrm{kWh}$ \\
\hline & Metallic Zinc & 3.19 & $\mathrm{~g} / \mathrm{kWh}$ \\
\hline & Hydrochloric acid & 3.11 & $\mathrm{~g} / \mathrm{kWh}$ \\
\hline & Deionised water & 164 & $\mathrm{~g} / \mathrm{kWh}$ \\
\hline & Ethanol & 123 & $\mathrm{~g} / \mathrm{kWh}$ \\
\hline & Isopropanol & 123 & $\mathrm{~g} / \mathrm{kWh}$ \\
\hline & Acetone & 123 & $\mathrm{~g} / \mathrm{kWh}$ \\
\hline & Soap (Hellmanex) & 4.48 & $\mathrm{~g} / \mathrm{kWh}$ \\
\hline & FTO sputtering, medium voltage & 0.491 & $\mathrm{MJ} / \mathrm{kWh}$ \\
\hline & Sonication, low voltage & 0.961 & $\mathrm{MJ} / \mathrm{kWh}$ \\
\hline & Ozone chamber, medium voltage & 0.184 & $\mathrm{MJ} / \mathrm{kWh}$ \\
\hline & Emissions - Ethanol & 126 & $\mathrm{~g} / \mathrm{kWh}$ \\
\hline & Emissions - Isopropanol & 125 & $\mathrm{~g} / \mathrm{kWh}$ \\
\hline & Emissions - Acetone & 126 & $\mathrm{~g} / \mathrm{kWh}$ \\
\hline & Emissions - Chloride & 0.906 & $\mathrm{~g} / \mathrm{kWh}$ \\
\hline & Transportation burden by lorry & 0.981 & $\mathrm{~km} \cdot \mathrm{T} / \mathrm{kWh}$ \\
\hline \multirow{7}{*}{$\begin{array}{l}\text { Electron } \\
\text { transporting } \\
\text { layer (ETM) }\end{array}$} & Titanium dioxide & 0.138 & $\mathrm{~g} / \mathrm{kWh}$ \\
\hline & Ethanol & 4.03 & $\mathrm{~g} / \mathrm{kWh}$ \\
\hline & Spin coating ( $2000 \mathrm{rpm}, 1 \mathrm{~min}$ ), low voltage & 0.327 & $\mathrm{MJ} / \mathrm{kWh}$ \\
\hline & Heating (120 ㄷ, $10 \mathrm{~min}$ ), low voltage & 2.09 & $\mathrm{MJ} / \mathrm{kWh}$ \\
\hline & Annealing (450 ㅇ, $4 \mathrm{~h}$ ), low voltage & 10.3 & $\mathrm{MJ} / \mathrm{kWh}$ \\
\hline & Emissions - Ethanol & 4.03 & $\mathrm{~g} / \mathrm{kWh}$ \\
\hline & Transportation burden by lorry & $4.11 \cdot 10^{-3}$ & $\mathrm{~km} \cdot \mathrm{T} / \mathrm{kWh}$ \\
\hline \multirow{6}{*}{ Scaffold } & Titanium dioxide & 2.62 & $\mathrm{~g} / \mathrm{kWh}$ \\
\hline & Ethanol & 1.96 & $\mathrm{~g} / \mathrm{kWh}$ \\
\hline & Spin-coating (4000 rpm, $60 \mathrm{~s}$ ), low voltage & 0.675 & $\mathrm{MJ} / \mathrm{kWh}$ \\
\hline & Heating ( $80 \stackrel{\circ}{ } \mathrm{C}, 15 \mathrm{~min}$ ), low voltage & 1.88 & $\mathrm{MJ} / \mathrm{kWh}$ \\
\hline & Annealing $(450 \stackrel{\circ}{ } \mathrm{C}, 4 \mathrm{~h})$, low voltage & 10.3 & $\mathrm{MJ} / \mathrm{kWh}$ \\
\hline & Emissions - Ethanol & 1.96. & $\mathrm{~g} / \mathrm{kWh}$ \\
\hline
\end{tabular}


Perovskite photovoltaic modules: life cycle assessment of pre-industrial production process

\begin{tabular}{|c|c|c|c|}
\hline Layer & Input/Output & Amount & Unit \\
\hline & Transportation burden by lorry & $4.15 \cdot 10^{-3}$ & $\mathrm{~km} \cdot \mathrm{T} / \mathrm{kWh}$ \\
\hline \multirow{5}{*}{$\begin{array}{l}\text { Hole } \\
\text { transporting } \\
\text { layer (HTM) }\end{array}$} & Spiro-MeOTAD & 0.374 & $\mathrm{~g} / \mathrm{kWh}$ \\
\hline & Chlorobenzene & 5.66 & $\mathrm{~g} / \mathrm{kWh}$ \\
\hline & Spin-coating (4000 rpm, $30 \mathrm{~s}$ ), low voltage & 0.348 & $\mathrm{MJ} / \mathrm{kWh}$ \\
\hline & Emissions - Chlorobenzene & 5.66 & $\mathrm{~g} / \mathrm{kWh}$ \\
\hline & Transportation burden by lorry & $5.46 \cdot 10^{-3}$ & $\mathrm{~km} \cdot \mathrm{T} / \mathrm{kWh}$ \\
\hline \multirow{3}{*}{ Cathode } & Gold & 0.0237 & $\mathrm{~g} / \mathrm{kWh}$ \\
\hline & Thermal evaporation, medium voltage & 5.85 & $\mathrm{MJ} / \mathrm{kWh}$ \\
\hline & Transportation burden by lorry & $2.15 \cdot 10^{-5}$ & $\mathrm{~km} \cdot \mathrm{T} / \mathrm{kWh}$ \\
\hline \multirow{10}{*}{ Perovskite } & Lead lodide & 3.28 & $\mathrm{~g} / \mathrm{kWh}$ \\
\hline & Methylammonium lodide & 1.13 & $\mathrm{~g} / \mathrm{kWh}$ \\
\hline & v-butyrolactone & 6.61 & $\mathrm{~g} / \mathrm{kWh}$ \\
\hline & Stirring (100 ㄷ, $10 \mathrm{~min})$ & 0.0818 & $\mathrm{MJ} / \mathrm{kWh}$ \\
\hline & Stirring ( $70 \stackrel{\circ}{ } \mathrm{C}, 30 \mathrm{~min}$ ), low voltage & 0.225 & $\mathrm{MJ} / \mathrm{kWh}$ \\
\hline & Spin-coating (500 rpm, 5 s), low voltage & 0.0204 & $\mathrm{MJ} / \mathrm{kWh}$ \\
\hline & Spin-coating (2000 rpm, $60 \mathrm{~s}$ ), low voltage & 0.327 & $\mathrm{MJ} / \mathrm{kWh}$ \\
\hline & Heating (100 ㄷ, $60 \mathrm{~min}$ ), low voltage & 0.409 & $\mathrm{MJ} / \mathrm{kWh}$ \\
\hline & Emissions $-\gamma$-butyrolactone & 6.61 & $\mathrm{~g} / \mathrm{kWh}$ \\
\hline & Transportation burden by lorry & $9.99 \cdot 10^{-3}$ & $\mathrm{~km} \cdot \mathrm{T} / \mathrm{kWh}$ \\
\hline \multirow{4}{*}{ Others } & Nitrogen gas & 2004 & $\mathrm{~g} / \mathrm{kWh}$ \\
\hline & Glove box, medium voltage & 10.9 & $\mathrm{MJ} / \mathrm{kWh}$ \\
\hline & Emissions - Nitrogen gas & 2004 & $\mathrm{~g} / \mathrm{kWh}$ \\
\hline & Transportation burden by lorry & 0.164 & $\mathrm{~km} \cdot \mathrm{T} / \mathrm{kWh}$ \\
\hline
\end{tabular}




\subsection{Ideal process of production of carbon stack perovskite modules}

Table S31. Inventory of the ideal process of production of the carbon stack perovskite module, related to Figure 23.

\begin{tabular}{|c|c|c|c|}
\hline Layer & Input/Output & Amount & Unit \\
\hline \multirow{4}{*}{$\begin{array}{l}\text { Anode (FTO) } \\
+ \text { Substrate } \\
\text { (glass) }\end{array}$} & Fluorine doped Tin Oxide & 0.0190 & $\mathrm{~g} / \mathrm{kWh}$ \\
\hline & Glass & 24.3 & $\mathrm{~g} / \mathrm{kWh}$ \\
\hline & FTO sputtering, medium voltage & $1.06 \cdot 10^{-5}$ & $\mathrm{MJ} / \mathrm{kWh}$ \\
\hline & Transportation burden by lorry & $6.73 \cdot 10^{-3}$ & $\mathrm{~km} \cdot \mathrm{T} / \mathrm{kWh}$ \\
\hline \multirow{4}{*}{$\begin{array}{l}\text { Blocking } \\
\text { layer }\end{array}$} & Titanium di-isopropoxide bis(acetylacetonate) & $4.26 \cdot 10^{-3}$ & $\mathrm{~g} / \mathrm{kWh}$ \\
\hline & Air compression & $7.97 \cdot 10^{-6}$ & $\mathrm{~m}^{3} / \mathrm{kWh}$ \\
\hline & 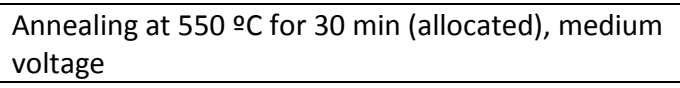 & $1.89 \cdot 10^{-3}$ & $\mathrm{MJ} / \mathrm{kWh}$ \\
\hline & Transportation burden by lorry & $1.00 \cdot 10^{-6}$ & $\mathrm{~km} \cdot \mathrm{T} / \mathrm{kWh}$ \\
\hline \multirow{5}{*}{$\begin{array}{l}\text { Semi } \\
\text { conducting } \\
\text { scaffold }\end{array}$} & Titania nanoparticles & 0.0149 & $\mathrm{~g} / \mathrm{kWh}$ \\
\hline & Screen printing, medium voltage & $6.95 \cdot 10^{-5}$ & $\mathrm{MJ} / \mathrm{kWh}$ \\
\hline & 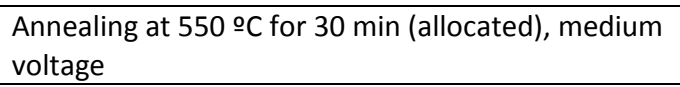 & $6.65 \cdot 10^{-3}$ & $\mathrm{MJ} / \mathrm{kWh}$ \\
\hline & Transportation burden by lorry & $3.42 \cdot 10^{-6}$ & $\mathrm{~km} \cdot \mathrm{T} / \mathrm{kWh}$ \\
\hline & Transportation burden by freight ship & $3.12 \cdot 10^{-4}$ & $\mathrm{~km} \cdot \mathrm{T} / \mathrm{kWh}$ \\
\hline \multirow{4}{*}{$\begin{array}{l}\text { Insulating } \\
\text { scaffold }\end{array}$} & Zirconia & 0.0301 & $\mathrm{~g} / \mathrm{kWh}$ \\
\hline & Screen printing, medium voltage & $6.95 \cdot 10^{-5}$ & $\mathrm{MJ} / \mathrm{kWh}$ \\
\hline & 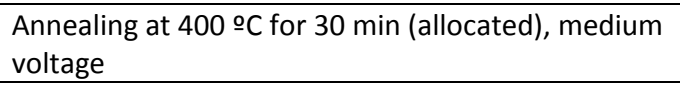 & $1.23 \cdot 10^{-3}$ & $\mathrm{MJ} / \mathrm{kWh}$ \\
\hline & Transportation burden by lorry & $3.66 \cdot 10^{-5}$ & $\mathrm{~km} \cdot \mathrm{T} / \mathrm{kWh}$ \\
\hline \multirow{4}{*}{ Cathode } & Carbon & 0.120 & $\mathrm{~g} / \mathrm{kWh}$ \\
\hline & Screen printing, medium voltage & $6.95 \cdot 10^{-5}$ & $\mathrm{MJ} / \mathrm{kWh}$ \\
\hline & 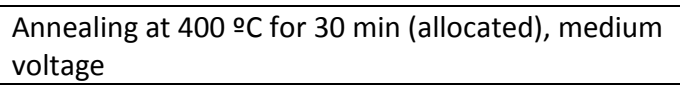 & $4.91 \cdot 10^{-3}$ & $\mathrm{MJ} / \mathrm{kWh}$ \\
\hline & Transportation burden by lorry & $1.09 \cdot 10^{-5}$ & $\mathrm{~km} \cdot \mathrm{T} / \mathrm{kWh}$ \\
\hline \multirow{7}{*}{ Perovskite } & Lead lodide & $2.96 \cdot 10^{-5}$ & $\mathrm{~g} / \mathrm{kWh}$ \\
\hline & Methylammonium lodide & $1.02 \cdot 10^{-5}$ & $\mathrm{~g} / \mathrm{kWh}$ \\
\hline & 5-ammonium valeric acid iodide & $1.56 \cdot 10^{-7}$ & $\mathrm{~g} / \mathrm{kWh}$ \\
\hline & Precursor solution mixture, low voltage & $9.76 \cdot 10^{-6}$ & $\mathrm{MJ} / \mathrm{kWh}$ \\
\hline & Annealing at $50 \stackrel{\circ}{\circ}$ for $60 \mathrm{~min}$, medium voltage & $4.09 \cdot 10^{-4}$ & $\mathrm{MJ} / \mathrm{kWh}$ \\
\hline & Transportation burden by lorry & $9.34 \cdot 10^{-9}$ & $\mathrm{~km} \cdot \mathrm{T} / \mathrm{kWh}$ \\
\hline & Transportation burden by freight & $2.16 \cdot 10^{-7}$ & $\mathrm{~km} \cdot \mathrm{T} / \mathrm{kWh}$ \\
\hline
\end{tabular}




\subsection{Inventory of ethyl cellulose model}

Table S32. Inventory for $\mathbf{1} \mathbf{~ k g}$ of ethyl cellulose, related to Figure $\mathbf{2 0}$ to Figure $\mathbf{2 3 .}$

\begin{tabular}{|l|l|l|}
\hline Name & Value & Unit \\
\hline Materials/fuels & 356.735 & $\mathrm{~g}$ \\
\hline Cellulose fibre, inclusive blowing in & 101.359 & $\mathrm{~g}$ \\
\hline Ethanol from ethylene & 80.202 & $\mathrm{~g}$ \\
\hline $\begin{array}{l}\text { Hydrochloric acid, from the reaction of hydrogen with } \\
\text { chlorine }\end{array}$ & $4 \cdot 10^{-10}$ & $\mathrm{p}$ \\
\hline Chemical plant, organics & $1.35 \cdot 10^{-6}$ & $\mathrm{kWh}$ \\
\hline Electricity/heat & 80.202 & $\mathrm{~g}$ \\
\hline Electricity, low voltage & 39.603 & $\mathrm{~g}$ \\
\hline Emissions to water & \\
\hline Hydrogen chloride & \multicolumn{2}{|l|}{} \\
\hline Water
\end{tabular}

\subsection{Inventory of $\alpha$-terpineol model}

Table S33. Inventory for $1 \mathrm{~kg}$ of $\alpha$-terpineol, related to Figure 20 to Figure 23.

\begin{tabular}{|l|l|l|}
\hline Name & Value & Unit \\
\hline Materials/fuels & 116.692 & $\mathrm{~g}$ \\
\hline Water, deionised & 550.611 & $\mathrm{~g}$ \\
\hline Dichloromethane & 25.935 & $\mathrm{~g}$ \\
\hline Hydrogen, liquid & 753.053 & $\mathrm{~g}$ \\
\hline Acetone, liquid & 337.602 & $\mathrm{~g}$ \\
\hline Acetylene & $4 \cdot 10^{-10}$ & $\mathrm{p}$ \\
\hline Chemical plant, organics & \multicolumn{2}{l|}{} \\
\hline Electricity/heat & 0.420 & $\mathrm{kWh}$ \\
\hline Electricity, low voltage & 236.366 & $\mathrm{~g}$ \\
\hline Emissions to water & 116.692 & $\mathrm{~g}$ \\
\hline Hydrogen chloride & 431.03 & $\mathrm{~g}$ \\
\hline Water & \multicolumn{2}{|l}{} \\
\hline Organic chlorine compounds (unspecified) &
\end{tabular}




\subsection{Inventory of titanium di-isopropoxide bis(acetylacetonate) model}

Table S34. Inventory for $\mathbf{1} \mathrm{kg}$ of titanium di-isopropoxide bis(acetylacetonate), related to Figure $\mathbf{2 0}$ to Figure 23.

\begin{tabular}{|l|l|l|}
\hline Name & Value & Unit \\
\hline Materials/fuels & 637.786 & $\mathrm{~g}$ \\
\hline Acetone, liquid, at plant & 520.724 & $\mathrm{~g}$ \\
\hline Titanium tetrachloride & 659.968 & $\mathrm{~g}$ \\
\hline Isopropanol & $4 \cdot 10^{-10}$ & $\mathrm{p}$ \\
\hline Chemical plant, organics & \multicolumn{2}{|l|}{} \\
\hline Electricity/heat & $1.35 \cdot 10^{-6}$ & $\mathrm{kWh}$ \\
\hline Electricity, low voltage & 329.984 & $\mathrm{~g}$ \\
\hline Emissions to water & 87.849 & $\mathrm{~g}$ \\
\hline 2-Propanol & 400.373 & $\mathrm{~g}$ \\
\hline Methane & \multicolumn{2}{|l|}{} \\
\hline Hydrogen chloride & \multicolumn{1}{|l|}{} \\
\hline
\end{tabular}

\subsection{Inventory of 5-ammonium valeric acid iodide}

Table S35. Inventory for $\mathbf{1} \mathbf{k g}$ of 5-ammonium valeric acid iodide, related to Figure $\mathbf{2 0}$ to Figure $\mathbf{2 3 .}$

\begin{tabular}{|l|l|l|}
\hline Name & Value & Unit \\
\hline Materials/fuels & 187.828 & $\mathrm{~g}$ \\
\hline Formic acid & 367.49 & $\mathrm{~g}$ \\
\hline Butane-1,4-diol & 69.541 & $\mathrm{~g}$ \\
\hline Ammonia, liquid & 4.083 & $\mathrm{~g}$ \\
\hline Hydrogen, liquid & 518.18 & $\mathrm{~g}$ \\
\hline lodine & $4 \cdot 10^{-10}$ & $\mathrm{p}$ \\
\hline Chemical plant, organics & \multicolumn{2}{|l|}{} \\
\hline Electricity/heat & $1.35 \cdot 10^{-6}$ & $\mathrm{kWh}$ \\
\hline Electricity, low voltage & 146.996 & $\mathrm{~g}$ \\
\hline Emissions to water & \multicolumn{2}{|l|}{} \\
\hline Water
\end{tabular}




\subsection{Inventory of 2-(2-butoxyethoxy) ethyl acetate model}

Table S36. Inventory for $1 \mathrm{~kg}$ of 2-(2-butoxyethoxy) ethyl acetate, related to Figure 20 to Figure 23.

\begin{tabular}{|l|l|l|}
\hline Name & Value & Unit \\
\hline Materials/fuels & 293.992 & $\mathrm{~g}$ \\
\hline Acetic acid from acetaldehyde & 519.528 & $\mathrm{~g}$ \\
\hline Diethylene glycol & 362.874 & $\mathrm{~g}$ \\
\hline 1-butanol, propylene hydroformylation & $4 \cdot 10^{-10}$ & $\mathrm{p}$ \\
\hline Chemical plant, organics & $1.35 \cdot 10^{-6}$ & $\mathrm{kWh}$ \\
\hline Electricity/heat & \multicolumn{2}{|l|}{} \\
\hline Electricity, low voltage & 78.329 & $\mathrm{~g}$ \\
\hline Emissions to air & 9.791 & \\
\hline Oxygen & \multicolumn{2}{|l|}{} \\
\hline Hydrogen & 88.12 & $\mathrm{~g}$ \\
\hline Emissions to water & \\
\hline Water
\end{tabular}

\subsection{Inventory of nitrocellulose model}

Table S37. Inventory for $1 \mathrm{~kg}$ of nitrocellulose, related to Figure 20 to Figure 23.

\begin{tabular}{|l|l|l|}
\hline Name & Value & Unit \\
\hline Materials/fuels & 162.237 & $\mathrm{~g}$ \\
\hline Cellulose fibre & 378.302 & $\mathrm{~g}$ \\
\hline Nitric acid & $4 \cdot 10^{-10}$ & $\mathrm{p}$ \\
\hline Chemical plant, organics & $1.35 \cdot 10^{-6}$ & $\mathrm{kWh}$ \\
\hline Electricity/heat & \multicolumn{2}{|l|}{} \\
\hline Electricity, low voltage & 243.183 & $\mathrm{~g}$ \\
\hline Emissions to water & & \\
\hline Water
\end{tabular}




\section{Results}

Table S38. Environmental impacts results for the carbon stack produced with the pre-industrial process given per kWh of electricity produced, related to Figure 20 to Figure 23.

ADP (kg Sb ADPF (MJ) GWP (kg ODP (kg POP (kg AP (kg SO

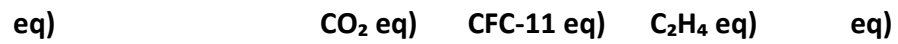

\begin{tabular}{|c|c|c|c|c|c|c|}
\hline Total & $1.70 \cdot 10^{-6}$ & 2.25 & 0.165 & $1.75 \cdot 10^{-8}$ & $7.57 \cdot 10^{-4}$ & $9.23 \cdot 10^{-4}$ \\
\hline Raw Materials & $1.66 \cdot 10^{-6}$ & 0.699 & 0.0445 & $1.14 \cdot 10^{-8}$ & $2.09 \cdot 10^{-5}$ & $3.52 \cdot 10^{-4}$ \\
\hline Anode + Substrate & $3.71 \cdot 10^{-7}$ & 0.350 & 0.0294 & $2.82 \cdot 10^{-9}$ & $9.49 \cdot 10^{-6}$ & $2.83 \cdot 10^{-4}$ \\
\hline Fluor Tin Oxide & $3.14 \cdot 10^{-7}$ & $4.82 \cdot 10^{-3}$ & $3.27 \cdot 10^{-4}$ & $2.98 \cdot 10^{-11}$ & $3.56 \cdot 10^{-7}$ & $8.10 \cdot 10^{-6}$ \\
\hline Solar glass, low-iron & $5.71 \cdot 10^{-8}$ & 0.345 & 0.0290 & $2.79 \cdot 10^{-9}$ & $9.14 \cdot 10^{-6}$ & $2.75 \cdot 10^{-4}$ \\
\hline Blocking layer & $1.79 \cdot 10^{-8}$ & 0.253 & $8.67 \cdot 10^{-3}$ & $4.87 \cdot 10^{-10}$ & $9.18 \cdot 10^{-6}$ & $3.80 \cdot 10^{-5}$ \\
\hline $\begin{array}{l}\text { Titanium } \\
\text { diisopropoxide } \\
\text { bis(acetylacetonate) }\end{array}$ & $4.71 \cdot 10^{-9}$ & 0.0458 & $2.00 \cdot 10^{-3}$ & $1.90 \cdot 10^{-10}$ & $1.79 \cdot 10^{-6}$ & $1.00 \cdot 10^{-5}$ \\
\hline Isopropanol & $1.32 \cdot 10^{-8}$ & 0.207 & $6.67 \cdot 10^{-3}$ & $2.96 \cdot 10^{-10}$ & $7.39 \cdot 10^{-6}$ & $2.80 \cdot 10^{-5}$ \\
\hline $\begin{array}{l}\text { Semi conducting } \\
\text { scaffold }\end{array}$ & $6.44 \cdot 10^{-10}$ & $7.19 \cdot 10^{-3}$ & $3.90 \cdot 10^{-4}$ & $2.19 \cdot 10^{-9}$ & $1.19 \cdot 10^{-7}$ & $2.03 \cdot 10^{-6}$ \\
\hline $\begin{array}{l}\text { Titanium dioxide, } \\
\text { chloride process }\end{array}$ & $1.35 \cdot 10^{-10}$ & $1.44 \cdot 10^{-3}$ & $8.08 \cdot 10^{-5}$ & $1.90 \cdot 10^{-11}$ & $1.74 \cdot 10^{-8}$ & $4.10 \cdot 10^{-7}$ \\
\hline Ethyl cellulose & $4.25 \cdot 10^{-11}$ & $8.20 \cdot 10^{-5}$ & $3.30 \cdot 10^{-6}$ & $1.56 \cdot 10^{-12}$ & $2.28 \cdot 10^{-9}$ & $2.23 \cdot 10^{-8}$ \\
\hline $\begin{array}{l}\text { 2-(2-butoxyethoxy) } \\
\text { ethyl acetate }\end{array}$ & $1.67 \cdot 10^{-10}$ & $1.20 \cdot 10^{-3}$ & $4.52 \cdot 10^{-5}$ & $2.78 \cdot 10^{-12}$ & $2.66 \cdot 10^{-8}$ & $1.43 \cdot 10^{-7}$ \\
\hline Terpineol & $3.00 \cdot 10^{-10}$ & $4.47 \cdot 10^{-3}$ & $2.60 \cdot 10^{-4}$ & $2.16 \cdot 10^{-9}$ & $7.29 \cdot 10^{-8}$ & $1.45 \cdot 10^{-6}$ \\
\hline Insulating scaffold & $1.19 \cdot 10^{-9}$ & $8.18 \cdot 10^{-3}$ & $5.17 \cdot 10^{-4}$ & $2.98 \cdot 10^{-9}$ & $1.36 \cdot 10^{-7}$ & $2.84 \cdot 10^{-6}$ \\
\hline Zirconia & $7.18 \cdot 10^{-10}$ & $1.95 \cdot 10^{-3}$ & $1.56 \cdot 10^{-4}$ & $1.08 \cdot 10^{-11}$ & $3.32 \cdot 10^{-8}$ & $8.21 \cdot 10^{-7}$ \\
\hline Ethyl cellulose & $5.71 \cdot 10^{-11}$ & $1.10 \cdot 10^{-4}$ & $4.43 \cdot 10^{-6}$ & $2.09 \cdot 10^{-12}$ & $3.06 \cdot 10^{-9}$ & $2.99 \cdot 10^{-8}$ \\
\hline Terpineol & $4.11 \cdot 10^{-10}$ & $6.12 \cdot 10^{-3}$ & $3.57 \cdot 10^{-4}$ & $2.96 \cdot 10^{-9}$ & $9.98 \cdot 10^{-8}$ & $1.99 \cdot 10^{-6}$ \\
\hline Cathode & $9.18 \cdot 10^{-10}$ & 0.0161 & $6.40 \cdot 10^{-4}$ & $2.64 \cdot 10^{-9}$ & $1.20 \cdot 10^{-7}$ & $2.63 \cdot 10^{-6}$ \\
\hline Carbon & $4.68 \cdot 10^{-10}$ & 0.0108 & $3.15 \cdot 10^{-4}$ & $1.74 \cdot 10^{-10}$ & $3.52 \cdot 10^{-8}$ & $8.81 \cdot 10^{-7}$ \\
\hline Nitrocellulose & $1.08 \cdot 10^{-10}$ & $1.35 \cdot 10^{-4}$ & $2.82 \cdot 10^{-5}$ & $1.09 \cdot 10^{-12}$ & $1.83 \cdot 10^{-9}$ & $9.03 \cdot 10^{-8}$ \\
\hline Terpineol & $3.41 \cdot 10^{-10}$ & $5.09 \cdot 10^{-3}$ & $2.97 \cdot 10^{-4}$ & $2.46 \cdot 10^{-9}$ & $8.30 \cdot 10^{-8}$ & $1.65 \cdot 10^{-6}$ \\
\hline Perovskite & $1.26 \cdot 10^{-6}$ & 0.0647 & $4.90 \cdot 10^{-3}$ & $2.95 \cdot 10^{-10}$ & $1.87 \cdot 10^{-6}$ & $2.36 \cdot 10^{-5}$ \\
\hline Lead iodide & $8.90 \cdot 10^{-7}$ & 0.0438 & $3.50 \cdot 10^{-3}$ & $1.90 \cdot 10^{-10}$ & $7.03 \cdot 10^{-7}$ & $1.77 \cdot 10^{-5}$ \\
\hline $\begin{array}{l}\text { Methylammonium } \\
\text { iodide }\end{array}$ & $3.63 \cdot 10^{-7}$ & 0.0126 & $9.59 \cdot 10^{-4}$ & $5.78 \cdot 10^{-11}$ & $1.06 \cdot 10^{-6}$ & $4.58 \cdot 10^{-6}$ \\
\hline $\begin{array}{l}\text { 5-ammonium } \\
\text { valeric acid iodide }\end{array}$ & $1.04 \cdot 10^{-8}$ & $6.08 \cdot 10^{-5}$ & $3.72 \cdot 10^{-6}$ & $5.72 \cdot 10^{-13}$ & $9.00 \cdot 10^{-10}$ & $1.50 \cdot 10^{-8}$ \\
\hline $\begin{array}{l}\text { Gamma- } \\
\text { butyrolactone }\end{array}$ & $7.99 \cdot 10^{-10}$ & $8.29 \cdot 10^{-3}$ & $4.40 \cdot 10^{-4}$ & $4.73 \cdot 10^{-11}$ & $1.05 \cdot 10^{-7}$ & $1.36 \cdot 10^{-6}$ \\
\hline Others & $8.73 \cdot 10^{-12}$ & $7.10 \cdot 10^{-5}$ & $2.80 \cdot 10^{-6}$ & $1.37 \cdot 10^{-13}$ & $6.19 \cdot 10^{-10}$ & $1.00 \cdot 10^{-8}$ \\
\hline
\end{tabular}


Perovskite photovoltaic modules: life cycle assessment of pre-industrial production process

\begin{tabular}{|c|c|c|c|c|c|c|}
\hline & $\begin{array}{c}\text { ADP (kg Sb } \\
\text { eq) }\end{array}$ & ADPF (MJ) & $\begin{array}{l}\text { GWP (kg } \\
\left.\mathrm{CO}_{2} \mathrm{eq}\right)\end{array}$ & $\begin{array}{c}\text { ODP (kg } \\
\text { CFC-11 eq) }\end{array}$ & $\begin{array}{l}\text { POP (kg } \\
\left.\mathrm{C}_{2} \mathrm{H}_{4} \mathrm{eq}\right)\end{array}$ & $\begin{array}{c}\mathrm{AP}\left(\mathrm{kg} \mathrm{SO} \mathrm{SO}_{2}\right. \\
\mathrm{eq})\end{array}$ \\
\hline $\begin{array}{l}\text { Screen } \\
\text { (polyethylene } \\
\text { terephtalate) }\end{array}$ & $8.73 \cdot 10^{-12}$ & $7.10 \cdot 10^{-5}$ & $2.80 \cdot 10^{-6}$ & $1.37 \cdot 10^{-13}$ & $6.19 \cdot 10^{-10}$ & $1.00 \cdot 10^{-8}$ \\
\hline $\begin{array}{l}\text { Amount of } \\
\text { transportation }\end{array}$ & $3.19 \cdot 10^{-9}$ & 0.0177 & $1.20 \cdot 10^{-3}$ & $1.93 \cdot 10^{-10}$ & $2.10 \cdot 10^{-7}$ & $6.99 \cdot 10^{-6}$ \\
\hline $\begin{array}{l}\text { Anode + Substrate } \\
\text { transport }\end{array}$ & $2.69 \cdot 10^{-9}$ & 0.0147 & $9.92 \cdot 10^{-4}$ & $1.61 \cdot 10^{-10}$ & $1.62 \cdot 10^{-7}$ & $5.41 \cdot 10^{-6}$ \\
\hline $\begin{array}{l}\text { Anode + Substrate, } \\
\text { lorry }\end{array}$ & $2.69 \cdot 10^{-9}$ & 0.0147 & $9.92 \cdot 10^{-4}$ & $1.61 \cdot 10^{-10}$ & $1.62 \cdot 10^{-7}$ & $5.41 \cdot 10^{-6}$ \\
\hline $\begin{array}{l}\text { Blocking layer } \\
\text { transport }\end{array}$ & $4.06 \cdot 10^{-10}$ & $2.21 \cdot 10^{-3}$ & $1.50 \cdot 10^{-4}$ & $2.42 \cdot 10^{-11}$ & $2.44 \cdot 10^{-8}$ & $8.16 \cdot 10^{-7}$ \\
\hline Blocking layer, lorry & $4.06 \cdot 10^{-10}$ & $2.21 \cdot 10^{-3}$ & $1.50 \cdot 10^{-4}$ & $2.42 \cdot 10^{-11}$ & $2.44 \cdot 10^{-8}$ & $8.16 \cdot 10^{-7}$ \\
\hline $\begin{array}{l}\text { Semi conducting } \\
\text { scaffold transport }\end{array}$ & $1.10 \cdot 10^{-11}$ & $3.45 \cdot 10^{-4}$ & $2.55 \cdot 10^{-5}$ & $3.07 \cdot 10^{-12}$ & $1.61 \cdot 10^{-8}$ & $5.08 \cdot 10^{-7}$ \\
\hline $\begin{array}{l}\text { Semi conducting } \\
\text { scaffold, lorry }\end{array}$ & $8.95 \cdot 10^{-12}$ & $4.87 \cdot 10^{-5}$ & $3.30 \cdot 10^{-6}$ & $5.34 \cdot 10^{-13}$ & $5.38 \cdot 10^{-10}$ & $1.80 \cdot 10^{-8}$ \\
\hline $\begin{array}{l}\text { Semi conducting } \\
\text { scaffold, freight }\end{array}$ & $2.04 \cdot 10^{-12}$ & $2.96 \cdot 10^{-4}$ & $2.22 \cdot 10^{-5}$ & $2.53 \cdot 10^{-12}$ & $1.56 \cdot 10^{-8}$ & $4.90 \cdot 10^{-7}$ \\
\hline $\begin{array}{l}\text { Insulating scaffold } \\
\text { transport }\end{array}$ & $5.85 \cdot 10^{-11}$ & $3.19 \cdot 10^{-4}$ & $2.16 \cdot 10^{-5}$ & $3.49 \cdot 10^{-12}$ & $3.52 \cdot 10^{-9}$ & $1.18 \cdot 10^{-7}$ \\
\hline $\begin{array}{l}\text { Insulating scaffold, } \\
\text { lorry }\end{array}$ & $5.85 \cdot 10^{-11}$ & $3.19 \cdot 10^{-4}$ & $2.16 \cdot 10^{-5}$ & $3.49 \cdot 10^{-12}$ & $3.52 \cdot 10^{-9}$ & $1.18 \cdot 10^{-7}$ \\
\hline Cathode transport & $7.29 \cdot 10^{-12}$ & $3.97 \cdot 10^{-5}$ & $2.69 \cdot 10^{-6}$ & $4.35 \cdot 10^{-13}$ & $4.38 \cdot 10^{-10}$ & $1.46 \cdot 10^{-8}$ \\
\hline Cathode, lorry & $7.29 \cdot 10^{-12}$ & $3.97 \cdot 10^{-5}$ & $2.69 \cdot 10^{-6}$ & $4.35 \cdot 10^{-13}$ & $4.38 \cdot 10^{-10}$ & $1.46 \cdot 10^{-8}$ \\
\hline Perovskite transport & $1.79 \cdot 10^{-11}$ & $1.52 \cdot 10^{-4}$ & $1.07 \cdot 10^{-5}$ & $1.53 \cdot 10^{-12}$ & $4.01 \cdot 10^{-9}$ & $1.28 \cdot 10^{-7}$ \\
\hline Perovskite, lorry & $1.75 \cdot 10^{-11}$ & $9.52 \cdot 10^{-5}$ & $6.45 \cdot 10^{-6}$ & $1.04 \cdot 10^{-12}$ & $1.05 \cdot 10^{-9}$ & $3.52 \cdot 10^{-8}$ \\
\hline Perovskite, freight & $3.88 \cdot 10^{-13}$ & $5.63 \cdot 10^{-5}$ & $4.21 \cdot 10^{-6}$ & $4.81 \cdot 10^{-13}$ & $2.96 \cdot 10^{-9}$ & $9.31 \cdot 10^{-8}$ \\
\hline Others transport & $1.35 \cdot 10^{-13}$ & $7.35 \cdot 10^{-7}$ & $4.98 \cdot 10^{-8}$ & $8.06 \cdot 10^{-15}$ & $8.11 \cdot 10^{-12}$ & $2.71 \cdot 10^{-10}$ \\
\hline Others, lorry & $1.35 \cdot 10^{-13}$ & $7.35 \cdot 10^{-7}$ & $4.98 \cdot 10^{-8}$ & $8.06 \cdot 10^{-15}$ & $8.11 \cdot 10^{-12}$ & $2.71 \cdot 10^{-10}$ \\
\hline Use of Energy & $3.84 \cdot 10^{-8}$ & 1.53 & 0.120 & $5.94 \cdot 10^{-9}$ & $2.23 \cdot 10^{-5}$ & $5.60 \cdot 10^{-4}$ \\
\hline Anode + Substrate & $1.92 \cdot 10^{-9}$ & 0.0788 & $6.17 \cdot 10^{-3}$ & $3.06 \cdot 10^{-10}$ & $1.15 \cdot 10^{-6}$ & $2.89 \cdot 10^{-5}$ \\
\hline Blocking layer & $8.96 \cdot 10^{-9}$ & 0.367 & 0.0287 & $1.42 \cdot 10^{-9}$ & $5.35 \cdot 10^{-6}$ & $1.34 \cdot 10^{-4}$ \\
\hline $\begin{array}{l}\text { Blocking layer, } \\
\text { medium voltage } \\
\text { (allocated } \\
\text { annealing) }\end{array}$ & $8.94 \cdot 10^{-9}$ & 0.367 & 0.0287 & $1.42 \cdot 10^{-9}$ & $5.35 \cdot 10^{-6}$ & $1.34 \cdot 10^{-4}$ \\
\hline $\begin{array}{l}\text { compressed air, } \\
1000 \mathrm{kPa} \text { gauge }\end{array}$ & $2.07 \cdot 10^{-11}$ & $1.52 \cdot 10^{-5}$ & $1.23 \cdot 10^{-6}$ & $7.04 \cdot 10^{-14}$ & $3.60 \cdot 10^{-10}$ & $7.62 \cdot 10^{-9}$ \\
\hline $\begin{array}{l}\text { Semi conducting } \\
\text { scaffold }\end{array}$ & $3.68 \cdot 10^{-10}$ & 0.0151 & $1.18 \cdot 10^{-3}$ & $5.87 \cdot 10^{-11}$ & $2.20 \cdot 10^{-7}$ & $5.53 \cdot 10^{-6}$ \\
\hline Insulating scaffold & $1.90 \cdot 10^{-9}$ & 0.0780 & $6.11 \cdot 10^{-3}$ & $3.03 \cdot 10^{-10}$ & $1.14 \cdot 10^{-6}$ & $2.86 \cdot 10^{-5}$ \\
\hline Cathode & $6.32 \cdot 10^{-9}$ & 0.259 & 0.0203 & $1.01 \cdot 10^{-9}$ & $3.78 \cdot 10^{-6}$ & $9.49 \cdot 10^{-5}$ \\
\hline Perovskite & $1.89 \cdot 10^{-8}$ & 0.731 & 0.0572 & $2.84 \cdot 10^{-9}$ & $1.07 \cdot 10^{-5}$ & $2.68 \cdot 10^{-4}$ \\
\hline
\end{tabular}




\begin{tabular}{|c|c|c|c|c|c|c|}
\hline & $\begin{array}{l}\text { ADP (kg Sb } \\
\text { eq) }\end{array}$ & ADPF (MJ) & $\begin{array}{l}\text { GWP (kg } \\
\mathrm{CO}_{2} \text { eq) }\end{array}$ & $\begin{array}{l}\text { ODP (kg } \\
\text { CFC-11 eq) }\end{array}$ & $\begin{array}{l}\text { POP (kg } \\
\left.\mathrm{C}_{2} \mathrm{H}_{4} \mathrm{eq}\right)\end{array}$ & $\begin{array}{c}\mathrm{AP}(\mathrm{kg} \mathrm{SO} \\
\text { eq) }\end{array}$ \\
\hline $\begin{array}{l}\text { Perovskite, low } \\
\text { voltage }\end{array}$ & $1.37 \cdot 10^{-9}$ & 0.0102 & $7.97 \cdot 10^{-4}$ & $3.95 \cdot 10^{-11}$ & $1.53 \cdot 10^{-7}$ & $3.83 \cdot 10^{-6}$ \\
\hline $\begin{array}{l}\text { Perovskite, medium } \\
\text { voltage }\end{array}$ & $1.76 \cdot 10^{-8}$ & 0.721 & 0.0564 & $2.80 \cdot 10^{-9}$ & $1.05 \cdot 10^{-5}$ & $2.64 \cdot 10^{-4}$ \\
\hline Emissions & 0 & 0 & $4.72 \cdot 10^{-5}$ & 0 & $7.13 \cdot 10^{-4}$ & $3.88 \cdot 10^{-6}$ \\
\hline $\begin{array}{l}\text { Anode + Substrate } \\
\text { emissions }\end{array}$ & 0 & 0 & 0 & 0 & 0 & 0 \\
\hline $\begin{array}{l}\text { Blocking layer } \\
\text { emissions }\end{array}$ & 0 & 0 & 0 & 0 & $7.13 \cdot 10^{-4}$ & 0 \\
\hline $\begin{array}{l}\text { Emissions - } \\
\text { Acetylacetone }\end{array}$ & 0 & 0 & 0 & 0 & 0 & 0 \\
\hline $\begin{array}{l}\text { Emissions - } \\
\text { isopropanol }\end{array}$ & 0 & 0 & 0 & 0 & $7.13 \cdot 10^{-4}$ & 0 \\
\hline $\begin{array}{l}\text { Semi conducting } \\
\text { scaffold emissions }\end{array}$ & 0 & 0 & $1.38 \cdot 10^{-5}$ & 0 & 0 & 0 \\
\hline $\begin{array}{l}\text { Emissions - Titanium } \\
\text { dioxide }\end{array}$ & 0 & 0 & 0 & 0 & 0 & 0 \\
\hline $\begin{array}{l}\text { Emissions - Ethyl } \\
\text { cellulose }\end{array}$ & 0 & 0 & 0 & 0 & 0 & 0 \\
\hline $\begin{array}{l}\text { Emissions - } \\
\text { Diethylene glycol } \\
\text { monobutyl ether } \\
\text { acetate }\end{array}$ & 0 & 0 & 0 & 0 & 0 & 0 \\
\hline $\begin{array}{l}\text { Emissions - } \\
\text { Terpineol }\end{array}$ & 0 & 0 & 0 & 0 & 0 & 0 \\
\hline $\begin{array}{l}\text { Emissions - Carbon } \\
\text { dioxide }\end{array}$ & 0 & 0 & $1.38 \cdot 10^{-5}$ & 0 & 0 & 0 \\
\hline $\begin{array}{l}\text { Emissions - Water } \\
\text { vapour }\end{array}$ & 0 & 0 & 0 & 0 & 0 & 0 \\
\hline $\begin{array}{l}\text { Insulating scaffold } \\
\text { emissions }\end{array}$ & 0 & 0 & $1.86 \cdot 10^{-5}$ & 0 & 0 & 0 \\
\hline $\begin{array}{l}\text { Emissions - } \\
\text { Zirconium dioxide }\end{array}$ & 0 & 0 & 0 & 0 & 0 & 0 \\
\hline $\begin{array}{l}\text { Emissions - Ethyl } \\
\text { cellulose }\end{array}$ & 0 & 0 & 0 & 0 & 0 & 0 \\
\hline $\begin{array}{l}\text { Emissions - } \\
\text { Terpineol }\end{array}$ & 0 & 0 & 0 & 0 & 0 & 0 \\
\hline $\begin{array}{l}\text { Emissions - Carbon } \\
\text { dioxide }\end{array}$ & 0 & 0 & $1.86 \cdot 10^{-5}$ & 0 & 0 & 0 \\
\hline $\begin{array}{l}\text { Emissions - Water } \\
\text { vapour }\end{array}$ & 0 & 0 & 0 & 0 & 0 & 0 \\
\hline Cathode emissions & 0 & 0 & $1.48 \cdot 10^{-5}$ & 0 & $2.17 \cdot 10^{-7}$ & $3.88 \cdot 10^{-6}$ \\
\hline Emissions - Carbon & 0 & 0 & 0 & 0 & 0 & 0 \\
\hline $\begin{array}{l}\text { Emissions - } \\
\text { Nitrocellulose }\end{array}$ & 0 & 0 & 0 & 0 & 0 & 0 \\
\hline $\begin{array}{l}\text { Emissions - } \\
\text { Terpineol }\end{array}$ & 0 & 0 & 0 & 0 & 0 & 0 \\
\hline
\end{tabular}


Perovskite photovoltaic modules: life cycle assessment of pre-industrial production process

\begin{tabular}{|c|c|c|c|c|c|c|}
\hline & $\begin{array}{c}\text { ADP (kg Sb } \\
\text { eq) }\end{array}$ & ADPF (MJ) & $\begin{array}{l}\text { GWP (kg } \\
\left.\mathrm{CO}_{2} \mathrm{eq}\right)\end{array}$ & $\begin{array}{c}\text { ODP (kg } \\
\text { CFC-11 eq) }\end{array}$ & $\begin{array}{l}\mathrm{POP}(\mathrm{kg} \\
\left.\mathrm{C}_{2} \mathrm{H}_{4} \mathrm{eq}\right)\end{array}$ & $\begin{array}{c}\mathrm{AP}\left(\mathrm{kg} \mathrm{SO} \mathrm{SO}_{2}\right. \\
\mathrm{eq})\end{array}$ \\
\hline $\begin{array}{l}\text { Emissions - Carbon } \\
\text { dioxide }\end{array}$ & 0 & 0 & $1.48 \cdot 10^{-5}$ & 0 & 0 & 0 \\
\hline $\begin{array}{l}\text { Emissions - Water } \\
\text { vapour }\end{array}$ & 0 & 0 & 0 & 0 & 0 & 0 \\
\hline $\begin{array}{l}\text { Emissions - Nitrogen } \\
\text { dioxide }\end{array}$ & 0 & 0 & 0 & 0 & $2.17 \cdot 10^{-7}$ & $3.88 \cdot 10^{-6}$ \\
\hline $\begin{array}{l}\text { Perovskite } \\
\text { emissions }\end{array}$ & 0 & 0 & 0 & 0 & 0 & 0 \\
\hline $\begin{array}{l}\text { Emissions - } \\
\text { butyrolactone }\end{array}$ & 0 & 0 & 0 & 0 & 0 & 0 \\
\hline
\end{tabular}


Table S38 Bis. Environmental impacts results for the carbon stack produced with the pre-industrial process given per kWh of electricity produced, related to Figure 20 to Figure 23.

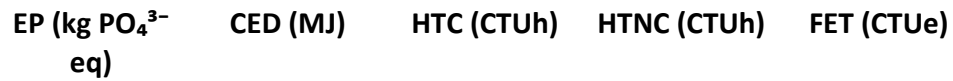

\begin{tabular}{|c|c|c|c|c|c|}
\hline Total & $4.41 \cdot 10^{-4}$ & 3.57 & $1.05 \cdot 10^{-8}$ & $3.97 \cdot 10^{-8}$ & 1.36 \\
\hline Raw Materials & $7.33 \cdot 10^{-5}$ & 0.799 & $1.43 \cdot 10^{-9}$ & $6.48 \cdot 10^{-9}$ & 0.140 \\
\hline Anode + Substrate & $3.61 \cdot 10^{-5}$ & 0.388 & $6.92 \cdot 10^{-10}$ & $3.01 \cdot 10^{-9}$ & 0.0640 \\
\hline Fluor Tin Oxide & $1.15 \cdot 10^{-6}$ & $6.76 \cdot 10^{-3}$ & $4.45 \cdot 10^{-11}$ & $1.06 \cdot 10^{-10}$ & $2.62 \cdot 10^{-3}$ \\
\hline Solar glass, low-iron & $3.50 \cdot 10^{-5}$ & 0.381 & $6.48 \cdot 10^{-10}$ & $2.90 \cdot 10^{-9}$ & 0.0614 \\
\hline Blocking layer & $1.94 \cdot 10^{-5}$ & 0.267 & $2.51 \cdot 10^{-10}$ & $1.01 \cdot 10^{-9}$ & 0.0277 \\
\hline $\begin{array}{l}\text { Titanium } \\
\text { diisopropoxide } \\
\text { bis(acetylacetonate) }\end{array}$ & $4.06 \cdot 10^{-6}$ & 0.0492 & $6.91 \cdot 10^{-11}$ & $3.21 \cdot 10^{-10}$ & 0.0116 \\
\hline Isopropanol & $1.53 \cdot 10^{-5}$ & 0.218 & $1.81 \cdot 10^{-10}$ & $6.86 \cdot 10^{-10}$ & 0.0161 \\
\hline $\begin{array}{l}\text { Semi conducting } \\
\text { scaffold }\end{array}$ & $5.97 \cdot 10^{-7}$ & $8.62 \cdot 10^{-3}$ & $1.90 \cdot 10^{-11}$ & $7.62 \cdot 10^{-11}$ & $1.76 \cdot 10^{-3}$ \\
\hline $\begin{array}{l}\text { Titanium dioxide, } \\
\text { chloride process }\end{array}$ & $2.35 \cdot 10^{-7}$ & $1.82 \cdot 10^{-3}$ & $4.33 \cdot 10^{-12}$ & $2.38 \cdot 10^{-11}$ & $7.27 \cdot 10^{-4}$ \\
\hline Ethyl cellulose & $1.01 \cdot 10^{-8}$ & $1.11 \cdot 10^{-4}$ & $3.54 \cdot 10^{-13}$ & $2.46 \cdot 10^{-12}$ & $4.68 \cdot 10^{-5}$ \\
\hline $\begin{array}{l}\text { 2-(2-butoxyethoxy) } \\
\text { ethyl acetate }\end{array}$ & $5.66 \cdot 10^{-8}$ & $1.32 \cdot 10^{-3}$ & $1.88 \cdot 10^{-12}$ & $9.62 \cdot 10^{-12}$ & $2.73 \cdot 10^{-4}$ \\
\hline Terpineol & $2.96 \cdot 10^{-7}$ & $5.37 \cdot 10^{-3}$ & $1.24 \cdot 10^{-11}$ & $4.04 \cdot 10^{-11}$ & $7.14 \cdot 10^{-4}$ \\
\hline Insulating scaffold & $8.27 \cdot 10^{-7}$ & 0.0104 & $2.92 \cdot 10^{-11}$ & $1.38 \cdot 10^{-10}$ & $2.21 \cdot 10^{-3}$ \\
\hline Zirconia & $4.08 \cdot 10^{-7}$ & $2.85 \cdot 10^{-3}$ & $1.17 \cdot 10^{-11}$ & $7.89 \cdot 10^{-11}$ & $1.17 \cdot 10^{-3}$ \\
\hline Ethyl cellulose & $1.36 \cdot 10^{-8}$ & $1.49 \cdot 10^{-4}$ & $4.75 \cdot 10^{-13}$ & $3.31 \cdot 10^{-12}$ & $6.28 \cdot 10^{-5}$ \\
\hline Terpineol & $4.05 \cdot 10^{-7}$ & $7.36 \cdot 10^{-3}$ & $1.70 \cdot 10^{-11}$ & $5.53 \cdot 10^{-11}$ & $9.78 \cdot 10^{-4}$ \\
\hline Cathode & $4.91 \cdot 10^{-7}$ & 0.0172 & $1.84 \cdot 10^{-11}$ & $7.28 \cdot 10^{-11}$ & $1.37 \cdot 10^{-3}$ \\
\hline Carbon & $1.08 \cdot 10^{-7}$ & 0.0109 & $3.68 \cdot 10^{-12}$ & $2.23 \cdot 10^{-11}$ & $4.64 \cdot 10^{-4}$ \\
\hline Nitrocellulose & $4.53 \cdot 10^{-8}$ & $1.63 \cdot 10^{-4}$ & $5.98 \cdot 10^{-13}$ & $4.48 \cdot 10^{-12}$ & $9.72 \cdot 10^{-5}$ \\
\hline Terpineol & $3.37 \cdot 10^{-7}$ & $6.12 \cdot 10^{-3}$ & $1.42 \cdot 10^{-11}$ & $4.60 \cdot 10^{-11}$ & $8.13 \cdot 10^{-4}$ \\
\hline Perovskite & $1.58 \cdot 10^{-5}$ & 0.108 & $4.22 \cdot 10^{-10}$ & $2.17 \cdot 10^{-9}$ & 0.0427 \\
\hline Lead iodide & $1.23 \cdot 10^{-5}$ & 0.0768 & $3.20 \cdot 10^{-10}$ & $1.74 \cdot 10^{-9}$ & 0.0328 \\
\hline $\begin{array}{l}\text { Methylammonium } \\
\text { iodide }\end{array}$ & $2.90 \cdot 10^{-6}$ & 0.0216 & $8.44 \cdot 10^{-11}$ & $3.48 \cdot 10^{-10}$ & $8.18 \cdot 10^{-3}$ \\
\hline $\begin{array}{l}\text { 5-ammonium } \\
\text { valeric acid iodide }\end{array}$ & $4.27 \cdot 10^{-9}$ & $6.79 \cdot 10^{-5}$ & $1.27 \cdot 10^{-13}$ & $7.81 \cdot 10^{-13}$ & $1.51 \cdot 10^{-5}$ \\
\hline $\begin{array}{l}\text { Gamma- } \\
\text { butyrolactone }\end{array}$ & $5.70 \cdot 10^{-7}$ & $9.58 \cdot 10^{-3}$ & $1.73 \cdot 10^{-11}$ & $8.17 \cdot 10^{-11}$ & $1.68 \cdot 10^{-3}$ \\
\hline Others & $3.44 \cdot 10^{-9}$ & $7.92 \cdot 10^{-5}$ & $1.59 \cdot 10^{-13}$ & $5.54 \cdot 10^{-13}$ & $1.32 \cdot 10^{-5}$ \\
\hline $\begin{array}{l}\text { Screen } \\
\text { (polyethylene } \\
\text { terephtalate) }\end{array}$ & $3.44 \cdot 10^{-9}$ & $7.92 \cdot 10^{-5}$ & $1.59 \cdot 10^{-13}$ & $5.54 \cdot 10^{-13}$ & $1.32 \cdot 10^{-5}$ \\
\hline $\begin{array}{l}\text { Amount of } \\
\text { transportation }\end{array}$ & $1.77 \cdot 10^{-6}$ & 0.0191 & $7.33 \cdot 10^{-11}$ & $2.18 \cdot 10^{-10}$ & $4.82 \cdot 10^{-3}$ \\
\hline
\end{tabular}


Perovskite photovoltaic modules: life cycle assessment of pre-industrial production process

\begin{tabular}{|c|c|c|c|c|c|}
\hline & $\begin{array}{c}\mathrm{EP}\left(\mathrm{kg} \mathrm{PO}{ }_{4}^{3-}\right. \\
\mathrm{eq})\end{array}$ & CED (MJ) & HTC (CTUh) & HTNC (CTUh) & FET (CTUe) \\
\hline $\begin{array}{l}\text { Anode + Substrate } \\
\text { transport }\end{array}$ & $1.44 \cdot 10^{-6}$ & 0.0158 & $6.11 \cdot 10^{-11}$ & $1.82 \cdot 10^{-10}$ & $4.03 \cdot 10^{-3}$ \\
\hline $\begin{array}{l}\text { Anode + Substrate, } \\
\text { lorry }\end{array}$ & $1.44 \cdot 10^{-6}$ & 0.0158 & $6.11 \cdot 10^{-11}$ & $1.82 \cdot 10^{-10}$ & $4.03 \cdot 10^{-3}$ \\
\hline $\begin{array}{l}\text { Blocking layer } \\
\text { transport }\end{array}$ & $2.18 \cdot 10^{-7}$ & $2.38 \cdot 10^{-3}$ & $9.22 \cdot 10^{-12}$ & $2.75 \cdot 10^{-11}$ & $6.08 \cdot 10^{-4}$ \\
\hline Blocking layer, lorry & $2.18 \cdot 10^{-7}$ & $2.38 \cdot 10^{-3}$ & $9.22 \cdot 10^{-12}$ & $2.75 \cdot 10^{-11}$ & $6.08 \cdot 10^{-4}$ \\
\hline $\begin{array}{l}\text { Semi conducting } \\
\text { scaffold transport }\end{array}$ & $5.84 \cdot 10^{-8}$ & $3.84 \cdot 10^{-4}$ & $9.50 \cdot 10^{-13}$ & $2.44 \cdot 10^{-12}$ & $5.05 \cdot 10^{-5}$ \\
\hline $\begin{array}{l}\text { Semi conducting } \\
\text { scaffold, lorry }\end{array}$ & $4.80 \cdot 10^{-9}$ & $5.25 \cdot 10^{-5}$ & $2.03 \cdot 10^{-13}$ & $6.05 \cdot 10^{-13}$ & $1.34 \cdot 10^{-5}$ \\
\hline $\begin{array}{l}\text { Semi conducting } \\
\text { scaffold, freight }\end{array}$ & $5.36 \cdot 10^{-8}$ & $3.31 \cdot 10^{-4}$ & $7.47 \cdot 10^{-13}$ & $1.83 \cdot 10^{-12}$ & $3.71 \cdot 10^{-5}$ \\
\hline $\begin{array}{l}\text { Insulating scaffold } \\
\text { transport }\end{array}$ & $3.14 \cdot 10^{-8}$ & $3.43 \cdot 10^{-4}$ & $1.33 \cdot 10^{-12}$ & $3.96 \cdot 10^{-12}$ & $8.76 \cdot 10^{-5}$ \\
\hline $\begin{array}{l}\text { Insulating scaffold, } \\
\text { lorry }\end{array}$ & $3.14 \cdot 10^{-8}$ & $3.43 \cdot 10^{-4}$ & $1.33 \cdot 10^{-12}$ & $3.96 \cdot 10^{-12}$ & $8.76 \cdot 10^{-5}$ \\
\hline Cathode transport & $3.91 \cdot 10^{-9}$ & $4.28 \cdot 10^{-5}$ & $1.65 \cdot 10^{-13}$ & $4.93 \cdot 10^{-13}$ & $1.09 \cdot 10^{-5}$ \\
\hline Cathode, lorry & $3.91 \cdot 10^{-9}$ & $4.28 \cdot 10^{-5}$ & $1.65 \cdot 10^{-13}$ & $4.93 \cdot 10^{-13}$ & $1.09 \cdot 10^{-5}$ \\
\hline Perovskite transport & $1.96 \cdot 10^{-8}$ & $1.66 \cdot 10^{-4}$ & $5.39 \cdot 10^{-13}$ & $1.53 \cdot 10^{-12}$ & $3.32 \cdot 10^{-5}$ \\
\hline Perovskite, lorry & $9.38 \cdot 10^{-9}$ & $1.03 \cdot 10^{-4}$ & $3.97 \cdot 10^{-13}$ & $1.18 \cdot 10^{-12}$ & $2.62 \cdot 10^{-5}$ \\
\hline Perovskite, freight & $1.02 \cdot 10^{-8}$ & $6.29 \cdot 10^{-5}$ & $1.42 \cdot 10^{-13}$ & $3.48 \cdot 10^{-13}$ & $7.04 \cdot 10^{-6}$ \\
\hline Others transport & $7.24 \cdot 10^{-11}$ & $7.92 \cdot 10^{-7}$ & $3.06 \cdot 10^{-15}$ & $9.13 \cdot 10^{-15}$ & $2.02 \cdot 10^{-7}$ \\
\hline Others, lorry & $7.24 \cdot 10^{-11}$ & $7.92 \cdot 10^{-7}$ & $3.06 \cdot 10^{-15}$ & $9.13 \cdot 10^{-15}$ & $2.02 \cdot 10^{-7}$ \\
\hline Use of Energy & $3.65 \cdot 10^{-4}$ & 2.75 & $8.99 \cdot 10^{-9}$ & $3.30 \cdot 10^{-8}$ & 0.799 \\
\hline Anode + Substrate & $1.88 \cdot 10^{-5}$ & 0.142 & $4.63 \cdot 10^{-10}$ & $1.70 \cdot 10^{-9}$ & 0.0411 \\
\hline Blocking layer & $8.75 \cdot 10^{-5}$ & 0.660 & $2.15 \cdot 10^{-9}$ & $7.91 \cdot 10^{-9}$ & 0.191 \\
\hline $\begin{array}{l}\text { Blocking layer, } \\
\text { medium voltage } \\
\text { (allocated } \\
\text { annealing) }\end{array}$ & $8.75 \cdot 10^{-5}$ & 0.660 & $2.15 \cdot 10^{-9}$ & $7.90 \cdot 10^{-9}$ & 0.191 \\
\hline $\begin{array}{l}\text { compressed air, } \\
1000 \mathrm{kPa} \text { gauge }\end{array}$ & $6.02 \cdot 10^{-9}$ & $2.49 \cdot 10^{-5}$ & $2.95 \cdot 10^{-13}$ & $1.92 \cdot 10^{-12}$ & $4.18 \cdot 10^{-5}$ \\
\hline $\begin{array}{l}\text { Semi conducting } \\
\text { scaffold }\end{array}$ & $3.60 \cdot 10^{-6}$ & 0.0272 & $8.86 \cdot 10^{-11}$ & $3.25 \cdot 10^{-10}$ & $7.87 \cdot 10^{-3}$ \\
\hline Insulating scaffold & $1.86 \cdot 10^{-5}$ & 0.140 & $4.58 \cdot 10^{-10}$ & $1.68 \cdot 10^{-9}$ & 0.0407 \\
\hline Cathode & $6.18 \cdot 10^{-5}$ & 0.466 & $1.52 \cdot 10^{-9}$ & $5.58 \cdot 10^{-9}$ & 0.135 \\
\hline Perovskite & $1.74 \cdot 10^{-4}$ & 1.31 & $4.30 \cdot 10^{-9}$ & $1.58 \cdot 10^{-8}$ & 0.383 \\
\hline $\begin{array}{l}\text { Perovskite, low } \\
\text { voltage }\end{array}$ & $2.55 \cdot 10^{-6}$ & 0.0183 & $7.45 \cdot 10^{-11}$ & $3.01 \cdot 10^{-10}$ & $7.14 \cdot 10^{-3}$ \\
\hline $\begin{array}{l}\text { Perovskite, medium } \\
\text { voltage }\end{array}$ & $1.72 \cdot 10^{-4}$ & 1.30 & $4.23 \cdot 10^{-9}$ & $1.55 \cdot 10^{-8}$ & 0.376 \\
\hline Emissions & $1.01 \cdot 10^{-6}$ & 0 & 0 & 0 & 0.412 \\
\hline
\end{tabular}




\begin{tabular}{|c|c|c|c|c|c|}
\hline & $\begin{array}{c}\mathrm{EP}\left(\mathrm{kg} \mathrm{PO}_{4}{ }^{3-}\right. \\
\mathrm{eq})\end{array}$ & CED (MJ) & HTC (CTUh) & HTNC (CTUh) & FET (CTUe) \\
\hline $\begin{array}{l}\text { Anode + Substrate } \\
\text { emissions }\end{array}$ & 0 & 0 & 0 & 0 & 0 \\
\hline $\begin{array}{l}\text { Blocking layer } \\
\text { emissions }\end{array}$ & 0 & 0 & 0 & 0 & 0.0646 \\
\hline $\begin{array}{l}\text { Emissions - } \\
\text { Acetylacetone }\end{array}$ & 0 & 0 & 0 & 0 & 0.0643 \\
\hline $\begin{array}{l}\text { Emissions - } \\
\text { isopropanol }\end{array}$ & 0 & 0 & 0 & 0 & $3.03 \cdot 10^{-4}$ \\
\hline $\begin{array}{l}\text { Semi conducting } \\
\text { scaffold emissions }\end{array}$ & 0 & 0 & 0 & 0 & 0.0978 \\
\hline $\begin{array}{l}\text { Emissions - Titanium } \\
\text { dioxide }\end{array}$ & 0 & 0 & 0 & 0 & 0 \\
\hline $\begin{array}{l}\text { Emissions - Ethyl } \\
\text { cellulose }\end{array}$ & 0 & 0 & 0 & 0 & 0 \\
\hline $\begin{array}{l}\text { Emissions - } \\
\text { Diethylene glycol } \\
\text { monobutyl ether } \\
\text { acetate }\end{array}$ & 0 & 0 & 0 & 0 & 0 \\
\hline $\begin{array}{l}\text { Emissions - } \\
\text { Terpineol }\end{array}$ & 0 & 0 & 0 & 0 & 0.0978 \\
\hline $\begin{array}{l}\text { Emissions - Carbon } \\
\text { dioxide }\end{array}$ & 0 & 0 & 0 & 0 & 0 \\
\hline $\begin{array}{l}\text { Emissions - Water } \\
\text { vapour }\end{array}$ & 0 & 0 & 0 & 0 & 0 \\
\hline $\begin{array}{l}\text { Insulating scaffold } \\
\text { emissions }\end{array}$ & 0 & 0 & 0 & 0 & 0.134 \\
\hline $\begin{array}{l}\text { Emissions - } \\
\text { Zirconium dioxide }\end{array}$ & 0 & 0 & 0 & 0 & 0 \\
\hline $\begin{array}{l}\text { Emissions - Ethyl } \\
\text { cellulose }\end{array}$ & 0 & 0 & 0 & 0 & 0 \\
\hline $\begin{array}{l}\text { Emissions - } \\
\text { Terpineol }\end{array}$ & 0 & 0 & 0 & 0 & 0.134 \\
\hline $\begin{array}{l}\text { Emissions - Carbon } \\
\text { dioxide }\end{array}$ & 0 & 0 & 0 & 0 & 0 \\
\hline $\begin{array}{l}\text { Emissions - Water } \\
\text { vapour }\end{array}$ & 0 & 0 & 0 & 0 & 0 \\
\hline Cathode emissions & $1.01 \cdot 10^{-6}$ & 0 & 0 & 0 & 0.112 \\
\hline Emissions - Carbon & 0 & 0 & 0 & 0 & 0 \\
\hline $\begin{array}{l}\text { Emissions - } \\
\text { Nitrocellulose }\end{array}$ & 0 & 0 & 0 & 0 & $1.10 \cdot 10^{-4}$ \\
\hline $\begin{array}{l}\text { Emissions - } \\
\text { Terpineol }\end{array}$ & 0 & 0 & 0 & 0 & 0.111 \\
\hline $\begin{array}{l}\text { Emissions - Carbon } \\
\text { dioxide }\end{array}$ & 0 & 0 & 0 & 0 & 0 \\
\hline $\begin{array}{l}\text { Emissions - Water } \\
\text { vapour }\end{array}$ & 0 & 0 & 0 & 0 & 0 \\
\hline $\begin{array}{l}\text { Emissions - Nitrogen } \\
\text { dioxide }\end{array}$ & $1.01 \cdot 10^{-6}$ & 0 & 0 & 0 & 0 \\
\hline
\end{tabular}


Perovskite photovoltaic modules: life cycle assessment of pre-industrial production process

\begin{tabular}{lccccc}
\hline & $\begin{array}{c}\text { EP (kg PO } \\
\text { eq) }\end{array}$ & CED (MJ) & HTC (CTUh) & HTNC (CTUh) & FET (CTUe) \\
\hline $\begin{array}{l}\text { Perovskite } \\
\text { emissions }\end{array}$ & 0 & 0 & 0 & 0 & $4.04 \cdot 10^{-3}$ \\
\hline $\begin{array}{l}\text { Emissions - } \\
\text { butyrolactone }\end{array}$ & 0 & 0 & 0 & 0 & $4.04 \cdot 10^{-3}$ \\
\hline
\end{tabular}


Table S39. Results of the PSC produced with the laboratory scale method given per kWh of electricity produced given per kWh of electricity produced, related to Figure 23. $\begin{array}{cccccc}\text { ADP (kg Sb } & \text { ADPF (MJ) } & \text { GWP (kg } & \text { ODP (kg } & \text { POP (kg } & \text { AP (kg SO} \\ \text { eq) } & & \mathrm{CO}_{2} \text { eq) } & \text { CFC-11 eq) } & \mathrm{C}_{2} \mathrm{H}_{4} \text { eq) } & \text { eq) }\end{array}$

(F-11 eq) $\quad \mathrm{C}_{2} \mathrm{H}_{4}$ eq)

\begin{tabular}{|c|c|c|c|c|c|c|}
\hline Total & $9.33 \cdot 10^{-4}$ & 133 & 9.50 & $5.35 \cdot 10^{-7}$ & 0.0906 & 0.0502 \\
\hline Raw Materials & $9.25 \cdot 10^{-4}$ & 48.6 & 2.89 & $1.89 \cdot 10^{-7}$ & $1.14 \cdot 10^{-3}$ & 0.0186 \\
\hline Front contact & $1.06 \cdot 10^{-5}$ & 29.3 & 1.42 & $9.13 \cdot 10^{-8}$ & $7.51 \cdot 10^{-4}$ & 0.0102 \\
\hline Fluor Tin Oxide & $8.35 \cdot 10^{-6}$ & 0.128 & $8.71 \cdot 10^{-3}$ & $7.94 \cdot 10^{-10}$ & $9.49 \cdot 10^{-6}$ & $2.16 \cdot 10^{-4}$ \\
\hline Solar glass, low-iron & $1.47 \cdot 10^{-6}$ & 8.90 & 0.749 & $7.19 \cdot 10^{-8}$ & $2.35 \cdot 10^{-4}$ & $7.07 \cdot 10^{-3}$ \\
\hline Metallic Zinc & $1.57 \cdot 10^{-8}$ & 0.126 & 0.0107 & $5.16 \cdot 10^{-10}$ & $5.31 \cdot 10^{-6}$ & $1.46 \cdot 10^{-4}$ \\
\hline Hydrochloric Acid & $1.96 \cdot 10^{-8}$ & 0.0341 & $2.56 \cdot 10^{-3}$ & $2.66 \cdot 10^{-9}$ & $5.77 \cdot 10^{-7}$ & $1.36 \cdot 10^{-5}$ \\
\hline Deionised Water & $7.30 \cdot 10^{-10}$ & 0.0116 & $1.39 \cdot 10^{-3}$ & $1.35 \cdot 10^{-10}$ & $2.36 \cdot 10^{-7}$ & $4.17 \cdot 10^{-6}$ \\
\hline Ethanol & $2.54 \cdot 10^{-7}$ & 5.36 & 0.152 & $4.78 \cdot 10^{-9}$ & $1.77 \cdot 10^{-4}$ & $4.38 \cdot 10^{-4}$ \\
\hline Isopropanol & $4.46 \cdot 10^{-7}$ & 6.99 & 0.225 & $1.00 \cdot 10^{-8}$ & $2.49 \cdot 10^{-4}$ & $9.45 \cdot 10^{-4}$ \\
\hline Acetone & $5.86 \cdot 10^{-8}$ & 7.68 & 0.273 & $7.06 \cdot 10^{-11}$ & $6.01 \cdot 10^{-5}$ & $1.30 \cdot 10^{-3}$ \\
\hline $\begin{array}{l}\text { Soap without } \\
\text { additives }\end{array}$ & $2.43 \cdot 10^{-8}$ & 0.0548 & $-4.73 \cdot 10^{-3}$ & $4.01 \cdot 10^{-10}$ & $1.31 \cdot 10^{-5}$ & $3.08 \cdot 10^{-5}$ \\
\hline ETM & $9.28 \cdot 10^{-9}$ & 0.186 & $5.56 \cdot 10^{-3}$ & $2.88 \cdot 10^{-10}$ & $5.94 \cdot 10^{-6}$ & $1.72 \cdot 10^{-5}$ \\
\hline Titanium dioxide & $9.35 \cdot 10^{-10}$ & 0.0100 & $5.60 \cdot 10^{-4}$ & $1.32 \cdot 10^{-10}$ & $1.21 \cdot 10^{-7}$ & $2.84 \cdot 10^{-6}$ \\
\hline Ethanol & $8.35 \cdot 10^{-9}$ & 0.176 & $5.00 \cdot 10^{-3}$ & $1.57 \cdot 10^{-10}$ & $5.82 \cdot 10^{-6}$ & $1.44 \cdot 10^{-5}$ \\
\hline Scaffold & $2.18 \cdot 10^{-8}$ & 0.276 & 0.0131 & $2.57 \cdot 10^{-9}$ & $5.13 \cdot 10^{-6}$ & $6.09 \cdot 10^{-5}$ \\
\hline Titanium dioxide & $1.77 \cdot 10^{-8}$ & 0.190 & 0.0106 & $2.50 \cdot 10^{-9}$ & $2.29 \cdot 10^{-6}$ & $5.39 \cdot 10^{-5}$ \\
\hline Ethanol & $4.07 \cdot 10^{-9}$ & 0.0857 & $2.43 \cdot 10^{-3}$ & $7.64 \cdot 10^{-11}$ & $2.84 \cdot 10^{-6}$ & $7.00 \cdot 10^{-6}$ \\
\hline HTM & $1.33 \cdot 10^{-6}$ & 0.339 & 0.0144 & $5.64 \cdot 10^{-9}$ & $2.53 \cdot 10^{-5}$ & $6.46 \cdot 10^{-5}$ \\
\hline Spiro-MeOTAD & $1.29 \cdot 10^{-6}$ & 0.0503 & $2.94 \cdot 10^{-3}$ & $3.08 \cdot 10^{-10}$ & $8.74 \cdot 10^{-7}$ & $1.63 \cdot 10^{-5}$ \\
\hline Chlorobenzene & $3.60 \cdot 10^{-8}$ & 0.288 & 0.0115 & $5.33 \cdot 10^{-9}$ & $2.44 \cdot 10^{-5}$ & $4.83 \cdot 10^{-5}$ \\
\hline Back contact & $8.34 \cdot 10^{-4}$ & 4.105 & 0.301 & $2.92 \cdot 10^{-8}$ & $7.96 \cdot 10^{-5}$ & $2.75 \cdot 10^{-3}$ \\
\hline Gold & $8.34 \cdot 10^{-4}$ & 4.105 & 0.301 & $2.92 \cdot 10^{-8}$ & $7.96 \cdot 10^{-5}$ & $2.75 \cdot 10^{-3}$ \\
\hline Perovskite & $7.82 \cdot 10^{-5}$ & 3.92 & 0.300 & $1.77 \cdot 10^{-8}$ & $1.15 \cdot 10^{-4}$ & $1.45 \cdot 10^{-3}$ \\
\hline Lead iodide & $5.55 \cdot 10^{-5}$ & 2.73 & 0.218 & $1.18 \cdot 10^{-8}$ & $4.38 \cdot 10^{-5}$ & $1.10 \cdot 10^{-3}$ \\
\hline $\begin{array}{l}\text { Methylammonium } \\
\text { iodide }\end{array}$ & $2.26 \cdot 10^{-5}$ & 0.783 & 0.0598 & $3.60 \cdot 10^{-9}$ & $6.59 \cdot 10^{-5}$ & $2.86 \cdot 10^{-4}$ \\
\hline $\begin{array}{l}\text { Gamma- } \\
\text { butyrolactone }\end{array}$ & $3.91 \cdot 10^{-8}$ & 0.405 & 0.0215 & $2.31 \cdot 10^{-9}$ & $5.14 \cdot 10^{-6}$ & $6.66 \cdot 10^{-5}$ \\
\hline Others & $3.05 \cdot 10^{-7}$ & 10.5 & 0.842 & $4.27 \cdot 10^{-8}$ & $1.62 \cdot 10^{-4}$ & $4.08 \cdot 10^{-3}$ \\
\hline $\begin{array}{l}\text { Nitrogen gas for the } \\
\text { glove box }\end{array}$ & $3.05 \cdot 10^{-7}$ & 10.5 & 0.842 & $4.27 \cdot 10^{-8}$ & $1.62 \cdot 10^{-4}$ & $4.08 \cdot 10^{-3}$ \\
\hline $\begin{array}{l}\text { Amount of } \\
\text { transportation }\end{array}$ & $4.21 \cdot 10^{-7}$ & 2.29 & 0.155 & $2.51 \cdot 10^{-8}$ & $2.53 \cdot 10^{-5}$ & $8.45 \cdot 10^{-4}$ \\
\hline $\begin{array}{l}\text { Front contact } \\
\text { transport }\end{array}$ & $3.53 \cdot 10^{-7}$ & 1.92 & 0.130 & $2.11 \cdot 10^{-8}$ & $2.12 \cdot 10^{-5}$ & $7.10 \cdot 10^{-4}$ \\
\hline
\end{tabular}


Perovskite photovoltaic modules: life cycle assessment of pre-industrial production process

\begin{tabular}{|c|c|c|c|c|c|c|}
\hline & $\begin{array}{c}\text { ADP (kg Sb } \\
\text { eq) }\end{array}$ & ADPF (MJ) & $\begin{array}{l}\text { GWP (kg } \\
\left.\mathrm{CO}_{2} \mathrm{eq}\right)\end{array}$ & $\begin{array}{c}\text { ODP (kg } \\
\text { CFC-11 eq) }\end{array}$ & $\begin{array}{l}\text { POP (kg } \\
\left.\mathrm{C}_{2} \mathrm{H}_{4} \mathrm{eq}\right)\end{array}$ & $\begin{array}{c}\mathrm{AP}\left(\mathrm{kg} \mathrm{SO} \mathrm{SO}_{2}\right. \\
\text { eq) }\end{array}$ \\
\hline ETM transport & $1.48 \cdot 10^{-9}$ & $8.05 \cdot 10^{-3}$ & $5.45 \cdot 10^{-4}$ & $8.83 \cdot 10^{-11}$ & $8.88 \cdot 10^{-8}$ & $2.97 \cdot 10^{-6}$ \\
\hline Scaffold transport & $1.49 \cdot 10^{-9}$ & $8.13 \cdot 10^{-3}$ & $5.51 \cdot 10^{-4}$ & $8.92 \cdot 10^{-11}$ & $8.98 \cdot 10^{-8}$ & $3.00 \cdot 10^{-6}$ \\
\hline HTM transport & $1.97 \cdot 10^{-9}$ & 0.0107 & $7.24 \cdot 10^{-4}$ & $1.17 \cdot 10^{-10}$ & $1.18 \cdot 10^{-7}$ & $3.95 \cdot 10^{-6}$ \\
\hline $\begin{array}{l}\text { Back contact } \\
\text { transport }\end{array}$ & $7.73 \cdot 10^{-12}$ & $4.21 \cdot 10^{-5}$ & $2.85 \cdot 10^{-6}$ & $4.61 \cdot 10^{-13}$ & $4.64 \cdot 10^{-10}$ & $1.55 \cdot 10^{-8}$ \\
\hline Perovskite transport & $3.59 \cdot 10^{-9}$ & 0.0196 & $1.33 \cdot 10^{-3}$ & $2.15 \cdot 10^{-10}$ & $2.16 \cdot 10^{-7}$ & $7.22 \cdot 10^{-6}$ \\
\hline Glove box transport & $5.89 \cdot 10^{-8}$ & 0.320 & 0.0217 & $3.51 \cdot 10^{-9}$ & $3.54 \cdot 10^{-6}$ & $1.18 \cdot 10^{-4}$ \\
\hline Use of Energy & $7.86 \cdot 10^{-6}$ & 82.4 & 6.45 & $3.20 \cdot 10^{-7}$ & $1.23 \cdot 10^{-3}$ & 0.0307 \\
\hline $\begin{array}{l}\text { Front contact } \\
\text { electricity }\end{array}$ & $2.73 \cdot 10^{-7}$ & 2.96 & 0.232 & $1.15 \cdot 10^{-8}$ & $4.40 \cdot 10^{-5}$ & $1.10 \cdot 10^{-3}$ \\
\hline $\begin{array}{l}\text { FTO sputtering, } \\
\text { medium voltage }\end{array}$ & $2.02 \cdot 10^{-8}$ & 0.830 & 0.0650 & $3.22 \cdot 10^{-9}$ & $1.21 \cdot 10^{-5}$ & $3.04 \cdot 10^{-4}$ \\
\hline $\begin{array}{l}\text { Sonication, low } \\
\text { voltage }\end{array}$ & $2.45 \cdot 10^{-7}$ & 1.82 & 0.142 & $7.06 \cdot 10^{-9}$ & $2.74 \cdot 10^{-5}$ & $6.85 \cdot 10^{-4}$ \\
\hline $\begin{array}{l}\text { Ozone chamber, } \\
\text { medium voltage }\end{array}$ & $7.59 \cdot 10^{-9}$ & 0.311 & 0.0244 & $1.21 \cdot 10^{-9}$ & $4.54 \cdot 10^{-6}$ & $1.14 \cdot 10^{-4}$ \\
\hline ETM electricity & $3.25 \cdot 10^{-6}$ & 24.1 & 1.89 & $9.36 \cdot 10^{-8}$ & $3.63 \cdot 10^{-4}$ & $9.08 \cdot 10^{-3}$ \\
\hline $\begin{array}{l}\text { Spin-coating ( } 2000 \\
\text { rpm, } 1 \text { min), low } \\
\text { voltage }\end{array}$ & $8.35 \cdot 10^{-8}$ & 0.619 & 0.0484 & $2.40 \cdot 10^{-9}$ & $9.32 \cdot 10^{-6}$ & $2.33 \cdot 10^{-4}$ \\
\hline $\begin{array}{l}\text { Heating ( } 120 \text { oc, } 10 \\
\text { min), low voltage }\end{array}$ & $5.32 \cdot 10^{-7}$ & 3.95 & 0.309 & $1.53 \cdot 10^{-8}$ & $5.94 \cdot 10^{-5}$ & $1.49 \cdot 10^{-3}$ \\
\hline $\begin{array}{l}\text { Annealing ( } 450 \stackrel{\circ}{ } \mathrm{C}, \\
45 \mathrm{~min}) \text {, low voltage }\end{array}$ & $2.64 \cdot 10^{-6}$ & 19.5 & 1.53 & $7.59 \cdot 10^{-8}$ & $2.94 \cdot 10^{-4}$ & $7.36 \cdot 10^{-3}$ \\
\hline Scaffold electricity & $3.29 \cdot 10^{-6}$ & 24.4 & 1.907 & $9.46 \cdot 10^{-8}$ & $3.67 \cdot 10^{-4}$ & $9.18 \cdot 10^{-3}$ \\
\hline $\begin{array}{l}\text { Spin-coating (4000 } \\
\text { rpm, } 60 \mathrm{~s})\end{array}$ & $1.72 \cdot 10^{-7}$ & 1.28 & 0.100 & $4.96 \cdot 10^{-9}$ & $1.92 \cdot 10^{-5}$ & $4.81 \cdot 10^{-4}$ \\
\hline $\begin{array}{l}\text { Heating }(80 \stackrel{\circ}{ } \text {, } 15 \\
\text { min) }\end{array}$ & $4.80 \cdot 10^{-7}$ & 3.56 & 0.279 & $1.38 \cdot 10^{-8}$ & $5.36 \cdot 10^{-5}$ & $1.34 \cdot 10^{-3}$ \\
\hline $\begin{array}{l}\text { Annealing ( } 450 \stackrel{\circ}{ } \mathrm{C}, 4 \\
\text { h) }\end{array}$ & $2.64 \cdot 10^{-6}$ & 19.5 & 1.53 & $7.59 \cdot 10^{-8}$ & $2.94 \cdot 10^{-4}$ & $7.36 \cdot 10^{-3}$ \\
\hline HTM electricity & $8.87 \cdot 10^{-8}$ & 0.658 & 0.0515 & $2.55 \cdot 10^{-9}$ & $9.90 \cdot 10^{-6}$ & $2.48 \cdot 10^{-4}$ \\
\hline $\begin{array}{l}\text { Spin-coating ( } 4000 \\
\text { rpm, } 30 \mathrm{~s} \text { ), low } \\
\text { voltage }\end{array}$ & $8.87 \cdot 10^{-8}$ & 0.658 & 0.0515 & $2.55 \cdot 10^{-9}$ & $9.90 \cdot 10^{-6}$ & $2.48 \cdot 10^{-4}$ \\
\hline $\begin{array}{l}\text { Back contact } \\
\text { electricity }\end{array}$ & $2.41 \cdot 10^{-7}$ & 9.89 & 0.774 & $3.84 \cdot 10^{-8}$ & $1.44 \cdot 10^{-4}$ & $3.62 \cdot 10^{-3}$ \\
\hline $\begin{array}{l}\text { Thermal } \\
\text { evaporation, } \\
\text { medium voltage }\end{array}$ & $2.41 \cdot 10^{-7}$ & 9.89 & 0.774 & $3.84 \cdot 10^{-8}$ & $1.44 \cdot 10^{-4}$ & $3.62 \cdot 10^{-3}$ \\
\hline $\begin{array}{l}\text { Perovskite } \\
\text { electricity }\end{array}$ & $2.71 \cdot 10^{-7}$ & 2.01 & 0.157 & $7.81 \cdot 10^{-9}$ & $3.03 \cdot 10^{-5}$ & $7.58 \cdot 10^{-4}$ \\
\hline $\begin{array}{l}\text { Stirring }(100 \stackrel{\circ}{ } \mathrm{C}, 10 \\
\text { min) }\end{array}$ & $2.09 \cdot 10^{-8}$ & 0.155 & 0.0121 & $6.01 \cdot 10^{-10}$ & $2.33 \cdot 10^{-6}$ & $5.83 \cdot 10^{-5}$ \\
\hline $\begin{array}{l}\text { Stirring ( } 70 \stackrel{\circ}{ } \text {, } 30 \\
\text { min), low voltage }\end{array}$ & $5.74 \cdot 10^{-8}$ & 0.426 & 0.0333 & $1.65 \cdot 10^{-9}$ & $6.41 \cdot 10^{-6}$ & $1.60 \cdot 10^{-4}$ \\
\hline
\end{tabular}




\begin{tabular}{|c|c|c|c|c|c|c|}
\hline & $\begin{array}{l}A D P(k g ~ S b \\
\text { eq) }\end{array}$ & ADPF (MJ) & $\begin{array}{l}\text { GWP (kg } \\
\mathrm{CO}_{2} \text { eq) }\end{array}$ & $\begin{array}{l}\text { ODP (kg } \\
\text { CFC-11 eq) }\end{array}$ & $\begin{array}{l}\mathrm{POP}(\mathrm{kg} \\
\mathrm{C}_{2} \mathrm{H}_{4} \text { eq) }\end{array}$ & $\begin{array}{l}\mathrm{AP}\left(\mathrm{kg} \mathrm{SO}{ }_{2}\right. \\
\text { eq) }\end{array}$ \\
\hline $\begin{array}{l}\text { Spin-coating (500 } \\
\text { rpm, } 5 \mathrm{~s} \text { ), low } \\
\text { voltage }\end{array}$ & $5.22 \cdot 10^{-9}$ & 0.0387 & $3.03 \cdot 10^{-3}$ & $1.50 \cdot 10^{-10}$ & $5.82 \cdot 10^{-7}$ & $1.46 \cdot 10^{-5}$ \\
\hline $\begin{array}{l}\text { Spin-coating ( } 2000 \\
\text { rpm, } 60 \text { s), low } \\
\text { voltage }\end{array}$ & $8.35 \cdot 10^{-8}$ & 0.619 & 0.0484 & $2.40 \cdot 10^{-9}$ & $9.32 \cdot 10^{-6}$ & $2.33 \cdot 10^{-4}$ \\
\hline $\begin{array}{l}\text { Heating (100 } \mathrm{C}, 60 \\
\text { min), low voltage }\end{array}$ & $1.04 \cdot 10^{-7}$ & 0.774 & 0.061 & $3.00 \cdot 10^{-9}$ & $1.16 \cdot 10^{-5}$ & $2.91 \cdot 10^{-4}$ \\
\hline Glove box electricity & $4.49 \cdot 10^{-7}$ & 18.4 & 1.44 & $7.16 \cdot 10^{-8}$ & $2.69 \cdot 10^{-4}$ & $6.75 \cdot 10^{-3}$ \\
\hline $\begin{array}{l}\text { Globe box, medium } \\
\text { voltage }\end{array}$ & $4.49 \cdot 10^{-7}$ & 18.4 & 1.44 & $7.16 \cdot 10^{-8}$ & $2.69 \cdot 10^{-4}$ & $6.75 \cdot 10^{-3}$ \\
\hline Emissions & 0 & 0 & 0 & 0 & 0.0882 & 0 \\
\hline $\begin{array}{l}\text { Front contact } \\
\text { emissions }\end{array}$ & 0 & 0 & 0 & 0 & 0.0858 & 0 \\
\hline Emissions - Ethanol & 0 & 0 & 0 & 0 & 0.0503 & 0 \\
\hline $\begin{array}{l}\text { Emissions - } \\
\text { Isopropanol }\end{array}$ & 0 & 0 & 0 & 0 & 0.0236 & 0 \\
\hline Emissions - Acetone & 0 & 0 & 0 & 0 & 0.0119 & 0 \\
\hline Emissions - Chloride & 0 & 0 & 0 & 0 & 0 & 0 \\
\hline ETM emissions & 0 & 0 & 0 & 0 & $1.61 \cdot 10^{-3}$ & 0 \\
\hline Emissions - Ethanol & 0 & 0 & 0 & 0 & $1.61 \cdot 10^{-3}$ & 0 \\
\hline Scaffold emissions & 0 & 0 & 0 & 0 & $7.83 \cdot 10^{-4}$ & 0 \\
\hline Emissions - Ethanol & 0 & 0 & 0 & 0 & $7.83 \cdot 10^{-4}$ & 0 \\
\hline HTM emissions & 0 & 0 & 0 & 0 & 0 & 0 \\
\hline $\begin{array}{l}\text { Emissions - } \\
\text { Chlorobenzene }\end{array}$ & 0 & 0 & 0 & 0 & 0 & 0 \\
\hline $\begin{array}{l}\text { Perovskite } \\
\text { emissions }\end{array}$ & 0 & 0 & 0 & 0 & 0 & 0 \\
\hline $\begin{array}{l}\text { Emissions - } \\
\text { Butyrolactone }\end{array}$ & 0 & 0 & 0 & 0 & 0 & 0 \\
\hline Glove box emissions & 0 & 0 & 0 & 0 & 0 & 0 \\
\hline Emissions - Nitrogen & 0 & 0 & 0 & 0 & 0 & 0 \\
\hline
\end{tabular}


Perovskite photovoltaic modules: life cycle assessment of pre-industrial production process

Table S39 Bis. Results of the PSC produced with the laboratory scale method given per kWh of electricity produced given per kWh of electricity produced, related to Figure 23 .

$$
\begin{aligned}
& \begin{array}{l}
\mathrm{EP}\left(\mathrm{kg} \mathrm{PO}_{4}{ }^{3-}\right. \\
\text { eq) }
\end{array} \\
& \mathrm{CED}(\mathrm{MJ}) \quad \mathrm{HTC} \text { (CTUh) HTNC (CTUh) }
\end{aligned}
$$

\begin{tabular}{|c|c|c|c|c|c|}
\hline Total & 0.886 & 213 & $1.04 \cdot 10^{-6}$ & $1.24 \cdot 10^{-5}$ & 287 \\
\hline Raw Materials & 0.0237 & 62.6 & $4.66 \cdot 10^{-7}$ & $1.02 \cdot 10^{-5}$ & 234 \\
\hline Front contact & $1.89 \cdot 10^{-3}$ & 31.5 & $3.58 \cdot 10^{-8}$ & $2.76 \cdot 10^{-7}$ & 3.46 \\
\hline Fluor Tin Oxide & $3.06 \cdot 10^{-5}$ & 0.180 & $1.18 \cdot 10^{-9}$ & $2.83 \cdot 10^{-9}$ & 0.0699 \\
\hline Solar glass, low-iron & $9.02 \cdot 10^{-4}$ & 9.82 & $1.67 \cdot 10^{-8}$ & $7.48 \cdot 10^{-8}$ & 1.58 \\
\hline Metallic Zinc & $6.91 \cdot 10^{-5}$ & 0.177 & $1.58 \cdot 10^{-9}$ & $1.53 \cdot 10^{-7}$ & 0.744 \\
\hline Hydrochloric Acid & $8.30 \cdot 10^{-6}$ & 0.0538 & $2.56 \cdot 10^{-10}$ & $2.03 \cdot 10^{-9}$ & 0.0286 \\
\hline Deionised Water & $9.96 \cdot 10^{-7}$ & 0.0171 & $3.54 \cdot 10^{-12}$ & $2.85 \cdot 10^{-11}$ & $1.04 \cdot 10^{-4}$ \\
\hline Ethanol & $2.10 \cdot 10^{-4}$ & 5.58 & $4.03 \cdot 10^{-9}$ & $1.42 \cdot 10^{-8}$ & 0.307 \\
\hline Isopropanol & $5.18 \cdot 10^{-4}$ & 7.35 & $6.13 \cdot 10^{-9}$ & $2.32 \cdot 10^{-8}$ & 0.544 \\
\hline Acetone & $1.36 \cdot 10^{-4}$ & 7.99 & $5.61 \cdot 10^{-9}$ & $3.86 \cdot 10^{-9}$ & 0.150 \\
\hline $\begin{array}{l}\text { Soap without } \\
\text { additives }\end{array}$ & $1.99 \cdot 10^{-5}$ & 0.285 & $2.84 \cdot 10^{-10}$ & $1.67 \cdot 10^{-9}$ & 0.0342 \\
\hline ETM & $8.51 \cdot 10^{-6}$ & 0.196 & $1.62 \cdot 10^{-10}$ & $6.32 \cdot 10^{-10}$ & 0.0151 \\
\hline Titanium dioxide & $1.63 \cdot 10^{-6}$ & 0.0126 & $3.00 \cdot 10^{-11}$ & $1.65 \cdot 10^{-10}$ & $5.04 \cdot 10^{-3}$ \\
\hline Ethanol & $6.88 \cdot 10^{-6}$ & 0.183 & $1.32 \cdot 10^{-10}$ & $4.67 \cdot 10^{-10}$ & 0.0101 \\
\hline Scaffold & $3.42 \cdot 10^{-5}$ & 0.328 & $6.34 \cdot 10^{-10}$ & $3.35 \cdot 10^{-9}$ & 0.101 \\
\hline Titanium dioxide & $3.09 \cdot 10^{-5}$ & 0.239 & $5.70 \cdot 10^{-10}$ & $3.12 \cdot 10^{-9}$ & 0.0957 \\
\hline Ethanol & $3.35 \cdot 10^{-6}$ & 0.0892 & $6.45 \cdot 10^{-11}$ & $2.28 \cdot 10^{-10}$ & $4.92 \cdot 10^{-3}$ \\
\hline HTM & $6.69 \cdot 10^{-5}$ & 0.390 & $8.87 \cdot 10^{-10}$ & $4.99 \cdot 10^{-9}$ & 0.252 \\
\hline Spiro-MeOTAD & $6.42 \cdot 10^{-6}$ & 0.0545 & $8.93 \cdot 10^{-11}$ & $5.28 \cdot 10^{-10}$ & 0.0120 \\
\hline Chlorobenzene & $6.05 \cdot 10^{-5}$ & 0.336 & $7.98 \cdot 10^{-10}$ & $4.46 \cdot 10^{-9}$ & 0.240 \\
\hline Back contact & 0.0178 & 5.02 & $3.32 \cdot 10^{-7}$ & $9.50 \cdot 10^{-6}$ & 221 \\
\hline Gold & 0.0178 & 5.02 & $3.32 \cdot 10^{-7}$ & $9.50 \cdot 10^{-6}$ & 221 \\
\hline Perovskite & $9.78 \cdot 10^{-4}$ & 6.61 & $2.61 \cdot 10^{-8}$ & $1.34 \cdot 10^{-7}$ & 2.64 \\
\hline Lead iodide & $7.70 \cdot 10^{-4}$ & 4.79 & $2.00 \cdot 10^{-8}$ & $1.09 \cdot 10^{-7}$ & 2.05 \\
\hline $\begin{array}{l}\text { Methylammonium } \\
\text { iodide }\end{array}$ & $1.81 \cdot 10^{-4}$ & 1.35 & $5.26 \cdot 10^{-9}$ & $2.17 \cdot 10^{-8}$ & 0.510 \\
\hline $\begin{array}{l}\text { Gamma- } \\
\text { butyrolactone }\end{array}$ & $2.79 \cdot 10^{-5}$ & 0.468 & $8.45 \cdot 10^{-10}$ & $3.99 \cdot 10^{-9}$ & 0.0823 \\
\hline Others & $2.89 \cdot 10^{-3}$ & 18.6 & $6.98 \cdot 10^{-8}$ & $2.50 \cdot 10^{-7}$ & 6.24 \\
\hline $\begin{array}{l}\text { Nitrogen gas for the } \\
\text { glove box }\end{array}$ & $2.89 \cdot 10^{-3}$ & 18.6 & $6.98 \cdot 10^{-8}$ & $2.50 \cdot 10^{-7}$ & 6.24 \\
\hline $\begin{array}{l}\text { Amount of } \\
\text { transportation }\end{array}$ & $2.25 \cdot 10^{-4}$ & 2.47 & $9.54 \cdot 10^{-9}$ & $2.84 \cdot 10^{-8}$ & 0.630 \\
\hline $\begin{array}{l}\text { Front contact } \\
\text { transport }\end{array}$ & $1.89 \cdot 10^{-4}$ & 2.07 & $8.01 \cdot 10^{-9}$ & $2.39 \cdot 10^{-8}$ & 0.529 \\
\hline
\end{tabular}




\begin{tabular}{|c|c|c|c|c|c|}
\hline & $\begin{array}{c}\mathrm{EP}\left(\mathrm{kg} \mathrm{PO}{ }_{4}^{3-}\right. \\
\mathrm{eq})\end{array}$ & CED (MJ) & HTC (CTUh) & HTNC (CTUh) & FET (CTUe) \\
\hline ETM transport & $7.93 \cdot 10^{-7}$ & $8.67 \cdot 10^{-3}$ & $3.36 \cdot 10^{-11}$ & $1.00 \cdot 10^{-10}$ & $2.21 \cdot 10^{-3}$ \\
\hline Scaffold transport & $8.01 \cdot 10^{-7}$ & $8.76 \cdot 10^{-3}$ & $3.39 \cdot 10^{-11}$ & $1.01 \cdot 10^{-10}$ & $2.24 \cdot 10^{-3}$ \\
\hline HTM transport & $1.05 \cdot 10^{-6}$ & 0.0115 & $4.46 \cdot 10^{-11}$ & $1.33 \cdot 10^{-10}$ & $2.94 \cdot 10^{-3}$ \\
\hline $\begin{array}{l}\text { Back contact } \\
\text { transport }\end{array}$ & $4.14 \cdot 10^{-9}$ & $4.53 \cdot 10^{-5}$ & $1.75 \cdot 10^{-13}$ & $5.22 \cdot 10^{-13}$ & $1.16 \cdot 10^{-5}$ \\
\hline Perovskite transport & $1.93 \cdot 10^{-6}$ & 0.0211 & $8.15 \cdot 10^{-11}$ & $2.43 \cdot 10^{-10}$ & $5.38 \cdot 10^{-3}$ \\
\hline Glove box transport & $3.15 \cdot 10^{-5}$ & 0.345 & $1.34 \cdot 10^{-9}$ & $3.98 \cdot 10^{-9}$ & 0.0882 \\
\hline Use of Energy & 0.0203 & 148 & $5.61 \cdot 10^{-7}$ & $2.20 \cdot 10^{-6}$ & 52.5 \\
\hline $\begin{array}{l}\text { Front contact } \\
\text { electricity }\end{array}$ & $7.28 \cdot 10^{-4}$ & 5.32 & $2.00 \cdot 10^{-8}$ & $7.84 \cdot 10^{-8}$ & 1.87 \\
\hline $\begin{array}{l}\text { FTO sputtering, } \\
\text { medium voltage }\end{array}$ & $1.98 \cdot 10^{-4}$ & 1.49 & $4.87 \cdot 10^{-9}$ & $1.79 \cdot 10^{-8}$ & 0.433 \\
\hline $\begin{array}{l}\text { Sonication, low } \\
\text { voltage }\end{array}$ & $4.56 \cdot 10^{-4}$ & 3.27 & $1.33 \cdot 10^{-8}$ & $5.38 \cdot 10^{-8}$ & 1.28 \\
\hline $\begin{array}{l}\text { Ozone chamber, } \\
\text { medium voltage }\end{array}$ & $7.42 \cdot 10^{-5}$ & 0.560 & $1.83 \cdot 10^{-9}$ & $6.71 \cdot 10^{-9}$ & 0.162 \\
\hline ETM electricity & $6.05 \cdot 10^{-3}$ & 43.3 & $1.76 \cdot 10^{-7}$ & $7.13 \cdot 10^{-7}$ & 16.9 \\
\hline $\begin{array}{l}\text { Spin-coating (2000 } \\
\text { rpm, } 1 \text { min), low } \\
\text { voltage }\end{array}$ & $1.55 \cdot 10^{-4}$ & 1.11 & $4.53 \cdot 10^{-9}$ & $1.83 \cdot 10^{-8}$ & 0.434 \\
\hline $\begin{array}{l}\text { Heating ( } 120 \text { oc, } 10 \\
\text { min), low voltage }\end{array}$ & $9.90 \cdot 10^{-4}$ & 7.09 & $2.89 \cdot 10^{-8}$ & $1.17 \cdot 10^{-7}$ & 2.77 \\
\hline $\begin{array}{l}\text { Annealing ( } 450 \stackrel{\circ}{ } \mathrm{C} \text {, } \\
45 \mathrm{~min} \text { ), low voltage }\end{array}$ & $4.90 \cdot 10^{-3}$ & 35.1 & $1.43 \cdot 10^{-7}$ & $5.78 \cdot 10^{-7}$ & 13.7 \\
\hline Scaffold electricity & $6.12 \cdot 10^{-3}$ & 43.8 & $1.78 \cdot 10^{-7}$ & $7.21 \cdot 10^{-7}$ & 17.1 \\
\hline $\begin{array}{l}\text { Spin-coating (4000 } \\
\text { rpm, } 60 \mathrm{~s})\end{array}$ & $3.20 \cdot 10^{-4}$ & 2.29 & $9.34 \cdot 10^{-9}$ & $3.78 \cdot 10^{-8}$ & 0.895 \\
\hline $\begin{array}{l}\text { Heating ( } 80 \stackrel{\circ}{ } \text {, } 15 \\
\text { min) }\end{array}$ & $8.93 \cdot 10^{-4}$ & 6.39 & $2.61 \cdot 10^{-8}$ & $1.05 \cdot 10^{-7}$ & 2.50 \\
\hline $\begin{array}{l}\text { Annealing ( } 450 \stackrel{\circ}{ } \mathrm{C}, 4 \\
\text { h) }\end{array}$ & $4.90 \cdot 10^{-3}$ & 35.1 & $1.43 \cdot 10^{-7}$ & $5.78 \cdot 10^{-7}$ & 13.7 \\
\hline HTM electricity & $1.65 \cdot 10^{-4}$ & 1.18 & $4.81 \cdot 10^{-9}$ & $1.95 \cdot 10^{-8}$ & 0.461 \\
\hline $\begin{array}{l}\text { Spin-coating ( } 4000 \\
\text { rpm, } 30 \mathrm{~s} \text { ), low } \\
\text { voltage }\end{array}$ & $1.65 \cdot 10^{-4}$ & 1.18 & $4.81 \cdot 10^{-9}$ & $1.95 \cdot 10^{-8}$ & 0.461 \\
\hline $\begin{array}{l}\text { Back contact } \\
\text { electricity }\end{array}$ & $2.36 \cdot 10^{-3}$ & 17.8 & $5.80 \cdot 10^{-8}$ & $2.13 \cdot 10^{-7}$ & 5.16 \\
\hline $\begin{array}{l}\text { Thermal } \\
\text { evaporation, } \\
\text { medium voltage }\end{array}$ & $2.36 \cdot 10^{-3}$ & 17.8 & $5.80 \cdot 10^{-8}$ & $2.13 \cdot 10^{-7}$ & 5.16 \\
\hline $\begin{array}{l}\text { Perovskite } \\
\text { electricity }\end{array}$ & $5.05 \cdot 10^{-4}$ & 3.61 & $1.47 \cdot 10^{-8}$ & $5.95 \cdot 10^{-8}$ & 1.41 \\
\hline 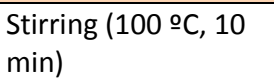 & $3.88 \cdot 10^{-5}$ & 0.278 & $1.13 \cdot 10^{-9}$ & $4.58 \cdot 10^{-9}$ & 0.109 \\
\hline $\begin{array}{l}\text { Stirring ( } 70 \stackrel{\circ}{ } \text { C, } 30 \\
\text { min), low voltage }\end{array}$ & $1.07 \cdot 10^{-4}$ & 0.764 & $3.11 \cdot 10^{-9}$ & $1.26 \cdot 10^{-8}$ & 0.298 \\
\hline
\end{tabular}


Perovskite photovoltaic modules: life cycle assessment of pre-industrial production process

\begin{tabular}{|c|c|c|c|c|c|}
\hline & $\begin{array}{l}\mathrm{EP}\left(\mathrm{kg} \mathrm{PO}_{4}{ }^{3-}\right. \\
\text { eq) }\end{array}$ & CED (MJ) & HTC (CTUh) & HTNC (CTUh) & FET (CTUe) \\
\hline $\begin{array}{l}\text { Spin-coating ( } 500 \\
\text { rpm, } 5 \text { s), low } \\
\text { voltage }\end{array}$ & $9.71 \cdot 10^{-6}$ & 0.0695 & $2.83 \cdot 10^{-10}$ & $1.14 \cdot 10^{-9}$ & 0.0271 \\
\hline $\begin{array}{l}\text { Spin-coating (2000 } \\
\text { rpm, } 60 \text { s), low } \\
\text { voltage }\end{array}$ & $1.55 \cdot 10^{-4}$ & 1.11 & $4.53 \cdot 10^{-9}$ & $1.83 \cdot 10^{-8}$ & 0.434 \\
\hline $\begin{array}{l}\text { Heating ( } 100 \stackrel{\circ}{ } \mathrm{C}, 60 \\
\text { min), low voltage }\end{array}$ & $1.94 \cdot 10^{-4}$ & 1.39 & $5.66 \cdot 10^{-9}$ & $2.29 \cdot 10^{-8}$ & 0.543 \\
\hline Glove box electricity & $4.39 \cdot 10^{-3}$ & 33.1 & $1.08 \cdot 10^{-7}$ & $3.97 \cdot 10^{-7}$ & 9.61 \\
\hline $\begin{array}{l}\text { Globe box, medium } \\
\text { voltage }\end{array}$ & $4.39 \cdot 10^{-3}$ & 33.1 & $1.08 \cdot 10^{-7}$ & $3.97 \cdot 10^{-7}$ & 9.61 \\
\hline Emissions & 0.842 & 0 & $8.77 \cdot 10^{-10}$ & $1.41 \cdot 10^{-9}$ & 0.243 \\
\hline $\begin{array}{l}\text { Front contact } \\
\text { emissions }\end{array}$ & 0 & 0 & $2.70 \cdot 10^{-10}$ & $7.90 \cdot 10^{-10}$ & 0.0393 \\
\hline Emissions - Ethanol & 0 & 0 & $2.70 \cdot 10^{-10}$ & 0 & 0.0193 \\
\hline $\begin{array}{l}\text { Emissions - } \\
\text { Isopropanol }\end{array}$ & 0 & 0 & 0 & 0 & 0.0100 \\
\hline Emissions - Acetone & 0 & 0 & 0 & $7.90 \cdot 10^{-10}$ & 0.0100 \\
\hline Emissions - Chloride & 0 & 0 & 0 & 0 & 0 \\
\hline ETM emissions & 0 & 0 & $8.62 \cdot 10^{-12}$ & 0 & $6.16 \cdot 10^{-4}$ \\
\hline Emissions - Ethanol & 0 & 0 & $8.62 \cdot 10^{-12}$ & 0 & $6.16 \cdot 10^{-4}$ \\
\hline Scaffold emissions & 0 & 0 & $4.20 \cdot 10^{-12}$ & 0 & $3.00 \cdot 10^{-4}$ \\
\hline Emissions - Ethanol & 0 & 0 & $4.20 \cdot 10^{-12}$ & 0 & $3.00 \cdot 10^{-4}$ \\
\hline HTM emissions & 0 & 0 & $5.95 \cdot 10^{-10}$ & $6.17 \cdot 10^{-10}$ & $4.79 \cdot 10^{-3}$ \\
\hline $\begin{array}{l}\text { Emissions - } \\
\text { Chlorobenzene }\end{array}$ & 0 & 0 & $5.95 \cdot 10^{-10}$ & $6.17 \cdot 10^{-10}$ & $4.79 \cdot 10^{-3}$ \\
\hline $\begin{array}{l}\text { Perovskite } \\
\text { emissions }\end{array}$ & 0 & 0 & 0 & 0 & 0.198 \\
\hline $\begin{array}{l}\text { Emissions - } \\
\text { Butyrolactone }\end{array}$ & 0 & 0 & 0 & 0 & 0.198 \\
\hline Glove box emissions & 0.842 & 0 & 0 & 0 & 0 \\
\hline Emissions - Nitrogen & 0.842 & 0 & 0 & 0 & 0 \\
\hline
\end{tabular}


Table S40. Results of the ideal process of production of a carbon stack perovskite module, related to Figure 23.

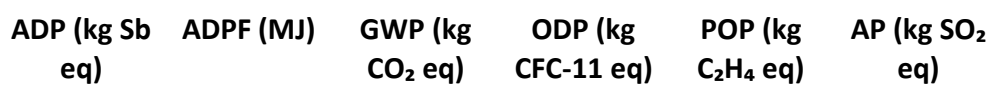

\begin{tabular}{|c|c|c|c|c|c|c|}
\hline Total & $3.39 \cdot 10^{-7}$ & 0.372 & 0.0302 & $3.01 \cdot 10^{-9}$ & $9.22 \cdot 10^{-6}$ & $2.73 \cdot 10^{-4}$ \\
\hline Raw Materials & $3.35 \cdot 10^{-7}$ & 0.328 & 0.0269 & $2.72 \cdot 10^{-9}$ & $8.63 \cdot 10^{-6}$ & $2.56 \cdot 10^{-4}$ \\
\hline Anode + Substrate & $3.34 \cdot 10^{-7}$ & 0.315 & 0.0264 & $2.54 \cdot 10^{-9}$ & $8.54 \cdot 10^{-6}$ & $2.54 \cdot 10^{-4}$ \\
\hline Fluor Tin Oxide & $2.82 \cdot 10^{-7}$ & $4.34 \cdot 10^{-3}$ & $2.94 \cdot 10^{-4}$ & $2.68 \cdot 10^{-11}$ & $3.21 \cdot 10^{-7}$ & $7.29 \cdot 10^{-6}$ \\
\hline Solar glass, low-iron & $5.14 \cdot 10^{-8}$ & 0.311 & 0.0261 & $2.51 \cdot 10^{-9}$ & $8.22 \cdot 10^{-6}$ & $2.47 \cdot 10^{-4}$ \\
\hline Blocking layer & $4.11 \cdot 10^{-11}$ & $3.99 \cdot 10^{-4}$ & $1.74 \cdot 10^{-5}$ & $1.66 \cdot 10^{-12}$ & $1.56 \cdot 10^{-8}$ & $8.73 \cdot 10^{-8}$ \\
\hline $\begin{array}{l}\text { Titanium } \\
\text { diisopropoxide } \\
\text { bis(acetylacetonate) }\end{array}$ & $4.11 \cdot 10^{-11}$ & $3.99 \cdot 10^{-4}$ & $1.74 \cdot 10^{-5}$ & $1.66 \cdot 10^{-12}$ & $1.56 \cdot 10^{-8}$ & $8.73 \cdot 10^{-8}$ \\
\hline $\begin{array}{l}\text { Semi conducting } \\
\text { scaffold }\end{array}$ & $1.01 \cdot 10^{-10}$ & $1.08 \cdot 10^{-3}$ & $6.06 \cdot 10^{-5}$ & $1.42 \cdot 10^{-11}$ & $1.31 \cdot 10^{-8}$ & $3.07 \cdot 10^{-7}$ \\
\hline $\begin{array}{l}\text { Titanium dioxide, } \\
\text { chloride process, at } \\
\text { plant/RER S }\end{array}$ & $1.01 \cdot 10^{-10}$ & $1.08 \cdot 10^{-3}$ & $6.06 \cdot 10^{-5}$ & $1.42 \cdot 10^{-11}$ & $1.31 \cdot 10^{-8}$ & $3.07 \cdot 10^{-7}$ \\
\hline Insulating scaffold & $5.38 \cdot 10^{-10}$ & $1.47 \cdot 10^{-3}$ & $1.17 \cdot 10^{-4}$ & $8.07 \cdot 10^{-12}$ & $2.49 \cdot 10^{-8}$ & $6.15 \cdot 10^{-7}$ \\
\hline Zirconia & $5.38 \cdot 10^{-10}$ & $1.47 \cdot 10^{-3}$ & $1.17 \cdot 10^{-4}$ & $8.07 \cdot 10^{-12}$ & $2.49 \cdot 10^{-8}$ & $6.15 \cdot 10^{-7}$ \\
\hline Cathode & $4.21 \cdot 10^{-10}$ & $9.76 \cdot 10^{-3}$ & $2.84 \cdot 10^{-4}$ & $1.56 \cdot 10^{-10}$ & $3.17 \cdot 10^{-8}$ & $7.92 \cdot 10^{-7}$ \\
\hline Carbon & $4.21 \cdot 10^{-10}$ & $9.76 \cdot 10^{-3}$ & $2.84 \cdot 10^{-4}$ & $1.56 \cdot 10^{-10}$ & $3.17 \cdot 10^{-8}$ & $7.92 \cdot 10^{-7}$ \\
\hline Perovskite & $7.07 \cdot 10^{-10}$ & $3.18 \cdot 10^{-5}$ & $2.51 \cdot 10^{-6}$ & $1.39 \cdot 10^{-13}$ & $9.91 \cdot 10^{-10}$ & $1.25 \cdot 10^{-8}$ \\
\hline Lead iodide & $5.01 \cdot 10^{-10}$ & $2.47 \cdot 10^{-5}$ & $1.97 \cdot 10^{-6}$ & $1.07 \cdot 10^{-13}$ & $3.96 \cdot 10^{-10}$ & $9.94 \cdot 10^{-9}$ \\
\hline $\begin{array}{l}\text { Methylammonium } \\
\text { iodide }\end{array}$ & $2.04 \cdot 10^{-10}$ & $7.07 \cdot 10^{-6}$ & $5.40 \cdot 10^{-7}$ & $3.25 \cdot 10^{-14}$ & $5.95 \cdot 10^{-10}$ & $2.58 \cdot 10^{-9}$ \\
\hline $\begin{array}{l}\text { 5-ammonium } \\
\text { valeric acid iodide }\end{array}$ & $2.02 \cdot 10^{-12}$ & $1.18 \cdot 10^{-8}$ & $7.22 \cdot 10^{-10}$ & $1.11 \cdot 10^{-16}$ & $1.75 \cdot 10^{-13}$ & $2.92 \cdot 10^{-12}$ \\
\hline $\begin{array}{l}\text { Amount of } \\
\text { transportation }\end{array}$ & $3.19 \cdot 10^{-9}$ & 0.0177 & $1.20 \cdot 10^{-3}$ & $1.93 \cdot 10^{-10}$ & $2.10 \cdot 10^{-7}$ & $6.99 \cdot 10^{-6}$ \\
\hline $\begin{array}{l}\text { Anode + Substrate } \\
\text { transport }\end{array}$ & $2.42 \cdot 10^{-9}$ & 0.0132 & $8.93 \cdot 10^{-4}$ & $1.45 \cdot 10^{-10}$ & $1.46 \cdot 10^{-7}$ & $4.87 \cdot 10^{-6}$ \\
\hline $\begin{array}{l}\text { Anode + Substrate, } \\
\text { lorry }\end{array}$ & $2.42 \cdot 10^{-9}$ & 0.0132 & $8.93 \cdot 10^{-4}$ & $1.45 \cdot 10^{-10}$ & $1.46 \cdot 10^{-7}$ & $4.87 \cdot 10^{-6}$ \\
\hline $\begin{array}{l}\text { Blocking layer } \\
\text { transport }\end{array}$ & $3.62 \cdot 10^{-13}$ & $1.97 \cdot 10^{-6}$ & $1.33 \cdot 10^{-7}$ & $2.16 \cdot 10^{-14}$ & $2.17 \cdot 10^{-11}$ & $7.27 \cdot 10^{-10}$ \\
\hline Blocking layer, lorry & $3.62 \cdot 10^{-13}$ & $1.97 \cdot 10^{-6}$ & $1.33 \cdot 10^{-7}$ & $2.16 \cdot 10^{-14}$ & $2.17 \cdot 10^{-11}$ & $7.27 \cdot 10^{-10}$ \\
\hline $\begin{array}{l}\text { Semi conducting } \\
\text { scaffold transport }\end{array}$ & $1.54 \cdot 10^{-12}$ & $5.11 \cdot 10^{-5}$ & $3.78 \cdot 10^{-6}$ & $4.54 \cdot 10^{-13}$ & $2.41 \cdot 10^{-9}$ & $7.60 \cdot 10^{-8}$ \\
\hline $\begin{array}{l}\text { Semi conducting } \\
\text { scaffold, lorry }\end{array}$ & $1.23 \cdot 10^{-12}$ & $6.70 \cdot 10^{-6}$ & $4.54 \cdot 10^{-7}$ & $7.35 \cdot 10^{-14}$ & $7.39 \cdot 10^{-11}$ & $2.47 \cdot 10^{-9}$ \\
\hline $\begin{array}{l}\text { Semi conducting } \\
\text { scaffold, freight }\end{array}$ & $3.07 \cdot 10^{-13}$ & $4.44 \cdot 10^{-5}$ & $3.33 \cdot 10^{-6}$ & $3.80 \cdot 10^{-13}$ & $2.34 \cdot 10^{-9}$ & $7.35 \cdot 10^{-8}$ \\
\hline $\begin{array}{l}\text { Insulating scaffold } \\
\text { transport }\end{array}$ & $1.32 \cdot 10^{-11}$ & $7.17 \cdot 10^{-5}$ & $4.85 \cdot 10^{-6}$ & $7.86 \cdot 10^{-13}$ & $7.91 \cdot 10^{-10}$ & $2.64 \cdot 10^{-8}$ \\
\hline
\end{tabular}


Perovskite photovoltaic modules: life cycle assessment of pre-industrial production process

\begin{tabular}{|c|c|c|c|c|c|c|}
\hline & $\begin{array}{l}\text { ADP (kg Sb } \\
\text { eq) }\end{array}$ & ADPF (MJ) & $\begin{array}{l}\text { GWP (kg } \\
\mathrm{CO}_{2} \text { eq) }\end{array}$ & $\begin{array}{l}\text { ODP (kg } \\
\text { CFC-11 eq) }\end{array}$ & $\begin{array}{l}\mathrm{POP}(\mathrm{kg} \\
\mathrm{C}_{2} \mathrm{H}_{4} \text { eq) }\end{array}$ & $\begin{array}{l}\mathrm{AP}\left(\mathrm{kg} \mathrm{SO} \mathrm{S}_{2}\right. \\
\text { eq) }\end{array}$ \\
\hline $\begin{array}{l}\text { Insulating scaffold, } \\
\text { lorry }\end{array}$ & $1.32 \cdot 10^{-11}$ & $7.17 \cdot 10^{-5}$ & $4.85 \cdot 10^{-6}$ & $7.86 \cdot 10^{-13}$ & $7.91 \cdot 10^{-10}$ & $2.64 \cdot 10^{-8}$ \\
\hline Cathode transport & $3.94 \cdot 10^{-12}$ & $2.14 \cdot 10^{-5}$ & $1.45 \cdot 10^{-6}$ & $2.35 \cdot 10^{-13}$ & $2.36 \cdot 10^{-10}$ & $7.91 \cdot 10^{-9}$ \\
\hline Cathode, lorry & $3.94 \cdot 10^{-12}$ & $2.14 \cdot 10^{-5}$ & $1.45 \cdot 10^{-6}$ & $2.35 \cdot 10^{-13}$ & $2.36 \cdot 10^{-10}$ & $7.91 \cdot 10^{-9}$ \\
\hline Perovskite transport & $3.58 \cdot 10^{-15}$ & $4.91 \cdot 10^{-8}$ & $3.55 \cdot 10^{-9}$ & $4.64 \cdot 10^{-16}$ & $1.82 \cdot 10^{-12}$ & $5.77 \cdot 10^{-11}$ \\
\hline Perovskite, lorry & $3.36 \cdot 10^{-15}$ & $1.83 \cdot 10^{-8}$ & $1.24 \cdot 10^{-9}$ & $2.01 \cdot 10^{-16}$ & $2.02 \cdot 10^{-13}$ & $6.76 \cdot 10^{-12}$ \\
\hline Perovskite, freight & $2.12 \cdot 10^{-16}$ & $3.08 \cdot 10^{-8}$ & $2.31 \cdot 10^{-9}$ & $2.63 \cdot 10^{-16}$ & $1.62 \cdot 10^{-12}$ & $5.10 \cdot 10^{-11}$ \\
\hline Use of Energy & $6.54 \cdot 10^{-10}$ & 0.0259 & $2.03 \cdot 10^{-3}$ & $1.01 \cdot 10^{-10}$ & $3.78 \cdot 10^{-7}$ & $9.50 \cdot 10^{-6}$ \\
\hline Anode + Substrate & $4.37 \cdot 10^{-13}$ & $1.79 \cdot 10^{-5}$ & $1.40 \cdot 10^{-6}$ & $6.96 \cdot 10^{-14}$ & $2.61 \cdot 10^{-10}$ & $6.56 \cdot 10^{-9}$ \\
\hline Blocking layer & $9.88 \cdot 10^{-11}$ & $3.22 \cdot 10^{-3}$ & $2.52 \cdot 10^{-4}$ & $1.25 \cdot 10^{-11}$ & $4.71 \cdot 10^{-8}$ & $1.18 \cdot 10^{-6}$ \\
\hline $\begin{array}{l}\text { Blocking layer, } \\
\text { medium voltage } \\
\text { (allocated } \\
\text { annealing) }\end{array}$ & $7.81 \cdot 10^{-11}$ & $3.20 \cdot 10^{-3}$ & $2.51 \cdot 10^{-4}$ & & & \\
\hline $\begin{array}{l}\text { compressed air, } \\
1000 \mathrm{kPa} \text { gauge }\end{array}$ & $2.07 \cdot 10^{-11}$ & $1.52 \cdot 10^{-5}$ & $1.23 \cdot 10^{-6}$ & $7.04 \cdot 10^{-14}$ & $3.60 \cdot 10^{-10}$ & $7.62 \cdot 10^{-9}$ \\
\hline $\begin{array}{l}\text { Semi conducting } \\
\text { scaffold }\end{array}$ & $2.77 \cdot 10^{-10}$ & 0.0114 & $8.89 \cdot 10^{-4}$ & $4.41 \cdot 10^{-11}$ & $1.66 \cdot 10^{-7}$ & $4.16 \cdot 10^{-6}$ \\
\hline Insulating scaffold & $5.36 \cdot 10^{-11}$ & $2.20 \cdot 10^{-3}$ & $1.72 \cdot 10^{-4}$ & $8.54 \cdot 10^{-12}$ & $3.20 \cdot 10^{-8}$ & $8.05 \cdot 10^{-7}$ \\
\hline Cathode & $2.05 \cdot 10^{-10}$ & $8.42 \cdot 10^{-3}$ & $6.59 \cdot 10^{-4}$ & $3.27 \cdot 10^{-11}$ & $1.23 \cdot 10^{-7}$ & $3.08 \cdot 10^{-6}$ \\
\hline Perovskite & $1.94 \cdot 10^{-11}$ & $7.11 \cdot 10^{-4}$ & $5.57 \cdot 10^{-5}$ & $2.76 \cdot 10^{-12}$ & $1.04 \cdot 10^{-8}$ & $2.61 \cdot 10^{-7}$ \\
\hline $\begin{array}{l}\text { Perovskite, low } \\
\text { voltage }\end{array}$ & $2.49 \cdot 10^{-12}$ & $1.85 \cdot 10^{-5}$ & $1.45 \cdot 10^{-6}$ & $7.17 \cdot 10^{-14}$ & $2.78 \cdot 10^{-10}$ & $6.96 \cdot 10^{-9}$ \\
\hline $\begin{array}{l}\text { Perovskite, medium } \\
\text { voltage }\end{array}$ & $1.69 \cdot 10^{-11}$ & $6.92 \cdot 10^{-4}$ & $5.42 \cdot 10^{-5}$ & $2.69 \cdot 10^{-12}$ & $1.01 \cdot 10^{-8}$ & $2.54 \cdot 10^{-7}$ \\
\hline
\end{tabular}




\section{Chapter 5}

Table S40 Bis. Results of the ideal process of production of a carbon stack perovskite module, related to Figure 23 .

$\mathrm{EP}\left(\mathrm{kg} \mathrm{PO}_{4}{ }^{3-}\right.$
eq)

\begin{tabular}{|c|c|c|c|c|c|}
\hline Total & $4.11 \cdot 10^{-5}$ & 0.429 & $8.65 \cdot 10^{-10}$ & $3.59 \cdot 10^{-9}$ & 0.0779 \\
\hline Raw Materials & $3.32 \cdot 10^{-5}$ & 0.363 & $6.39 \cdot 10^{-10}$ & $2.81 \cdot 10^{-9}$ & 0.0596 \\
\hline Anode + Substrate & $3.25 \cdot 10^{-5}$ & 0.349 & $6.23 \cdot 10^{-10}$ & $2.71 \cdot 10^{-9}$ & 0.0576 \\
\hline Fluor Tin Oxide & $1.03 \cdot 10^{-6}$ & $6.09 \cdot 10^{-3}$ & $4.00 \cdot 10^{-11}$ & $9.57 \cdot 10^{-11}$ & $2.36 \cdot 10^{-3}$ \\
\hline Solar glass, low-iron & $3.15 \cdot 10^{-5}$ & 0.343 & $5.83 \cdot 10^{-10}$ & $2.61 \cdot 10^{-9}$ & 0.0552 \\
\hline Blocking layer & $3.55 \cdot 10^{-8}$ & $4.29 \cdot 10^{-4}$ & $6.03 \cdot 10^{-13}$ & $2.80 \cdot 10^{-12}$ & $1.01 \cdot 10^{-4}$ \\
\hline $\begin{array}{l}\text { Titanium } \\
\text { diisopropoxide } \\
\text { bis(acetylacetonate) }\end{array}$ & $3.55 \cdot 10^{-8}$ & $4.29 \cdot 10^{-4}$ & $6.03 \cdot 10^{-13}$ & $2.80 \cdot 10^{-12}$ & $1.01 \cdot 10^{-4}$ \\
\hline $\begin{array}{l}\text { Semi conducting } \\
\text { scaffold }\end{array}$ & $1.76 \cdot 10^{-7}$ & $1.36 \cdot 10^{-3}$ & $3.25 \cdot 10^{-12}$ & $1.78 \cdot 10^{-11}$ & $5.46 \cdot 10^{-4}$ \\
\hline $\begin{array}{l}\text { Titanium dioxide, } \\
\text { chloride process, at } \\
\text { plant/RER S }\end{array}$ & $1.76 \cdot 10^{-7}$ & $1.36 \cdot 10^{-3}$ & $3.25 \cdot 10^{-12}$ & $1.78 \cdot 10^{-11}$ & $5.46 \cdot 10^{-4}$ \\
\hline Insulating scaffold & $3.06 \cdot 10^{-7}$ & $2.14 \cdot 10^{-3}$ & $8.78 \cdot 10^{-12}$ & $5.92 \cdot 10^{-11}$ & $8.78 \cdot 10^{-4}$ \\
\hline Zirconia & $3.06 \cdot 10^{-7}$ & $2.14 \cdot 10^{-3}$ & $8.78 \cdot 10^{-12}$ & $5.92 \cdot 10^{-11}$ & $8.78 \cdot 10^{-4}$ \\
\hline Cathode & $9.74 \cdot 10^{-8}$ & $9.82 \cdot 10^{-3}$ & $3.31 \cdot 10^{-12}$ & $2.01 \cdot 10^{-11}$ & $4.18 \cdot 10^{-4}$ \\
\hline Carbon & $9.74 \cdot 10^{-8}$ & $9.82 \cdot 10^{-3}$ & $3.31 \cdot 10^{-12}$ & $2.01 \cdot 10^{-11}$ & $4.18 \cdot 10^{-4}$ \\
\hline Perovskite & $8.58 \cdot 10^{-9}$ & $5.54 \cdot 10^{-5}$ & $2.28 \cdot 10^{-13}$ & $1.18 \cdot 10^{-12}$ & $2.31 \cdot 10^{-5}$ \\
\hline Lead iodide & $6.95 \cdot 10^{-9}$ & $4.32 \cdot 10^{-5}$ & $1.80 \cdot 10^{-13}$ & $9.81 \cdot 10^{-13}$ & $1.85 \cdot 10^{-5}$ \\
\hline $\begin{array}{l}\text { Methylammonium } \\
\text { iodide }\end{array}$ & $1.63 \cdot 10^{-9}$ & $1.21 \cdot 10^{-5}$ & $4.75 \cdot 10^{-14}$ & $1.96 \cdot 10^{-13}$ & $4.60 \cdot 10^{-6}$ \\
\hline $\begin{array}{l}5 \text {-ammonium } \\
\text { valeric acid iodide }\end{array}$ & $8.29 \cdot 10^{-13}$ & $1.32 \cdot 10^{-8}$ & $2.46 \cdot 10^{-17}$ & $1.52 \cdot 10^{-16}$ & $2.94 \cdot 10^{-9}$ \\
\hline $\begin{array}{l}\text { Amount of } \\
\text { transportation }\end{array}$ & $1.77 \cdot 10^{-6}$ & 0.0191 & $7.33 \cdot 10^{-11}$ & $2.18 \cdot 10^{-10}$ & $4.82 \cdot 10^{-3}$ \\
\hline $\begin{array}{l}\text { Anode + Substrate } \\
\text { transport }\end{array}$ & $1.30 \cdot 10^{-6}$ & 0.0142 & $5.50 \cdot 10^{-11}$ & $1.64 \cdot 10^{-10}$ & $3.63 \cdot 10^{-3}$ \\
\hline $\begin{array}{l}\text { Anode + Substrate, } \\
\text { lorry }\end{array}$ & $1.30 \cdot 10^{-6}$ & 0.0142 & $5.50 \cdot 10^{-11}$ & $1.64 \cdot 10^{-10}$ & $3.63 \cdot 10^{-3}$ \\
\hline $\begin{array}{l}\text { Blocking layer } \\
\text { transport }\end{array}$ & $1.94 \cdot 10^{-10}$ & $2.12 \cdot 10^{-6}$ & $8.21 \cdot 10^{-15}$ & $2.45 \cdot 10^{-14}$ & $5.42 \cdot 10^{-7}$ \\
\hline Blocking layer, lorry & $1.94 \cdot 10^{-10}$ & $2.12 \cdot 10^{-6}$ & $8.21 \cdot 10^{-15}$ & $2.45 \cdot 10^{-14}$ & $5.42 \cdot 10^{-7}$ \\
\hline $\begin{array}{l}\text { Semi conducting } \\
\text { scaffold transport }\end{array}$ & $8.70 \cdot 10^{-9}$ & $5.69 \cdot 10^{-5}$ & $1.40 \cdot 10^{-13}$ & $3.58 \cdot 10^{-13}$ & $7.40 \cdot 10^{-6}$ \\
\hline $\begin{array}{l}\text { Semi conducting } \\
\text { scaffold, lorry }\end{array}$ & $6.60 \cdot 10^{-10}$ & $7.22 \cdot 10^{-6}$ & $2.79 \cdot 10^{-14}$ & $8.32 \cdot 10^{-14}$ & $1.84 \cdot 10^{-6}$ \\
\hline $\begin{array}{l}\text { Semi conducting } \\
\text { scaffold, freight }\end{array}$ & $8.04 \cdot 10^{-9}$ & $4.97 \cdot 10^{-5}$ & $1.12 \cdot 10^{-13}$ & $2.75 \cdot 10^{-13}$ & $5.56 \cdot 10^{-6}$ \\
\hline $\begin{array}{l}\text { Insulating scaffold } \\
\text { transport }\end{array}$ & $7.05 \cdot 10^{-9}$ & $7.72 \cdot 10^{-5}$ & $2.99 \cdot 10^{-13}$ & $8.90 \cdot 10^{-13}$ & $1.97 \cdot 10^{-5}$ \\
\hline
\end{tabular}


Perovskite photovoltaic modules: life cycle assessment of pre-industrial production process

\begin{tabular}{|c|c|c|c|c|c|}
\hline & $\begin{array}{c}\mathrm{EP}\left(\mathrm{kg} \mathrm{PO}_{4}{ }^{3-}\right. \\
\text { eq) }\end{array}$ & CED (MJ) & HTC (CTUh) & HTNC (CTUh) & FET (CTUe) \\
\hline $\begin{array}{l}\text { Insulating scaffold, } \\
\text { lorry }\end{array}$ & $7.05 \cdot 10^{-9}$ & $7.72 \cdot 10^{-5}$ & $2.99 \cdot 10^{-13}$ & $8.90 \cdot 10^{-13}$ & $1.97 \cdot 10^{-5}$ \\
\hline Cathode transport & $2.11 \cdot 10^{-9}$ & $2.31 \cdot 10^{-5}$ & $8.93 \cdot 10^{-14}$ & $2.66 \cdot 10^{-13}$ & $5.90 \cdot 10^{-6}$ \\
\hline Cathode, lorry & $2.11 \cdot 10^{-9}$ & $2.31 \cdot 10^{-5}$ & $8.93 \cdot 10^{-14}$ & $2.66 \cdot 10^{-13}$ & $5.90 \cdot 10^{-6}$ \\
\hline Perovskite transport & $7.37 \cdot 10^{-12}$ & $5.41 \cdot 10^{-8}$ & $1.54 \cdot 10^{-16}$ & $4.18 \cdot 10^{-16}$ & $8.89 \cdot 10^{-9}$ \\
\hline Perovskite, lorry & $1.80 \cdot 10^{-12}$ & $1.97 \cdot 10^{-8}$ & $7.63 \cdot 10^{-17}$ & $2.27 \cdot 10^{-16}$ & $5.04 \cdot 10^{-9}$ \\
\hline Perovskite, freight & $5.57 \cdot 10^{-12}$ & $3.44 \cdot 10^{-8}$ & $7.76 \cdot 10^{-17}$ & $1.90 \cdot 10^{-16}$ & $3.85 \cdot 10^{-9}$ \\
\hline Use of Energy & $6.18 \cdot 10^{-6}$ & 0.0466 & $1.52 \cdot 10^{-10}$ & $5.60 \cdot 10^{-10}$ & 0.0136 \\
\hline Anode + Substrate & $4.27 \cdot 10^{-9}$ & $3.22 \cdot 10^{-5}$ & $1.05 \cdot 10^{-13}$ & $3.86 \cdot 10^{-13}$ & $9.34 \cdot 10^{-6}$ \\
\hline Blocking layer & $7.70 \cdot 10^{-7}$ & $5.79 \cdot 10^{-3}$ & $1.91 \cdot 10^{-11}$ & $7.10 \cdot 10^{-11}$ & $1.71 \cdot 10^{-3}$ \\
\hline $\begin{array}{l}\text { Blocking layer, } \\
\text { medium voltage } \\
\text { (allocated } \\
\text { annealing) }\end{array}$ & $7.64 \cdot 10^{-7}$ & $5.76 \cdot 10^{-3}$ & $1.88 \cdot 10^{-11}$ & $6.91 \cdot 10^{-11}$ & $1.67 \cdot 10^{-3}$ \\
\hline $\begin{array}{l}\text { compressed air, } \\
1000 \mathrm{kPa} \text { gauge }\end{array}$ & $6.02 \cdot 10^{-9}$ & $2.49 \cdot 10^{-5}$ & $2.95 \cdot 10^{-13}$ & $1.92 \cdot 10^{-12}$ & $4.18 \cdot 10^{-5}$ \\
\hline $\begin{array}{l}\text { Semi conducting } \\
\text { scaffold }\end{array}$ & $2.71 \cdot 10^{-6}$ & 0.0204 & $6.66 \cdot 10^{-11}$ & $2.45 \cdot 10^{-10}$ & $5.92 \cdot 10^{-3}$ \\
\hline Insulating scaffold & $5.24 \cdot 10^{-7}$ & $3.95 \cdot 10^{-3}$ & $1.29 \cdot 10^{-11}$ & $4.74 \cdot 10^{-11}$ & $1.15 \cdot 10^{-3}$ \\
\hline Cathode & $2.01 \cdot 10^{-6}$ & 0.0151 & $4.94 \cdot 10^{-11}$ & $1.81 \cdot 10^{-10}$ & $4.39 \cdot 10^{-3}$ \\
\hline Perovskite & $1.70 \cdot 10^{-7}$ & $1.28 \cdot 10^{-3}$ & $4.20 \cdot 10^{-12}$ & $1.55 \cdot 10^{-11}$ & $3.74 \cdot 10^{-4}$ \\
\hline $\begin{array}{l}\text { Perovskite, low } \\
\text { voltage }\end{array}$ & $4.64 \cdot 10^{-9}$ & $3.32 \cdot 10^{-5}$ & $1.35 \cdot 10^{-13}$ & $5.47 \cdot 10^{-13}$ & $1.30 \cdot 10^{-5}$ \\
\hline $\begin{array}{l}\text { Perovskite, medium } \\
\text { voltage }\end{array}$ & $1.65 \cdot 10^{-7}$ & $1.25 \cdot 10^{-3}$ & $4.06 \cdot 10^{-12}$ & $1.49 \cdot 10^{-11}$ & $3.61 \cdot 10^{-4}$ \\
\hline
\end{tabular}




\section{Transparent methods}

\subsection{Goal and scope definition}

In this study, environmental impacts of a pre-industrial perovskite solar module production process are evaluated to assist researchers in their task of designing this process. We talk about pre-industrial process as large area substrates are employed in addition to industrial friendly architecture, deposition and processing techniques, however they are not fully integrated in a full production line. For this purpose, a process, close to large scale production, for fabricating perovskite modules based on a mesoporous triple stack (pre-industrial module) is analysed through life cycle assessment. In this work, $1 \mathrm{kWh}$ of energy is assumed as a functional unit and an evaluation of the environmental impacts, from cradle to gate, is performed. This $\mathrm{kWh}$ of electricity was simulated/modelled to be produced assuming the actual power conversion efficiency value of the pre-industrial device (11\%), the average solar radiation $\left(1.361 \mathrm{~kW} \cdot \mathrm{m}^{-2}\right)$ [300] and the best-currently-reported lifetime of a carbon stack configuration (10000 h) [78]. The size of the module is assumed to be A4-sized $(210 \times 297 \mathrm{~mm})$.

\subsection{System boundary}

To simulate the environmental mark of the pre-industrial module, a production process developed in a pilot plant was considered, based on the architecture with great potential for commercialisation, i.e. the printed mesoporous stack $[152,166]$. Figure S26 describes the diagram of the process studied in the cradle-to-gate life cycle assessment. Therefore, this analysis accounted for the environmental impacts ranging from the extraction of raw materials to the moment in which the device production is finished. Nevertheless, inputs generating negligible impacts such as equipment assets, maintenance, lighting, environment conditioning and labour force were disregarded $[221,223]$. Equipment assets encompass screen printer, belt oven, drying oven and squeegees together with auxiliary equipment. Polyethylene terephthalate screens - without including the metallic frame- were considered consumables because they can last for just a thousand of print cycles. As deposition of all layers, including the fluorine-doped tin oxide (FTO) film, was assumed to be completed right after the production of the substrate and the anode, the cleaning process usually applied to FTO-glass substrates was omitted as it is unnecessary. Production of encapsulation and contacts of the module were also dismissed due to its primitive state of development and thus the uncertainty of their final layout. 


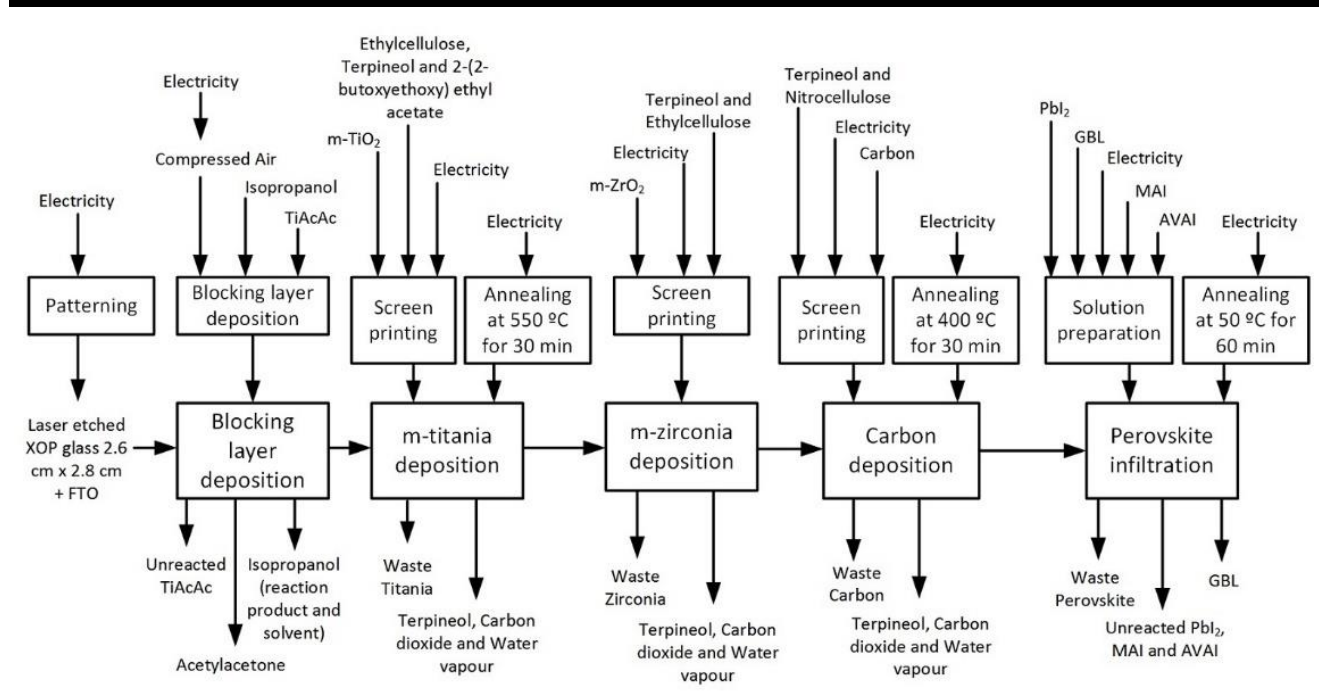

Figure S26. System boundary of the pre-industrial process of production of the carbon stack perovskite photovoltaic module, related to Figure 20 to Figure 23.

As shown in Figure S27, the pre-industrial module consisted of a FTO layer on top of a glass substrate, which was used as the anode and $\mathrm{Nb}: \mathrm{YVO}_{4}$ laser (532 nm) patterned before depositing any other layer. A layer of compact titania $\left(\mathrm{c}-\mathrm{TiO}_{2}\right)$ was deposited by spraying a solution of titanium di-isopropoxide bis(acetylacetonate) (TiACAc) in isopropanol (75wt\%), which reacts to form the blocking layer by hydrolysis [192,301]. An additional amount of isopropanol was added to achieve good conditions to deposit the solution. Over the blocking layer, a mesoporous layer of titania $\left(\mathrm{m}-\mathrm{TiO}_{2}\right)$ was screen printed from a paste with $\alpha$-terpineol, 2-(2butoxyethoxy) ethyl acetate and ethylcellulose, as a semi conducting scaffold. An additional amount of $\alpha$-terpineol was also added to the titania paste to reduce the final $\mathrm{TiO}_{2}$ thickness. Both compact and $\mathrm{m}-\mathrm{TiO}_{2}$ were annealed in a belt electric oven at $550 \stackrel{\circ}{ } \mathrm{C}$ for $30 \mathrm{~min}$. Subsequently, a paste of mesoporous zirconia $\left(\mathrm{m}-\mathrm{ZrO}_{2}\right)$ with $\alpha$ terpineol and ethylcellulose was screen printed to form the insulating scaffold. It was deposited by screen printing a paste of carbon with nitrocellulose and $\alpha$-terpineol. Afterwards, $\mathrm{m}-\mathrm{ZrO}_{2}$ and carbon layers were annealed at 400 o $\mathrm{C}$ for $30 \mathrm{~min}$ in the same oven as titania layers. Finally, perovskite was infiltrated to fill the pores in $\mathrm{m}$ $\mathrm{TiO}_{2}, \mathrm{~m}-\mathrm{ZrO}_{2}$ and carbon layers. It was lastly annealed at 50 ㅇ for $1 \mathrm{~h}$ in a drying oven with forced convection. 


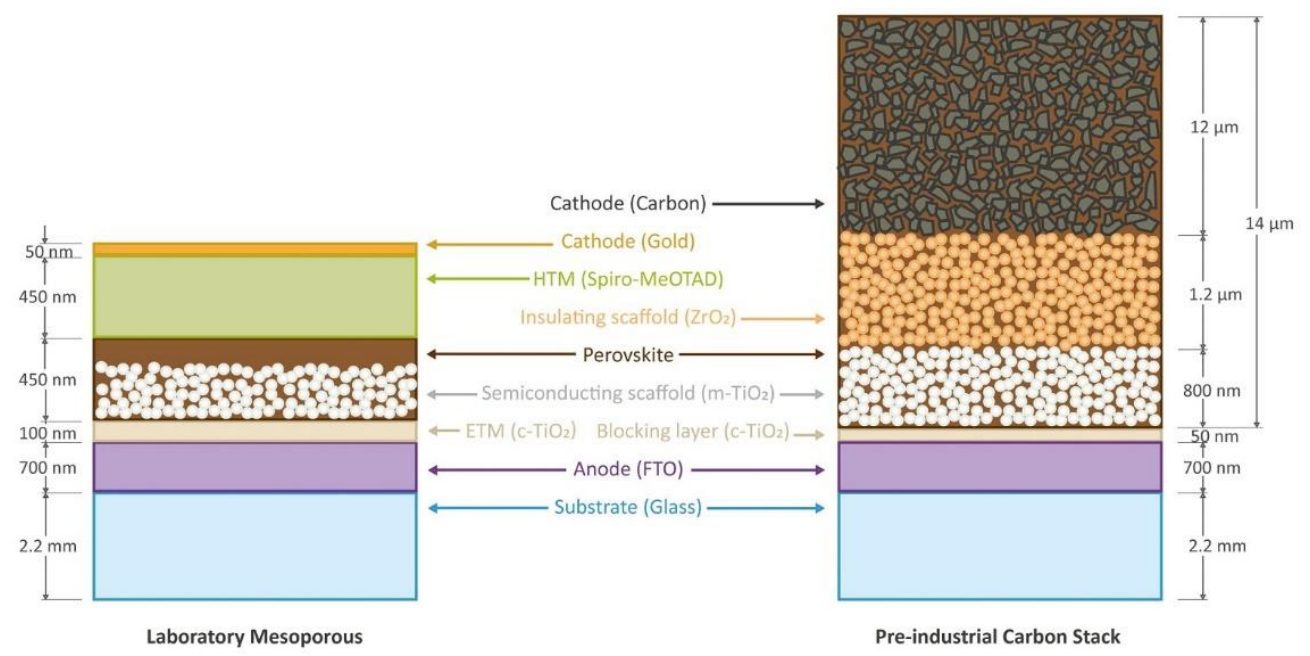

Figure S27. Dimensional cross section of the perovskite solar module produced at a pre-industrial scale (right) and the perovskite solar cell produced at a laboratory scale (left), related to Figure 20 to Figure 23.

\subsection{Inventory}

For the absorber layer of the pre-industrial module assessed in this work, a standard

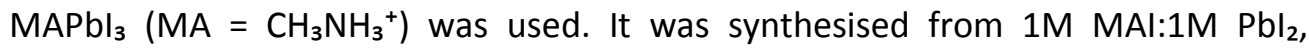
according to the most generalised recipe for the synthesis of perovskite [74], adding 5-ammonium valeric acid iodide (AVAI) to improve its stability [78].

To gather data for the raw materials flow, amounts of reagents for the perovskite and $\mathrm{c}-\mathrm{TiO}_{2}$ syntheses, inclusive of solvents, as well as amounts of $\mathrm{m}-\mathrm{TiO}_{2}, \mathrm{~m}-\mathrm{ZrO}_{2}$ and carbon pastes used for the production of the module were measured directly from the process. $\mathrm{m}-\mathrm{TiO}_{2}, \mathrm{~m}-\mathrm{ZrO}_{2}$ and carbon pastes compositions were obtained from their respective producers, i.e., Greatcell Solar, Solaronix and Gwent Electronic Materials respectively. The glass and FTO film were produced by the NSG Group; in this case, as their final mass was considered, their impacts are probably underestimated.

Most of the datasets of the materials used were available at the Ecoinvent database [302]. Datasets missing in the Ecoinvent database, such as ethylcellulose, nitrocellulose [303], $\alpha$-terpineol [304-311], 2-(2-butoxyethoxy) ethyl acetate [312314], TiAcAc [315-319] and FTO [202,203] together with perovskite reagents MAI [199], $\mathrm{Pbl}_{2}$ [261] and AVAI [320-323], were modelled from synthesis routes encountered in the literature. The inventories of ethyl cellulose, $\alpha$-terpineol, titanium di-isopropoxide bis(acetylacetonate), 5-ammonium valeric acid iodide, 2(2-butoxyethoxy) ethyl acetate and nitrocellulose models are shown in Table S32, 
Table S33, Table S34, Table S35, Table S36 and Table S37, respectively. In contrast, inventories of processes of production of $\mathrm{FTO}, \mathrm{MAl}$ and $\mathrm{Pbl}_{2}$ were extracted from the literature $[89,113]$.

Energy flow and energy consumption of most of the steps of the process, which are screen printing and annealing of $\mathrm{m}-\mathrm{TiO}_{2}, \mathrm{~m}-\mathrm{ZrO}_{2}$ and Carbon pastes, annealing of perovskite and laser etching of the substrate were directly monitored from the production facilities. The energy consumption of compressed air for the screen printer was dismissed in this study as it is low in comparison to that of other steps of this process. Again, there was no information about the deposition process of the FTO layer, which was assumed to be sputtered onto the glass substrate, whose energetic consumption was obtained from other works [203]. Energy consumption to prepare the perovskite solution, by stirring and heating to $70 \stackrel{\circ}{ } \mathrm{C}$, is obtained from a consumption value of a similar process in a previous work [113]. This value is recalculated to be in function of $\mathrm{kWh}$ (the current functional unit), as initially it was given per $\mathrm{cm}^{2}$ of active area. It was not possible to allocate the energy consumption of the air compressor, as its use is shared by several processes, therefore, its air consumption was estimated from the amount of TiAcAc sprayed and an air to liquid ratio of $2 \mathrm{wt} \%$ [324]. Afterwards, the environmental impacts were directly obtained from a process dataset of compressed air in the Ecoinvent database, whose functional unit is the volume of compressed air [302]. As the blocking layer and the insulating scaffold are annealed simultaneously with the semi conducting layer and the cathode, respectively, just as Figure S26 shows, the energy consumption of each annealing process was allocated to each layer on a mass basis. Environmental impacts of the electricity consumption were established from the medium voltage and low voltage continental mix datasets for Europe (RER in Ecoinvent) [325].

Process outputs were included in the emissions flow. They were calculated stoichiometrically from the release of byproducts of the reactions of TiAcAc, which were isopropanol and acetylacetone. Likewise, combustion of ethylcellulose produced carbon dioxide and water vapour. Alongside these two gases, nitrocellulose combustion generated nitrogen oxide. Solvents of $\mathrm{c}-\mathrm{TiO}_{2}$ reaction, perovskite reaction and $\mathrm{m}-\mathrm{TiO}_{2}$, and $\mathrm{m}-\mathrm{ZrO}_{2}$ and carbon pastes were evaporated during annealing processes. These outputs were simulated with the coefficients for fate of emissions to the corresponding compartment available in SimaPro software [259].

The amount of transportation flow was established by using the distances between each supplier and the facilities of SPECIFIC, Swansea University (UK) where the process was carried out. Transoceanic distances were considered from the closest port of each supplier to Swansea port. 


\subsection{Ideality analysis}

Two further scenarios are used for comparison purposes: a perovskite module produced with an ideal process (ideal module) to estimate the ideality coefficient, based on the optimisation of the pre-industrial one, and a perovskite solar cell produced at laboratory scale (lab-scale PSC) to verify the extent of improvement in the pre-industrial process. From the point of view of LCA, the comparison with the lab-scale process arises from the necessity of giving sense to the results [326]. In order to obtain the electric output of both types of device, the same parameters as the pre-industrial process were assumed, except for the efficiency of the PSC in the lab process, which was $19 \%$ [327]. The ideal scenario was estimated from the preindustrial module, where the amounts of material used and the use of energy is ideally optimised. The environmental results of the lab-scale PSC were extracted from a previous study [113], choosing a cell architecture with $\mathrm{MAPbl}_{3}$ embedded into a mesoporous titania scaffold $[200,201]$.

The ideal process of production of perovskite solar modules was elaborated from the pre-industrial process: materials and their amounts were reduced to those strictly necessary to assemble the module and even solvents were dismissed from the system. Furthermore, energy consumption of heating steps, which were initially the most energy consuming by large, were thermodynamically estimated, considering that all the energy consumed is spent on heating the materials only and the equipment is perfectly insulated. Lastly, emissions to the environment in the ideal process were considered void, assuming a good recycling of the outputs of the process.

In the ideal process of production of perovskite modules, quantities were obtained by measuring the thicknesses of the layers in a perovskite photovoltaic module produced in a highly scalable process $[152,166]$. Losses of materials during processing were excluded from this ideal scenario. Once the volume of each material was calculated by multiplying the thickness by the active module area, it was multiplied by the density to obtain the amount of each material. The transportation was re-adjusted to the reduced amount of materials for this scenario. Energy consumption of the three annealing steps and the heating and stirring of perovskite reagents was estimated by using thermodynamic equations which describe the heating process and the synthesis of the $\mathrm{c}^{-\mathrm{TiO}_{2}}$ and the perovskite $[225,227,228,328-331]$. No energy losses were considered during those steps. To allocate the energy of the annealing steps to each of the layers the same criteria used for the pre-industrial process is used. Since the module was considered as a single cell and divisions between cells were not necessary, laser etching was removed from the calculation. The screen printing step and consumption of air compressed for the 
spraying of $\mathrm{c}-\mathrm{TiO}_{2}$ were considered to consume the same energy as the pre-industrial process. Energy consumption of both perovskite carbon stack module and ideal process are compared in Table S41.

Table S41. Energy consumption of the carbon stack perovskite photovoltaic module produced in the pre-industrial process in comparison to the same module produced in the ideal industrial process, related to Figure 20 to Figure 23.

\begin{tabular}{|c|c|c|c|}
\hline Step & Process & $\begin{array}{c}\text { Carbon stack module } \\
\text { electricity consumption } \\
\text { (MJ/kWh) }\end{array}$ & $\begin{array}{l}\text { Ideal process electricity } \\
\text { (MJ/kWh) }\end{array}$ \\
\hline \multirow{2}{*}{$\begin{array}{l}\text { Substrate } \\
\text { production }\end{array}$} & FTO sputtering & 0.0003 & 0.0003 \\
\hline & $\begin{array}{c}\text { Laser substrate } \\
\text { etching }\end{array}$ & 1.1654 & \\
\hline $\begin{array}{l}\text { Blocking layer } \\
\text { deposition }\end{array}$ & Spraying solution & \multicolumn{2}{|c|}{$0.0002\left(\mathrm{~m}^{3}\right.$ of air compressed) } \\
\hline \multirow{2}{*}{$\begin{array}{c}\mathrm{m}-\mathrm{TiO}_{2} \\
\text { deposition }\end{array}$} & Screen printing & 0.0019 & 0.0019 \\
\hline & $\begin{array}{l}\text { Annealing }(550 \stackrel{\circ}{\circ}, \\
30 \mathrm{~min})\end{array}$ & 5.6437 & 0.2373 \\
\hline $\begin{array}{c}\mathrm{m}-\mathrm{ZrO}_{2} \\
\text { deposition }\end{array}$ & Screen printing & 0.0019 & 0.0019 \\
\hline \multirow{2}{*}{$\begin{array}{c}\text { Carbon } \\
\text { deposition }\end{array}$} & Screen printing & 0.0019 & 0.0019 \\
\hline & 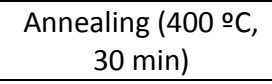 & 4.979 & 0.1704 \\
\hline \multirow{2}{*}{$\begin{array}{l}\text { Perovskite AVA } \\
\text { infiltration }\end{array}$} & 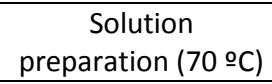 & 8.944 & $2.4410^{-4}$ \\
\hline & $\begin{array}{c}\text { Annealing }(50 \stackrel{\circ}{ } \mathrm{C}, 1 \\
\text { hour) }\end{array}$ & 10.655 & 0.011 \\
\hline \multicolumn{2}{|c|}{ Total } & 31.393 & 1.172 \\
\hline
\end{tabular}

Inventory data of the lab-scale PSC (glass/FTO/c- $\mathrm{TiO}_{2} / \mathrm{m}-\mathrm{TiO}_{2} / \mathrm{MAPI} /$ spiro/gold) were obtained from a previous life cycle assessment study [113] and are shown in Table S30, where every parameter has been readjusted for the production of $1 \mathrm{kWh}$ instead of $1 \mathrm{~m}^{2}$. The diagram of the lab-scale PSC appears in Figure S27 compared with that of the pre-industrial module. When both pre-industrial module and labscale PSC were contrasted, electron and hole transporting material (ETM and HTM) and Au cathode were equated with the blocking layer, the insulating scaffold and the carbon cathode respectively.

The process of production of the lab-scale PSC consisted of a cleaning treatment of the FTO substrate, right before a compact $\mathrm{TiO}_{2}$ layer deposition. This procedure consisted in etching a part of the FTO layer with metallic zinc and hydrochloric acid, a subsequent cleaning with $2 \%$ Hallmanex detergent and water, a sonication in isopropanol and acetone, a washing with ethanol and a final treatment with ozone plasma. Then, a mild solution of titanium isopropoxide in ethanol was deposited via 
spin-coating at $2000 \mathrm{rpm}$ for 1 minute to obtain the compact $\mathrm{TiO}_{2}$ layer, after which

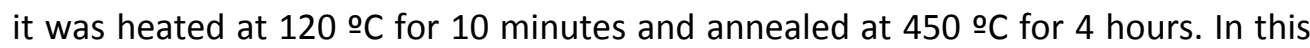
step, isopropanol and ethanol vapours were emitted to the atmosphere. Onto the compact $\mathrm{TiO}_{2}$, the perovskite layer was deposited into a $400 \mathrm{~nm}$ thick mesoporous $\mathrm{TiO}_{2}$ scaffold, where $\mathrm{TiO}_{2}$ in ethanol was spin-coated at $4000 \mathrm{rpm}$ for $60 \mathrm{~s}$, heated at $80 \stackrel{\circ}{\circ}$ for 15 minutes and annealed at 450 ㅇ C for 4 hours. In order to deposit the perovskite into the scaffold a mixture of methylamine iodide and lead (II) iodide in

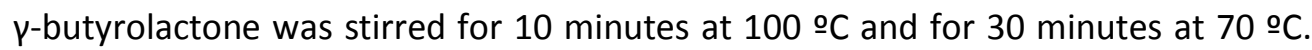
Then, the perovskite was spin-coated for $5 \mathrm{~s}$ at $500 \mathrm{rpm}$ and for $60 \mathrm{~s}$ at $2000 \mathrm{rpm}$ and finally heated at $100 \stackrel{\circ}{C}$ for 60 minutes in a drying oven. On top of it, spiro-MeOTAD in chlorobenzene was deposited by spin-coating for 30 seconds at $4000 \mathrm{rpm}$. For the back contact, gold was deposited by thermal evaporation. Nitrogen gas and electricity consumption of a glove box were also included in the inventory. The amount of electricity consumed was directly measured in the laboratory facilities and the amount of transportation was estimated from the supplier to Castelló (Spain).

\subsection{Life cycle inventory assessment}

Eleven impact categories were chosen and from the most developed impact models, the most representative categories were selected. Seven categories out of this group are included in the CML baseline V3.02 [254,258]. These categories encompassed: abiotic depletion, abiotic depletion (fossil fuels), global warming, ozone layer depletion, photochemical oxidation, acidification and eutrophication. Among these categories, one of the most significant to measure the environmental performance of a solar energy collector device is global warming (also known as carbon footprint), as one of the main benefits of energy stemming from such devices is the mitigation of greenhouse effect. Nonetheless, the other categories enlisted represent a broad panoply of the most concerning categories which should be taken into consideration in order to avoid environmental charge transference, from global warming category to these categories.

Energy is a fundamental aspect of perovskite modules as it is their only valuable output. Knowing the amount of energy necessary to produce them emerges as a good practice to envision how viable their production is. From the Cumulative energy demand method V1.09 (CED) [212], the total cradle-to-gate energy invested in the production of the perovskite module is obtained by adding cumulative energies obtained from the different renewable and non-renewable sources provided by the method. 
$\mathrm{Pb}$ content still remains as one of the main concerns of the possible commercialization of photovoltaics based on perovskite [124]. Therefore, it was necessary to include into the assessment the impact categories Human toxicity (cancer), Human toxicity (non-cancer) and Freshwater ecotoxicity from USEtox V1.04 method [208].

CML, CED and USEtox methods are incorporated within the SimaPro ${ }^{\circledR}$ 8.0.3.14 software [259]. In this manuscript, abbreviations listed in Table S42 are used to name the selected impact categories.

Table S42. List of impact categories, their abbreviations, units and methodologies in which they are included, related to Figure 20 to Figure 23.

\begin{tabular}{|c|c|c|c|}
\hline Category & Abbreviation & Unit & Methodology \\
\hline Abiotic depletion & ADP & $\mathrm{kg} \mathrm{Sb} \mathrm{eq}$ & \multirow{7}{*}{ CML baseline V3.02 } \\
\hline Abiotic depletion, fossil fuels & ADPF & MJ & \\
\hline Climate change & GWP & $\mathrm{kg} \mathrm{CO}_{2} \mathrm{eq}$ & \\
\hline Ozone layer depletion & ODP & kg CFC-11 eq & \\
\hline Photochemical oxidation & POP & $\mathrm{kg} \mathrm{C}_{2} \mathrm{H}_{4}$ eq & \\
\hline Acidification & AP & $\mathrm{kg} \mathrm{SO}_{2}$ eq & \\
\hline Eutrophication & EP & $\mathrm{kg} \mathrm{PO}_{4}{ }^{3-}$ eq & \\
\hline Cumulative energy demand & CED & MJ & $\begin{array}{l}\text { Cumulative energy demand } \\
\text { V1.09 }\end{array}$ \\
\hline Human toxicity, cancer effects & HTC & CTUh & \multirow{3}{*}{ Usetox V1.04 } \\
\hline $\begin{array}{l}\text { Human toxicity, non-cancer } \\
\text { effects }\end{array}$ & HTNC & CTUh & \\
\hline Freshwater ecotoxicity & FET & CTUe & \\
\hline
\end{tabular}



Chapter 6 Conclusions 



\subsection{Overview}

As described in the Chapter 1 , the present thesis aims to assist the decision-making of researchers in the emerging realm of photovoltaic (PV) devices based on halide perovskite. In order to fulfil this goal, three research lines are stablished, in which Life Cycle Assessment (LCA) is applied to Perovskite solar cells (PSCs) at an elementary stage of development, to four perovskite compositions improving key features of PSCs, and to a PV module based on perovskite at an advanced stage towards commercialisation. A recapitulation of the contribution and the results emerged in this thesis is presented below.

\subsubsection{LCA applied to PSCs at an elementary stage of development}

A LCA study is applied to some of the most promising perovskite synthesis routes at laboratory scale at that time. The two perovskite layer configurations planar and mesoporous are also included in the same LCA study.

In addition, three end of life scenarios for PSCs are designed and evaluated. These scenarios consist of (1) landfilling PSCs after halide perovskite is decomposed, (2) a recovery of the layers of the PSCs after perovskite is decomposed until 10 cycles with a final landfill, and (3) 10 recovery cycles similar to those in the scenario 2 with a final recycling.

In spite of the fact that the common layers that present the four PSCs have the highest impact, the perovskite layer synthesised from both an equimolar mixture and a mixture with excess of methylammonium by spin coating generate lower environmental impacts. In addition, these PSCs present lower energy (EPBT) and human toxicity cancer payback (HTCPBT) times. In contrast to the concern raised about the lead content in PSCs, this element presents a low impact in comparison to that of the entire PSC.

The perovskite with a mesoporous scaffold has higher human toxicity and cumulative energy demand than those fully deposited by spin coating. However, these impacts are a little lower than the perovskite layer deposited with the two-step deposition method.

Despite the fact that PSCs are considered an advantageous PV technology in terms of energy consumed for their production, the impact it generates at this preliminary stage is excessively high.

The environmental impact of the three end of life scenarios is chiefly contrasted in terms of the EPBT and HTCPBT. Results of these indicators attribute a shorter time 
of recovery of the energy consumed and the toxicity generated at the production stage for scenario (3) and (2) respect (1).

\subsubsection{LCA applied to four perovskite compositions improving key features of PSCs}

A cradle-to-gate LCA study is applied to halide perovskite compositions that improve the stability, reproducibility and efficiency of PSCs in comparison with the standard methylammonium lead triiodide. The improvement in these features is achieved by introducing a mixture of methylammonium (MA), formamidinium (FA) and caesium in the cationic position of perovskite. Different mixtures of halides are also included in the perovskite formula. The materials and the lab-scale deposition of the perovskite layer are the only accounted environmental interventions. The environmental impacts of four combinations of perovskite are contrasted with a canonical $\mathrm{MAPbl}_{3}$ perovskite.

An additional economic analysis is performed by accounting the cost of precursors.

Moreover, a deposition method appropriate for laboratory scale consisting in the deposition of a drop of "anti-solvent" during the spin-coating is evaluated.

Results of the comparison reveal that the four perovskites with multiple cations and anions are more harmful to the environment than the canonical one, except for the abiotic depletion category. The reasons behind this are the higher impact generated by the synthesis of the FAI precursor, together with a slightly larger amount of energy consumed. Consequently, optimised synthetic procedures for FAl will reduce the environmental impacts of the halide perovskite compositions that currently present the highest performance, where FA plays a key role.

FAl is also the most expensive precursor, which raises the price of the multication perovskite. In contrast, the introduction of lead bromide instead of lead iodide precursors reduces the price.

After comparing the "anti-solvent" deposition method to the conventional spin coating, the former presents a higher environmental impact, because an uncontrolled amount of chlorobenzene used in the second. For this reason, besides technical inconveniences, the "anti-solvent" method is not considered appropriate for large-scale manufacturing. 


\subsubsection{LCA applied to a PV module based on perovskite at an advanced stage of development}

A process of production of PV modules at pilot scale is evaluated through a cradleto-gate LCA. A MAPbl 3 perovskite enclosed in a carbon-stack module is chosen as the most favourable device for commercial production. The environmental performance of the production process of this module is contrasted with an idealised production process where the material and energy consumptions are optimised. Their environmental impacts are also compared with those of a PSC laboratory-scale production process.

In the pilot scale production process, the perovskite layer deposition results the most pernicious step for most of the environmental categories, owing to the higher energy consumed while preparing the precursors and the annealing. In consequence, the perovskite layer has the highest potential for optimisation when contrasted with the idealised production process. The comparison of the environmental impacts of the pilot scale process with the laboratory-scale process reveal that the former presents a significant improvement, even in the energy consumption aspect.

\subsection{Fulfilment of research objectives}

For the conclusion of the present thesis, every research objective stablished is fulfilled. The description of how these research objectives are addressed is described below.

The first research objective is to provide information about the environmental performance of PSCs at an elementary state of development. This objective is mostly fulfilled in Chapter 3, where a prospective LCA is applied to four different PSCs produced at laboratory scale. In this prospective LCA study, the environmental performance of three lab-scale halide perovskite synthesis routes is contrasted. These synthesis routes comprise (1) a mixture of reagents with excess of methylammonium halide deposited by spin coating, (2) an equimolar mixture of reagents deposited by spin coating, and (3) an equimolar mixture of reagents deposited by a two-step process. In addition, the environmental performance of these three PSCs, who have a planar configuration, is contrasted with that of a PSC synthesised through the equimolar spin-coated route into a mesoporous titania scaffold. Finally, the environmental footprint of the "anti-solvent" lab-scale deposition method, which provides excellent results in efficiency and stability, is contrasted with that produced by the spin coating method. This latter subobjective is fulfilled in Chapter 4. 
The second research objective is to provide information about the environmental performance of different halide perovskite compositions intended to improve stability, reproducibility, and efficiency of PSCs. The environmental performance of four different compositions of halide perovskite is evaluated through LCA. These compositions vary the proportions of Cs-FA-MA cations and I-Br anions used. These compositions are contrasted among them and with a canonical perovskite with a methylammonium lead iodide. This objective is entirely covered in Chapter 4.

The third research objective is to provide information about the environmental performance of a PV device based on halide perovskite at a pre-industrial development stage. Most of this objective is fulfilled in Chapter 5. In this chapter, the production of a large-area PV module based on halide perovskite is evaluated through LCA. This module is considered to accomplish the conditions for its commercial deployment, such as containing inexpensive raw materials, being highly reproducible, having a good efficiency. A newly defined ideality coefficient is used to evaluate the level of optimisation of the carbon-stack PV device production process by contrasting its environmental performance with that of a PSC produced at laboratory scale. In Chapter 3, the last subobjective of is addressed. Although it is designed and evaluated for PSCs produced at laboratory scale, a recycling process is intended to ameliorate the environmental performance of a commercial halide perovskite PV device.

\subsection{Validation of hypotheses}

In the course of the present thesis, the validity of the hypotheses set at the beginning (Chapter 1 ) is examined along the LCA studies performed on the different stages of development of PSCs. How these hypotheses are confirmed or refuted is explained below.

1. As PSCs are a promising PV technology because, among other advantages, their assembly needs relatively little energy, the environmental impacts arising from this input are not expected to be remarkable.

In comparison to the highly deployed and energy-demanding crystalline Si PV devices, PSCs promise equivalent amount of energy generated with less energy consumption for their production. However, LCA applied to both PSCs assembled at laboratory scale and at pre-industrial scale revealed that the energy consumed is the most detrimental input. In the LCA applied to the pre-industrial process (Chapter 5), a comparison of its environmental impacts with these of a simulated ideal process demonstrate that there is more progress to be done in order to diminish the energy consumption. 
2. In line with the results of previous toxicity analyses to the lead content of PSCs, it is not expected to pose such a hazard to reject its usage.

From the previous LCA studies applied to lab-scale PSCs, it could be concluded that lead did not pose a significant toxicity risk. A similar conclusion arises from the LCA performed in the present thesis. In contrast to this outcome, some empirical toxicity analyses recently published found the lead content of perovskite severely harmful for living species such as Mentha spicata plants, as described in section 2.3 of Chapter 2. Further studies about this should be performed in order to stablish the real consequences of lead usage in halide perovskite PVs.

3. Due to the amount of materials used to produce PSCs is marginal, the time of functioning of the PSCs necessary to offset the toxicity generated to produce them is relatively low.

In fact, amounts of precursors necessary for the production of PSCs are reduced, as highly thin active and charge transporting layers are enough to make the most of these materials. However, in Chapter 3 the analysis of the HTCPBT (the equivalent of the EPBT for the category human toxicity cancer effects) reveals that when PSCs are produced at laboratory scale (with efficiencies of $12.3 \%$ on average) the HTCPBT lasts longer than their lifetime (an average time of 10.9 years). Fortunately, the HTCPBT decreases to a value closer to current lifetimes (an average of 6.6 years) when the efficiency is enhanced to $20 \%$, which is an efficiency achievable at laboratory scale. This time is finally decreased to an HTCPBT within current lifetimes (an average of 1.3 years), when the precursors of a $20 \%$-efficient PSC are recovered ten cycles, after which it is entirely recycled. The HTCPBT results of a halide perovskite PV device are expected to further decrease when produced through an optimised process.

4. End-of-life scenarios are expected to improve the environmental performance of the life cycle of PSCs as their materials are reused and recycled.

Reusing and recycling products reaching the end of life avoid the extraction of more raw materials and the production of these products. As long as these processes do not generate a higher impact than the production and extraction processes, it can be expected an eventual reduction of impacts in the environment. In the case of the PSCs evaluated in Chapter 3 , the end of life scenarios considering raw materials reuse and recycling do not reduce the impacts of the perovskite layer, except for the device with the titania scaffold. In contrast, when the entire PSC is accounted these two scenarios significantly diminish their environmental footprint, as demonstrate both EPBT and HTCPBT results. 
5. The "anti-solvent" perovskite deposition method is expected to increase the environmental impacts because it uses an additional amount of an organic solvent.

The "anti-solvent" deposition method uses an extra amount of organic solvent to remove the solvents during the spin coating. This extra amount of chlorobenzene solvent used was not expected to generate a significant impact because not much amount of it is necessary. However, as it is a lab-scale deposition method, the amount consumed of this solvent is not optimised. As a result, the impact generated by the usage of this solvent is disproportionate. These results can be seen in Chapter 4.

6. The price of the canonical perovskite is expected to be lower than the multication halide perovskite for the former uses more ordinary reagents.

As described early in the discussion of the hypothesis 5 , methylammonium lead iodide perovskite needs a slightly less quantity of reagents and solvents than the four perovskites with three different cations. As shown in Chapter 4, the price of the former perovskite is lower as expected. However, the difference in the overall price of perovskites is motivated by the higher cost of the FA reagent, again optimisation of formamidinium iodide fabrication could affect the current cost.

7. The pre-industrial production process is expected to notably improve the environmental performance respect the laboratory scale process.

In the pre-industrial manufacturing process the energy consumption and the usage of raw materials are optimised to make it economically viable. As a result, the environmental impacts arising from the pre-industrial process are expected to be notably diminished. In Chapter 5 , an ideality coefficient of the pre-industrial process, estimated by comparison to a simulated ideal process, is compared with that of a laboratory-scale process. This comparison confirms that the pre-industrial process is clearly less harmful for the environment than the laboratory scale process, as it is closer to its ideal process. 
References 

[1] IPCC, Climate Change 2014: Synthesis Report. Contribution of Working Groups I, II and III to the Fifth Assessment Report of the Intergovernmental Panel on Climate Change [Core Writing Team, R.K. Pachauri and L.A. Meyer (eds.)]., Geneva, 2014. https://archive.ipcc.ch/report/ar5/syr/.

[2] UNFCCC, Kyoto Protocol to the United Nations Framework Convention on Climate Change, Kyoto, 1998. https://unfccc.int/process/the-kyotoprotocol/history-of-the-kyoto-protocol/text-of-the-kyoto-protocol.

[3] P. Tans, R. Keeling, Trends in Atmospheric Carbon Dioxide, (2020). https://www.esrl.noaa.gov/gmd/ccgg/trends/data.html.

[4] E. Hawkins, P. Ortega, E. Suckling, A. Schurer, G. Hegerl, P. Jones, M. Joshi, T.J. Osborn, V. Masson-Delmotte, J. Mignot, P. Thorne, G.J. van Oldenborgh, Estimating Changes in Global Temperature since the Preindustrial Period, Bull. Am. Meteorol. Soc. 98 (2017) 1841-1856. doi:10.1175/BAMS-D-160007.1.

[5] H. Ritchie, M. Roser, $\mathrm{CO}_{2}$ and Greenhouse Gas Emissions, Our World Data. (2019) 1-4. https://ourworldindata.org/co2-and-other-greenhouse-gasemissions.

[6] IPCC, Climate Change 2014: Impacts, Adaptation, and Vulnerability. Part A: Global and Sectoral Aspects. Contribution of Working Group II to the Fifth Assessment Report of the Intergovernmental Panel on Climate Change, New York, 2014. https://www.ipcc.ch/report/ar5/wg2/.

[7] D. Wallace-Wells, The Uninhabitable Earth, Intellingencer. (2017). https://nymag.com/intelligencer/2017/07/climate-change-earth-too-hotfor-humans.html.

[8] UNFCCC, Climate Change, (2020). https://www.un.org/en/sections/issuesdepth/climate-change/ (accessed February 18, 2020).

[9] IPCC, Global Warming of $1.5{ }^{\circ} \mathrm{C}$, Incheon, Republic of Korea, 2018. https://www.ipcc.ch/sr15/.

[10] UNEP, Emissions Gap Report 2019, Nairobi, 2019. http://www.unenvironment.org/emissionsgap.

[11] IEA, Global Energy \& CO2 Status Report 2019, Paris, 2019. https://www.iea.org/reports/global-energy-co2-status-report-2019.

[12] A. Widiyanto, S. Kato, N. Maruyama, Y. Kojima, Environmental Impact of Fossil Fuel Fired Co-Generation Plants Using a Numerically Standardized LCA Scheme, J. Energy Resour. Technol. 125 (2003) 9. doi:10.1115/1.1510521. 
[13] G.D. Najafpour, S.J. Mehdizadeh, M. Asadi, Environmental impact of fossil fuel utilization in neka thermal power plant, Int. J. Eng. Trans. B Appl. 23 (2010) 115-120. http://www.ije.ir/article_71842.html.

[14] F.P. Perera, Pollution from Fossil-Fuel Combustion is the Leading Environmental Threat to Global Pediatric Health and Equity: Solutions Exist, Int. J. Environ. Res. Public Health. 15 (2017) 16. doi:10.3390/ijerph15010016.

[15] A. Voiland, R. Simmon, Aerosols: Tiny Particles, Big Impact, Nasa Earth Obs. (2010). https://earthobservatory.nasa.gov/features/Aerosols (accessed April $4,2020)$.

[16] M. Chin, T. Diehl, P. Ginoux, W. Malm, Intercontinental transport of pollution and dust aerosols: implications for regional air quality, Atmos. Chem. Phys. 7 (2007) 5501-5517. doi:10.5194/acp-7-5501-2007.

[17] F.P. Perera, Multiple Threats to Child Health from Fossil Fuel Combustion: Impacts of Air Pollution and Climate Change, Environ. Health Perspect. 125 (2017) 141-148. doi:10.1289/EHP299.

[18] WHO, Ambient air pollution: A global assessment of exposure and burden of disease, 2016. https://www.who.int/phe/publications/air-pollution-globalassessment/en/.

[19] U. Bulut, G. Muratoglu, Renewable energy in Turkey: Great potential, low but increasing utilization, and an empirical analysis on renewable energy-growth nexus, Energy Policy. 123 (2018) 240-250. doi:10.1016/j.enpol.2018.08.057.

[20] IEA, World Energy Outlook 2019, Paris, 2019. https://www.iea.org/reports/world-energy-outlook-2019.

[21] IEA, World Energy Balances 2019, Paris, 2019. doi:10.1787/3a876031-en.

[22] NRC, Energy Resources, National Academies Press, Washington, D.C., 1962. doi:10.17226/21066.

[23] M.K. Hubbert, Nuclear Energy and the Fossil Fuel, Drill. Prod. Pract. (1956) 19. https://web.archive.org/web/20080527233843/http://www.hubbertpeak.c om/hubbert/1956/1956.pdf.

[24] C.J. Campbell, Introduction, in: Campbell's Atlas Oil Gas Deplet., 2013: pp. 39. doi:10.1007/978-1-4614-3576-1_1.

[25] IEA, World Energy Outlook 2016, International Energy Agency, 2016. doi:10.1787/weo-2016-en. 
[26] P.M. Jackson, L.K. Smith, Exploring the undulating plateau: the future of global oil supply, Philos. Trans. R. Soc. A Math. Phys. Eng. Sci. 372 (2014) 20120491. doi:10.1098/rsta.2012.0491.

[27] S.H. Mohr, J. Wang, G. Ellem, J. Ward, D. Giurco, Projection of world fossil fuels by country, Fuel. 141 (2015) 120-135. doi:10.1016/j.fuel.2014.10.030.

[28] BP, BP Statistical Review of World Energy, London, 2019. https://www.bp.com/content/dam/bp/business-

sites/en/global/corporate/pdfs/energy-economics/statistical-review/bpstats-review-2019-full-report.pdf.

[29] M. Dittmar, The end of cheap uranium, Sci. Total Environ. 461-462 (2013) 792-798. doi:10.1016/j.scitotenv.2013.04.035.

[30] N.Y. Amponsah, M. Troldborg, B. Kington, I. Aalders, R.L. Hough, Greenhouse gas emissions from renewable energy sources: A review of lifecycle considerations, Renew. Sustain. Energy Rev. 39 (2014) 461-475. doi:10.1016/j.rser.2014.07.087.

[31] A. Alvarez-Herranz, D. Balsalobre-Lorente, M. Shahbaz, J.M. Cantos, Energy innovation and renewable energy consumption in the correction of air pollution levels, Energy Policy. $105 \quad$ (2017) 386-397. doi:10.1016/j.enpol.2017.03.009.

[32] D. Gielen, F. Boshell, D. Saygin, M.D. Bazilian, N. Wagner, R. Gorini, The role of renewable energy in the global energy transformation, Energy Strateg. Rev. 24 (2019) 38-50. doi:10.1016/j.esr.2019.01.006.

[33] M.A. Destek, A. Aslan, Disaggregated renewable energy consumption and environmental pollution nexus in G-7 countries, Renew. Energy. 151 (2020) 1298-1306. doi:10.1016/j.renene.2019.11.138.

[34] Lazard, Lazard's Levelized Cost of Energy version 13.0, 2019. https://www.lazard.com/perspective/lcoe2019 (accessed November 21, 2019).

[35] A. García-Olivares, J. Ballabrera-Poy, E. García-Ladona, A. Turiel, A global renewable mix with proven technologies and common materials, Energy Policy. 41 (2012) 561-574. doi:10.1016/j.enpol.2011.11.018.

[36] IEA, World Energy Outlook 2018, OECD, Paris, 2018. doi:10.1787/weo-2018en.

[37] J. Solé, A. García-Olivares, A. Turiel, J. Ballabrera-Poy, Renewable transitions and the net energy from oil liquids: A scenarios study, Renew. Energy. 116 
(2018) 258-271. doi:10.1016/j.renene.2017.09.035.

[38] M. Mediavilla, C. de Castro, I. Capellán, L. Javier Miguel, I. Arto, F. Frechoso, The transition towards renewable energies: Physical limits and temporal conditions, Energy Policy. 52 (2013) 297-311. doi:10.1016/j.enpol.2012.09.033.

[39] A. García-Olivares, J. Solé, End of growth and the structural instability of capitalism -From capitalism to a Symbiotic Economy, Futures. 68 (2015) $31-$ 43. doi:10.1016/j.futures.2014.09.004.

[40] M. Ram, D. Bogdanov, A. Aghahosseini, A. Gulagi, S.A. Oyewo, M. Child, U. Caldera, K. Sadovskaia, J. Farfan, L.S.N.S. Barbosa, M. Fasihi, S. Khalili, B. Dalheimer, G. Gruber, T. Traber, F. De Caluwe, H.-J. Fell, C. Breyer, Global Energy System based on 100\% Renewable Energy -Power, Heat, Transport and Desalination Sectors, Berlin; Lappeenranta, 2019. http://energywatchgroup.org/wpcontent/uploads/EWG_LUT_100RE_All_Sectors_Global_Report_2019.pdf.

[41] A. García-Olivares, Substituting silver in solar photovoltaics is feasible and allows for decentralization in smart regional grids, Environ. Innov. Soc. Transitions. 17 (2015) 15-21. doi:10.1016/j.eist.2015.05.004.

[42] R. Vidal, J.-A. Alberola-Borràs, I. Mora-Seró, Abiotic depletion and the potential risk to the supply of cesium, Resour. Policy. 68 (2020) 101792. doi:10.1016/j.resourpol.2020.101792.

[43] L. Grandell, A. Thorenz, Silver supply risk analysis for the solar sector, Renew. Energy. 69 (2014) 157-165. doi:10.1016/j.renene.2014.03.032.

[44] W.A. Hermann, Quantifying global exergy resources, Energy. 31 (2006) 16851702. doi:10.1016/j.energy.2005.09.006.

[45] W. Shockley, H.J. Queisser, Detailed Balance Limit of Efficiency of p-n Junction Solar Cells, J. Appl. Phys. 32 (1961) 510-519. doi:10.1063/1.1736034.

[46] S. Rühle, Tabulated values of the Shockley-Queisser limit for single junction solar cells, Sol. Energy. $130 \quad$ (2016) 139-147. doi:10.1016/j.solener.2016.02.015.

[47] ISE, Photovoltaics 2020. https://www.ise.fraunhofer.de/en/publications/studies/photovoltaicsreport.html.

[48] REN21, Renewables 2019 Global Status Report, Paris, 2019. http://www.ren21.net/gsr. 
[49] R. Frischknecht, R. Itten, P. Sinha, M. de Wild-Scholten, J. Zhang, V. Fthenakis, H.C. Kim, M. Raugei, M. Stucki, Life Cycle Inventories and Life Cycle Assessments of Photovoltaic Systems PVPS Task 12, Report T12-04:2015, 2015. http://iea-pvps.org/index.php?id=315 (accessed September 14, 2017).

[50] E.A. Alsema, M.J. de Wild-Schoten, Reduction of the environmental impacts in crystalline silicon module manufacturing, in: 22nd Eur. Photovolt. Sol. Energy Conf., Milano, Italy, 2007: pp. 829-836. http://dspace.library.uu.nl/handle/1874/27297.

[51] L.-A. Pessina, Silicon-perovskite solar cells achieve record efficiency of $25,2 \%$, EPFL News. (2018). https://actu.epfl.ch/news/silicon-perovskite-solar-cellsachieve-record-effi/.

[52] M. Powalla, S. Paetel, D. Hariskos, R. Wuerz, F. Kessler, P. Lechner, W. Wischmann, T.M. Friedlmeier, Advances in Cost-Efficient Thin-Film Photovoltaics Based on Cu(In,Ga)Se 2, Engineering. 3 (2017) 445-451. doi:10.1016/J.ENG.2017.04.015.

[53] R. Vidal, J. Alberola-Borràs, N. Sánchez-Pantoja, I. Mora-Seró, Comparison of Perovskite Solar Cells with other Photovoltaics Technologies from the Point of View of Life Cycle Assessment, Adv. Energy Sustain. Res. 2 (2021) 2000088. doi:10.1002/aesr.202000088.

[54] S. Moon, K. Kim, Y. Kim, J. Heo, J. Lee, Highly efficient single-junction GaAs thin-film solar cell on flexible substrate, Sci. Rep. 6 (2016) 30107. doi:10.1038/srep30107.

[55] A. Feltrin, A. Freundlich, Material considerations for terawatt level deployment of photovoltaics, Renew. Energy. 33 (2008) 180-185. doi:10.1016/j.renene.2007.05.024.

[56] S. Messina, M.T.S. Nair, P.K. Nair, Antimony Selenide Absorber Thin Films in All-Chemically Deposited Solar Cells, J. Electrochem. Soc. 156 (2009) H327. doi:10.1149/1.3089358.

[57] C. Wadia, A.P. Alivisatos, D.M. Kammen, Materials Availability Expands the Opportunity for Large-Scale Photovoltaics Deployment, Environ. Sci. Technol. 43 (2009) 2072-2077. doi:10.1021/es8019534.

[58] T.S. Gershon, M.J.P. Hopstaken, J. Kim, Y.S. Lee, Bandgap grading of CZTS solar cell, US9722120B2, 2017. https://patents.google.com/patent/US9722120B2/en.

[59] T. Sherahilo, Perovskite solar cell achieves 28\% efficiency, Oxford PV. (2018). https://www.oxfordpv.com/news/oxford-pv-perovskite-solar-cell-achieves- 
28-efficiency.

[60] A.S. Brown, M.A. Green, Limiting efficiency for current-constrained twoterminal tandem cell stacks, Prog. Photovoltaics Res. Appl. 10 (2002) 299307. doi:10.1002/pip.425.

[61] N. Espinosa, M. Hösel, D. Angmo, F.C. Krebs, Solar cells with one-day energy payback for the factories of the future, Energy Environ. Sci. 5 (2012) 51175132. doi:10.1039/C1EE02728J.

[62] H.J. Snaith, Perovskites: The Emergence of a New Era for Low-Cost, HighEfficiency Solar Cells, J. Phys. Chem. Lett. 4 (2013) 3623-3630. doi:10.1021/jz4020162.

[63] A. Kojima, K. Teshima, Y. Shirai, T. Miyasaka, Organometal halide perovskites as visible-light sensitizers for photovoltaic cells, J. Am. Chem. Soc. 131 (2009) 6050-6051. doi:10.1021/ja809598r.

[64] NREL, Best Research-Cell Efficiency, Photovolt. Res. (2021). https://www.nrel.gov/pv/cell-efficiency.html (accessed April 12, 2021).

[65] M.A. Green, E.D. Dunlop, J. Hohl-Ebinger, M. Yoshita, N. Kopidakis, A.W.Y. HoBaillie, Solar cell efficiency tables (Version 55), Prog. Photovoltaics Res. Appl. 28 (2020) 3-15. doi:10.1002/pip.3228.

[66] M. Graetzel, R.A.J. Janssen, D.B. Mitzi, E.H. Sargent, Materials interface engineering for solution-processed photovoltaics, Nature. 488 (2012) 304312. doi:10.1038/nature11476.

[67] J. You, Z. Hong, Y. (Michael) Yang, Q. Chen, M. Cai, T.-B. Song, C.-C. Chen, S. Lu, Y. Liu, H. Zhou, Y. Yang, Low-Temperature Solution-Processed Perovskite Solar Cells with High Efficiency and Flexibility, ACS Nano. 8 (2014) 1674-1680. doi:10.1021/nn406020d.

[68] N. Espinosa, R. García-Valverde, A. Urbina, F.C. Krebs, A life cycle analysis of polymer solar cell modules prepared using roll-to-roll methods under ambient conditions, Sol. Energy Mater. Sol. Cells. 95 (2011) 1293-1302. doi:10.1016/j.solmat.2010.08.020.

[69] F.C. Krebs, Fabrication and processing of polymer solar cells: A review of printing and coating techniques, Sol. Energy Mater. Sol. Cells. 93 (2009) 394412. doi:10.1016/j.solmat.2008.10.004.

[70] M.H. Kumar, N. Yantara, S. Dharani, M. Graetzel, S. Mhaisalkar, P.P. Boix, N. Mathews, Flexible, low-temperature, solution processed ZnO-based perovskite solid state solar cells, Chem. Commun. 49 (2013) 11089. 
doi:10.1039/c3cc46534a.

[71] M. Kaltenbrunner, G. Adam, E.D. Głowacki, M. Drack, R. Schwödiauer, L. Leonat, D.H. Apaydin, H. Groiss, M.C. Scharber, M.S. White, N.S. Sariciftci, S. Bauer, Flexible high power-per-weight perovskite solar cells with chromium oxide-metal contacts for improved stability in air, Nat. Mater. 14 (2015) 1032-1039. doi:10.1038/nmat4388.

[72] G.E. Eperon, V.M. Burlakov, P. Docampo, A. Goriely, H.J. Snaith, Morphological Control for High Performance, Solution-Processed Planar Heterojunction Perovskite Solar Cells, Adv. Funct. Mater. 24 (2014) 151-157. doi:10.1002/adfm.201302090.

[73] J.-H. Im, C.-R. Lee, J.-W. Lee, S.-W. Park, N.-G. Park, 6.5\% efficient perovskite quantum-dot-sensitized solar cell, Nanoscale. $3 \quad$ (2011) 4088. doi:10.1039/c1nr10867k.

[74] H.-S. Kim, C.-R. Lee, J.-H. Im, K.-B. Lee, T. Moehl, A. Marchioro, S.-J. Moon, R. Humphry-Baker, J.-H. Yum, J.E. Moser, M. Grätzel, N.-G. Park, Lead lodide Perovskite Sensitized All-Solid-State Submicron Thin Film Mesoscopic Solar Cell with Efficiency Exceeding 9\%, Sci. Rep. 2 (2012) 591. doi:10.1038/srep00591.

[75] J. Burschka, N. Pellet, S.-J. Moon, R. Humphry-Baker, P. Gao, M.K. Nazeeruddin, M. Grätzel, Sequential deposition as a route to highperformance perovskite-sensitized solar cells, Nature. 499 (2013) 316-319. doi:10.1038/nature12340.

[76] M. Saliba, Perovskite solar cells must come of age, Science. 359 (2018) 388389. doi:10.1126/science.aar5684.

[77] A. Mei, Y. Sheng, Y. Ming, Y. Hu, Y. Rong, W. Zhang, S. Luo, G. Na, C. Tian, X. Hou, Y. Xiong, Z. Zhang, S. Liu, S. Uchida, T.-W. Kim, Y. Yuan, L. Zhang, Y. Zhou, H. Han, Stabilizing Perovskite Solar Cells to IEC61215:2016 Standards with over 9,000-h Operational Tracking, Joule. 4 (2020) 2646-2660. doi:10.1016/j.joule.2020.09.010.

[78] G. Grancini, C. Roldán-Carmona, I. Zimmermann, E. Mosconi, X. Lee, D. Martineau, S. Narbey, F. Oswald, F. De Angelis, M. Graetzel, M.K. Nazeeruddin, One-Year stable perovskite solar cells by 2D/3D interface engineering, Nat. Commun. 8 (2017) 15684. doi:10.1038/ncomms15684.

[79] L.K. Ono, Y. Qi, S. (Frank) Liu, Progress toward Stable Lead Halide Perovskite Solar Cells, Joule. 2 (2018) 1961-1990. doi:10.1016/j.joule.2018.07.007.

[80] IEC, IEC 61215-1:2016: Terrestrial photovoltaic (PV) modules - Design 
qualification and type approval - Part 1: Test requirements, (2016) 1-18. https://webstore.iec.ch/publication/24312.

[81] M. V Khenkin, E.A. Katz, A. Abate, G. Bardizza, J.J. Berry, C. Brabec, F. Brunetti, V. Bulović, Q. Burlingame, A. Di Carlo, R. Cheacharoen, Y.-B. Cheng, A. Colsmann, S. Cros, K. Domanski, M. Dusza, C.J. Fell, S.R. Forrest, Y. Galagan, D. Di Girolamo, M. Grätzel, A. Hagfeldt, E. von Hauff, H. Hoppe, J. Kettle, H. Köbler, M.S. Leite, S. Liu, Y.-L. Loo, J.M. Luther, C.-Q. Ma, M. Madsen, M. Manceau, M. Matheron, M. McGehee, R. Meitzner, M.K. Nazeeruddin, A.F. Nogueira, Ç. Odabaşı, A. Osherov, N.-G. Park, M.O. Reese, F. De Rossi, M. Saliba, U.S. Schubert, H.J. Snaith, S.D. Stranks, W. Tress, P.A. Troshin, V. Turkovic, S. Veenstra, I. Visoly-Fisher, A. Walsh, T. Watson, H. Xie, R. Yıldırım, S.M. Zakeeruddin, K. Zhu, M. Lira-Cantu, Consensus statement for stability assessment and reporting for perovskite photovoltaics based on ISOS procedures, Nat. Energy. 5 (2020) 35-49. doi:10.1038/s41560-019-0529-5.

[82] M.O. Reese, S.A. Gevorgyan, M. Jørgensen, E. Bundgaard, S.R. Kurtz, D.S. Ginley, D.C. Olson, M.T. Lloyd, P. Morvillo, E.A. Katz, A. Elschner, O. Haillant, T.R. Currier, V. Shrotriya, M. Hermenau, M. Riede, K. R. Kirov, G. Trimmel, T. Rath, O. Inganäs, F. Zhang, M. Andersson, K. Tvingstedt, M. Lira-Cantu, D. Laird, C. McGuiness, S. (Jimmy) Gowrisanker, M. Pannone, M. Xiao, J. Hauch, R. Steim, D.M. DeLongchamp, R. Rösch, H. Hoppe, N. Espinosa, A. Urbina, G. Yaman-Uzunoglu, J.-B. Bonekamp, A.J.J.M. van Breemen, C. Girotto, E. Voroshazi, F.C. Krebs, Consensus stability testing protocols for organic photovoltaic materials and devices, Sol. Energy Mater. Sol. Cells. 95 (2011) 1253-1267. doi:10.1016/j.solmat.2011.01.036.

[83] M. V Khenkin, A. K. M., I. Visoly-Fisher, Y. Galagan, F. Di Giacomo, B.R. Patil, G. Sherafatipour, V. Turkovic, H.-G. Rubahn, M. Madsen, T. Merckx, G. Uytterhoeven, J.P.A. Bastos, T. Aernouts, F. Brunetti, M. Lira-Cantu, E.A. Katz, Reconsidering figures of merit for performance and stability of perovskite photovoltaics, Energy Environ. Sci. 11 (2018) 739-743. doi:10.1039/C7EE02956J.

[84] F. De Rossi, J. Barbé, D.M. Tanenbaum, L. Cinà, L.A. Castriotta, V. Stoichkov, Z. Wei, W.C. Tsoi, J. Kettle, A. Sadula, J. Chircop, B. Azzopardi, H. Xie, A. Di Carlo, M. Lira-Cantú, E.A. Katz, T.M. Watson, F. Brunetti, An Interlaboratory Study on the Stability of All-Printable Hole Transport Material-Free Perovskite Solar Cells, Energy Technol. n/a (2020) 2000134. doi:10.1002/ente.202000134.

[85] A. Urbina, The balance between efficiency, stability and environmental impacts in perovskite solar cells: a review, J. Phys. Energy. 2 (2020) 022001. doi:10.1088/2515-7655/ab5eee. 
[86] E.S. Parrott, R.L. Milot, T. Stergiopoulos, H.J. Snaith, M.B. Johnston, L.M. Herz, Effect of Structural Phase Transition on Charge-Carrier Lifetimes and Defects in CH 3 NH 3 Snl 3 Perovskite, J. Phys. Chem. Lett. 7 (2016) 1321-1326. doi:10.1021/acs.jpclett.6b00322.

[87] N.J. Jeon, J.H. Noh, Y.C. Kim, W.S. Yang, S. Ryu, S. II Seok, Solvent engineering for high-performance inorganic-organic hybrid perovskite solar cells, Nat. Mater. 13 (2014) 897-903. doi:10.1038/nmat4014.

[88] M. Saliba, T. Matsui, J.-Y. Seo, K. Domanski, J.-P. Correa-Baena, M.K. Nazeeruddin, S.M. Zakeeruddin, W. Tress, A. Abate, A. Hagfeldt, M. Grätzel, Cesium-containing triple cation perovskite solar cells: improved stability, reproducibility and high efficiency, Energy Environ. Sci. 9 (2016) 1989-1997. doi:10.1039/C5EE03874J.

[89] J.-A. Alberola-Borràs, R. Vidal, I. Mora-Seró, Evaluation of multiple cation/anion perovskite solar cells through life cycle assessment, Sustain. Energy Fuels. 2 (2018) 1600-1609. doi:10.1039/C8SE00053K.

[90] H.E. Sánchez-Godoy, E.A. Erazo, A.F. Gualdrón-Reyes, A.H. Khan, S. Agouram, E.M. Barea, R.A. Rodriguez, I. Zarazúa, P. Ortiz, M.T. Cortés, V. MuñozSanjosé, I. Moreels, S. Masi, I. Mora-Seró, Preferred Growth Direction by PbS Nanoplatelets Preserves Perovskite Infrared Light Harvesting for Stable, Reproducible, and Efficient Solar Cells, Adv. Energy Mater. 10 (2020) 2002422. doi:10.1002/aenm.202002422.

[91] K.-C. Wang, J.-Y. Jeng, P.-S. Shen, Y.-C. Chang, E.W.-G. Diau, C.-H. Tsai, T.-Y. Chao, H.-C. Hsu, P.-Y. Lin, P. Chen, T.-F. Guo, T.-C. Wen, p-type Mesoscopic Nickel Oxide/Organometallic Perovskite Heterojunction Solar Cells, Sci. Rep. 4 (2015) 4756. doi:10.1038/srep04756.

[92] J. You, L. Meng, T.-B. Song, T.-F. Guo, Y. (Michael) Yang, W.-H. Chang, Z. Hong, H. Chen, H. Zhou, Q. Chen, Y. Liu, N. De Marco, Y. Yang, Improved air stability of perovskite solar cells via solution-processed metal oxide transport layers, Nat. Nanotechnol. 11 (2016) 75-81. doi:10.1038/nnano.2015.230.

[93] D. Shen, W. Zhang, F. Xie, Y. Li, A. Abate, M. Wei, Graphene quantum dots decorated TiO2 mesoporous film as an efficient electron transport layer for high-performance perovskite solar cells, J. Power Sources. 402 (2018) 320326. doi:10.1016/j.jpowsour.2018.09.056.

[94] A. Agresti, S. Pescetelli, B. Taheri, A.E. Del Rio Castillo, L. Cinà, F. Bonaccorso, A. Di Carlo, Graphene-Perovskite Solar Cells Exceed 18 \% Efficiency: A Stability Study, ChemSusChem. 9 (2016) 2609-2619. doi:10.1002/cssc.201600942. 
[95] G.A. dos Reis Benatto, B. Roth, M. V. Madsen, M. Hösel, R.R. Søndergaard, M. Jørgensen, F.C. Krebs, Carbon: The Ultimate Electrode Choice for Widely Distributed Polymer Solar Cells, Adv. Energy Mater. 4 (2014) 1400732. doi:10.1002/aenm.201400732.

[96] A. Mei, X. Li, L. Liu, Z. Ku, T. Liu, Y. Rong, M. Xu, M. Hu, J. Chen, Y. Yang, M. Gratzel, H. Han, A hole-conductor-free, fully printable mesoscopic perovskite solar cell with high stability, Science. 345 (2014) 295-298. doi:10.1126/science.1254763.

[97] X. Li, M. Tschumi, H. Han, S.S. Babkair, R.A. Alzubaydi, A.A. Ansari, S.S. Habib, M.K. Nazeeruddin, S.M. Zakeeruddin, M. Grätzel, Outdoor Performance and Stability under Elevated Temperatures and Long-Term Light Soaking of TripleLayer Mesoporous Perovskite Photovoltaics, Energy Technol. 3 (2015) 551555. doi:10.1002/ente.201500045.

[98] J.-A. Alberola-Borràs, J.A. Baker, F. De Rossi, R. Vidal, D. Beynon, K.E.A. Hooper, T.M. Watson, I. Mora-Seró, Perovskite photovoltaic modules: Life cycle assessment of pre-industrial production process, IScience. 9 (2018) 542-551. doi:10.1016/j.isci.2018.10.020.

[99] T. Leijtens, K. Bush, R. Cheacharoen, R. Beal, A. Bowring, M.D. McGehee, Towards enabling stable lead halide perovskite solar cells; interplay between structural, environmental, and thermal stability, J. Mater. Chem. A. 5 (2017) 11483-11500. doi:10.1039/C7TA00434F.

[100] A.K. Baranwal, H. Kanda, N. Shibayama, H. Masutani, T.A.N. Peiris, S. Kanaya, H. Segawa, T. Miyasaka, S. Ito, Thermal Degradation Analysis of Sealed Perovskite Solar Cell with Porous Carbon Electrode at $100{ }^{\circ} \mathrm{C}$ for $7000 \mathrm{~h}$, Energy Technol. 7 (2019) 245-252. doi:10.1002/ente.201800572.

[101] B. McKenna, J.R. Troughton, T.M. Watson, R.C. Evans, Enhancing the stability of organolead halide perovskite films through polymer encapsulation, RSC Adv. 7 (2017) 32942-32951. doi:10.1039/C7RA06002E.

[102] L. Shi, M.P. Bucknall, T.L. Young, M. Zhang, L. Hu, J. Bing, D.S. Lee, J. Kim, T. Wu, N. Takamure, D.R. McKenzie, S. Huang, M.A. Green, A.W.Y. Ho-Baillie, Gas chromatography-mass spectrometry analyses of encapsulated stable perovskite solar cells, Science. (2020) eaba2412. doi:10.1126/science.aba2412.

[103] A.J. Huckaba, D.T. Sun, A.A. Sutanto, M. Mensi, Y. Zhang, W.L. Queen, M.K. Nazeeruddin, Lead Sequestration from Perovskite Solar Cells Using a MetalOrganic Framework Polymer Composite, Energy Technol. 8 (2020) 2000239. doi:10.1002/ente.202000239. 
[104] X. Li, F. Zhang, H. He, J.J. Berry, K. Zhu, T. Xu, On-device lead sequestration for perovskite solar cells, Nature. 578 (2020) 555-558. doi:10.1038/s41586-0202001-x.

[105] D.B. Mitzi, S. Wang, C.A. Feild, C.A. Chess, A.M. Guloy, Conducting Layered Organic-inorganic Halides Containing <110>-Oriented Perovskite Sheets, Science. 267 (1995) 1473-1476. doi:10.1126/science.267.5203.1473.

[106] Z. Cheng, J. Lin, Layered organic-inorganic hybrid perovskites: structure, optical properties, film preparation, patterning and templating engineering, CrystEngComm. 12 (2010) 2646. doi:10.1039/c001929a.

[107] R.F. Service, Perovskite Solar Cells Keep On Surging, Science. 344 (2014) 458458. doi:10.1126/science.344.6183.458.

[108] A.F. Palmstrom, G.E. Eperon, T. Leijtens, R. Prasanna, S.N. Habisreutinger, W. Nemeth, E.A. Gaulding, S.P. Dunfield, M. Reese, S. Nanayakkara, T. Moot, J. Werner, J. Liu, B. To, S.T. Christensen, M.D. McGehee, M.F.A.M. van Hest, J.M. Luther, J.J. Berry, D.T. Moore, Enabling Flexible All-Perovskite Tandem Solar Cells, Joule. (2019). doi:10.1016/j.joule.2019.05.009.

[109] B.A. Wender, R.W. Foley, V. Prado-Lopez, D. Ravikumar, D.A. Eisenberg, T.A. Hottle, J. Sadowski, W.P. Flanagan, A. Fisher, L. Laurin, M.E. Bates, I. Linkov, T.P. Seager, M.P. Fraser, D.H. Guston, Illustrating Anticipatory Life Cycle Assessment for Emerging Photovoltaic Technologies, Environ. Sci. Technol. 48 (2014) 10531-10538. doi:10.1021/es5016923.

[110] N. Espinosa, L. Serrano-Luján, A. Urbina, F.C. Krebs, Solution and vapour deposited lead perovskite solar cells: Ecotoxicity from a life cycle assessment perspective, Sol. Energy Mater. Sol. Cells. 137 (2015) 303-310. doi:10.1016/j.solmat.2015.02.013.

[111] J. Gong, S.B. Darling, F. You, Perovskite photovoltaics: life-cycle assessment of energy and environmental impacts, Energy Environ. Sci. 8 (2015) 19531968. doi:10.1039/C5EE00615E.

[112] J. Zhang, X. Gao, Y. Deng, B. Li, C. Yuan, Life Cycle Assessment of Titania Perovskite Solar Cell Technology for Sustainable Design and Manufacturing, ChemSusChem. 8 (2015) 3882-3891. doi:10.1002/cssc.201500848.

[113] J.-A. Alberola-Borràs, R. Vidal, E.J. Juárez-Pérez, E. Mas-Marzá, A. Guerrero, I. Mora-Seró, Relative impacts of methylammonium lead triiodide perovskite solar cells based on life cycle assessment, Sol. Energy Mater. Sol. Cells. 179 (2018) 169-177. doi:10.1016/j.solmat.2017.11.008.

[114] W.S. Yang, J.H. Noh, N.J. Jeon, Y.C. Kim, S. Ryu, J. Seo, S.I. II Seok, High- 
performance photovoltaic perovskite layers fabricated through intramolecular exchange, Science. $348 \quad$ (2015) 1234-1237. doi:10.1126/science.aaa9272.

[115] N.J. Jeon, J.H. Noh, W.S. Yang, Y.C. Kim, S. Ryu, J. Seo, S. II Seok, Compositional engineering of perovskite materials for high-performance solar cells, Nature. 517 (2015) 476-480. doi:10.1038/nature14133.

[116] K.A. Bush, K. Frohna, R. Prasanna, R.E. Beal, T. Leijtens, S.A. Swifter, M.D. McGehee, Compositional Engineering for Efficient Wide Band Gap Perovskites with Improved Stability to Photoinduced Phase Segregation, ACS Energy Lett. (2018) acsenergylett.7b01255. doi:10.1021/acsenergylett.7b01255.

[117] T. Matsui, T. Yamamoto, T. Nishihara, R. Morisawa, T. Yokoyama, T. Sekiguchi, T. Negami, Compositional Engineering for Thermally Stable, Highly Efficient Perovskite Solar Cells Exceeding 20\% Power Conversion Efficiency with 85 ${ }^{\circ} \mathrm{C} / 85 \% 1000 \mathrm{~h}$ Stability, Adv. Mater. 0 (2019) 1806823. doi:10.1002/adma.201806823.

[118] J. Zhang, X. Gao, Y. Deng, Y. Zha, C. Yuan, Comparison of life cycle environmental impacts of different perovskite solar cell systems, Sol. Energy Mater. Sol. Cells. 166 (2017) 9-17. doi:10.1016/j.solmat.2017.03.008.

[119] T. Ibn-Mohammed, S.C.L. Koh, I.M. Reaney, A. Acquaye, G. Schileo, K.B. Mustapha, R. Greenough, Perovskite solar cells: An integrated hybrid lifecycle assessment and review in comparison with other photovoltaic technologies, Renew. Sustain. Energy Rev. 80 (2017) 1321-1344. doi:10.1016/j.rser.2017.05.095.

[120] H. Sun, Z. Yang, M. Wei, W. Sun, X. Li, S. Ye, Y. Zhao, H. Tan, E.L. Kynaston, T.B. Schon, H. Yan, Z.-H. Lu, G.A. Ozin, E.H. Sargent, D.S. Seferos, Chemically Addressable Perovskite Nanocrystals for Light-Emitting Applications, Adv. Mater. 29 (2017) 1701153. doi:10.1002/adma.201701153.

[121] C. Klaassen, Goodman and Gilman's The Pharmacological Basis of Therapeutics, in: A. Goodman, L. S. \& Gilman (Ed.), Goodman Gilman's Pharmacol. Basis Ther., 6th ed., Mcmillan, 1980: pp. 1615-1637. https://drive.google.com/file/d/OB7RoFpW2gyFU1IPd1VMQ1YtZnc/view?pref=2\&pli=1.

[122] European Parliament, Directive 2002/95/EC of the European Parliament and of the Council of 27 January 2003 on the restriction of the use of certain hazardous substances in electrical and electronic equipment, Official Journal of the European Union, Brussels, Belgium, 2003. http://eur- 
lex.europa.eu/legal-content/EN/NOT/?uri=CELEX:32002L0095.

[123] J. Li, H.-L. Cao, W.-B. Jiao, Q. Wang, M. Wei, I. Cantone, J. Lü, A. Abate, Biological impact of lead from halide perovskites reveals the risk of introducing a safe threshold, Nat. Commun. 11 (2020) 310. doi:10.1038/s41467-019-13910-y.

[124] J.M. Kadro, A. Hagfeldt, The End-of-Life of Perovskite PV, Joule. 1 (2017) 2946. doi:10.1016/j.joule.2017.07.013.

[125] P. Billen, E. Leccisi, S. Dastidar, S. Li, L. Lobaton, S. Spatari, A.T. Fafarman, V.M. Fthenakis, J.B. Baxter, Comparative evaluation of lead emissions and toxicity potential in the life cycle of lead halide perovskite photovoltaics, Energy. 166 (2019) 1089-1096. doi:10.1016/j.energy.2018.10.141.

[126] M. Hauck, T. Ligthart, M. Schaap, E. Boukris, D. Brouwer, Environmental benefits of reduced electricity use exceed impacts from lead use for perovskite based tandem solar cell, Renew. Energy. 111 (2017) 906-913. doi:10.1016/j.renene.2017.04.044.

[127] L. Serrano-Lujan, N. Espinosa, T.T. Larsen-Olsen, J. Abad, A. Urbina, F.C. Krebs, Tin- and Lead-Based Perovskite Solar Cells under Scrutiny: An Environmental Perspective, Adv. Energy Mater. 5 (2015) 1501119. doi:10.1002/aenm.201501119.

[128] J. Zhang, X. Gao, Y. Deng, Y. Zha, C. Yuan, Cradle-to-Grave Life Cycle Assessment of Solid-State Perovskite Solar Cells, in: The American Association of Mechanical Engineers (Ed.), Vol. 4 Bio Sustain. Manuf., ASME, Los Angeles, California, USA, 2017: p. V004T05A021. doi:10.1115/MSEC2017-2970.

[129] I. Celik, Z. Song, M.J. Heben, Y. Yan, D.S. Apul, Life cycle toxicity analysis of emerging PV cells, in: 2016 IEEE 43rd Photovolt. Spec. Conf., IEEE, Portland, OR, USA, 2016: pp. 3598-3601. doi:10.1109/PVSC.2016.7750343.

[130] I. Celik, Z. Song, A.J. Cimaroli, Y. Yan, M.J. Heben, D. Apul, Life Cycle Assessment (LCA) of perovskite PV cells projected from lab to fab, Sol. Energy Mater. Sol. Cells. 156 (2016) 157-169. doi:10.1016/j.solmat.2016.04.037.

[131] A. Babayigit, A. Ethirajan, M. Muller, B. Conings, Toxicity of organometal halide perovskite solar cells, Nat. Mater. 15 (2016) 247-251. doi:10.1038/nmat4572.

[132] J. II Kwak, S.-H. Nam, L. Kim, Y.-J. An, Potential environmental risk of solar cells: Current knowledge and future challenges, J. Hazard. Mater. 392 (2020) 122297. doi:10.1016/j.jhazmat.2020.122297. 
[133] A. Babayigit, D. Duy Thanh, A. Ethirajan, J. Manca, M. Muller, H.-G. Boyen, B. Conings, Assessing the toxicity of $\mathrm{Pb}$ - and $\mathrm{Sn}$-based perovskite solar cells in model organism Danio rerio, Sci. Rep. 6 (2016) 18721. doi:10.1038/srep18721.

[134] A.J. Hill, H. Teraoka, W. Heideman, R.E. Peterson, Zebrafish as a Model Vertebrate for Investigating Chemical Toxicity, Toxicol. Sci. 86 (2005) 6-19. doi:10.1093/toxsci/kfi110.

[135] B. Hailegnaw, S. Kirmayer, E. Edri, G. Hodes, D. Cahen, Rain on Methylammonium Lead lodide Based Perovskites: Possible Environmental Effects of Perovskite Solar Cells, J. Phys. Chem. Lett. 6 (2015) 1543-1547. doi:10.1021/acs.jpclett.5b00504.

[136] Y. Jiang, L. Qiu, E.J. Juarez-Perez, L.K. Ono, Z. Hu, Z. Liu, Z. Wu, L. Meng, Q. Wang, Y. Qi, Reduction of lead leakage from damaged lead halide perovskite solar modules using self-healing polymer-based encapsulation, Nat. Energy. 4 (2019) 585-593. doi:10.1038/s41560-019-0406-2.

[137] B. Conings, A. Babayigit, H.-G. Boyen, Fire Safety of Lead Halide Perovskite Photovoltaics, ACS Energy Lett. 4 (2019) 873-878. doi:10.1021/acsenergylett.9b00546.

[138] S.M. Jain, T. Edvinsson, J.R. Durrant, Green fabrication of stable lead-free bismuth based perovskite solar cells using a non-toxic solvent, Commun. Chem. 2 (2019) 91. doi:10.1038/s42004-019-0195-3.

[139] T. Krishnamoorthy, H. Ding, C. Yan, W.L. Leong, T. Baikie, Z. Zhang, M. Sherburne, S. Li, M. Asta, N. Mathews, S.G. Mhaisalkar, Lead-free germanium iodide perovskite materials for photovoltaic applications, J. Mater. Chem. A. 3 (2015) 23829-23832. doi:10.1039/C5TA05741H.

[140] X.-P. Cui, K.-J. Jiang, J.-H. Huang, Q.-Q. Zhang, M.-J. Su, L.-M. Yang, Y.-L. Song, X.-Q. Zhou, Cupric bromide hybrid perovskite heterojunction solar cells, Synth. Met. 209 (2015) 247-250. doi:10.1016/j.synthmet.2015.07.013.

[141] B. Saparov, F. Hong, J.-P. Sun, H.-S. Duan, W. Meng, S. Cameron, I.G. Hill, Y. Yan, D.B. Mitzi, Thin-Film Preparation and Characterization of Cs 3 Sb 2 I 9 : A Lead-Free Layered Perovskite Semiconductor, Chem. Mater. 27 (2015) 56225632. doi:10.1021/acs.chemmater.5b01989.

[142] L. Liang, P. Gao, Lead-Free Hybrid Perovskite Absorbers for Viable Application: Can We Eat the Cake and Have It too?, Adv. Sci. 5 (2018) 1700331. doi:10.1002/advs.201700331.

[143] S.A.A. Shah, M.H. Sayyad, K. Khan, K. Guo, F. Shen, J. Sun, A.K. Tareen, Y. 
Gong, Z. Guo, Progress towards High-Efficiency and Stable Tin-Based Perovskite Solar Cells, Energies. 13 (2020) 5092. doi:10.3390/en13195092.

[144] C. Liu, W. Li, J. Fan, Y. Mai, A brief review on the lead element substitution in perovskite solar cells, J. Energy Chem. 27 (2018) 1054-1066. doi:10.1016/j.jechem.2017.10.028.

[145] Q. Zhang, F. Hao, J. Li, Y. Zhou, Y. Wei, H. Lin, Perovskite solar cells: must lead be replaced - and can it be done?, Sci. Technol. Adv. Mater. 19 (2018) 425442. doi:10.1080/14686996.2018.1460176.

[146] L. Qiu, L.K. Ono, Y. Qi, Advances and challenges to the commercialization of organic-inorganic halide perovskite solar cell technology, Mater. Today Energy. 7 (2018) 169-189. doi:10.1016/j.mtener.2017.09.008.

[147] Y. Chen, L. Zhang, Y. Zhang, H. Gao, H. Yan, Large-area perovskite solar cells a review of recent progress and issues, RSC Adv. 8 (2018) 10489-10508. doi:10.1039/C8RA00384J.

[148] Y. Rong, Y. Hu, A. Mei, H. Tan, M.I. Saidaminov, S. II Seok, M.D. McGehee, E.H. Sargent, H. Han, Challenges for commercializing perovskite solar cells, Science. 361 (2018) eaat8235. doi:10.1126/science.aat8235.

[149] J.E. Bishop, J.A. Smith, C. Greenland, V. Kumar, N. Vaenas, O.S. Game, T.J. Routledge, M. Wong-Stringer, C. Rodenburg, D.G. Lidzey, High-Efficiency Spray-Coated Perovskite Solar Cells Utilizing Vacuum-Assisted Solution Processing, ACS Appl. Mater. Interfaces. 10 (2018) 39428-39434. doi:10.1021/acsami.8b14859.

[150] B. Smith, J. Troughton, A. Lewis, J. McGettrick, A. Pockett, M. Carnie, C. Charbonneau, C. Pleydell-Pearce, J. Searle, P. Warren, S. Varma, T. Watson, Mass Manufactured Glass Substrates Incorporating Prefabricated Electron Transport Layers for Perovskite Solar Cells, Adv. Mater. Interfaces. 0 (2019) 1801773. doi:10.1002/admi.201801773.

[151] S. Sánchez, J. Jerónimo-Rendon, M. Saliba, A. Hagfeldt, Highly efficient and rapid manufactured perovskite solar cells via Flash InfraRed Annealing, Mater. Today. 35 (2020) 9-15. doi:10.1016/j.mattod.2019.11.003.

[152] J. Baker, K. Hooper, S. Meroni, A. Pockett, J. McGettrick, Z. Wei, R. Escalante, G. Oskam, M. Carnie, T. Watson, High throughput fabrication of mesoporous carbon perovskite solar cells, J. Mater. Chem. A. 5 (2017) 18643-18650. doi:10.1039/C7TA05674E.

[153] Panasonic Corporation, Japan's NEDO and Panasonic Achieve the World's Highest Conversion Efficiency of $\mathbf{1 6 . 0 9 \%}$ for Largest-area Perovskite Solar Cell 
Module,

(2020)

$1-3$.

https://news.panasonic.com/global/press/data/2020/02/en200207-

2/en200207-

2.html?fbclid=IwAR1iz6nVkb7_YdbUO9TgX4uqdqhMp4ZOSEy8FhSeqAs_8Nz uRy_9LZn32B8.

[154] A.A. Asif, R. Singh, G.F. Alapatt, Technical and economic assessment of perovskite solar cells for large scale manufacturing, J. Renew. Sustain. Energy. 7 (2015) 043120. doi:10.1063/1.4927329.

[155] M. Cai, Y. Wu, H. Chen, X. Yang, Y. Qiang, L. Han, Cost-Performance Analysis of Perovskite Solar Modules, Adv. Sci. $4 \quad$ (2017) 1600269. doi:10.1002/advs.201600269.

[156] N.L. Chang, A.W. Yi Ho-Baillie, P.A. Basore, T.L. Young, R. Evans, R.J. Egan, A manufacturing cost estimation method with uncertainty analysis and its application to perovskite on glass photovoltaic modules, Prog. Photovoltaics Res. Appl. 25 (2017) 390-405. doi:10.1002/pip.2871.

[157] N.L. Chang, A.W.Y. Ho-Baillie, D. Vak, M. Gao, M.A. Green, R.J. Egan, Manufacturing cost and market potential analysis of demonstrated roll-toroll perovskite photovoltaic cell processes, Sol. Energy Mater. Sol. Cells. 174 (2018) 314-324. doi:10.1016/j.solmat.2017.08.038.

[158] Z. Song, C.L. McElvany, A.B. Phillips, I. Celik, P.W. Krantz, S.C. Watthage, G.K. Liyanage, D. Apul, M.J. Heben, A technoeconomic analysis of perovskite solar module manufacturing with low-cost materials and techniques, Energy Environ. Sci. 10 (2017) 1297-1305. doi:10.1039/C7EE00757D.

[159] A. Valero, A. Valero, G. Calvo, A. Ortego, Material bottlenecks in the future development of green technologies, Renew. Sustain. Energy Rev. 93 (2018) 178-200. doi:10.1016/j.rser.2018.05.041.

[160] E. Leccisi, V. Fthenakis, Life-cycle environmental impacts of single-junction and tandem perovskite PVs: a critical review and future perspectives, Prog. Energy. 2 (2020) 032002. doi:10.1088/2516-1083/ab7e84.

[161] S. Maranghi, M.L. Parisi, R. Basosi, A. Sinicropi, LCA as a Support Tool for the Evaluation of Industrial Scale-Up, in: S. Maranghi, C. Brondi (Eds.), Life Cycle Assess. Chem. Prod. Chain, Springer International Publishing, Cham, 2020: pp. 125-143. doi:10.1007/978-3-030-34424-5_6.

[162] S. Sánchez, M. Vallés-Pelarda, J.A. Alberola-Borràs, R. Vidal, J.J. JerónimoRendón, M. Saliba, P.P. Boix, I. Mora-Seró, Flash infrared annealing as a costeffective and low environmental impact processing method for planar 
perovskite solar cells, Mater. Today. 31 (2019) 39-46. doi:10.1016/j.mattod.2019.04.021.

[163] W. Zhu, Q. Chen, Y. Yamaguchi, F. Zhao, D. Hao, X. Liu, X. Dou, Perovskite solar cells prepared under infrared irradiation during fabrication process in air ambience, J. Mater. Sci. Mater. Electron. 31 (2020) 9535-9542. doi:10.1007/s10854-020-03495-4.

[164] G. Niu, X. Guo, L. Wang, Review of recent progress in chemical stability of perovskite solar cells, J. Mater. Chem. A. 3 (2015) 8970-8980. doi:10.1039/C4TA04994B.

[165] S.M.P. Meroni, Y. Mouhamad, F. De Rossi, A. Pockett, J. Baker, R. Escalante, J. Searle, M.J. Carnie, E. Jewell, G. Oskam, T.M. Watson, Homogeneous and highly controlled deposition of low viscosity inks and application on fully printable perovskite solar cells, Sci. Technol. Adv. Mater. 19 (2018) 1-9. doi:10.1080/14686996.2017.1406777.

[166] F. De Rossi, J.A. Baker, D. Beynon, K.E.A. Hooper, S.M.P. Meroni, D. Williams, Z. Wei, A. Yasin, C. Charbonneau, E.H. Jewell, T.M. Watson, All Printable Perovskite Solar Modules with $198 \mathrm{~cm} 2$ Active Area and Over 6\% Efficiency, Adv. Mater. Technol. 3 (2018) 1800156. doi:10.1002/admt.201800156.

[167] H. Sarialtin, R. Geyer, C. Zafer, Life cycle assessment of hole transport free planar-mesoscopic perovskite solar cells, J. Renew. Sustain. Energy. 12 (2020) 023502. doi:10.1063/1.5129784.

[168] R.M. Izatt, S.R. Izatt, R.L. Bruening, N.E. Izatt, B.A. Moyer, Challenges to achievement of metal sustainability in our high-tech society, Chem. Soc. Rev. 43 (2014) 2451. doi:10.1039/c3cs60440c.

[169] P.-Y. Chen, J. Qi, M.T. Klug, X. Dang, P.T. Hammond, A.M. Belcher, Environmentally responsible fabrication of efficient perovskite solar cells from recycled car batteries, Energy Environ. Sci. 7 (2014) 3659-3665. doi:10.1039/C4EE00965G.

[170] C.G. Poll, G.W. Nelson, D.M. Pickup, A. V Chadwick, D.J. Riley, D.J. Payne, Electrochemical recycling of lead from hybrid organic-inorganic perovskites using deep eutectic solvents, Green Chem. 18 (2016) 2946-2955. doi:10.1039/C5GC02734A.

[171] J. Xu, Z. Hu, L. Huang, X. Huang, X. Jia, J. Zhang, J. Zhang, Y. Zhu, In situ recycle of $\mathrm{Pbl} 2$ as a step towards sustainable perovskite solar cells, Prog. Photovoltaics Res. Appl. 25 (2017) 1022-1033. doi:10.1002/pip.2916.

[172] Y.-Y. Huang, G. Gollavelli, Y.-H. Chao, C.-S. Hsu, Rejuvenation of perovskite 
solar cells, J. Mater. Chem. C. 4 (2016) 7595-7600. doi:10.1039/C6TC02307J.

[173] J.M. Kadro, N. Pellet, F. Giordano, A. Ulianov, O. Müntener, J. Maier, M. Grätzel, A. Hagfeldt, Proof-of-concept for facile perovskite solar cell recycling, Energy Environ. Sci. 9 (2016) 3172-3179. doi:10.1039/C6EE02013E.

[174] A. Binek, M.L. Petrus, N. Huber, H. Bristow, Y. Hu, T. Bein, P. Docampo, Recycling Perovskite Solar Cells To Avoid Lead Waste, ACS Appl. Mater. Interfaces. 8 (2016) 12881-12886. doi:10.1021/acsami.6b03767.

[175] L. Huang, Z. Hu, J. Xu, X. Sun, Y. Du, J. Ni, H. Cai, J. Li, J. Zhang, Efficient electron-transport layer-free planar perovskite solar cells via recycling the FTO/glass substrates from degraded devices, Sol. Energy Mater. Sol. Cells. 152 (2016) 118-124. doi:10.1016/j.solmat.2016.03.035.

[176] B.J. Kim, D.H. Kim, S.L. Kwon, S.Y. Park, Z. Li, K. Zhu, H.S. Jung, Selective dissolution of halide perovskites as a step towards recycling solar cells, Nat. Commun. 7 (2016) 11735. doi:10.1038/ncomms11735.

[177] M. Monteiro Lunardi, A. Wing Yi Ho-Baillie, J.P. Alvarez-Gaitan, S. Moore, R. Corkish, A life cycle assessment of perovskite/silicon tandem solar cells, Prog. Photovoltaics Res. Appl. 25 (2017) 679-695. doi:10.1002/pip.2877.

[178] I. Celik, A.B. Philips, Z. Song, Y. Yan, R.J. Ellingson, M.J. Heben, D. Apul, Energy Payback Time (EPBT) and Energy Return on Energy Invested (EROI) of Perovskite Tandem Photovoltaic Solar Cells, IEEE J. Photovoltaics. 8 (2018) 305-309. doi:10.1109/JPHOTOV.2017.2768961.

[179] R. Itten, M. Stucki, Highly Efficient 3rd Generation Multi-Junction Solar Cells Using Silicon Heterojunction and Perovskite Tandem: Prospective Life Cycle Environmental Impacts, Energies. 10 (2017) 841. doi:10.3390/en10070841.

[180] R. Jones-Albertus, D. Feldman, R. Fu, K. Horowitz, M. Woodhouse, Technology advances needed for photovoltaics to achieve widespread grid price parity, Prog. Photovoltaics Res. Appl. 24 (2016) 1272-1283. doi:10.1002/pip.2755.

[181] J. Qian, M. Ernst, N. Wu, A. Blakers, Impact of perovskite solar cell degradation on the lifetime energy yield and economic viability of perovskite/silicon tandem modules, Sustain. Energy Fuels. 3 (2019) 14391447. doi:10.1039/C9SE00143C.

[182] D. Pourjafari, D. Peralta, R.A. Escalante Quijano, G. Oskam, J. Baker, S. Meroni, A. Yasin, C. Charbonneau, Feasibility Study of Economics, Facilities and Skills for Production of Printed Photovoltaics Utilising Resources Available in Merida Mexico, in: 15th Photovolt. Sci. Appl. Technol. Conf., Warwick, 2019: pp. 1-4. https://www.pvsat.org.uk/Files/Other/wr/thu/19 Pourjafari.pdf. 
[183] M.A. Green, K. Emery, Y. Hishikawa, W. Warta, E.D. Dunlop, Solar cell efficiency tables (version 47), Prog. Photovoltaics Res. Appl. 24 (2016) 3-11. doi:10.1002/pip.2728.

[184] National Renewable Energy Laboratory, Best Research-Cell Efficiencies, (2019). https://www.nrel.gov/pv/assets/images/efficiency-chart.png (accessed March 4, 2019).

[185] I. Almansouri, A. Ho-Baillie, M.A. Green, Ultimate efficiency limit of singlejunction perovskite and dual-junction perovskite/silicon two-terminal devices, Jpn. J. Appl. Phys. 54 (2015) 08KD04. doi:10.7567/JJAP.54.08KD04.

[186] T. Leijtens, G.E. Eperon, N.K. Noel, S.N. Habisreutinger, A. Petrozza, H.J. Snaith, Stability of Metal Halide Perovskite Solar Cells, Adv. Energy Mater. 5 (2015) 1500963. doi:10.1002/aenm.201500963.

[187] C.A. Sutherland, E.F. Milner, R.C. Kerby, H. Teindl, A. Melin, H.M. Bolt, Lead, in: Ullmann's Encycl. Ind. Chem., Wiley-VCH Verlag GmbH \& Co. KGaA, 2000. doi:10.1002/14356007.a15_193.pub2.

[188] E.J. Juarez-Perez, M. Wußler, F. Fabregat-Santiago, K. Lakus-Wollny, E. Mankel, T. Mayer, W. Jaegermann, I. Mora-Sero, Role of the Selective Contacts in the Performance of Lead Halide Perovskite Solar Cells, J. Phys. Chem. Lett. 5 (2014) 680-685. doi:10.1021/jz500059v.

[189] D. Marsitzky, J. Murray, J.C. Scott, K.R. Carter, Amorphous Poly-2,7-fluorene Networks, Chem. Mater. 13 (2001) 4285-4289. doi:10.1021/cm010282h.

[190] J. Salbeck, N. Yu, J. Bauer, F. Weissörtel, H. Bestgen, Low molecular organic glasses for blue electroluminescence, Synth. Met. 91 (1997) 209-215. http://www.scopus.com/inward/record.url?eid=2-s2.00031381007\&partnerID=tZOtx3y1.

[191] U. Bach, D. Lupo, P. Comte, J.E. Moser, F. Weissörtel, J. Salbeck, H. Spreitzer, M. Grätzel, Solid-state dye-sensitized mesoporous TiO2 solar cells with high photon-to-electron conversion efficiencies, Nature. 395 (1998) 583-585. doi:10.1038/26936.

[192] D.A.H. Hanaor, I. Chironi, I. Karatchevtseva, G. Triani, C.C. Sorrell, Single and mixed phase TiO 2 powders prepared by excess hydrolysis of titanium alkoxide, Adv. Appl. Ceram. 111 (2012) 149-158. doi:10.1179/1743676111Y.0000000059.

[193] A.N. Banerjee, S. Kundoo, P. Saha, K.K. Chattopadhyay, Synthesis and Characterization of Nano-Crystalline Fluorine-Doped Tin Oxide Thin Films by Sol-Gel Method, J. Sol-Gel Sci. Technol. 28 (2003) 105-110. 
doi:10.1023/A:1025697322395.

[194] J. Zhang, E.J. Juárez-Pérez, I. Mora-Seró, B. Viana, T. Pauporté, Fast and low temperature growth of electron transport layers for efficient perovskite solar cells, J. Mater. Chem. A. 3 (2015) 4909-4915. doi:10.1039/C4TA06416J.

[195] A. Listorti, E.J. Juarez-Perez, C. Frontera, V. Roiati, L. Garcia-Andrade, S. Colella, A. Rizzo, P. Ortiz, I. Mora-Sero, Effect of Mesostructured Layer upon Crystalline Properties and Device Performance on Perovskite Solar Cells., J. Phys. Chem. Lett. 6 (2015) 1628-37. doi:10.1021/acs.jpclett.5b00483.

[196] ISO 14040:2006, Environmental management. Life cycle assessment. Principles and framework (14040: 2006), European Comittee for Standarization, Brussels, Belgium, 2006. http://www.iso.org/iso/catalogue_detail?csnumber=37456 (accessed February 10, 2015).

[197] ISO 14044:2006, Environmental management. Life cycle assessment. Requierements and guidelines (14044: 2006), European Comittee for Standarization, Brussels, Belgium, 2006. http://www.iso.org/iso/catalogue_detail?csnumber=38498 (accessed February 10, 2015).

[198] D. Bi, W. Tress, M.I. Dar, P. Gao, J. Luo, C. Renevier, K. Schenk, A. Abate, F. Giordano, J.-P. Correa Baena, J.-D. Decoppet, S.M. Zakeeruddin, M.K. Nazeeruddin, M. Grätzel, A. Hagfeldt, Efficient luminescent solar cells based on tailored mixed-cation perovskites, Sci. Adv. 2 (2016) e1501170. doi:10.1126/sciadv.1501170.

[199] J.H. Noh, N.J. Jeon, Y.C. Choi, M.K. Nazeeruddin, M. Grätzel, S. II Seok, Nanostructured $\mathrm{TiO} 2 / \mathrm{CH} 3 \mathrm{NH} 3 \mathrm{Pbl} 3$ heterojunction solar cells employing spiro-OMeTAD/Co-complex as hole-transporting material, J. Mater. Chem. A. 1 (2013) 11842. doi:10.1039/c3ta12681a.

[200] Y. Zhao, A.M. Nardes, K. Zhu, Solid-State Mesostructured Perovskite CH 3 NH 3 Pbl 3 Solar Cells: Charge Transport, Recombination, and Diffusion Length, J. Phys. Chem. Lett. 5 (2014) 490-494. doi:10.1021/jz500003v.

[201] J.M. Ball, M.M. Lee, A. Hey, H.J. Snaith, Low-temperature processed mesosuperstructured to thin-film perovskite solar cells, Energy Environ. Sci. 6 (2013) 1739. doi:10.1039/c3ee40810h.

[202] Z. Banyamin, P. Kelly, G. West, J. Boardman, Electrical and Optical Properties of Fluorine Doped Tin Oxide Thin Films Prepared by Magnetron Sputtering, Coatings. 4 (2014) 732-746. doi:10.3390/coatings4040732. 
[203] M.P. Tsang, G.W. Sonnemann, D.M. Bassani, A comparative human health, ecotoxicity, and product environmental assessment on the production of organic and silicon solar cells, Prog. Photovoltaics Res. Appl. 24 (2016) 645655. doi:10.1002/pip.2704.

[204] R. García-Valverde, J.A. Cherni, A. Urbina, Life cycle analysis of organic photovoltaic technologies, Prog. Photovoltaics Res. Appl. 18 (2010) 535-558. doi:10.1002/pip.967.

[205] The ecoinvent database v3.1. Swiss Centre for Life Cycle Inventories, (2014).

[206] G. Sandin, G.M. Peters, M. Svanström, Life cycle assessment of construction materials: The influence of assumptions in end-of-life modelling, Int. J. Life Cycle Assess. 19 (2014) 723-731. doi:10.1007/s11367-013-0686-x.

[207] G. Doka, Life Cycle Inventories of Waste Treatment Services, Dübendorf, 2009. http://www.doka.ch/13_I_WasteTreatmentGeneral.pdf.

[208] R.K. Rosenbaum, T.M. Bachmann, L.S. Gold, M.A.J. Huijbregts, O. Jolliet, R. Juraske, A. Koehler, H.F. Larsen, M. MacLeod, M. Margni, T.E. McKone, J. Payet, M. Schuhmacher, D. van de Meent, M.Z. Hauschild, USEtox-the UNEP-SETAC toxicity model: recommended characterisation factors for human toxicity and freshwater ecotoxicity in life cycle impact assessment, Int. J. Life Cycle Assess. 13 (2008) 532-546. doi:10.1007/s11367-008-0038-4.

[209] M.Z. Hauschild, M. Goedkoop, J. Guinée, R. Heijungs, M. Huijbregts, O. Jolliet, M. Margni, A. De Schryver, S. Humbert, A. Laurent, S. Sala, R. Pant, Identifying best existing practice for characterization modeling in life cycle impact assessment, Int. J. Life Cycle Assess. 18 (2013) 683-697. doi:10.1007/s11367012-0489-5.

[210] M. Pizzol, P. Christensen, J. Schmidt, M. Thomsen, Impacts of "metals" on human health: a comparison between nine different methodologies for Life Cycle Impact Assessment (LCIA), J. Clean. Prod. 19 (2011) 646-656. http://www.sciencedirect.com/science/article/pii/S0959652610001800 (accessed May 21, 2015).

[211] J.B. Guinee, Handbook on life cycle assessment operational guide to the ISO standards, Int. J. Life Cycle Assess. 7 (2002) 311-313. doi:10.1007/BF02978897.

[212] R. Frischknecht, N. Jungbluth, H.-J. Althaus, G. Doka, R. Dones, T. Heck, S. Hellweg, R. Hischier, T. Nemecek, G. Rebitzer, M. Spielmann, The ecoinvent Database: Overview and Methodological Framework (7 pp), Int. J. Life Cycle Assess. 10 (2005) 3-9. doi:10.1065/Ica2004.10.181.1. 
[213] P. Forster, V. Ramaswamy, P. Artaxo, T. Berntsen, R. Betts, D.W. Fahey, J. Haywood, J. Lean, D.C. Lowe, G. Myhre, J. Nganga, R. Prinn, G. Raga, M. Schultz, R. Van Dorland, Changes in atmospheric constituents and in radiative forcing, in: S.Q. Solomon D; Manning, M; Chen, Z; Marquis, M; Averyt, KB; Tignor, M; Miller, HL (Ed.), Clim. Chang. 2007 Phys. Sci. Basis, Cambridge University Press, Cambridge, United Kingdom, 2007: pp. 129-234. http://www.ipcc.ch/pdf/assessment-report/ar4/wg1/ar4-wg1-chapter2.pdf.

[214] M. Hauschild, M. Goedkoop, J. Guinee, R. Heijungs, M. Huijbregts, O. Jolliet, M. Margni, A. De Schryver, Recommendations for Life Cycle Impact Assessment in the European context - based on existing environmental impact assessment models and factors (International Reference Life Cycle Data System - ILCD handbook), Publications Office of the European Union, 2010. doi:10.2788/33030.

[215] E.J. Armendáriz-Villegas, M. de los Á. Covarrubias-García, E. Troyo-Diéguez, E. Lagunes, A. Arreola-Lizárraga, A. Nieto-Garibay, L.F. Beltrán-Morales, A. Ortega-Rubio, Metal mining and natural protected areas in Mexico: Geographic overlaps and environmental implications, Environ. Sci. Policy. 48 (2015) 9-19. doi:10.1016/j.envsci.2014.12.016.

[216] N.A. Hassan, M. Sahani, R. Hod, N.A. Yahya, A study on exposure to cyanide among a community living near a gold mine in Malaysia., J. Environ. Health. 77 (2015) 42-8. http://www.scopus.com/inward/record.url?eid=2-s2.084925581141\&partnerID=tZOtx3y1.

[217] S. Ncube-Phiri, A. Ncube, B. Mucherera, M. Ncube, Artisanal small-scale mining: Potential ecological disaster in Mzingwane District, Zimbabwe, Jàmbá J. Disaster Risk Stud. 7 (2015). doi:10.4102/jamba.v7i1.158.

[218] A. Marcucci, H. Turton, Induced technological change in moderate and fragmented climate change mitigation regimes, Technol. Forecast. Soc. Change. 90 (2015) 230-242. doi:10.1016/j.techfore.2013.10.027.

[219] OECD/IEA, World energy trends: Energy balances of non-OECD countries, 2015. http://www.iea.org/bookshop/663-Energy_Balances_of_NonOECD_Countries.

[220] European Commission, Renewable Energy. 2020 renewable energy targets., (2015). http://ec.europa.eu/energy/en/topics/renewable-energy (accessed February 5, 2016).

[221] M.D. Chatzisideris, N. Espinosa, A. Laurent, F.C. Krebs, Ecodesign perspectives of thin-film photovoltaic technologies: A review of life cycle assessment studies, Sol. Energy Mater. Sol. Cells. 156 (2016) 2-10. 
doi:10.1016/j.solmat.2016.05.048.

[222] N. Espinosa, R.R. Søndergaard, M. Jørgensen, F.C. Krebs, Flow Synthesis of Silver Nanowires for Semitransparent Solar Cell Electrodes: A Life Cycle Perspective, ChemSusChem. 9 (2016) 893-899. doi:10.1002/cssc.201501437.

[223] S. Amarakoon, C. Vallet, M.A. Curran, P. Haldar, D. Metacarpa, D. Fobare, J. Bell, Life cycle assessment of photovoltaic manufacturing consortium (PVMC) copper indium gallium (di)selenide (CIGS) modules, Int. J. Life Cycle Assess. 23 (2018) 851-866. doi:10.1007/s11367-017-1345-4.

[224] E. Carnevale, L. Lombardi, L. Zanchi, Life Cycle Assessment of solar energy systems: Comparison of photovoltaic and water thermal heater at domestic scale, Energy. 77 (2014) 434-446. doi:10.1016/j.energy.2014.09.028.

[225] S. Saremi-Yarahmadi, W. Whittow, B. Vaidhyanathan, Electromagnetic simulation studies of microwave assisted heating for the processing of nanostructured iron oxide for solar driven water splitting, Appl. Surf. Sci. 275 (2013) 65-70. doi:10.1016/j.apsusc.2013.01.124.

[226] K.K. Kelley, Contributions to the data on theoretical metallurgy XIII, Hightemperature heat-content, heat-capacity, and entropy data for the elements and inorganic compounds, U.S. Dept. of the Interior, Bureau of Mines : G.P.O., [Washington D.C.], 1960. http://digital.library.unt.edu/ark:/67531/metadc12739.

[227] O. Knop, R.E. Wasylishen, M.A. White, T.S. Cameron, M.J.M. Van Oort, Alkylammonium lead halides. Part 2. $\mathrm{CH} 3 \mathrm{NH} 3 \mathrm{PbX} 3(\mathrm{X}=\mathrm{Cl}, \mathrm{Br}$, I) perovskites: cuboctahedral halide cages with isotropic cation reorientation, Can. J. Chem. 68 (1990) 412-422. doi:10.1139/v90-063.

[228] N. Onoda-Yamamuro, T. Matsuo, H. Suga, Calorimetric and IR spectroscopic studies of phase transitions in methylammonium trihalogenoplumbates (II) ${ }^{\dagger}$, J. Phys. Chem. Solids. 51 (1990) 1383-1395. doi:10.1016/00223697(90)90021-7.

[229] N.J. Jeon, H.G. Lee, Y.C. Kim, J. Seo, J.H. Noh, J. Lee, S. II Seok, o-Methoxy substituents in spiro-OMeTAD for efficient inorganic-organic hybrid perovskite solar cells., J. Am. Chem. Soc. 136 (2014) 7837-40. doi:10.1021/ja502824c.

[230] X. Zhang, J.-B. Han, P.-F. Li, X. Ji, Z. Zhang, Improved, Highly Efficient, and Green Synthesis of Bromofluorenones and Nitrofluorenones in Water, Synth. Commun. 39 (2009) 3804-3815. doi:10.1080/00397910902838904.

[231] D. Hyatt, Preparation of stannous chloride, Google Patents, 1974. 
http://www.google.com/patents/US3816602.

[232] C.C. Stoumpos, C.D. Malliakas, M.G. Kanatzidis, Semiconducting tin and lead iodide perovskites with organic cations: phase transitions, high mobilities, and near-infrared photoluminescent properties., Inorg. Chem. 52 (2013) 9019-38. doi:10.1021/ic401215x.

[233] A.W. Larsen, H. Merrild, T.H. Christensen, Recycling of glass: accounting of greenhouse gases and global warming contributions, Waste Manag. Res. 27 (2009) 754-762. doi:10.1177/0734242X09342148.

[234] W.S. Yang, B.-W. Park, E.H. Jung, N.J. Jeon, Y.C. Kim, D.U. Lee, S.S. Shin, J. Seo, E.K. Kim, J.H. Noh, S. II Seok, lodide management in formamidinium-leadhalide-based perovskite layers for efficient solar cells, Science. 356 (2017) 1376-1379. doi:10.1126/science.aan2301.

[235] N.-G. Park, M. Grätzel, T. Miyasaka, K. Zhu, K. Emery, Towards stable and commercially available perovskite solar cells, Nat. Energy. 1 (2016) 16152. doi:10.1038/nenergy.2016.152.

[236] J.A. Christians, P. Schulz, J.S. Tinkham, T.H. Schloemer, S.P. Harvey, B.J. Tremolet De Villers, A. Sellinger, J.J. Berry, J.M. Luther, Tailored interfaces of unencapsulated perovskite solar cells for $>1,000$ hour operational stability, Nat. Energy. 3 (2018) 68-74. doi:10.1038/s41560-017-0067-y.

[237] F. Zhang, S. Wang, X. Li, Y. Xiao, Recent progress of perovskite solar cells, Curr. Nanosci. $12 \quad$ (2016) 137-156. http://www.ingentaconnect.com/contentone/ben/cnano/2016/00000012/ $00000002 /$ art00004.

[238] J.-W. Lee, D.-J. Seol, A.-N. Cho, N.-G. Park, High-Efficiency Perovskite Solar Cells Based on the Black Polymorph of $\mathrm{HC}(\mathrm{NH} 2) 2$ Pbl 3, Adv. Mater. 26 (2014) 4991-4998. doi:10.1002/adma.201401137.

[239] J.H. Noh, S.H. Im, J.H. Heo, T.N. Mandal, S. II Seok, Chemical Management for Colorful, Efficient, and Stable Inorganic-Organic Hybrid Nanostructured Solar Cells, Nano Lett. 13 (2013) 1764-1769. doi:10.1021/n1400349b.

[240] N. Pellet, P. Gao, G. Gregori, T.Y. Yang, M.K. Nazeeruddin, J. Maier, M. Grätzel, Mixed-organic-cation perovskite photovoltaics for enhanced solar-light harvesting, Angew. Chemie - Int. Ed. 53 (2014) 3151-3157. doi:10.1002/anie.201309361.

[241] F. Giordano, A. Abate, J.P. Correa Baena, M. Saliba, T. Matsui, S.H. Im, S.M. Zakeeruddin, M.K. Nazeeruddin, A. Hagfeldt, M. Graetzel, Enhanced electronic properties in mesoporous $\mathrm{TiO} 2$ via lithium doping for high- 
efficiency perovskite solar cells, Nat. Commun. 7 (2016) 10379. doi:10.1038/ncomms10379.

[242] H. Cho, S.-H. Jeong, M.-H. Park, Y.-H. Kim, C. Wolf, C.-L. Lee, J.H. Heo, A. Sadhanala, N. Myoung, S. Yoo, S.H. Im, R.H. Friend, T.-W. Lee, Overcoming the electroluminescence efficiency limitations of perovskite light-emitting diodes, Science. 350 (2015) 1222-1225. doi:10.1126/science.aad1818.

[243] M. Kulbak, D. Cahen, G. Hodes, How Important Is the Organic Part of Lead Halide Perovskite Photovoltaic Cells? Efficient CsPbBr 3 Cells, J. Phys. Chem. Lett. 6 (2015) 2452-2456. doi:10.1021/acs.jpclett.5b00968.

[244] F. Fabregat-Santiago, M. Kulbak, A. Zohar, M. Vallés-Pelarda, G. Hodes, D. Cahen, I. Mora-Seró, Deleterious Effect of Negative Capacitance on the Performance of Halide Perovskite Solar Cells, ACS Energy Lett. 2 (2017) 20072013. doi:10.1021/acsenergylett.7b00542.

[245] C.K. M $\varnothing L L E R$, Crystal Structure and Photoconductivity of Cæsium Plumbohalides, Nature. 182 (1958) 1436-1436. doi:10.1038/1821436a0.

[246] J.-W. Lee, D.-H. Kim, H.-S. Kim, S.-W. Seo, S.M. Cho, N.-G. Park, Formamidinium and Cesium Hybridization for Photo- and Moisture-Stable Perovskite Solar Cell, Adv. Energy Mater. 5 (2015) 1501310. doi:10.1002/aenm.201501310.

[247] G.B. Haxel, J.B. Hedrick, G.J. Orris, P.H. Stauffer, J.W. Hendley II, Rare earth elements: critical resources for high technology, 2002. http://pubs.er.usgs.gov/publication/fs08702.

[248] F. Consoli, Guidelines for life-cycle assessment: a code of practice, Society of Environmental Toxicology and Chemistry, Brussels, Belgium, 1993. http://books.google.es/books/about/Guidelines_for_Life_cycle_Assessment .html?id=SFGOJAAACAAJ\&redir_esc=y.

[249] Guidelines for Life-Cycle Assessment:, Environ. Sci. Pollut. Res. 1 (1994) 5555. doi:10.1007/BF02986927.

[250] Y. Jiang, M.R. Leyden, L. Qiu, S. Wang, L.K. Ono, Z. Wu, E.J. Juarez-Perez, Y. Qi, Combination of Hybrid CVD and Cation Exchange for Upscaling Cs-Substituted Mixed Cation Perovskite Solar Cells with High Efficiency and Stability, Adv. Funct. Mater. 28 (2018) 1703835. doi:10.1002/adfm.201703835.

[251] F. Eloy, R. Lenaers, C. Moussebois, Synthèse de dérivés acylés de la formamidoxime, Helv. Chim. Acta. 45 (1962) 437-441. doi:10.1002/hlca.19620450202. 
[252] W. Lossen, P. Schifferdecker, Ueber Isuretin, eine dem Harnstoff isomere Base, Justus Liebig's Ann. Der Chemie Und Pharm. 166 (1873) 295-320. doi:10.1002/jlac.18731660304.

[253] P.M. Brown, M.C. Northrup, B.F. Bakke, Process for producing a predetermined cesium compound, US6436879B1, 2002. https://www.google.ch/patents/US6436879.

[254] H. de Bruijn, R. van Duin, M.A.J. Huijbregts, Handbook on Life Cycle Assessment, Springer Netherlands, Dordrecht, 2002. doi:10.1007/0-30648055-7.

[255] M. Gorrée, J.B. Guinée, G. Huppes, L. van Oers, Environmental life cycle assessment of linoleum, Int. J. Life Cycle Assess. 7 (2002) 158-166. doi:10.1007/BF02994050.

[256] J. Emsley, Nature's Building Blocks: An A-Z Guide to the Elements, Oxford University Press, Oxford, 2001. https://books.google.es/books/about/Nature_s_Building_Blocks.html?id=Yh i5X70wuGkC\&redir_esc=y.

[257] U.S. Geological Survey, Mineral Commodities Summaries 2017, Reston, Virginia, 2017. doi:10.3133/70180197.

[258] O. Jolliet, M. Margni, R. Charles, S. Humbert, J. Payet, G. Rebitzer, R. Rosenbaum, IMPACT 2002+: A new life cycle impact assessment methodology, Int. J. Life Cycle Assess. 8 (2003) 324-330. doi:10.1007/BF02978505.

[259] Pré Sustainability, SimaPro, (2016). https://simapro.com/.

[260] The ecoinvent database v3.4. Swiss Centre for Life Cycle Inventories, (2014).

[261] S. Ahmad, G.V. Prakash, Fabrication of excitonic luminescent inorganicorganic hybrid nano and microcrystals, in: Int. Conf. Fibre Opt. Photonics, OSA, Washington, D.C., 2012: p. MPo.40. doi:10.1364/PHOTONICS.2012.MPo.40.

[262] S. Chu, Y. Cui, N. Liu, The path towards sustainable energy, Nat. Mater. 16 (2017) 16-22. doi:10.1038/nmat4834.

[263] M.K. Assadi, S. Bakhoda, R. Saidur, H. Hanaei, Recent progress in perovskite solar cells, Renew. Sustain. Energy Rev. 81 (2018) 2812-2822. doi:10.1016/j.rser.2017.06.088.

[264] R. Fang, W. Zhang, S. Zhang, W. Chen, The rising star in photovoltaics- 
perovskite solar cells: The past, present and future, Sci. China Technol. Sci. (2016) 1-18. doi:10.1007/s11431-016-6056-8.

[265] W. Zhang, G.E. Eperon, H.J. Snaith, Metal halide perovskites for energy applications, Nat. Energy. 1 (2016) 16048. doi:10.1038/nenergy.2016.48.

[266] Q. Chen, N. De Marco, Y. (Michael) Yang, T.-B. Song, C.-C. Chen, H. Zhao, Z. Hong, H. Zhou, Y. Yang, Under the spotlight: The organic-inorganic hybrid halide perovskite for optoelectronic applications, Nano Today. 10 (2015) 355-396. doi:10.1016/j.nantod.2015.04.009.

[267] T. Edis, Dyesol awarded $\$ 0.5 \mathrm{~m}$ grant to pursue high efficiency, low cost solar cell, Aust. (2015). https://www.theaustralian.com.au/business/businessspectator/dyesol-awarded-05m-grant-to-pursue-high-efficiency-low-costsolar-cell/news-story/02bc43e776185abe903642bc8129c79b (accessed October 30, 2018).

[268] R. Peleg, Saule Technologies secures Japanese investor, Perovskite-Info. (2015). https://compoundsemiconductor.net/article/97858-polishperovskite-firm-attracts-japanese-investor.html (accessed October 30, 2018).

[269] J. Gifford, Dyesol claims perovskite stability breakthrough, Pv Mag. (2015). https://www.pv-magazine.com/2015/09/09/dyesol-claims-perovskitestability-breakthrough_100021002/\#axzz3IF0szmdL (accessed October 30, 2018).

[270] T. Sherahilo, Oxford PV sets world record for perovskite solar cell, Oxford PV. (2018). https://www.oxfordpv.com/news/oxford-pv-sets-world-recordperovskite-solar-cell.

[271] J.A. Baker, Y. Mouhamad, K.E.A. Hooper, D. Burkitt, M. Geoghegan, T.M. Watson, From spin coating to roll-to-roll: investigating the challenge of upscaling lead halide perovskite solar cells, IET Renew. Power Gener. 11 (2017) 546-549. doi:10.1049/iet-rpg.2016.0683.

[272] G. Cotella, J. Baker, D. Worsley, F. De Rossi, C. Pleydell-Pearce, M. Carnie, T. Watson, One-step deposition by slot-die coating of mixed lead halide perovskite for photovoltaic applications, Sol. Energy Mater. Sol. Cells. 159 (2017) 362-369. doi:10.1016/j.solmat.2016.09.013.

[273] D. Burkitt, J. Searle, T. Watson, Perovskite solar cells in N-I-P structure with four slot-die-coated layers, R. Soc. Open Sci. 5 (2018) 172158. doi:10.1098/rsos.172158.

[274] T.M. Schmidt, T.T. Larsen-Olsen, J.E. Carlé, D. Angmo, F.C. Krebs, Upscaling of 
Perovskite Solar Cells: Fully Ambient Roll Processing of Flexible Perovskite Solar Cells with Printed Back Electrodes, Adv. Energy Mater. 5 (2015) 1500569. doi:10.1002/aenm.201500569.

[275] F. Matteocci, S. Razza, F. Di Giacomo, S. Casaluci, G. Mincuzzi, T.M. Brown, A. D’Epifanio, S. Licoccia, A. Di Carlo, Solid-state solar modules based on mesoscopic organometal halide perovskite: a route towards the up-scaling process, Phys. Chem. Chem. Phys. 16 (2014) 3918. doi:10.1039/c3cp55313b.

[276] F. Di Giacomo, V. Zardetto, A. D’Epifanio, S. Pescetelli, F. Matteocci, S. Razza, A. Di Carlo, S. Licoccia, W.M.M. Kessels, M. Creatore, T.M. Brown, Flexible Perovskite Photovoltaic Modules and Solar Cells Based on Atomic Layer Deposited Compact Layers and UV-Irradiated TiO 2 Scaffolds on Plastic Substrates, Adv. Energy Mater. 5 (2015) 1401808. doi:10.1002/aenm.201401808.

[277] H. Chen, F. Ye, W. Tang, J. He, M. Yin, Y. Wang, F. Xie, E. Bi, X. Yang, M. Grätzel, L. Han, A solvent- and vacuum-free route to large-area perovskite films for efficient solar modules, Nature. 550 (2017) 92. doi:10.1038/nature23877.

[278] K. Hooper, B. Smith, J. Baker, P. Greenwood, T. Watson, Spray PEDOT:PSS coated perovskite with a transparent conducting electrode for low cost scalable photovoltaic devices, Mater. Res. Innov. 19 (2015) 482-487. doi:10.1080/14328917.2015.1105572.

[279] D. Bryant, P. Greenwood, J. Troughton, M. Wijdekop, M. Carnie, M. Davies, K. Wojciechowski, H.J. Snaith, T. Watson, D. Worsley, A Transparent Conductive Adhesive Laminate Electrode for High-Efficiency Organic-Inorganic Lead Halide Perovskite Solar Cells, Adv. Mater. 26 (2014) 7499-7504. doi:10.1002/adma.201403939.

[280] J.F. Moulder, W.F. Stickle, P.E. Sobol, K.D. Bomben, Handbook of X-ray Photoelectron Spectroscopy: A Reference Book of Standard Spectra for Identification and Interpretation of XPS Data, Physical Electronics Division, Perkin-Elmer Corporation, Minnesota, USA, 1992. https://books.google.es/books?id=A_XGQgAACAAJ.

[281] B. Philip, E. Jewell, P. Greenwood, C. Weirman, Material and process optimization screen printing carbon graphite pastes for mass production of heating elements, J. Manuf. Process. 22 (2016) 185-191. doi:10.1016/j.jmapro.2016.03.001.

[282] A. Yasin, F. Guo, G.P. Demopoulos, Aqueous, Screen-Printable Paste for Fabrication of Mesoporous Composite Anatase-Rutile TiO 2 Nanoparticle Thin Films for (Photo)electrochemical Devices, ACS Sustain. Chem. Eng. 4 
(2016) 2173-2181. doi:10.1021/acssuschemeng.5b01625.

[283] H. Zhang, H. Wang, S.T. Williams, D. Xiong, W. Zhang, C.-C. Chueh, W. Chen, A.K.-Y. Jen, $\mathrm{SrCl} 2$ Derived Perovskite Facilitating a High Efficiency of $16 \%$ in Hole-Conductor-Free Fully Printable Mesoscopic Perovskite Solar Cells, Adv. Mater. 29 (2017) 1606608. doi:10.1002/adma.201606608.

[284] K. Hooper, M. Carnie, C. Charbonneau, T. Watson, Near Infrared Radiation as a Rapid Heating Technique for TiO 2 Films on Glass Mounted Dye-Sensitized Solar Cells, Int. J. Photoenergy. 2014 (2014) 1-8. doi:10.1155/2014/953623.

[285] A. Rajagopal, K. Yao, A.K.-Y. Jen, Toward Perovskite Solar Cell Commercialization: A Perspective and Research Roadmap Based on Interfacial Engineering, Adv. Mater. $0 \quad$ (2018) 1800455. doi:10.1002/adma.201800455.

[286] L. Fewtrell, R. Kaufmann, A. Prüss-Üstün, Lead: Assessing the environmental burden of disease at national and local levels, World Health Organization, Geneva, 2003. http://apps.who.int/iris/handle/10665/42715.

[287] P. Gottesfeld, A.K. Pokhrel, Review: Lead Exposure in Battery Manufacturing and Recycling in Developing Countries and Among Children in Nearby Communities, J. Occup. Environ. Hyg. 8 (2011) 520-532. doi:10.1080/15459624.2011.601710.

[288] European Parliament, Directive 2011/65/EU of the European Parliament and of the Council of 8 June 2011, on the restriction of the use of certain hazardous substances in electrical and electronic equipment (RoHS), Off. J. Eur. Communities. 54 (2011) 88-110. https://eur-lex.europa.eu/legalcontent/EN/TXT/?uri=OJ:L:2011:174:TOC.

[289] W. Zhang, J. Yang, X. Wu, Y. Hu, W. Yu, J. Wang, J. Dong, M. Li, S. Liang, J. Hu, R.V. Kumar, A critical review on secondary lead recycling technology and its prospect, Renew. Sustain. Energy Rev. 61 (2016) 108-122. doi:10.1016/j.rser.2016.03.046.

[290] S.M. Jain, D. Phuyal, M.L. Davies, M. Li, B. Philippe, C. De Castro, Z. Qiu, J. Kim, T. Watson, W.C. Tsoi, O. Karis, H. Rensmo, G. Boschloo, T. Edvinsson, J.R. Durrant, An effective approach of vapour assisted morphological tailoring for reducing metal defect sites in lead-free, $(\mathrm{CH} 3 \mathrm{NH} 3) 3 \mathrm{Bi} 2$ I 9 bismuth-based perovskite solar cells for improved performance and long-term stability, Nano Energy. 49 (2018) 614-624. doi:10.1016/j.nanoen.2018.05.003.

[291] A. Abate, Perovskite Solar Cells Go Lead Free, Joule. 1 (2017) 659-664. doi:10.1016/j.joule.2017.09.007. 
[292] I. Celik, A.B. Phillips, Z. Song, Y. Yan, R.J. Ellingson, M.J. Heben, D. Apul, Environmental analysis of perovskites and other relevant solar cell technologies in a tandem configuration, Energy Environ. Sci. 10 (2017) 18741884. doi:10.1039/C7EE01650F.

[293] C. Li, Y. Li, Y. Xing, Z. Zhang, X. Zhang, Z. Li, Y. Shi, T. Ma, R. Ma, K. Wang, J. Wei, Perovskite Solar Cell Using a Two-Dimensional Titania Nanosheet Thin Film as the Compact Layer, ACS Appl. Mater. Interfaces. 7 (2015) 1511715122. doi:10.1021/acsami.5b01959.

[294] H. Krýsová, J. Krýsa, L. Kavan, Semi-automatic spray pyrolysis deposition of thin, transparent, titania films as blocking layers for dye-sensitized and perovskite solar cells, Beilstein J. Nanotechnol. 9 (2018) 1135-1145. doi:10.3762/bjnano.9.105.

[295] J.E. Bishop, D.K. Mohamad, M. Wong-Stringer, A. Smith, D.G. Lidzey, Spraycast multilayer perovskite solar cells with an active-area of $1.5 \mathrm{~cm} 2$, Sci. Rep. 7 (2017) 7962. doi:10.1038/s41598-017-08642-2.

[296] D. Bryant, I. Mabbett, P. Greenwood, T. Watson, M. Wijdekop, D. Worsley, Ultrafast near-infrared curing of PEDOT:PSS, Org. Electron. 15 (2014) 11261130. doi:10.1016/j.orgel.2014.03.001.

[297] J. Troughton, C. Charbonneau, M.J. Carnie, M.L. Davies, D.A. Worsley, T.M. Watson, Rapid processing of perovskite solar cells in under 2.5 seconds, J. Mater. Chem. A. 3 (2015) 9123-9127. doi:10.1039/C5TA00568J.

[298] J. Troughton, M.J. Carnie, M.L. Davies, C. Charbonneau, E.H. Jewell, D.A. Worsley, T.M. Watson, Photonic flash-annealing of lead halide perovskite solar cells in $1 \mathrm{~ms}$, J. Mater. Chem. A. 4 (2016) 3471-3476. doi:10.1039/C5TA09431C.

[299] M. Kim, G.-H. Kim, K.S. Oh, Y. Jo, H. Yoon, K.-H. Kim, H. Lee, J.Y. Kim, D.S. Kim, High-Temperature-Short-Time Annealing Process for High-Performance Large-Area Perovskite Solar Cells, ACS Nano. 11 (2017) 6057-6064. doi:10.1021/acsnano.7b02015.

[300] C.A. Gueymard, A reevaluation of the solar constant based on a 42-year total solar irradiance time series and a reconciliation of spaceborne observations, Sol. Energy. (2018). doi:10.1016/j.solener.2018.04.001.

[301] J. Qin, Z. Zhang, W. Shi, Y. Liu, H. Gao, Y. Mao, The optimum titanium precursor of fabricating $\mathrm{TiO} 2$ compact layer for perovskite solar cells, Nanoscale Res. Lett. 12 (2017) 640. doi:10.1186/s11671-017-2418-9.

[302] G. Wernet, C. Bauer, B. Steubing, J. Reinhard, E. Moreno-Ruiz, B. Weidema, 
The ecoinvent database version 3 (part I): overview and methodology, Int. J. Life Cycle Assess. 21 (2016) 1218-1230. doi:10.1007/s11367-016-1087-8.

[303] T. Urbanski, Chemistry and technology of explosives. Volume 1, Pergamon, Oxford, 1964. http://pyrobin.com/files/Chemistry and Technology of Explosives 1.pdf.

[304] O. Cori, L. Chayet, L.M. Perez, C.A. Bunton, D. Hachey, Rearrangement of linalool, geraniol, nerol and their derivatives, J. Org. Chem. 51 (1986) 13101316. doi:10.1021/jo00358a028.

[305] F. Bellesia, R. Grandi, U.M. Pagnoni, R. Trave, Some anomalous products from the attempted halogenation of unsaturated alcohols by the complex from dimethyl sulphide and N-halogenosuccinimide, J. Chem. Soc. Perkin Trans. 1. (1979) 851. doi:10.1039/p19790000851.

[306] M. Xiao, Z. Wenle, Z. Xiangru, Z. Jianping, L. Guangyin, C. Weichao, M. Shuzhao, Method for continuously preparing linalool from allylic alcohol by isomerization process, CN105218312 A, 2016. https://www.google.co.uk/patents/CN105218312A.

[307] G. Wienhöfer, F.A. Westerhaus, K. Junge, R. Ludwig, M. Beller, A Molecularly Defined Iron-Catalyst for the Selective Hydrogenation of $\alpha, \beta$-Unsaturated Aldehydes, Chem. - A Eur. J. 19 (2013) 7701-7707. doi:10.1002/chem.201300660.

[308] N. Goetz, R. Fischer, Production of high molecular weight $\alpha, \beta$-unsaturated aldehydes, US3965193

A, 1976. https://www.google.com/patents/US3965193.

[309] X. Lu, W.-J. Zhou, H. Wu, A. Liebens, P. Wu, Selective synthesis of ethylene oxide through liquid-phase epoxidation of ethylene with titanosilicate/H2O2 catalytic systems, Appl. Catal. A Gen. 515 (2016) 51-59. doi:10.1016/j.apcata.2016.02.001.

[310] P.V.S.N. Vani, A.S. Chida, R. Srinivasan, M. Chandrasekharam, A.K. Singh, SYNTHESIS OF $\beta$-IONONE, Synth. Commun. 31 (2001) 219-224. doi:10.1081/SCC-100000202.

[311] A. V Markin, N.N. Smirnova, I.S. Il'ichev, T.I. Dolinsky, A.B. Radbil, Thermodynamic properties of $\alpha$-terpineol over the range from $T \rightarrow(0$ to 345$)$ K, J. Therm. Anal. Calorim. 123 (2016) 1451-1458. doi:10.1007/s10973-0155068-0.

[312] W. Jung-Chung, H. Ming-Yu, C. Jen-Chun, L. Jann-Chen, Method of Fabricating Glycol Monoalkyl Ether Acetate Using Acidic Ionic Liquid Catalyst, 
US20110184207A1,

https://patents.google.com/patent/US20110184207.

[313] M.L. Tulchinsky, J.R. Briggs, C.L. Rand, Polyol ethers and process for making them, US20100048940A1, 2010. https://worldwide.espacenet.com/publicationDetails/biblio?CC=US\&NR=20 $10048940 A 1 \& K C=A 1 \& F T=D \& N D=\&$ date $=20100225 \& D B=\& l o c a l e=e n \_E P \#$.

[314] W. Dongchu, L. Bing, Alpha, beta-unsaturated carbonyl compound production method, CN105439786A, 2016. https://worldwide.espacenet.com/publicationDetails/biblio?CC=CN\&NR=10 $5439786 \& K C=\& F T=E \& l o c a l e=e n \_E P \#$.

[315] M.M. Rahman, K.M. Krishna, T. Soga, T. Jimbo, M. Umeno, Optical properties and $\mathrm{X}$-ray photoelectron spectroscopic study of pure and $\mathrm{Pb}$-doped TiO2 thin films, J. Phys. Chem. Solids. 60 (1999) 201-210. doi:10.1016/S00223697(98)00264-9.

[316] H. Siegel, M. Eggersdorfer, Ketones, in: Ullmann's Encycl. Ind. Chem., Wiley$\mathrm{VCH}$ Verlag GmbH \& Co. KGaA, Weinheim, Germany, 2000. doi:10.1002/14356007.a15_077.

[317] R. Miller, C. Abaecherli, A. Said, B. Jackson, Ketenes, in: Ullmann's Encycl. Ind. Chem., Wiley-VCH Verlag GmbH \& Co. KGaA, Weinheim, Germany, 2001. doi:10.1002/14356007.a15_063.

[318] C. Weygand, Weygand/Hilgetag Preparative organic chemistry, John Wiley \& Sons, Inc., 1972. https://books.google.co.uk/books/about/Preparative_Organic_Chemistry.ht $\mathrm{ml}$ ?id=cispnQAACAAJ\&redir_esc=y.

[319] D.C. Bradley, R.C. Mehrotra, I.P. Rothwell, A. Singh, Alkoxo and Aryloxo Derivatives of Metals, 1st ed., Academic Press, London, 2001. doi:10.1016/B978-012124140-7/50000-1.

[320] H. Hoshi, N. Shigeeda, T. Dai, Improved oxidation stability of tin iodide cubic perovskite treated by 5 -ammonium valeric acid iodide, Mater. Lett. 183 (2016) 391-393. doi:https://doi.org/10.1016/j.matlet.2016.07.048.

[321] S. Nomoto, K. Harada, Flame-Induced Carboxylation of Unsaturated Amines in an Aqueous Formic Acid Solution, Chem. Lett. 14 (1985) 145-148. doi:10.1246/cl.1985.145.

[322] T. Sato, K. Ota, Method for producing unsaturated amine, JP2016193871 (A), 2016.

https://worldwide.espacenet.com/publicationDetails/biblio?CC=JP\&NR=201 
6193871A\&KC=A\&FT=D\&ND=\&date $=20161117 \& D B=\&$ locale $=e n \_E P \#$.

[323] T. Schaub, B. Buschhaus, M.K. Brinks, M. Schelwies, R. Paciello, J.-P. Melder, M. Merger, Process for the preparation of primary amines by homogeneously catalyzed alcohol amination, US20120232309A1, 2012. https://worldwide.espacenet.com/publicationDetails/biblio?CC=US\&NR=20 12232309A1\&KC=A1\&FT=D\&ND=\&date=20120913\&DB=\&locale=en_EP\#.

[324] F. Portoghese, L. Ferrante, F. Berruti, C. Briens, E. Chan, Effect of injectionnozzle operating parameters on the interaction between a gas-liquid jet and a gas-solid fluidized bed, Powder Technol. 184 (2008) 1-10. doi:10.1016/j.powtec.2007.07.029.

[325] K. Treyer, C. Bauer, Life cycle inventories of electricity generation and power supply in version 3 of the ecoinvent database-part I: electricity generation, Int. J. Life Cycle Assess. 21 (2016) 1236-1254. doi:10.1007/s11367-013-06652.

[326] H. Baumann, A.-M. Tillman, The hitch hiker's guide to LCA : an orientation in life cycle assessment methodology and application, Studentlitteratur, Lund, 2004. http://cataleg.uji.es/record=b1176134 S1*cat (accessed June 7, 2016).

[327] C. Roldán-Carmona, P. Gratia, I. Zimmermann, G. Grancini, P. Gao, M. Graetzel, M.K. Nazeeruddin, High efficiency methylammonium lead triiodide perovskite solar cells: the relevance of non-stoichiometric precursors, Energy Environ. Sci. 8 (2015) 3550-3556. doi:10.1039/C5EE02555A.

[328] P. Buerger, D. Nurkowski, J. Akroyd, S. Mosbach, M. Kraft, First-Principles Thermochemistry for the Thermal Decomposition of Titanium Tetraisopropoxide, J. Phys. Chem. A. 119 (2015) 8376-8387. doi:10.1021/acs.jpca.5b01721.

[329] C. Degueldre, P. Tissot, H. Lartigue, M. Pouchon, Specific heat capacity and Debye temperature of zirconia and its solid solution, Thermochim. Acta. 403 (2003) 267-273. doi:10.1016/S0040-6031(03)00060-1.

[330] K. Shinzato, T. Baba, A Laser Flash Apparatus for Thermal Diffusivity and Specific Heat Capacity Measurements, J. Therm. Anal. Calorim. 64 (2001) 413-422. doi:10.1023/A:1011594609521.

[331] I.L. Ivanov, A.S. Steparuk, M.S. Bolyachkina, D.S. Tsvetkov, A.P. Safronov, A.Y. Zuev, Thermodynamics of formation of hybrid perovskite-type methylammonium lead halides, J. Chem. Thermodyn. 116 (2018) 253-258. doi:10.1016/j.jct.2017.09.026. 
References

$-206-$ 
Annexes 

List of publications not included in the thesis but related to the topic:

S. Sánchez, M. Vallés-Pelarda, J.-A. Alberola-Borràs, R. Vidal, J.J. Jerónimo-Rendón, M. Saliba, P.P. Boix, I. Mora-Seró, Flash infrared annealing as a cost-effective and low environmental impact processing method for planar perovskite solar cells, Materials Today/Elsevier. 31 (2019) 39-46.

doi: 10.1016/j.mattod.2019.04.021

Impact factor (2018): 26.416

R. Vidal, J.-A. Alberola-Borràs, I. Mora-Seró, Abiotic depletion and the potential risk to the supply of cesium, Resources Policy/Elsevier. 68 (2020) 101792.

doi: 10.1016/j.resourpol.2020.101792

Impact factor (2019): 3.986

R. Vidal, J.-A. Alberola-Borràs, S.N. Habisreutinger, J.-L. Gimeno-Molina, D.T. Moore, T.H. Schloemer, I. Mora-Seró, J.J. Berry, J.M. Luther, Assessing health and environmental impacts of solvents for producing perovskite solar cells, Nature Sustainability/Nature. 4 (2021) 277-285.

doi: $10.1038 / s 41893-020-00645-8$

Impact factor (2019): 12.080

R. Vidal, J. Alberola-Borràs, N. Sánchez-Pantoja, I. Mora-Seró, Comparison of Perovskite Solar Cells with other Photovoltaics Technologies from the Point of View of Life Cycle Assessment, Advanced Energy \& Sustainability Research/Wiley (2021) 2000088.

doi: $10.1002 /$ aesr. 202000088 